Portland State University

PDXScholar

Spring 6-5-2013

\title{
Evaluating Alternative High Schools: Program Evaluation in Action
}

Drew Samuel Wayne Hinds

Portland State University

Follow this and additional works at: https://pdxscholar.library.pdx.edu/open_access_etds

Part of the Educational Assessment, Evaluation, and Research Commons, Educational Leadership Commons, and the Higher Education Administration Commons Let us know how access to this document benefits you.

\section{Recommended Citation}

Hinds, Drew Samuel Wayne, "Evaluating Alternative High Schools: Program Evaluation in Action" (2013). Dissertations and Theses. Paper 1076.

https://doi.org/10.15760/etd.1076

This Dissertation is brought to you for free and open access. It has been accepted for inclusion in Dissertations and Theses by an authorized administrator of PDXScholar. Please contact us if we can make this document more accessible: pdxscholar@pdx.edu. 
Evaluating Alternative High Schools:

Program Evaluation in Action

by

Drew Samuel Wayne Hinds

A dissertation submitted in partial fulfillment of the requirements for the degree of

Doctor of Education

in

Educational Leadership: Administration

Dissertation Committee:

Thomas Chenoweth, Chair

Patrick Burk

Samuel Henry

Yves Labissiere

Portland State University

2013 
(C) 2013 Drew Samuel Wayne Hinds 


\begin{abstract}
Alternative high schools serve some of the most vulnerable students and their programs present a significant challenge to evaluate. Determining the impact of an alternative high school that serves mostly at-risk students presented a significant research problem. Few studies exist that dig deeper into the characteristics and strategies of successful alternative schooling. Moreover valid program evaluation methods to identify successful alternative school practices are hit and miss. As a result, public policy and systems of accountability have either disregarded information relating to alternative high schools or unjustifiably included them in comparisons with traditional high schools.

This dissertation studied the issue of how best to evaluate alternative high schools and what tools support leaders in planning a thorough and accurate program evaluation. The Alternative High School Program Evaluation Toolkit was developed to support school leaders and evaluation teams made up of internal and external stakeholders as they facilitate the program evaluation process. The features of the Toolkit address the need for alternative school evaluation to be practical, useful, fair and accurate. The Evaluation Toolkit includes training materials, protocols, an evaluation planning worksheet and an evaluation planning matrix that supports the team in conducting the evaluation.

The research represented in this dissertation is theoretically and practically grounded in Bridges and Hallinger's (1995) Problem-Based Learning (PBL) and Borg and Gall's (1989) Research and Development (R\&D) Cycle. The product of the R\&D Cycle was the Alternative High School Program Evaluation Toolkit and a process for use by evaluation teams assigned the task of planning and carrying out program evaluations.
\end{abstract}




\section{Acknowledgments}

I would like to acknowledge my doctoral chair, Dr. Tom Chenoweth, who ignited a fire within me that will burn for a lifetime. Without Dr. Chenoweth this dissertation would not have been possible. I would also like to thank the members of my committee, Dr. Henry, Dr. Burk, and Dr. Labissiere for their suggestions, fellow researcher Chet Edwards for his collaboration, and Dr. Ray Lindley, Dr. Gerry Balaban, Dr. Verne Duncan, Dr. Ray Morley and Dr. Dannelle Stevens for challenging me to consider how research can be ethically combined with action in the educational research ecology.

I would like to thank my mentors Mark Hinds (father), Paul Hinds (grandfather), Butch Lovall (Youth Pastor), Dr. Irving Laird (Second Paul), Dr. Randy Green, Don Wildfang, LeRoy Hedberg, Dr. Joe Broeker and Dr. Ray Lindley. Thanks to Dr. Gerry Balaban and Dr. Ray Lindley (previously mentioned), Dr. Kenneth Peterson, Pati Sluys and Donna Hinds (mother) for edits and support. I owe a debt of gratitude to my wife of 15 years Christin Hinds for attending to our children Zechariah Hinds and Alicia Hinds and for their patience while my office door remained locked late into the night.

Finally, I would like to thank previous researchers in this field of study, including Dr. Tom Chenoweth and Dr. Ray Morley (previously mentioned), Dr. Larry Cuban, Dr. Bob Barr, Dr. Terry Cash and the late Dr. Mary Anne Raywid as well as others who have paved the way for practical application of common sense approaches in leadership and policy that result in equipping children for life. It is my humble hope that I am able to "carry the torch" through research and practice in a way that honors their contributions. "It is God who arms me with strength and keeps my way secure." (NIV, 2 Samuel 22:33) 
TABLE OF CONTENTS

Page

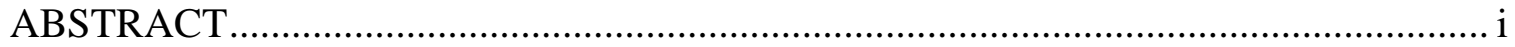

ACKNOWLEDGMENTS ................................................................................ ii

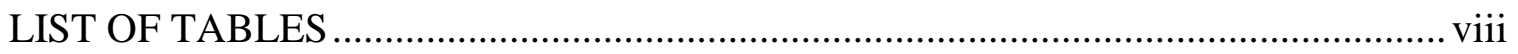

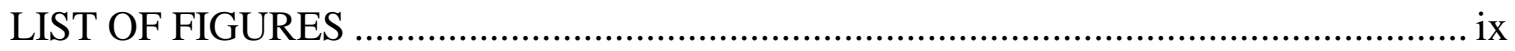

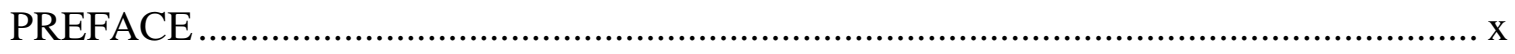

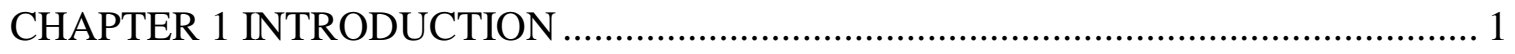

Statement of the Problem .................................................................................... 4

Elements of Successful Alternative Schools ........................................................ 6

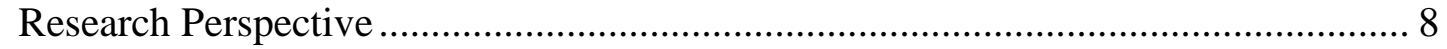

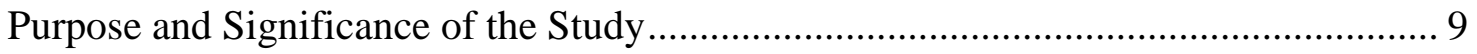

The Need for Evaluation Tools ....................................................................... 12

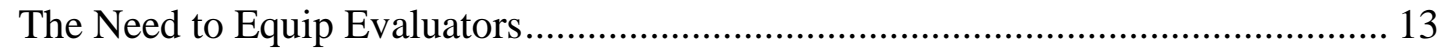

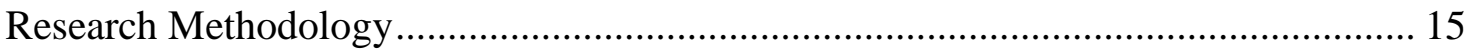

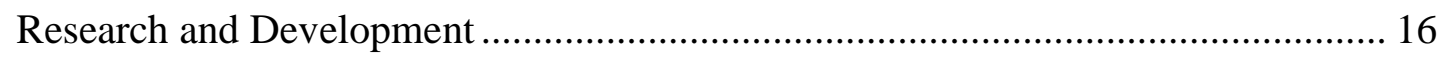

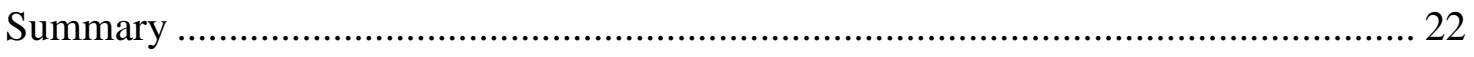

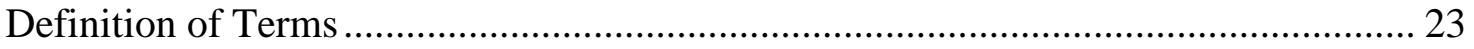

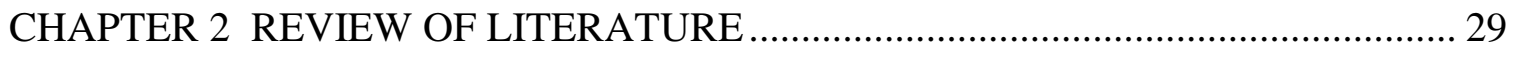

Types and Purposes of Alternative Schools .......................................................... 31

Standards for Educational Program Evaluation .......................................................... 39

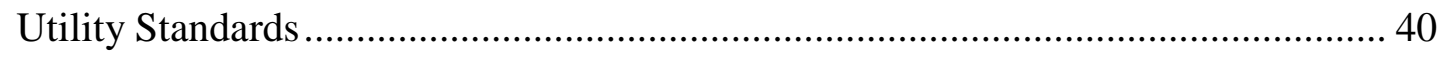




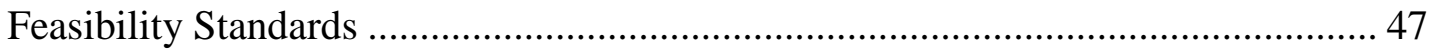

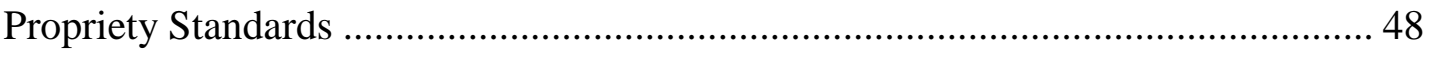

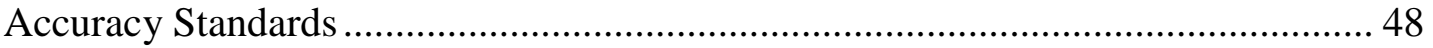

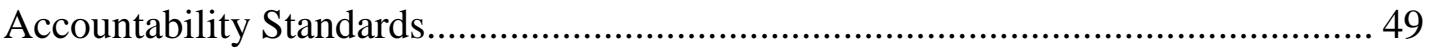

Summative and Formative Evaluation ............................................................. 49

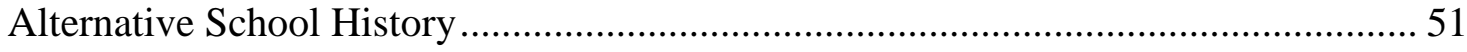

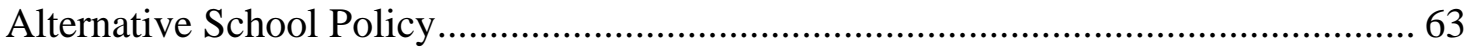

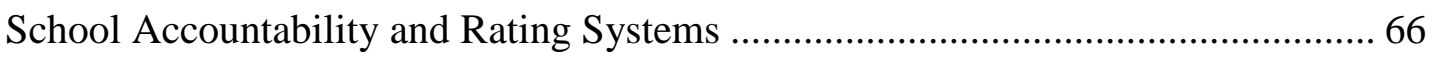

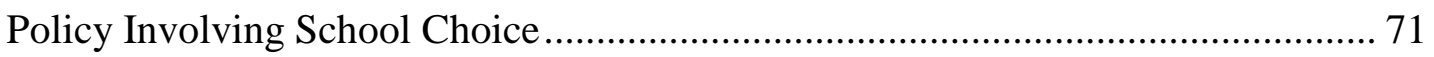

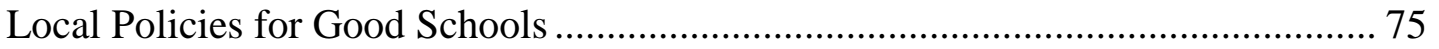

Evaluation Studies and Reports on Effective Alternative Schools ............................ 77

School Evaluation Studies-Traditional Schools ................................................. 77

School Evaluation Studies-Alternative Schools ................................................. 81

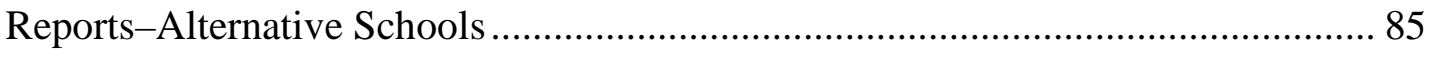

Alternative School Evaluation Processes and Tools ............................................ 88

Accreditation Standards as Framework for the Evaluation Process........................ 89

Evaluators' Objective Determination of Quality ................................................... 93

Evaluating the Organizational Leadership in Alternative High Schools.................. 95

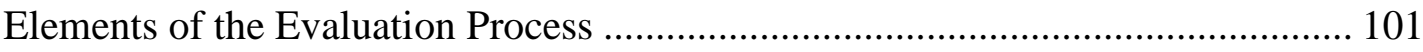

Characteristics of the Alternative High School Program Evaluation Process ............ 104

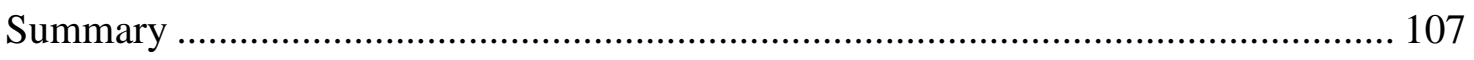

CHAPTER 3 RESEARCH METHODOLOGY ..................................................... 110

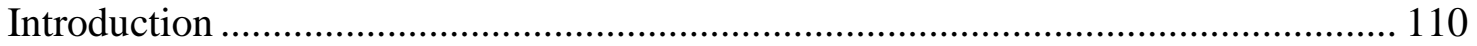

Elements, Characteristics and Assumptions of the Evaluation Toolkit Recipe ......... 111

Evaluation Toolkit Elements....................................................................... 112

Evaluation Process Characteristics ............................................................... 113

Assumptions about Program Evaluation ......................................................... 115

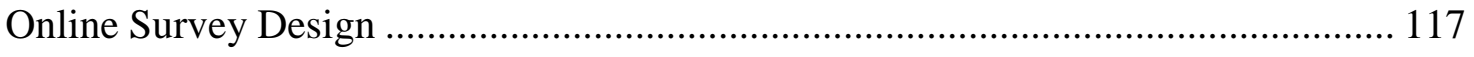

Approach to Program Evaluation and Research Design Explained.......................... 118 
Dimensions of an Effective School Program Evaluation.......................................... 119

Differences Between Research and Evaluation..................................................... 121

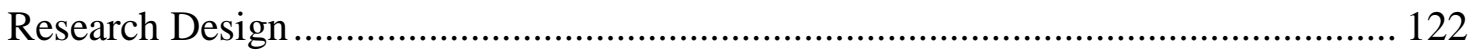

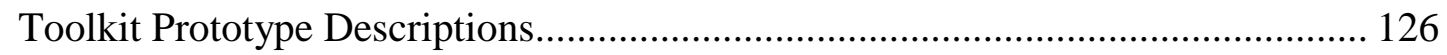

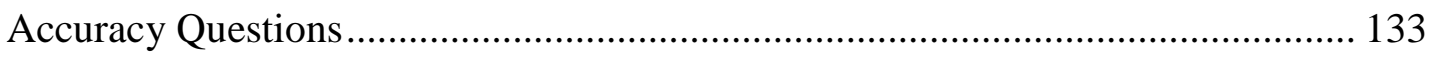

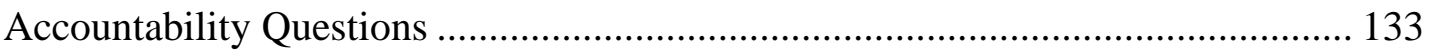

Steps in the Research Design .............................................................................. 134

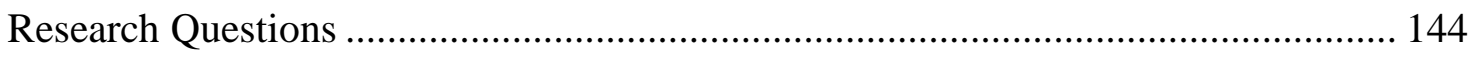

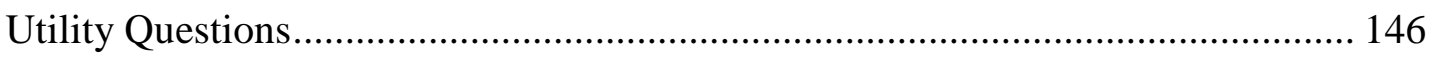

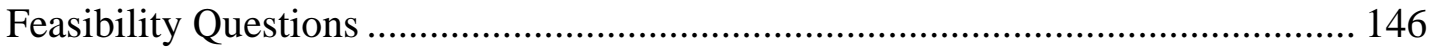

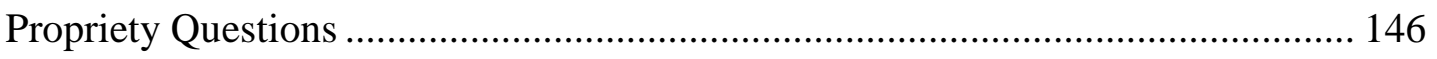

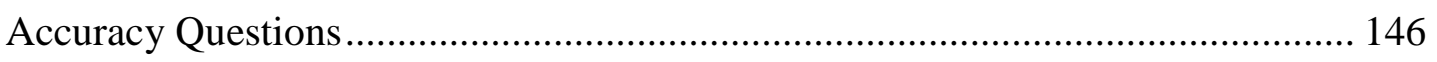

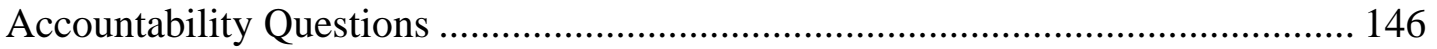

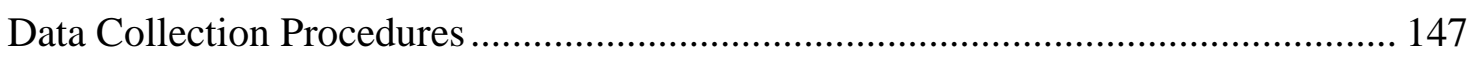

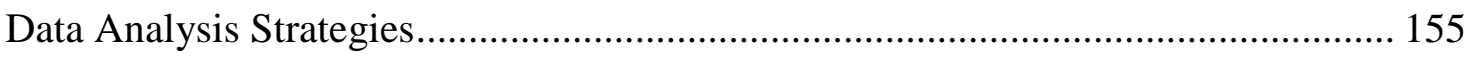

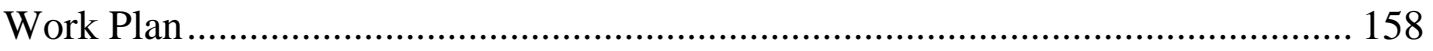

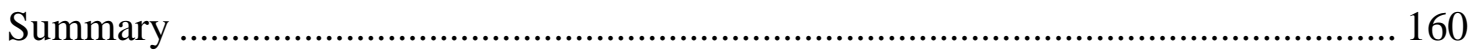

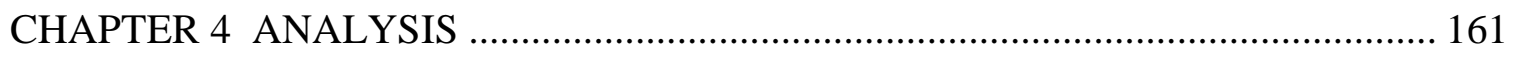

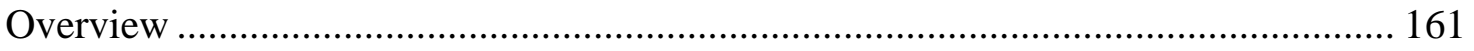

Research Questions and General Design .............................................................. 165

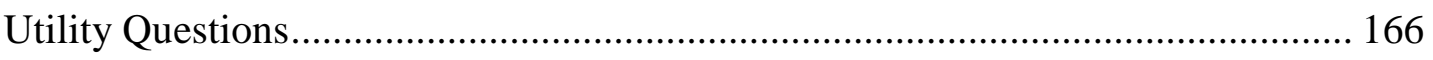

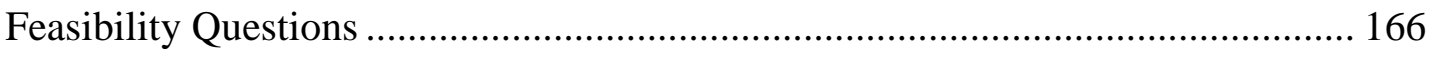

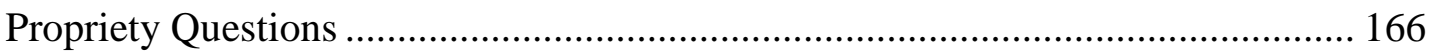

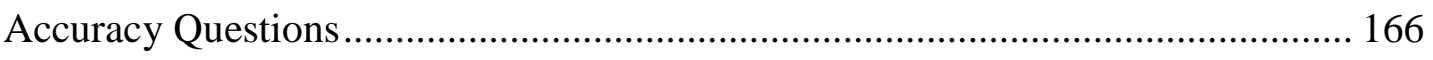

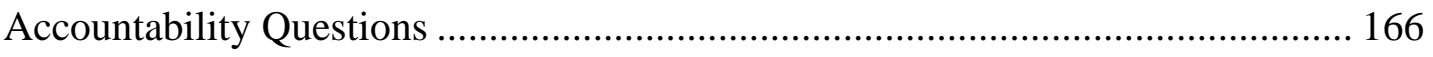

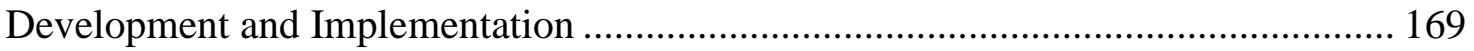

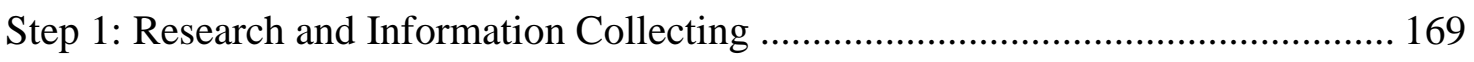

Step 2: Planning, Objectives, Learning Activities, and Small-Scale Testing ............. 171

Step 3: Develop Preliminary Form of the Product..................................................... 172 


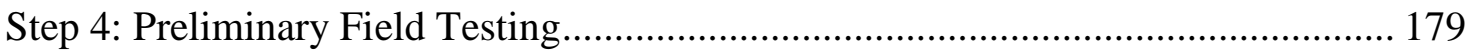

Step 5: Main Product Revision........................................................................... 182

Utility Questions (useful or purposeful) ........................................................ 183

Feasibility Questions (practical or realistic) .................................................... 185

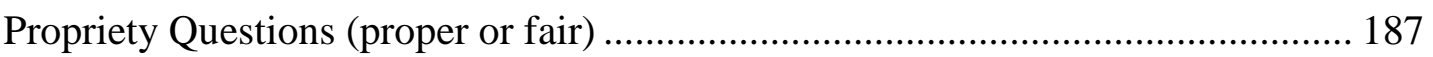

Accuracy Questions (adequately conveys analysis) ............................................ 189

Accountability Questions (contextualized and produces value) .......................... 191

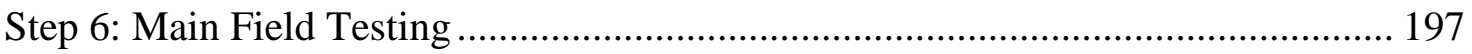

Step 7: Operational Product Revision ............................................................ 232

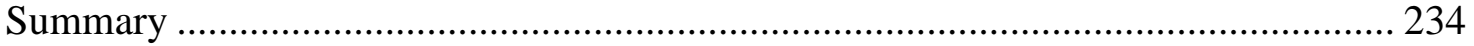

\section{CHAPTER 5 CONCLUSIONS AND RECOMMENDATIONS FOR LEADERSHIP 236}

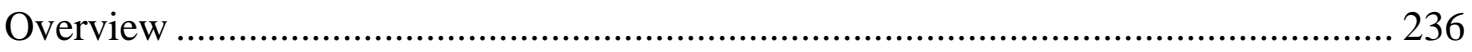

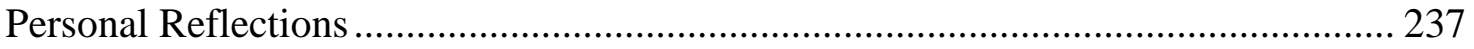

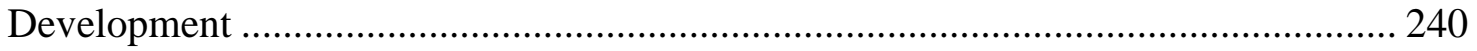

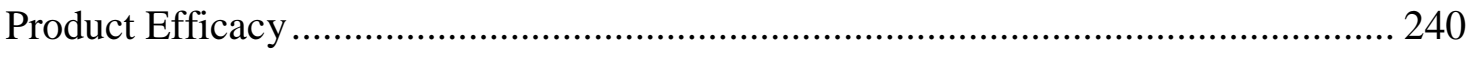

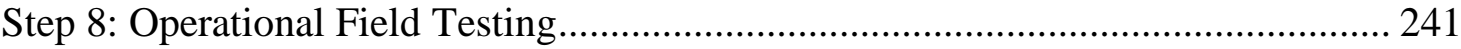

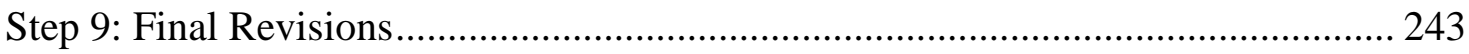

Step 10: Dissemination and Implementation .................................................. 244

Overall Conclusions and Assessment of the Experience ........................................ 246

Conclusions about the Efficacy of the Evaluation Toolkit........................................ 247

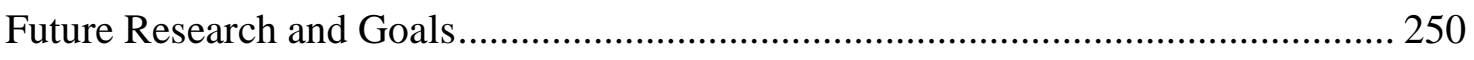

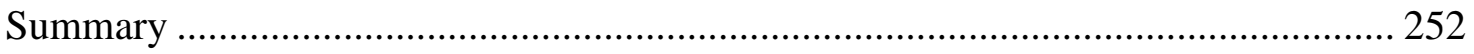

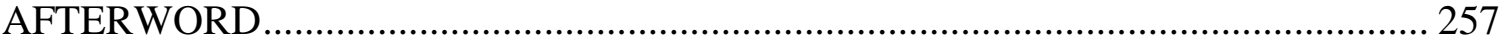

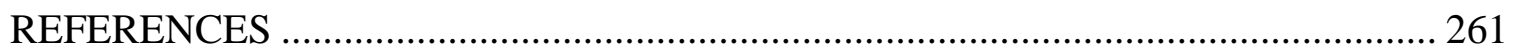

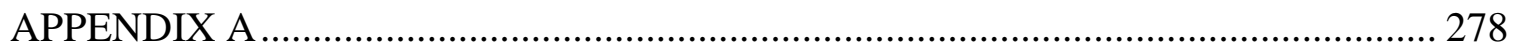

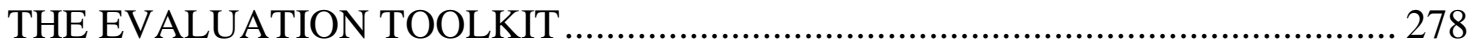


Alternative High School Program Evaluation Toolkit ........................................... 279

Alternative High School Evaluation Planning Worksheet ................................... 281

Alternative High School Evaluation Tool: Assessment ...................................... 283

Alternative High School Evaluation Tool: Curriculum......................................... 285

Alternative High School Evaluation Tool: Engagement .................................... 287

Alternative High School Evaluation Tool: Instruction....................................... 289

Alternative High School Evaluation Tool: Leadership ....................................... 291

Alternative High School Evaluation Tool: Structures........................................ 293

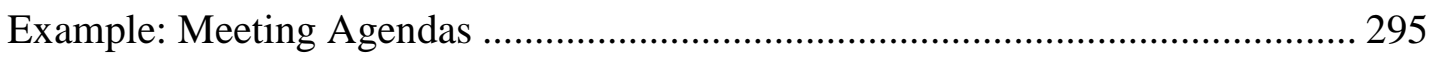

Example: Zeeland School District Alternative School Evaluation Scope of Work 305

Example: Evaluation Planning Worksheet (Completed)..................................... 307

Example: Alternative High School Accountability Metrics................................. 309

Example: Whyroads Alternative School Evaluation Report ................................. 310

APPENDIX B: DISTRICT ALTERNATIVE EDUCATION POLICIES .................... 345

APPENDIX C: DRAFT OREGON INDICATORS FOR SCHOOL DISTRICTS ........ 348

APPENDIX D: OREGON ACHIEVEMENT COMPACT DESCRIPTIONS.............. 351

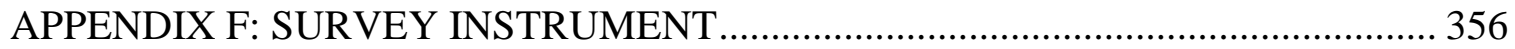

APPENDIX G: 2012 OREGON ALTERNATIVE EDUCATION REPORT ................ 364 


\section{LIST OF TABLES}

Page

Table 1: Elements of Exemplary Oregon Alternative Schools ............................................ 7

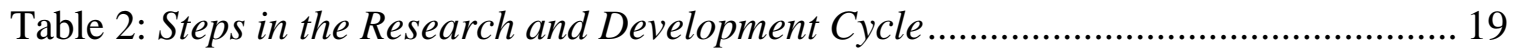

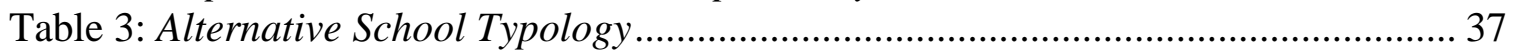

Table 4: Typology Based Upon Student Needs and Educational Challenges .................. 38

Table 5: Qualitative Information for District/State Policy-Level Program Evaluation ... 42

Table 6: Quantitative Information for District/State Policy-Level Program Evaluation . 43

Table 7: Evaluator Competencies Derived from Standards .......................................... 44

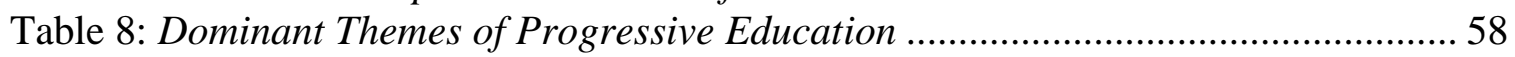

Table 9: Comparative Analysis of State Law and Sample District Policies ..................... 61

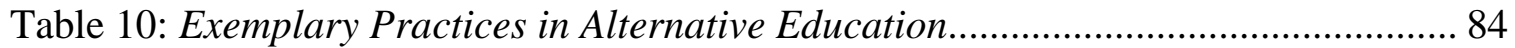

Table 11: Trends and Innovations Likely to Impact Your Evaluation Practice ............. 104

Table 12: Alternative High School Program Evaluation Toolkit Characteristics.......... 105

Table 13: Materials and Resources Needed for the Program Evaluation....................... 127

Table 14: Timeline for Evaluation for the Program Evaluation..................................... 127

Table 15: Six Tools for Evaluation Teams ............................................................... 128

Table 16: Evaluation Planning Matrix (Assessment Evaluation Workgroup Example). 130

Table 17: Evaluation Plan (Assessment Evaluation Workgroup Example)................... 131

Table 18: Dimensions and Underlying Purpose of the Evaluation Toolkit for Teams... 132

Table 19: Conference Presentations on Alternative School Evaluation......................... 135

Table 20: Secondary (Guiding) Questions Organized by Element ............................... 146

Table 21: Sources of Data Used in This Study ............................................................ 154

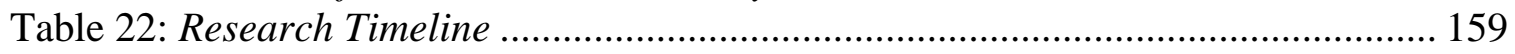

Table 23: Secondary (Guiding) Questions Organized by Standard Element ................ 166

Table 24: Utility Guiding Research Questions ......................................................... 183

Table 25: Feasibility Guiding Research Questions .................................................. 185

Table 26: Propriety Guiding Research Questions ....................................................... 187

Table 27: Accuracy Guiding Research Questions ....................................................... 189

Table 28: Accountability Guiding Research Questions .............................................. 191

Table 29: Participants, Roles and Meeting Attendance .............................................. 200

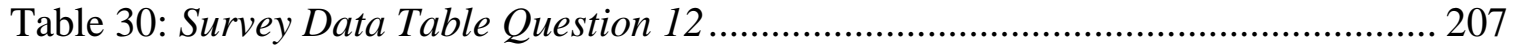

Table 31: Survey Data Table Question 21 .................................................................. 209

Table 32: Survey Data Table Question 22 ................................................................. 213

Table 33: Characteristics in Rank-Order Based on Average Ranking Method.............. 215

Table 34: Characteristics in Rank-Order Based on Mean Rank of Rank Method.......... 217

Table 35: Survey Data Table Question 23 ............................................................... 220

Table 36: Toolkit Elements in Rank-Order Based on Average Ranking Method ........... 225

Table 37: Toolkit Elements in Rank-Order Based on Mean Rank of Rank Method ....... 226

Table 38: Future Uses of the Evaluation Toolkit ............................................................ 251 


\section{LIST OF FIGURES}

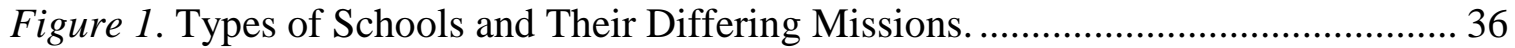

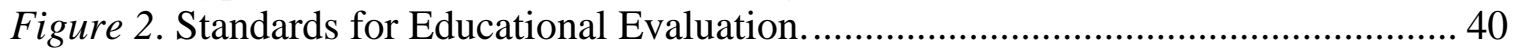

Figure 3. Historical Context of Alternative Schools Over the Last 100 Years. ............... 52

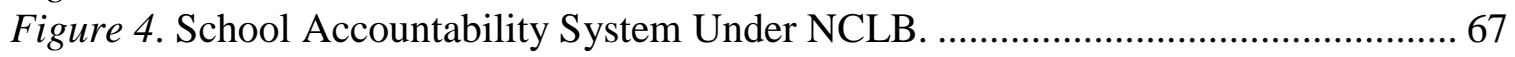

Figure 5. School Typology Alternative Accountability Framework............................ 109

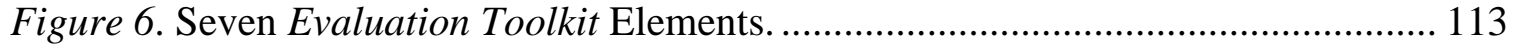

Figure 7. Ten Evaluation Process Characteristics ...................................................... 114

Figure 8. Eight Assumptions About Program Evaluation............................................. 116

Figure 9. Dimensions of Alternative Aaccountability and Evaluation......................... 120

Figure 10. Framework for the Design and Evaluation Process................................. 125

Figure 11. Survey Data Figure Question 12 (Participation in Evaluation Process)...... 207

Figure 12. Survey Data Figure Question 21 (Assumptions About Evaluation Process). 210

Figure 13. Survey Data Figure Question 22 (Ranking of Process Characteristics)...... 214

Figure 14. Survey Data Figure Question 23 (Ranking of Toolkit Elements). ............... 221

Figure 15. Framework for the Design and Evaluation of Alternative High Schools. .... 249 
Preface

Crossroads Alternative High School had been identified as a school "in need of improvement" for the third year in a row. As the Oregon State Alternative Education Specialist, I was asked to work with school district and regional office administrators to evaluate the school. After doing some background research, speaking with the school administrator and reviewing information reported on their State-issued school report card, I assembled an evaluation team and visited the school in an attempt to make sense of what was happening.

Crossroads School is an alternative high school located near an urban area in Oregon. Student attendance at the school fluctuates during the course of the year but in September approximately 100 students are enrolled, by winter break there are usually around 125 and by April the enrollment has swelled to around 150. Most of the new students who join mid-year had experienced an event that resulted in them being given several options for their schooling such as other programs or tutoring. School placement is made with consultation of the parent and students typically choose Crossroads over some other school placement. As additional students enroll throughout the year, others may drop out, move, transition back to the school where they came from or transfer.

Crossroads operates out of a building that was previously an elementary school but there is now a full-time counselor, social worker and half-time nurse on campus that attends to the diverse needs of students. The school has a full time administrator, Mr. Lovall, who gets to know each student as a part of the student intake process. Most of the teachers, parents and students would remark that Mr. Lovall has provided strong 
leadership in the school and that the school operates like a large family. The newly painted walls demonstrate a summer-time artistic contribution of high school students, there is a child-care facility for children of teen moms and night school that allows students to access the computer lab and tutoring until late-evening. Teachers demonstrate they care for the students in many visible ways, greeting each student with a personal sense of care and attention. Teachers quietly make individualized comments of encouragement as students participate in learning activities and submit classwork.

At Crossroads students refer to their teachers by their first names and often share meals together in the school cafeteria. The day begins with "homeroom" when students connect with one another and their homeroom teacher in smaller class groups. Class sizes are small and behavior expectations are made clear and reinforced regularly. An “advisory" period provides time each day for teachers and mentors to communicate lifeskills emphasizes the development of students' non-academic skills. Specialized curriculum is used during the advisory period that provides opportunities for students to discover learn and reinforce these non-academic skills.

Teachers work with students in small groups using projects and relevant examples to help students make sense of the content. Class sizes are smaller than traditional schools, ranging from 6 to 12 in a class and students comment that work is difficult but credits and rewards are attainable with hard work and persistence. Students would also describe that their teachers have high expectations for their achievement that are reinforced regularly by celebration for attendance demonstrating proficiency in standards and achieving academic credit that demonstrate progress toward high school graduation. 
Students are encouraged to utilize the computer lab and study hall after the school day has concluded and flexible schedules for courses provide students the ability to participate actively in both afternoon and evening classes.

The school has a low staff-to-student ratio, individualized instruction and flexible scheduling to support students in meeting learning goals. As is the case with most of Oregon's alternative high schools, most of the students enrolled at Crossroads have significant academic challenges but initial observation made by the school evaluation team during the school visit indicate that the school is in compliance with the law and meeting the academic as well as the non-academic and behavior needs of students.

Following the school visit, the evaluation team met with school administrators from the school, district and regional office to go over the "compliance indicators" described in the State-provided toolkit for district program approval, evaluation and review of policies and procedures. The old toolkit was designed, several years ago by a previous Oregon state alternative education specialist, to assess compliance and document that the school was or was not following identified statutes and rules. Examples of the compliance indicators include health inspections, county fire marshal approval for building occupancy and assurance of background checks of staff working in direct unsupervised contact with students. While these indicators provided some assurance of safety for students, it was commented on by district staff that the toolkit did not address the school purpose, mission, educational setting, and curriculum or include indicators for quality programming that was demonstrated by the leadership, staff and students during the school visit. I had often felt that the toolkits did little to consider the 
context of the school or evaluate on the basis of "quality" practices and strategies seen at high performing alternative high schools.

As one former State Alternative Specialist put it, quality policies and practices account for the challenges that students bring to school and measures that against what the school is doing or not doing that contributes to those challenges (R. Morley, personal communication, December 29, 2011). Quality alternative education programs account for the challenges that students are facing and where he/she wants to go next. The result of these quality program policies is student achievement, demonstrated by increased attendance and academic engagement. The tools we currently use in holding alternative schools accountable are inadequate to address this need.

The current Oregon Alternative Education Toolkits include only a checklist-style summative review of compliance indicators such as adopted policies, contracts, financial statements, and student attendance, assessment and behavior records. The toolkits do little to provide guidance for districts assembling an evaluation team to conduct a formative review and do not identify what quality policies to look for in evaluating the impact of alternative high schools within the context of the region. In Oregon, the job of annually evaluating alternative programs is left entirely to the local school district.

The evaluation team I had assembled to visit Crossroads included members with first-hand knowledge of the school's purpose and policies, had background in alternative school leadership, teaching and assessment, school support systems, continuous improvement planning and special purpose school accreditation. After the visit, the team met briefly and informally regarding the old evaluation toolkits. The team members 
expressed that they felt constrained by these evaluation tools and didn't find the “compliance indicators" particularly helpful in determining overall program quality. Staff from the school and school district made similar comments when asked to provide feedback on the toolkits.

When members of the evaluation team were asked how they would improve the Evaluation Toolkit, some offered references to their previous experience with federal programs, special purpose school regional accreditation, and others made recommendations similar to the continuous improvement planning processes currently required for all Oregon schools. A few members of the evaluation team who had visited different types of alternative high schools and conducted evaluations for a variety of purposes articulately described quality indicators that were somewhat complex but identifiable in schools that served a special purpose, such as alternative high schools. Based upon the feedback of this evaluation team I began to assemble some assumptions about improvements that could be made to evaluation process and the toolkit.

With a limited understanding of how to address these improvements or what some of those quality indicators might include, I set out to contact alternative specialists in several other states, regional education research laboratories, the United States (U.S) Department of Education and national organizations in pursuit of an existing framework for determining quality in alternative schools. I would spend the better part of a year reviewing and collecting evaluation instruments and became immersed in the different types of schooling and evaluation methods utilized in public education, specifically those used in evaluating alternative high schools. 
I discovered that indicators of quality programming had recently been described by alternative specialists from Tennessee working with fellow officers at the National Alternative Education Association as the "Exemplary Practices in Alternative Education." They included indicators organized in the categories of mission and purpose, leadership, climate and culture, staffing and professional development, curriculum and instruction, student assessment, transitional planning and support, parent/guardian involvement, collaboration, and program evaluation (Witty, 2009). During a similar period of time, a retired alternative specialist from Iowa had worked within his state alternative education organization to develop “A Framework for Learning Alternatives Environments." His work included an" Inventory of Policies and Practices Related to Student Failure and Dropping Out" and a "Checklist of Quality Indicators for Alternative Learning Environments” (R. Morley, personal communication, January 14, 2012).

The tools I had observed up until this point were frameworks of quality indicators without context of school culture or student population. I believed improved tools may better serve the needs of the school, district and state than the current compliance toolkit. Unfortunately, the new tools were designed in the Southern and Mid-West regions of the United States and used nomenclature specific to the originating state laws in that region. The Iowa Inventory and Checklist would be useful but the summative method suggested by the tools themselves did not address the qualifications of the evaluator(s) and, being somewhat dated, did not represent the latest research on formative and impact evaluation. The framework and indicators of alternative school quality was the best I had seen over 
the course of the year and, based on my experience, would transfer across different types of alternative high schools.

It was clear to me and several other members of the evaluation team that Crossroads Alternative High School needed more of a formative evaluation, rather than a report card and an annual checklist for compliance. These tools had served their purpose in contributing toward increased awareness of the laws relating to alternative education in Oregon but had done little to contribute to quality district programming or the improvement of alternative schools themselves. From my observation, over the past five years as the alternative education specialist for the state of Oregon, such quality indicators were infrequently addressed in school district program evaluations. Moreover the evaluations themselves were not generally accepted as useful by schools.

Annual alternative high school planning and goal setting primarily addresses state-identified outcomes and does not describe program specific results or strategies used to support students. The State and districts need better information regarding the purpose of the school, guiding policies and information about the governance and leadership of the school. In addition, the State and district needs information regarding the curriculum, instruction, assessment, leadership and support systems that are being used for both district and school continuous improvement. Members of the evaluation team at Crossroads expressed that, in the case of alternative high schools, a summative checklist or school report card is similar to reading an obituary in the newspaper because it gives little room for improvement and by the time the information is assembled there is not much that could be done about it, but grieve the loss of life and potential. 


\section{CHAPTER 1 \\ INTRODUCTION}

I have spent the past several years as an Education Specialist at the Oregon Department of Education (ODE) and among the assignments I have at the Department is the monitoring of Alternative Education. In recent years I have been fortunate to work alongside a variety of stakeholder groups, professional organizations, contractors and consultants to facilitate both design and evaluation of alternative high schools that have contributed a great deal to me professionally. These experiences have resulted in a unique set of understandings about the connection points between alternative high school environments and the professional field of program evaluation. From these observations I have come to understand that evaluation is an absolutely integral part of the formation of the day-to-day operation of an alternative high school. I define alternative high school evaluation as the ongoing monitoring and adjusting that goes on in the school to assure that its programming is continually improving the way students are served.

Alternative high schools serve some of the most vulnerable students but their educational programs are challenging to evaluate. I define vulnerable students as those with two or more at-risk indicators such as pregnant/parenting, irregular attendance patterns, patterns of disruptive behavior or discipline issues, drug or alcohol abuse, learning disabilities, and/or not meeting or exceeding academic standards. Described characteristics of vulnerability may include qualification for free or reduced lunch, 
identification as an English Language Learner or the need of Special Education. Varying definitions of what an alternative school is make it difficult to determine indicators that would reliably indicate quality. Varying types of schools and student populations make even identifying valid indicators problematic. Despite these challenges, the need for program evaluation and improvement in alternative high schools has never been greater.

The past decade has thrust forward a new era in education accountability based primarily upon standardized assessments and measurement systems that are intended to hold traditional schools responsible for student achievement; however; there were 10,900 alternative schools operating in the United States (NCES, 2002a). A national survey, conducted in the 2007-2008 school year, reported that there were approximately 10,300 district-administered alternative schools and programs for at-risk students but did not include reference to newly publicly funded charter schools providing different forms of choice and options within public education. In that survey, $64 \%$ of districts reported having at least one alternative school or program for at-risk students that was administered either by the district or by another entity (NCES, 2010). These alternative schools continue to introduce new and innovative ways of working with learners and provide an opportunity for small-scale experimentation with public resources. It is clear that these alternative schools are not traditional schools; however, they are often included in traditional forms of educational accountability. Researchers, such as Aron, 2003, 2006; Barr \& Parrett, 1997, 2001, 2010; Moreley, 2012; R. Morley, 1996; Raywid, 1981, 1994; Reimer \& Cash, 2003; Schargel \& Smink, 2001; Smink \& Schargel, 2004 have studied innovations and evaluation of alternative high schools. 
This dissertation introduces and further explores definitions, significance, and analysis of the problem of how best to evaluate alternative high schools and describes methods for a process that will result in a product intended for use by evaluation teams in evaluating the impact of alternative high schools throughout Oregon. A review of relevant literature, in chapter 2 , provides a historical perspective and references previous work from the broader field of program evaluation. The review also includes the generalized debated perspectives that have contributed toward my understandings in the development of the alternative high school evaluation tools.

As I have considered differences in alternative high school evaluations, I have come to a deeper understanding and respect for the Joint Committee on Standards for Educational Evaluation's Program Evaluation Standards (Yarbrough, Shulha, Hopson, \& Caruthers, 2011), which include standards organized in five parts. Brief descriptions of the five parts provide generalized best practices in the field of program evaluation as applied in educational settings. The standards are included in the definitions section in chapter 1 and are expanded upon in the literature section of this dissertation and used as organizers for the research questions in the study described.

The first part of the Standards for Educational Evaluation describe "Utility" which is used to describe the extent to which program stakeholders find the evaluation process and products valuable in meeting their needs. "Feasibility" is the second part and refers to the degree of the evaluations effectiveness. The third part is "Propriety" which depicts what is proper, fair, legal, right, acceptable and ethical in an evaluation. "Accuracy" refers to the truthfulness of evaluation representations, propositions, and 
findings that occur as a part of the evaluation. The fifth part is "Accountability" which, in the context of program evaluation, refers to the responsible use of resources to produce value as a result of the evaluation. These parts and the underlying Standards put forth by the Joint Committee on Standards for Educational Evaluations (Yarbrough et al., 2011) provide a first glimpse of what the field of program evaluation can offer those who seek to determine the impact of alternative high schools.

\section{Statement of the Problem}

The problem involved the investigation of how best to evaluate alternative schools. More explicitly, districts do not have adequate tools to evaluate the quality of their alternative programs. The Alternative High School Program Evaluation Toolkit is intended for use by evaluation teams assigned the task of determining the purpose and impact of alternative high schools. Alternative schools serve some of the most vulnerable students and their educational programs are difficult to evaluate. Varying definitions of what is an alternative school make it difficult to determine quality. Varying types of schools and student populations make identifying valid indicators problematic. School evaluators often act in isolation and often only address issues of compliance based upon what they know about traditional schooling. Evaluation tools made available to evaluators are usually limited to checklists and are inadequate in accounting for a deeper understanding of how alternative schools are serving students. It is because of these challenges that the need for evaluation in alternative education has never been greater.

There is more to holding schools accountable than outcomes such as test scores, attendance, and graduation (Barr \& Parrett, 2010; Goodlad, 2004; Kohn, 1999; Koretz, 
2008; Milliken, 2007; Popham, 2001; Ravitch, 2010); especially when it comes to determining the impact of alternative high schools (Barr \& Parrett, 2010; Leiding, 2008; Reimer \& Cash, 2003; Schargel, 2005; Smink \& Schargel, 2004). If methods of using these simplistic measures continue to be found not to be adequate in comparing quality among traditional high schools, they are especially inadequate in determining the impact of alternative high schools.

Variance between types of schools and experience among educational evaluators causes considerable problems with measurement, especially when it comes to alternative schools (Barr \& Parrett, 1997; R. E. Morley, 2002; Reimer \& Cash, 2003; Schargel, 2005). In my experience as the Oregon State Alternative Education Specialist, I have found that the principles described by the Joint Committee's Standards for Educational Evaluation (Yarbrough et al., 2011), introduced previously in this dissertation and used as a theoretical framework in this dissertation, are rarely referenced in the context of evaluating alternative schools and are not addressed by the elements of evaluation tools made available to support required annual evaluations. Practitioners and stakeholders alike haphazardly apply their own personal opinion about the quality of schooling in their communities. After all, most adults experience schooling in one form or another when growing up, have likely spent considerable time reflecting on those experiences, and some even went back to school to serve as a teacher or school administrator; making them an expert. However, educational experience differs widely depending upon the state, district, school and programs attended, level of involvement in the school, and if the institutions were public, private, traditional, charter, magnet, or alternative. 


\section{Elements of Successful Alternative Schools}

As described previously, alternative education settings vary in both mission and goals but previous researchers have identified elements intended to be used in describing successful alternative schools. However, methods of applying these elements in program evaluation are not often explored in the literature. The Northwest Regional Educational Laboratory (NWREL) (Cotton \& Paglin, 1995) have described observed elements that would indicate success. Others have recorded the observation of elements from site visits and program evaluations (Barr \& Parrett, 1997; Leiding, 2008; ODE, 2006a; Schargel \& Smink, 2001). Reimer and Cash (2003, p. 15) described characteristics (elements) of successful alternative schools in a synthesis of previous research and are further described the review of literature in this dissertation.

\section{Essential Elements of Effective Alternative Schools}

Barr and Parrett (1997) reported that effective alternative schools have a shared vision, educational diversity, relevant and focused curriculum, creative instructional approaches, student assessment, caring and demanding teachers, voluntary participation (school choice), comprehensive programs, small school size, and shared governance and local autonomy. Table 1contributes a dozen Elements of Exemplary Oregon Alternative Schools I observed during alternative school visits in 2006. Elements 11 and 12 describe new forms of program evaluation to inform alternative school improvement the Toolkit supports. 
Table 1:

Elements of Exemplary Oregon Alternative Schools

1. Strong mission and sense of purpose

2. Caring and committed staff

3. Services to meet the emotional, physical and academic needs of students

4. Sustainable structures of funding and leadership

5. High expectations for student achievement

6. Low adult to student ratios that allow individual attention and care

7. Individualized learning programs to meet the needs of the students

8. Varied instructional strategies with an emphasis on active learning

9. Rigorous academic standards and clearly communicated performance expectations

10. Flexible schedule that meets the needs of students

11. Customized program evaluation that is alternative school evaluation to be practical, useful, fair and accurate

12. Communication of both summative and formative program results

Sources: Hinds (2010); ODE (2006a)

The elements of this framework are representative of more than 50 years of research on successful and effective forms of alternative schooling. During the past 25 years, thousands of alternative public schools, magnet schools, experimental schools and other non-traditional programs have been developed and documented to be effective in teaching reluctant learners (Barr \& Parrett, 2001, p. x). As mentioned in the introduction to this dissertation, much of this research can be described as "common sense findings" and serve to only superficially benefit educational innovators in the evaluation of alternative high schools. The framework provides starting place to continue the work of developing tools for evaluation teams to inventory and report (take into account) their existing programs and use those reflections to improve others. 


\section{Research Perspective}

In addition to reviewing literature on this topic, I have served in positions at the classroom, program, school, district and state levels that have exposed me to a widerange of experiences and involvement in school evaluation. In particular, my role at the Oregon State Department of Education (ODE) has required that I lead and participate in a variety of program, school and district evaluations as well as federal monitoring visits, civil rights, curriculum and school financial audits. I have participated in school accreditation and program evaluation visits that have provided a unique and diverse lens of alternative and special purpose education in Oregon and the Pacific Northwest.

I have participated in accreditation and school visits in other parts of the United States (Southwest, Mid-West, South, and Northeast) and in Egypt. In addition, I have written legislative concepts and bills, testified in front of the Oregon legislature, written guidance and rules, presented at state, regional and national conferences and implemented new state guidelines relating to various program areas such as private schools, home schooling, GED Options, High School Diploma, Credit by Proficiency, Instructional Materials, and Common Core State Standards. These experiences have allowed me to, in the words of Ravitch (2010), "think like a policy maker, looking at schools, teachers and students from an altitude of 20,000 feet" (p. 10) and view firsthand, the challenges of implementing both state and federal policy with local districts, schools, and alternative high school programs. However, I have paid special attention to my perspective as a researcher and practitioner by making regular visits and spending time in alternative school settings and grounding myself in literature in this field. 
The access and experiences described have also permitted me to contrast my observations with local school district educational policy, having served as a teacher, school and district administrator. I draw upon decade of experience spent in the field of education serving in the roles of a teacher, school administrator, district administrator, college instructor, and state education program coordinator. I have been fortunate to work with other state alternative school specialists from Arkansas, California, District of Columbia, Georgia, Idaho, Iowa, Michigan, Massachusetts, New Jersey, Tennessee, and Utah. While there are differences between state laws and nomenclature used, there are often similarities in the kinds of challenges program, school, district and state leaders face in evaluating alternative high schools. Those commonalities provide for supportive dialogue and rich professional learning as state administrators collaborate.

\section{Purpose and Significance of the Study}

The product of the Research and Development (R\&D) Cycle is an Alternative High School Program Evaluation Toolkit (Evaluation Toolkit) intended for use by evaluation teams assigned the task of determining the purpose and impact of alternative high schools. This research is theoretically and practically grounded in Bridges and Hallinger's (1995) Problem-Based Learning (PBL) and Borg and Gall's (1989) R\&D Cycle. The research proposes a method of research study that includes information collecting, learning activities and small-scale field testing that involved evaluation teams and education stakeholders in the development, revision and refinement of a prototype of the Evaluation Toolkit. 
Alternative high schools serve some of the most vulnerable students and their educational programs are challenging to evaluate. This research study was significant because, from the perspectives of the district and state, alternative schools are difficult to hold accountable. Tools are needed to support evaluation teams in determining the purpose and impact of alternative high schools. Current methods of alternative school accountability utilize a one-size-fits-all school report card or a summative compliance checklist as a part of required annual evaluations. These tools are inadequate and are not perceived to be generally useful for the school, district or the state.

Oregon's educational accountability system primarily addresses district and school-level accountability and reports Adequate Yearly Progress (AYP) indicators for attendance, test scores and graduation rate. The evaluation of district alternative programs is annually required and district-approved programs are reported to the State annually and included in the district-level reporting. A toolkit for the evaluation of alternative education programs is provided to support this district evaluation and the State annually produces district report cards.

The "next generation accountability system" proposed in Oregon's request for a waiver of No Child Left Behind (2001) and AYP is based upon a student-level growth comparison that continues to mainly rely on student test scores in reading and math. This new system also proposes an early-warning system for ninth grade students not on-track to graduate with their 4-year cohort. While these new systems proposes improvements to AYP's one-size-fits-all approaches to accountability, it still falls short of providing better 
ways to hold alternative high schools accountable or validly identifying their purpose and impact on student success (ODE, 2012).

While varying definitions of what an alternative school is make evaluation difficult, it is possible to identify elements of quality school policies within the context of alternative high school program evaluation. A toolkit is needed to support evaluation teams in identifying these generalizable characteristics of quality. Varying student populations makes identifying valid quality indicators problematic but these issues may be addressed through other tools in the toolkit such as an inventory of policies and practices (R. Morley, 1996), identification of characteristics of quality (National Alternative Education Association [NAEA], 2009), assurances of compliance (ODE, 2006b), combined with formative and mixed method program evaluation conducted by an evaluation team. These alternative high schools are primarily serving students at risk of dropping out of school and require special attention and methods of accountability that reach beyond traditional forms of school reporting.

About four of every five students attend traditional high school in America (NCES, 2010). It is easy to throw students out of school, but it is much harder to help them redirect their energy to become successful in school (Reimer \& Cash, 2003, p. 36). Traditional public high schools were never designed to meet the educational needs of all students who enroll in them, nor have they kept up with changing demands of student demographics (Barr \& Parrett, 1997). The need for program evaluation and alternative school improvement has never been greater and the field of educational program 
evaluation has a lot to offer alternative education, if only there were adequate tools to support their improvement.

Recent articles published in The Oregonian, a daily newspaper, maintain that inclusive comprehensive (traditional) high schools are the answer to challenges in student performance on state tests and graduation. Betsy Hammond, educational writer for The Oregonian, reported that Oregon's largest urban school district moves around struggling students and places them in mostly unaccountable alternative schools where at least $80 \%$ drop out (Hammond, 2012a). This article represents evidence that this problem of holding alternative schools accountable is significant and worthy of study.

\section{The Need for Evaluation Tools}

Program evaluation tools used by evaluation teams may offer support in making the process useful to the school, district and state. I sought out the previous Oregon Deputy Superintendent of Schools who is now an urban district administrator and supervises the operation of a variety of district operated alternative schools. He said that evaluation tools must balance valid measurement (validity) indicators that may represent complex characteristics with ease of use (reliability) by the evaluation team (S. Noor, personal communication, January 2010). The development of valid and reliable tools for use with a variety of alternative schools would prove to be a significant challenge.

Failing to properly train the evaluation team can have serious negative effects on the outcome of the data collection process in evaluating an alternative schools (Reimer \& Cash, 2003, p. 36). Many school district leaders today are involved in developing and evaluating new kinds of schools and are in need of simple research-based tools and 
evaluation protocols (McDonald, 2007) to accomplish their work. Not many of these leaders have the experience of working within a broad range of schools and few have had professional experience or graduate courses in organizational assessment or program evaluation.

\section{The Need to Equip Evaluators}

A mix of internal (from inside the organization) and external (from outside the organization) evaluation team members are necessary for a valid program evaluation (Patton, 2011). Forming an evaluation leadership team is a key ingredient to strengthening, sustaining and widely investing participants in the renewal of their schools (Chenoweth \& Everhart, 2002, p. 17). Evaluation team members are carefully selected based on qualifications, selection guidelines and team responsibilities (Chenoweth \& Everhart, 2002, pp. 17-21) with specific attention paid to context of the school and effort to produce value as a result of the evaluation.

Members of the evaluation team may have not had the experience of participating in district monitoring or accreditation visits and may have never been involved in alternative high school evaluation. Evaluation team members may have had involvement in district or school-level continuous school improvement activities such as setting performance goals for attendance, setting smart goals, considering theories of action, curriculum audits, school improvement and assessment and perhaps even budget planning. Few educational leaders have had the time or reason to investigate regional or national trends in educational innovation, program effectiveness or have had opportunity to interact with state or federal policy makers in relationship to what is being found to 
work in other parts of the state or country. Moreover, many district leaders have not had a single graduate level course in program evaluation and consequently do not have adequate training to evaluate diverse schools.

Rick Stiggins from the Assessment Training Institute asserts that administrators and teachers should be adequately trained to use student assessment and evaluation and that it should always begin with the intended learning if it is to benefit (for learning) students (Stiggins, Arter, Chappuis, \& Chappuis, 2005). The development of an Evaluation Toolkit and accompanying guidance (protocols) for the evaluation process will contribute a great deal toward alternative school improvement and improve the usefulness of annual evaluations by addressing the weaknesses discussed here. The Evaluation Toolkit may generate discourse among educators about the value of assessment, program evaluation and different types of data in the context of alternative high school evaluation.

The development of state educational policies for evaluating alternative school effectiveness will involve significant challenge (Chalker, 1996; Reimer \& Cash, 2003). Developing a useful toolkit for use in evaluating different types of alternative high schools is a significant step in state-wide program improvement. This is a significant challenge, in part, because there are so few published research studies on the topic. The school accountability information maintained by the state and used for accountability could be described as a "blunt" instrument for evaluating traditional schools, containing only information such as attendance, graduation rate and test scores to determine school quality. Newer models for school accountability simply look at those 
same indicators over a specified period of time (growth) for traditional schools (ODE, 2012; Quality Education Commission, 2012, p. 13). Test scores, graduation rates and attendance are not sufficient measures to capture the mission and goals of alternative programs such as increased engagement in school by the student in effort toward school work, evidence of academic progress that is not test-based as well as increased aspirations for completion of school or post-secondary education.

\section{Research Methodology}

The research was theoretically and practically grounded in Bridges and Hallinger's (1995) PBL and Borg and Gall's (1989) R\&D Cycle. The methods employed information collection, planning objectives and activities and small-scale field testing. The product of the R\&D Cycle is an evaluation toolkit used by evaluation teams assigned the task of determining the impact of alternative high schools. This research methodology proposes a method of research and information collecting, small-scale testing, development, field testing, and refinement of a prototype of the Toolkit. References used were books, refereed journals, reports associated with alternative schools, evaluation tools and my own experiences as an experienced alternative school program evaluator.

The terms "alternative school" and "alternative program" are used interchangeably throughout the literature (Barr \& Parrett, 2001; Conley, 2002; Lange \& Sletten, 2002), with "alternative education" as a term that includes both schools and programs. Research terms such as "dropout prevention" (Milliken, 2007) and "at-risk students" (Chalker, 1996) are also referred to in research and information collecting. 


\section{Research and Development}

Having spent the greater part of the past several years collecting, using and reflecting on various school and educational program quality evaluation instruments, I set out, as a part of my position at the ODE, to develop a Toolkit that would support teams in building consensus among evaluators. The Toolkit began with an open (funneling approach) determination of "quality" or "not quality" (yes or no) intended to guide the evaluation teams toward indicators and the development of a logic model (theory of action) development exercise.

Information and feedback gathered in this planning phase from colleagues and school site directors provided important information in moving forward. For example, although I provided space in first portion of the instrument for both the yes/no statement and for comments, the narrow scope and early determination of quality or not quality was problematic. It lacked indicators that would provide evaluators an opportunity for an ordinal response for recorded results. It was too unstructured, especially for evaluators with little experience with organizational theory and evaluating alternative high schools.

Former state agency directors noted to me that an evaluators experience plays an important role in evaluation and those differences in evaluation experience cause variance in the interpretation of the standards or indicators used (R. Morley \& R. Lindley, personal communication, January 2012). The recommendation was made that the statements be modified to include more traditional Likert Scale response format of strongly agree, agree, neutral, disagree, strongly disagree which were made in future revisions of the toolkit. Accompanying the Evaluation Toolkit development, I needed to 
develop a process that involved stakeholders in a small-scale research and information collecting that would both serve to improve the Toolkit and contribute toward the current evaluation and monitoring of alternative schools.

Regional accreditation processes require school officials complete a self-study that includes a written reflection of how the school meets each of the standard indicators and requires documentation to support each indicator (AdvancEd, 2012a). Accreditation visits rely heavily on this self-reported documentation and seek to validate claims made in the self-study as a part of the formal evaluation visit and corresponding report written by members of the accreditation team. The team offers responses to standard statements supported by collaboration and consensus building.

Essential to this work was collaboration with Chet Edwards' in his efforts to establish a design process for alternative high schools that asks members of a Leadership Team to "start over" based upon a clear set of standards and elements. In collaboration with Mr. Edwards I observed that the school design process appeared to benefit from participation in more formative evaluations that, to borrow from Covey (2004), "begin with the end in mind" (p. 97). These teams appeared to benefit from an initial inventory (needs assessment) that includes reporting of student information (impact), followed by consideration of policies that provide assurance of both compliance and quality.

Portions of the original Toolkit will likely be carried forward and entire portions may be removed as it moves through preliminary field testing and operational produce revisions. Future versions may include an inventory of policies as well as updated compliance components that account for curriculum, instruction and assessment. These 
early steps in the R\&D cycle were an organized and collaborative effort that included coming back regularly to the original planning objectives of inventory, compliance and quality; the components of the evaluation process originally expressed to be of value along with the characteristics of quality evaluation mentioned earlier and are described further in Figure 9 (Reporting, Compliance and Quality Assurance).

Preliminary field testing of the prototype (product) involved a single alternative school in southern Oregon and was later expanded upon as a part of operational field testing to involve additional school leaders, district administrators and participants that better represent the alternative schools throughout the State. The process sought to narrow the Toolkit's focus to those topics that are perceived as generally useful for accountability and decision making. Product revisions improve the Toolkits' usefulness. The main field testing included the use of the Toolkit in evaluating an alternative school in an urban region in Oregon. The desired result of the evaluation should be that staff at the school, district, and the state perceive the evaluation to be generally useful for decision making. The Toolkit should assist the evaluation team and stakeholders in conducting a thorough and accurate evaluation that describes the impact of the alternative high school and contributes to a better understanding of what is occurring at the school.

An approach to develop such a process (alternative high school program evaluation) is to create an educational product (Toolkit) that serves to inform and equip educational leaders and school evaluation teams tasked with evaluating an alternative high school. I developed a preliminary form of the product, an Evaluation Toolkit, but further work needed to be done to revise, test and operationalize the tools. To accomplish 
this work, I used a form of educational research known as PBL (Bridges \& Hallinger, 1995). PBL involves the development of a product to address an actual problem and provides the opportunity to collect information, plan objectives and learning activities that result in small-scale testing and the development of preliminary form of the product. The study involved experienced school leaders and external program evaluators in the product revision and field testing in order to improve a prototype of the Alternative High School Program Evaluation Toolkit. Borg and Gall (1989, p. 782) identify 10 steps in an R\&D Cycle, presented in Table 2.

Table 2:

Steps in the Research and Development Cycle

1. Research and information collecting

2. Planning objectives, learning activities, and small-scale testing

3. Develop preliminary form of the product

4. Preliminary field testing

5. Main product revision

6. Main field testing

7. Operational product revision

8. Operational field testing

9. Final product revision

10. Dissemination and implementation

Source: Borg and Gall (1989, pp. 784-785)

PBL involves addressing and fixing real world problems and in this study it involved the field testing of the Evaluation Toolkit in order to develop an improved evaluation process for alternative high schools. The product development and prototyping process, resulted in the development of a preliminary form of the product (Step 3) is 
justified and linked to the R\&D cycle described by Borg and Gall (1989) as a process used to validate educational products. Operational Product Revision (Step 7) completes the R\&D Cycle for PBL. For purposes of this dissertation, only steps 1 through 7 were employed. Steps 8-10 will be utilized for future research and work agenda discussed in future chapters. The study stops short of dissemination and implementation and concludes with step 7, operational produce revision.

In my role at ODE, my intent is to work with school districts and stakeholders to conduct Operational Field Testing and make Final Product Revisions and disseminate my findings to ODE and alternative high schools around the state. This dissertation reports on the problem-based approach that improved the Evaluation Toolkit for use with Alternative High Schools. Borg and Gall's (1989) four salient questions, responded to below, provide a framework considered in the R\&D:

1. Does the product meet an important educational need? Yes, the evaluation of alternative schools is an essential contributing factor in serving the most vulnerable students. A handful of similar products exist, including several developed by school districts and other states but some educational leaders have expressed a need for additional tools to support evaluations.

2. Is the state of the art (in relation to need or problem) sufficiently advanced that there is reasonable probability that a successful product can be built?

Yes. A compliance checklist tool already exists (ODE, 2006c) and is used in annual summative evaluations of alternative schools conducted by school districts. While it addresses practices of learning and compliance with indicators that seek to assure 
student safety, it fails to include policy or practice quality indicators that might result in a determination of program quality that might be generally useful for decision making. Logic models are used frequently in new forms of program evaluation that have been successfully evaluating very complex organizations in the professional fields of medicine, and humanities, as well as in industry (Patton, 2011). Currently in most cases, alternative school evaluations are cursory or are conducted by outside contractors, perhaps demonstrating a district's lack of interest in programs that serve the most vulnerable students. The product includes characteristics of the most recent forms of school and program evaluation, including policy inventory, new results reporting and is based upon the most recent accreditation standards and involves forms of alternative accountability

3. Are personnel available who have the skills, knowledge, and experience necessary to build this product?

Yes. In some cases, those who cooperate in current evaluations and accredit special purpose and alternative schools are those who operate similar programs in the region and state. Both formal and information professional networks and associations exist and support these evaluators with training and professional development related to evaluation. As a part of my responsibilities at ODE, I meet with a number of these networks regularly and many of them have contributed toward refinement of my thinking about the tool and the elements that are included in the most recent version.

4. Can the product be developed within a reasonable period of time? 
Yes. I have spent the past five years in my position at the ODE and the better part of six years in graduate courses exploring different types of educational programs and schools and methods used to design and evaluate them. I sometimes comment that I spent a year (2011) exploring in the "typology forest" during which I explored, visited and literally built a library of resources from research and innovative school publications, toolkits, blueprints, instruments and handbooks. I have collected little-known historical anecdotes and more than 30 instruments that have been developed over the past few decades that have been used to evaluate various types of alternative programs and schools. I compiled the frameworks side-by-side in a spreadsheet for comparison and presented this information at several conferences. These tools were each designed for an explicit purpose and were designed to benefit a specific audience.

\section{Summary}

Few research studies exist that explore the characteristics and strategies of successful alternative high schools and link them with methods of compliance and quality program evaluation. The focus of the research is development, refinement and field testing of the Toolkit. None of the previous practice and research I am aware has sought to field test, modify and improve an educational product such as an Evaluation Toolkit. As a result of the lack of research in the area of evaluating alternative high schools, public policy and school accountability systems have either disregarded information relating to these schools or unjustifiably included them in comparisons with traditional high schools. Identifying methods to determine the impact of alternative high schools presents a significant research problem in an area of tremendous need for research. 
The focus of the dissertation research was the Evaluation Toolkit. The purpose is to improve the educational product through the R\&D Cycle, with the intended result of a more useful evaluation process for alternative high schools in Oregon. The research is theoretically and practically grounded in Bridges and Hallinger's (1995) PBL and Borg and Gall's (1989) R\&D Cycle. Future chapters describe the supporting literature and further explain the method.

\section{Definition of Terms}

- Accountability: In the context of alternative high school program evaluation, accountability refers to the responsible use of resources (time and tools) to produce value as a result of the evaluation for the community of students, parents and members of the region or state.

- Alternative High School: A public or private school or separate class group designed to best serve students' educational needs and interests and assist students in achieving the academic standards of the school district and the state. The majority of alternative high school students are enrolled in secondary grades (9-12). The school offers individualized instruction, low teacher/student ratios, flexible scheduling, and varied instructional methods to meet the learning needs of students. For the purpose of this research, alternative high schools include magnet schools and innovative schools that draw students from outside the school or district boundary. Although some charter and private parochial schools may also be considered to be alternative under this definition; they are outside the scope of this research study.

- Alternative High School Evaluation: A combination of both formative and summative observational records, data and information about what is happening in the school. Evaluation and information collecting is conducted to inform decision-making and may be referred to as value-added or mixedmethod evaluation. In general, evaluation examines schools to inform recommendations regarding annual state registration, school district approval and to make recommendations for programmatic refinement that positively impact alternative high school students. For the purpose of this study, alternative high school evaluation must involve a mix of both formative (ongoing information that describes the schools impact on students) and summative (multiple day school-site visits that includes a descriptive summary) methods. 
- Alternative Program: There exists some confusion about the definitions of a school and a school program in both federal and state policy. For the purposes of this research study, a program may have some features of an alternative school, but a program, especially an "alternative school program," is part of and in service to a larger and more comprehensive school. That is to say a program is not a comprehensive school. A school, including an alternative high school, is able to stand alone to meet regional accreditation standards, including (a) an autonomous mission, (b) educational program (curriculum, instruction, and assessment system), (c) leadership and organization, (d) supports for learning, (e) finance and facilities, and (g) plans for improvement. School programs, in service to a larger traditional school, may have one or more of the features of alternative high schools, but the focus of this research study is the evaluation of comprehensive alternative high schools rather than programs within a traditional school. "School program," as defined here, is also distinguished from "educational program" (commonly referred to as the curriculum, instruction, and assessment methods of a school).

- At-risk Students: Students with two or more at-risk indicators such as not meeting or exceeding state standards, behind in credits earned, pregnant/parenting, multiple suspensions, expulsion or infrequent attendance. At-risk students are referred to as vulnerable students or students at risk of educational failure (dropping out of school) in this research.

- Benchmark Evaluation: Evaluation that provides the means for organizations (alternative high schools) to evaluate their success in meeting a given set of standards and outcomes. Benchmark evaluations are usually designed as a resource, not as a mandate for programs.

- Charter School: A charter school, in Oregon, is a school of choice operated under a contract (charter) between a charter authorizer and a group of parents, teachers, and members of the community. Charter schools are required to meet requirements set forth in Oregon Revised Statute which include the use of flexible learning environments and innovative teaching and assessment methods that better meet individual student academic needs and interest.

- Compliance Indicators: Statements designed to support in the determination of whether or not the alternative program practice is in accordance with the law.

- Comprehensive School: A school able to offer credits, services and instruction in standards and essential skills to support students in graduation with a regular high school diploma.

- Criteria: A set description by which something can be judged. In an alternative high school program evaluation, criteria must be simple enough for evaluators to understand, yet complex enough to thoroughly explain the tools and indicators that describe what is being observed. 
- Design (Evaluation): A plan for conducting an evaluation; e.g., data collection schedule, report schedules, questions to be addressed, analysis plan, management plan, etc. Designs may be either preordinate (designed ahead of time) or emergent (emerging over time).

- Evaluation: A systematic investigation of the value, importance, or significance of something or someone along defined dimensions (e.g., a program, project, or specific program or project component) (Yarbrough et al., 2011, p. 287)

- Emergent Design: An implementation plan in which the specification of every step depends upon the results of the previous steps, sometimes also known as cascading or rolling design (Yarbrough et al., 2011, p. 287)

- Evaluation Team: Balanced evaluation team made up of both internal stakeholders and external members who are knowledgeable about the school's mission, purpose and policies, leadership, curriculum, instruction and assessment, support systems and planning.

- Evaluation Utility: Is used to describe the extent to which program stakeholders find the evaluation process and products valuable in meeting their needs (Yarbrough et al., 2011).

- Evaluation Checklist: A list that serves as a reminder of the process, procedures, and tasks that needs to be addressed during an evaluation.

- Evaluation Propriety: Depicts what is proper, fair, legal, right, acceptable and ethical in an evaluation. Considers the rights of stakeholders and intent to ensure that an evaluation will be conducted legally, ethically, and with due regard for the welfare of those involved in the evaluation as well as those affected by its results (Yarbrough et al., 2011).

- Evaluability: The degree to which it is possible to meaningfully evaluate a specific program at a specific time and place (Feasibility; Yarbrough et al., 2011, p. 287).

- Experimental Design: The plan of an experiment, including selection of subjects, order of administration of experimental treatment, the kind of treatment, the procedures by which it is administered, and the recording of data (with special reference to the particular statistical and other analyses to be performed (Yarbrough et al., 2011, p. 286).

- External Stakeholders: Those not having, or having less of, a stake in the school.

- External Evaluator: An evaluator from outside the school that is the subject of the evaluation and may serve as the facilitator as well as a member of the 
evaluation team. Typically external evaluators have entered into some form of a contract with the school district or regional education service district and offer an objective viewpoint to the team.

- Externally Validated: Confirmation of the shared beliefs of the school, its mission, function and the results being achieved from members that are outside the school organization. School visits often serve as a consensusbuilding process where internal and external stakeholders come to some level of agreement about the strengths of the school and the needed improvements, based upon established findings.

- Feasibility: In the context of program evaluation, feasibility refers to the extent to which resources and other factors allow an evaluation to be conducted in a satisfactory manner (Yarbrough et al., 2011, p. 288)

- Field Test: The study of a program, project or instructional material in a setting similar to that in which it is to be used. Field tests may range from preliminary primitive investigations to full-scale summative studies (Yarbrough et al., 2011, p. 288).

- Formative Evaluation: Evaluation designed and used to improve an alternative high school, especially when it is still being developed or redesigned (Yarbrough et al., 2011, p. 288)

- Focus Group: A group selected for is relevance to an evaluation or research that is engaged by a trained facilitator in a series of discussions guiding questions designed for sharing insights, ideas and observations on a topic of concern (Yarbrough et al., 2011, p. 288)

- Goals: Strategic and specific, measurable, attainable, results-based, timebound (SMART) objectives usually established by schools during annual school improvement planning (O'Neill, 2006).

- Holistic Evaluation: An evaluation that takes into account multiple and mixed methods of evaluation in order to describe what is happening in the current context (Sometimes referred to as mixed method, experimental, holistic, value-added evaluation).

- Indicators: Specific narrative descriptors that describe a particular degree to which practice, performance or behavior are observed to have been achieved.

- Internally Validated: Shared beliefs about the school, its mission, function and the results being achieved. School visits often serve as a consensus-building process where internal and external stakeholders come to some level of agreement about the strengths of the school and the needed improvements, based upon established findings. 
- Internal Stakeholders: Those inside the local district or school who are affected by or with interest in the school and/or the students who attend the school.

- Impact Evaluation: An evaluation that includes an identifiable assessment of academic and/or non-academic growth over a specified time period.

- Logic Model: Schematic organizer that accounts for the characteristics of students, staff, administrators and members of the community. The graphic organizer supports drawing conclusions (left to right) about strategies, resources and information involved in accomplishing desired results in order to accomplish desirable outcomes. Logic models are often used in program evaluations involving complex organizations, such as alternative high schools, that serve an evaluation purpose that requires a mixed of both method and approach.

- Mixed-Method Program Evaluation: Evaluation that involves multiple measures and information used to determine school results and outcomes. This type of evaluation may be referred to as value-added evaluation conducted to describe program results.

- Program: A set of specific activities and dedicated resources (inputs) designed for an intended purpose, or to achieve an intended process, product, service output with quantifiable goals and objectives. An example of a program within an alternative high school would be a program for young parents, a behavior or reading intervention program.

- Qualitative Information: Representations of experiences, performances, characteristics, or other descriptions presented in narrative or other symbolic but not numerical form (Yarbrough et al., 2011, p. 291).

- Quantitative Information: Representations of experiences, performances, characteristics, or other descriptions modeled by or summarized by ordered numerical systems (Yarbrough et al., 2011, p. 291).

- Regional Accreditation: A valid and standards-based school review that includes annual reports, self-assessments, school-site visits and assurance of reciprocity of credits and diplomas earned from other regionally or nationally accredited schools.

- Rubric: Tool that includes indicators that describe ordinal descriptors for predetermined categories of characteristics. Rubrics include descriptive indicators for each level of performance that may be described by an evaluator.

- School Design: A process of using conceptual frameworks, assumptions, and procedural steps to complete planning that follows an educational needs 
assessment, and before the implementation and full development of a designed school. For the purpose of this research study, it is assumed that program evaluation is imbedded in effective school design.

- School Quality Indicators: Statements designed to describe the degree to which the program is performing, with fidelity, to its mission, goals and expectations.

- Summative Evaluation: An evaluation designed to present conclusions about the merit or worth of an object program or organization and recommendations about whether it should be retained, altered, or eliminated.

- Time Series Study: A study in which periodic measurements are obtained prior to, during, and following the introduction of an intervention or treatment in order to reach conclusions about effects of the intervention.(Yarbrough et al., 2011, p. 293).

- Triangulation: The use of multiple sources and methods to gather similar information about an object of study, such as a program characteristic, indicator or specific outcome.

- Vulnerable Student: Student with two or more at-risk indicators such as pregnant/parenting, irregular attendance patterns, patterns of disruptive behavior or discipline issues, drug or alcohol abuse, learning disabilities, and/or not meeting or exceeding standards. Characteristics of vulnerability may also include qualification for free or reduced lunch, identification as an English Language Learner or in need of Special Education. 


\section{CHAPTER 2}

\section{REVIEW OF LITERATURE}

The following review of literature is a synthesis of content issues involving evaluation of alternative high schools. The exposition of these topics serves as a starting point for the product in this research study: an Evaluation Toolkit. This review of literature is not intended to lead to the identification of a researchable problem or identify research solutions. The literature selected is intended to ground the Toolkit in existing research findings and frameworks in an effort to support Toolkit development and the practical contribution to the field of alternative school evaluation. The literature studied will have an additive effect throughout future steps in the research cycle described in future chapters. The Evaluation Toolkit is already more useful in the alternative school evaluation process as a result of the literature reviewed in this section.

As stated in chapter 1, this research study is theoretically and practically grounded in Bridges and Hallinger's (1995) PBL and Borg and Gall's (1989) R\&D Cycle. PBL and $R \& D$ provide a framework for the development and field testing of an educational product designed to address an actual problem. Five topics have been selected to support this research study and contribute toward the grounding of the Evaluation Toolkit: types and purposes of alternative schools, standards for educational evaluation, alternative school history and policy, evaluation studies and reports on alternative schools and alternative school evaluation processes and tools. 
The first section describes types and purposes of alternative schools in the context of other types of schools and describes related frameworks for considering different types of alternative schools. The second provides a set of standards for educational evaluation that support the objective consideration of programs that have a mission and purpose different than what most adult educators experienced in their schooling. The section on alternative school history and policy describes where alternative schools came from and what general policies impact their operation. The section on evaluation studies and reports on alternative schools provides reference to research and evaluation conducted in the area of alternative education. The final section describes alternative school evaluation processes and tools that formed development of the Evaluation Toolkit.

It is important to emphasize that the field of evaluation, especially program evaluation, has much to offer alternative schools, including standards to support evaluations that are useful in the improvement process. This emphasis is included throughout the review of literature. Determining the level of quality in alternative schools is more difficult however, largely because there are a widespread variety of research studies that include descriptions of quality alternative schools. The impact of the school relies on valid feedback and evaluation. Traditional schools were probably never designed to serve all students (Barr \& Parrett, 2001; Ravitch, 2010; Reimer \& Cash, 2003; Schargel \& Smink, 2001; Smink \& Schargel, 2004); alternative school evaluation begins with needs assessment and evaluation planning that intends on providing ongoing (formative) feedback about how the school is doing and how to improve. 


\section{Types and Purposes of Alternative Schools}

The definitions of school organizations, including alternative high schools, are as diverse as the schools themselves, which result in high levels of complexity in efforts to evaluate them. In the past several decades researchers have developed typologies and frameworks for alternative schools with differing purposes (Aron, 2003, 2006; Barr \& Parrett, 2001; Raywid, 1994). Some have described different types of alternative schools within the context of broader school reform while others described them in reference to innovations in schooling that seeks to personalize student learning. A definitive typology of the many types of alternative education schools and programs has yet to be accepted by the field (Aron, 2006, p. 3).

The term "alternative education" in its broadest sense includes all activities that fall outside traditional neighborhood schooling in the K-12 school system-including home schooling, GED Options Programs, special education programs, residential and treatment programs, correctional settings, programs for gifted children, charter schools, magnet schools, charter schools, online/blended learning, etc. (Lange \& Sletten, 2002). As described earlier in the definitions section, for the purposes of the review of literature and this research study, an alternative program may have some features of an alternative school, but a program, especially an alternative program, is part of and in service to a larger and more comprehensive school. That is to say a program is not a comprehensive school. A school, including an alternative high school, must be recognized and reported as an institution and be able to stand alone to meet regional accreditation standards, including (a) an autonomous mission, (b) educational program (curriculum, instruction, 
and assessment system), (c) leadership and organization, (d) supports for learning, (e) finance and facilities, and (g) plans for improvement (AdvancEd, 2012b).

Comprehensive alternative high schools often serve a variety of some of the most vulnerable students and their programs are often difficult to evaluate. Varying definitions of what is an alternative school make it difficult to determine quality, especially because alternative schools primarily serve students who have failed or dropped out of traditional high schools (Aron, 2003, 2006). In some cases attending students have been suspended, expelled or removed from a traditional school setting because they have been disruptive, violent or have been identified to be able to benefit from an alternative educational setting. Traditional school policies and practices are often among the factors that contribute toward a student failing or dropping out prior to enrolling in an alternative high school (R. E. Morley, 2002). For this reason, some alternative educators describe serving as a teacher at an alternative school as "missionary work" where they employ practices that "awaken the dead" (Crossroads Staff, personal communication, January, 2010). This is not to say that they are engaged in saving the "souls" of students, the teacher statements speak to the personal investment necessary in reaching vulnerable students who have not found success in traditional learning environments.

Alternative high schools are public or private schools that are described as a school, program or separate class group designed to best serve students' educational needs and interests and assist students in achieving the academic standards of the school district and the state (ODE, 2006b). The majority of students at the school are enrolled in secondary grades (9-12) with an educational plan to achieve proficiency in academic 
standards resulting in the completion of a high school diploma or other equivalency certificate that will facilitate post-secondary school enrollment. As described earlier, traditional schools were probably never designed to serve all students (Barr \& Parrett, 2001; Ravitch, 2010; Reimer \& Cash, 2003; Schargel \& Smink, 2001; Smink \& Schargel, 2004). Alternative high schools offer, low teacher/student ratios, individualized instruction, flexible scheduling, and varied instructional methods to meet the learning needs of students (Barr \& Parrett, 1997; Chalker, 1996; Raywid, 1994). Alternative high school evaluation begins with needs assessment and evaluation planning that intends on providing ongoing feedback about how the school is doing and how to improve.

Schools are most accurately measured by its students and this philosophy is evident by schools current focus on adopting academic standards, improving accountability, and achieving excellence, while at the same time increasing corrective actions taken on violations of school disciplinary codes (Leone \& Drakeford, 1999). Varying types of alternative high school purposes and student populations make identifying valid evaluation indicators problematic. A school is made up students and those students make up the school. Information may be captured about student characteristics and a particular schools' purpose but the variety of types of schools is as wide as the array of students who attend them.

In 1999, the Florida Department of Education (1999) proposed "Quality Standards for Dropout Prevention Programs" and developed a self-assessment tool for practitioners. In 2001, alternative schools were broadly defined in Pennsylvania state policies as any institution that is not a traditional school. Arkansas Department of 
Education state policies attempted to further define specific program characteristics and eligible students. Dr. Raymond Morley (as cited in Reimer \& Cash, 2003, p. 23) was one of the first researchers to begin looking at formulating a model to evaluate alternative schools. Rather than describing students as "at-risk," the schools were considered at-risk of failing the students (R. E. Morley, 2002; Sanders, 2000). Morley developed indicators and rubrics that serve as a framework for establishing and maintaining quality alternative schools in Iowa.

For the purposes of state school comparisons as measured by the National Assessment of Education Progress (NAEP), the U.S. Department of Education (USDE, as cited in ODE, 2006b) defines a school as an autonomous institution offering instruction and counseling services with a school administrator and teachers. Often these definitions are found in public policy, administrative rule or data system business rules. The Federal Institution for Education Sciences (NCES, 2010) stated that alternative schools and programs are designed to address the needs of students who typically cannot be met in regular schools. The students who attend alternative schools and programs are typically at-risk of educational failure (as indicated by poor grades, truancy, disruptive behavior, pregnancy, or similar factors associated with temporary or permanent withdrawal from school). Alternative schools are usually housed in a separate facility where students are removed from regular schools, while alternative programs are usually housed within regular schools (NCES, 2010).

Oregon Revised Statute (ORS) 336.615 defines alternative education program as “a school or separate class group designed to best serve students' educational needs and 
interests and assist students in achieving the academic standards of the school district and the state" (ODE, 2006b). The ORS definition is further clarified by requirements found in Oregon Administrative Rules (OAR) 581-022-1350 which require that "each public or private alternative program approved by a school district board" comply with certain requirements such as student placement, maintaining plans for student transition and transportation.

Figure 1is a visual representation of the typology of alternative schools and describes the differing mission of traditional, charter and alternative schools. Alternative High Schools are schools that are an alternative to traditional school. Their mission and goals are related (education) but different as represented by the overlapping areas. The overlap between alternative and charter schools represents situations where charter organizations operate a school that may also serve as a traditional or alternative school. Figure 1 does not specifically distinguish between sub-types of alternative schools such as private, public alternative schools and demonstrates a simplified picture of the landscape that contextualizes alterative high schools as having different mission and goals than other types of schools. School choice and contextualized program evaluation are described in later chapters and reflected upon in throughout the R\&D process. The degree of actual school choice and its impact on students is also described. 


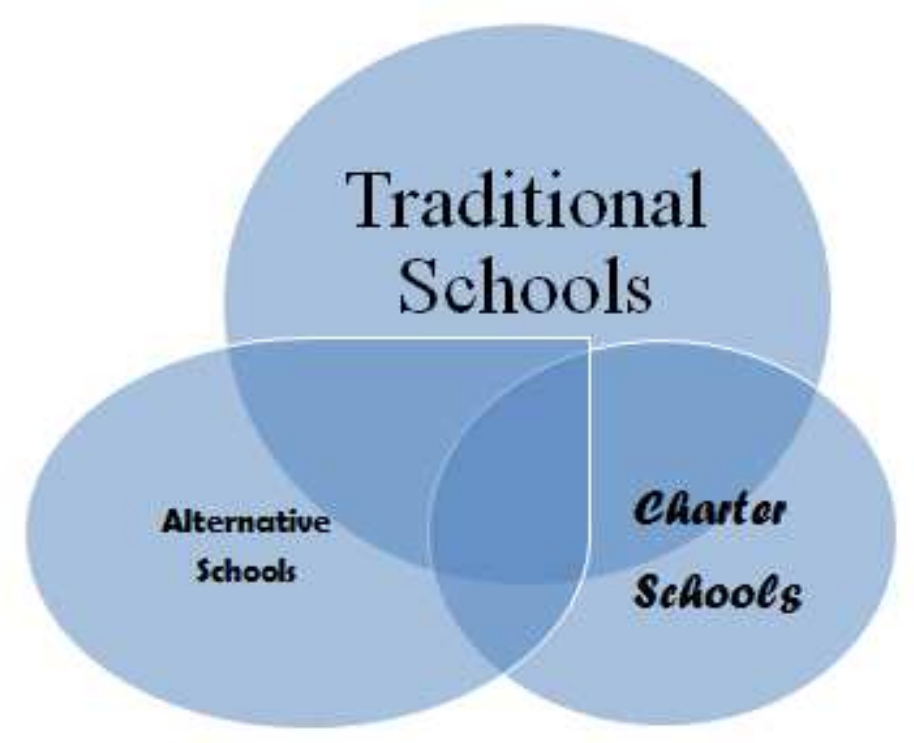

Figure 1. Types of Schools and Their Differing Missions. Adapted with permission (Chenoweth \& Everhart, 2002)

Schools are complex organizations made up of a specific climates and sets of cultural norms that have emerged over time in that setting. Each school includes students and educators unique to that educational setting. Alternative schools are especially difficult to define because of the particularly wide-spread variety of school characteristics (how alternative are they?) and students (how vulnerable are they?). These two enduring consistencies (how alternative and how vulnerable) have characterized a typology of alternatives schools that have been used throughout 50 years of research by (Barr \& Parrett, 1997, 2001, 2010; R. E. Morley, 2002; Raywid, 1981, 1994; Schargel \& Smink, 2001; Schargel, 2003, 2005; Smink \& Schargel, 2004).

Raywid (1994) suggested three types of schools ranging from an innovative school to a school with a special focus to what she and others call "soft jail" (p. 26). 
Furthermore, Raywid suggested that when structures and policies act as barriers to innovation, they must be modified if innovative schools are to flourish (Raywid, 1994). She further contended that alternative schools fall within three categories: transitional, last-chance, and change schools, sometimes referred to as Type I, Type II, and Type III (Aron, 2003; Lange \& Sletten, 2002; Raywid, 1994). Regardless of the category, alternative schools have one commonality-a focus on the individualized success of students. Defining what alternative schools are is absolutely essential as one considers the variety of innovative educational environments with intent to evaluate them. These types are described in the evaluator training along with Figure 1 as the evaluation team considers the purpose and desired outcomes of the evaluation planning. Table 3 describes the three-tier typology that is a common starting point for considering the mission of alternative schools.

Table 3:

Alternative School Typology

\section{School Type I - "Transitional” Program or School of Choice}

- Focus is on providing students with temporary placement while helping them transition back into a traditional schooling environment.

\section{School Type II - "last chance" schools or Assignment Schools}

- Provide education opportunities to students who are at-risk of dropping out, or those who are close to being expelled, or students who have been incarcerated.

\section{School Type III - "change schools" or Referral Programs}

- Seek to create a new type of learning environment for students, an environment that is not based on conventional schooling or based on a student's behavior. Often charter schools and magnet schools fall into this category.

Source: Raywid (1994). 
Another promising typology was developed by Melissa Rodderick (as cited in

Aron, 2003) of the University of Chicago, who focused her typology descriptions on the students' educational needs and challenges rather than their demographic characteristics.

She argued that by targeting a particular student population (demographic) a single

school or program will have significant challenge in handling such a wide array of needs.

Table 4 describes Roderick's identified typology.

Table 4:

Typology Based Upon Student Needs and Educational Challenges

\section{Student Population Type 1}

- Off track because they have gotten in to trouble

- Need short-term systems of recovery to route them back into traditional school

- Goal of getting back into traditional school is both appropriate and realistic

\section{Student Population Type II}

- Prematurely transitioned to adulthood either because they are (about to become) parents or have home situations that do not allow them to attend school regularly

\section{Student Population Type III}

- Substantially off track educationally, but are older and are returning to obtain the credits they need to transition into community college (or other programs) very rapidly

\section{Student Population Type IV}

- Substantially off track educationally, have significant problems

- Very low reading-levels and are often over-age for grade with few, if any, credits

- May have been retained repeatedly or previously enrolled in special education

- Includes late teenage students with third and fourth grade reading levels who may not been promoted from eighth grade; who may have gone to high school for a few years but have few, if any, credits earned toward graduation

Source: Aron (2006, p. 5)

If a chosen typology defines the quality of schooling only based upon its students' generalized characteristics, alternative schools are likely not to perform well in systems 
that seek to hold them accountable. Typologies that help us more accurately describe alternative high schools cannot be one-size-fits-all and should not be based upon comparison with traditional schools. A program evaluation that uses quality indicators that account for impact on students with similar needs and educational challenges will present a more fair and accurate comparison. In fact, in such a comparison some alternative schools may outperform traditional schools. It is because of these challenges that the need for program evaluation in alternative education has never been greater. Regardless of the policy changes that result from discourse and debates about alternative education, school choice and accountability, most educators agree that there is more to measuring schools than test scores, attendance, and graduation rates.

\section{Standards for Educational Program Evaluation}

The Joint Committee on Standards for Educational Evaluation has developed its Third Edition of Program Evaluation Standards. The 30 standards are organized into five groups corresponding to key attributes of educational evaluation: utility, feasibility, propriety, accuracy, and accountability (Yarbrough et al., 2011). The Standards provide guidance on when to evaluate, how to select evaluators, communication and technical issues in planning, designing, and managing evaluations.

The framework of standards and best practices in evaluation used throughout this study to frame the review of literature, research questions, and the Toolkit development and is used in describing the Toolkit efficacy. Figure 2 depicts the framework and suggests descriptions that are expanded upon later in this section. 


\section{Standard Evaluation Elements with Descriptions}

- Utility (useful and purposeful)

- Feasibility (practical or realistic)

- Propriety (proper or fair)

- Accuracy (adequately conveys analysis)

- Accountability (contextualized and produces value) (Yarbrough \&Joint Committee on Standards for Educational Evaluation, 2011)

Figure 2. Standards for Educational Evaluation.

Source: Yarbrough et al. (2011)

\section{Utility Standards}

The group of "utility" standards addresses use, usefulness, influence and misuse of program evaluations. They describe evaluator credibility, evaluation purpose and the need to attend to multiple audiences at the same time; before, during and after evaluation takes place. Judgments about an evaluation's utility are made based on the extent to which program stakeholders find evaluation processes and products valuable in meeting their needs (Yarbrough et al., 2011, p. 4)

On-site evaluation teams, sometimes called collaboration teams should be made up of both internal and external stakeholders (Chalker, 1996, p. 147). Members of evaluation teams should have experience in holistic, or what is sometimes called valueadded, or mixed methods methodologies of program evaluation. Onsite teams may use 
tools such as data analysis, in depth interviews, focus groups, student, parent, teacher and staff surveys, document review, curriculum analysis, student work analysis, classroom observation, strategic planning, professional development and training (Dunsworth \& Billings, 2010). This review of literature and study will focus on the field testing of an educational product, the Evaluation Toolkit and its respective characteristics and on achieving quality evaluation standards established by the Joint Committee on Standards for Educational Evaluation. As describe earlier evaluation team members are carefully selected based on qualifications, selection guidelines and team responsibilities that meet the assist in providing context and producing value as a part of the evaluation (Chenoweth \& Everhart, 2002, pp. 17-21) in combination with evaluator competencies describe later in this chapter.

Program evaluation methodologies. Evaluations are more credible and useful if members of the evaluation team have experiences in program evaluation that took place in a variety of settings and were conducted for different purposes. Examples of other settings and purposes might include special purpose school accreditation, state standardization, district improvement, program improvement, school or program closure, audit or compliance. Diverse experience in educational organizations in combination with experiences in program evaluation provide the evaluator sets of generalizable principles that generally lead to more purposeful questioning and investigation of what is going on in the school. Today, alternative schools may look different from their predecessors, but they exist because of the same philosophy; one size does not fit all (Cable \& Spradlin, 2009, p. 2). The following adage could be considered cliché but is appropriate here, 
"methods are many but principles are few, methods may change but principles rarely do" (Author unknown).

The principle of individualized learning combined with a focus on students' noncognitive skills (life skills) held by alternative school educators is one such principle. The phenomenon may be measured in multiple ways by a variety of methods but it is a principle that has rarely changed over time in schools that serve students at-risk of academic failure. Methodologies used in school evaluations, especially alternative school program evaluation, should include a mixture of quantitative and qualitative tools and be perceived as generally useful to the school, district and the state. Examples of qualitative data gathered during this kind of a visit is described by Fowler (2004, pp. 310-311) is described in Table 5.

\section{Table 5:}

Qualitative Information for District/State Policy-Level Program Evaluation

- Transcripts of interviews

- Transcripts of focus group discussions

- Notes on observations

- Open-ended surveys

- Personal statements

- Diaries/Journals

- Minutes from meetings

- Official reports

- Legal documents

- Books and materials

- Photographs

Source: Fowler (2004, p. 311)

As a follow-up to a podcast that a fellow graduate student (Chet Edwards) and I were asked to do, I had the opportunity to communicate with Dr. Ray Morley (personal 
communication, January 28, 2012). He remarked that the Inventory of Policies and Practices Related to Student Failure and Dropping Out needed to be updated. The Inventory begins with a survey intended for use with students to help guide professional decisions regarding changes in policies and practices. Student responses can be ranked and utilized to prioritize policies and practices needing change (R. Morley, 1996, p. 21). Table 6 describes other types of quantitative information that could inform evaluations that seek to contribute toward systems of accountability and contribute toward district or state policy making (Fowler, 2004, p. 311).

Table 6:

Quantitative Information for District/State Policy-Level Program Evaluation

- Test scores

- Retention rates

- Attendance figures

- Dropout rates

- Per-pupil expenditure

- Teachers' salaries

- Teacher-pupil ratios

- Percentage of students on free and reduced lunch

- Enrollment figures

- Percentage of teachers with master's degrees

Source: (Fowler, 2004, p. 311)

Evaluator competencies. Credible evaluators could be described as good researchers with the ability to communicate effectively, attend to multiple problems at once, and manage multi-dimensional projects successfully. Schools considering making use of program evaluation would do well to consider "evaluator competencies" and domains, described in Table 7 derived from standards, textbooks and evaluator training programs (Russ-Eft, 2008, p. 34). 
Table 7:

Evaluator Competencies Derived from Standards

\section{Professional Foundations and Competence:}

- Communicate accurately and effectively

- Observe ethical standards

- Obtain and maintain needed skills

- Understand evaluation background and history

Professional Responsibility, Integrity, Accountability

- Accurately represent skills

- Disclose conflicts of interest

- Negotiate honestly

- Communicate accurately and fairly

- Understand politics

Respect for People

- Use informed consent

- Maintain confidentiality

- Maximize benefits and reduce harms

- Communicate respect for stakeholders

- Understand multicultural and cross-cultural aspects

Social Responsibility

- Consider wider implications and side effects

- Recognize obligations for public good

Evaluation Understanding and Practice

- Understand and use alternative evaluation theories, models, and approaches

- Focus the evaluation

- Work with stakeholders to determine evaluation questions

- Understand and use program theory or logic modeling

- Communicate and report progress and results

- Ensure use of findings

- Evaluate the evaluation i.e., conduct a meta-evaluation

- Build and sustain support for evaluation i.e., build organizational capacity for evaluation

Research Skills

- Develop or select an evaluation design

- Develop appropriate data collection instruments and procedures

- Use appropriate data collection methods

- Understand and use appropriate sampling methods

- Use appropriate qualitative and quantitative analysis procedures

Project Management Skills

- Plan and negotiate the evaluation

- Develop, plan for, and manage communications

- Develop, plan for, and manage the budget

- Develop, plan for, and manage the schedule

Source: Domains and Competencies (Russ-Eft, 2008, p. 34) 
Current practice varies with regard to school district attention to evaluator competencies but in most cases district or school administrators conduct a school visit once a year with the compliance tool provided by the state (ODE, 2006b). The evaluation of alternative schools needs to account for students, curriculum and teaching and requires a mixed method analysis by evaluators who have an understanding about principles of learning, are familiar with both traditional and alternative school settings, and are aware of common issues and political structures involved in school systems.

Evaluation is best conducted with the involvement of both internal and external stakeholders (Patton, 2011) in a process where practitioners and stakeholders come to consensus about the school's strengths and needed improvements. The outcomes and processes should be agreed upon and contextually designed to meet the needs of the school so that school staff may make use of the evaluation. The tools used in the evaluation process must be complex enough to capture identified characteristics but simple enough to be valid and understood.

From my experience, the alternative school evaluation needs to somehow account for the curriculum, instruction, and assessment as well as those factors that are evident in student engagement and the programmatic structures and leadership. Academic learning principles may be generally true in the process of teaching and learning but may not be observably present in an alternative school during the particular period that it is being evaluated. Evaluators need to understand what to look for as a "proxy" (in place of) for observational characteristic being observed. For example, during an alternative school evaluation, students might be observed while they are involved in a project that 
demonstrates proficiency in a particular subject and may not appear to be on task to someone not familiar with the context relevant to the project. If the teacher demonstrated good classroom management and had communicated standards and clear learning objectives, the observer should be compelled to explore with a sampling of students to ask if they understood what they were learning and why they were learning it. This will largely confirm or cause the evaluator to question, if effective instructional practices were present on the days leading up to the observed project.

Learning may be easier to identify in a short amount of time with such tools as an observation check list or inventory. However, these forms of evaluation are often less helpful for the school. Alternative school evaluations must account for differences in the philosophy and mission of the program. Program evaluation must access fidelity to the alternative school's vision and the school's effect on student learning. An effective evaluation should evaluate fidelity to the program's design and assess its impact on student learning (Chenoweth \& Everhart, 2002). Some of the most innovative and successful programs may employ practices that are not conventional or commonly understood and thus are difficult to evaluate. In these situations it is critically important that evaluators be prepared for diverse learning environments designed to serve unique student populations. It is recommended that evaluators work in teams made up of professionals from both inside and outside the organization who together, represent a wide array of knowledge and experience (Patton 2011). 


\section{Feasibility Standards}

The group of "feasibility" standards attends to the degree of evaluation effectiveness. The feasibility standards are intended to ensure that the evaluation will be practical, realistic, prudent, diplomatic, and frugal (Russ-Eft, 2008, p. 116; Yarbrough et al., 2011, p. xxviii). Feasibility addresses the effects of context, cultures, costs, politics, power and available resources. If annual alternative high school program evaluations are required, as they are in Oregon, school districts must find a way for them to be feasible. Most districts and schools are frugal, may not understand or weigh heavily the benefits of program evaluation, and as a result, do not seek to expend precious resources for professional evaluation of their schools. The cliché statement, "you get what you pay for" may accurately depict alternative school program evaluation. In Oregon, the typical evaluation, conducted by the district or school administrator costs nothing. If alternative high schools are to improve, high quality evaluations are needed.

Reimer and Cash (2003) addressed issues of feasibility and cost in alternative school program evaluation by describing checklists and rubrics, used primarily in selfevaluation, as "Level One Analysis." Level Two is a more in depth analysis of the school that includes staff and stakeholder interviews and on-site observations resulting in a significantly more detailed report of the findings (Reimer \& Cash, 2003, p. 24). The best practices for development and evaluation are intended to contribute toward the National Dropout Prevention Center's (NDPC) Fifteen Effective Strategies for School Improvement and Dropout Prevention, which includes Alternative Schooling as a Basic Core Strategy (Reimer \& Cash, 2003, p. 5). The Fifteen Strategies (NDPC, 2011) and 
approaches to alternative school evaluation developed by Reimer and Cash contributed toward my understandings about evaluation tools and informed new versions of my product.

\section{Propriety Standards}

The group of "propriety" standards depicts what is proper, fair, legal, right, acceptable and ethical in an evaluation. These standards consider the rights of stakeholders and are intended to ensure that an evaluation will be conducted legally, ethically, and with due regard for the welfare of those involved in the evaluation as well as those affected by its results (Russ-Eft, 2008, p. 17; Yarbrough et al., 2011, p. xxviii). Evaluators must attend to the perceptions of multiple stakeholders' values or conceptions of what is fair, which can play a significant role in evaluation propriety. If program evaluation required a sanctioned human subject's review, as academic research does, the propriety standards would provide the basis for review. Although, program evaluation does not always require a human subjects review, program evaluators and members of evaluation teams need to remain aware of requirements in federal, state, or local district policies that would require they request permission from subjects prior to the evaluation or analysis of data.

\section{Accuracy Standards}

The "accuracy" standards are intended to ensure that an evaluation will reveal and convey technically adequate information about the features that determine worth of the program being evaluated. They address bias, logic and conclusions and describe validity, reliability, information management, design, analysis, and reporting as it pertains to 
program evaluation. The standards call for clear and accurate documentation, the analysis in context to which the program exists, defensible information sources and accurate analysis of both qualitative and quantitative information that result in justified conclusions. The standards also point out how to minimize inconsistencies, distortions and misconceptions that can undermine accuracy in evaluations (Russ-Eft, 2008, p. 118; Yarbrough et al., 2011, p. 158).

\section{Accountability Standards}

The "accountability" standards, compiled by the Joint Committee on Standards for Educational Evaluation, refer to the context of program evaluation and not state, district or school accountability. The Standards refers to the responsible use of resources to produce value as a result of the evaluation. The standards require that evaluations fully document their negotiated purposes and implemented designs, procedures, data and outcomes. They call for both an internal meta-evaluation (Standards-based selfevaluation of the evaluation) and external meta-evaluation (evaluation of the evaluation by someone other than those affected by, or with a legitimate interest in the program or program evaluation (Yarbrough et al., 2011, pp. 255-252).

\section{Summative and Formative Evaluation}

There is utility in summative evaluation but the majority of evaluations should be conducted on the formative happenings combined with summative outcomes of program activities (Chalker, 1996, pp. 146-147). In the preface to this study, members of the evaluation team, (sometimes called the collaborative team), at Crossroads expressed that, in the case of alternative high schools, summative evaluations and school report cards 
were comparative to reading an obituary in the newspaper because it gave them little room for improvement in the sense that by the time the information was assembled there was not much that could be done about it, but grieve the loss of life and potential.

To use the language described in the Standards developed by the Joint Committee on Standards for Educational Evaluation, summative evaluations might be found lacking in "utility," because the reports are potentially not valuable in meeting the program needs. From the perspective, of the state, it could be argued that summative evaluations, such as school report cards, containing average test scores, attendance and graduation rates, were designed to hold schools accountable, not the students. To again draw from the Joint Committee for Standards for Educational Evaluation in the context of alternative program evaluation, the accountability standards apply to the responsible use of resources to produce value as a result of the alternative program evaluation (Yarbrough et al., 2011).

Evaluators and evaluation teams should avoid implementing methods without first considering the context of the alternative school. It is recommended that evaluators work in teams made up of professionals from both inside and outside the school (Patton 2011). As discussed in the introduction and policy sections of this study, a variety of alternative schools exist that serve students with a wide array of characteristics. Each of these programs employs learning principles but include different learning practices that are contextually relevant and motivating to their target student population.

Effective school design and evaluation needs to include members of the community and occur with regular updates of the school's vitality and relevance, rather 
than its final obituary report. Evaluation needs to involve observations of student learning (growth) and impact made by the school because as students improve the school improves. Evaluation planning must precede the actual evaluation. Formative evaluation methods are be used over time to make accurate observations of what is actually happening. Similar to the experience, described earlier in the preface, formative evaluation enables evaluation teams to achieve a better result because they become aware of the context of the school and the impact it may be making on students.

In the preface Crossroads Alternative High School did not meet state requirements for progress. Few benefits came as a result of labeling the school a "failure" but the blunt action increased predictability in house prices and average annual income in the resident neighborhood. The failing label further marginalized the school and the students at risk of educational failure that were receiving support to graduate. Outcomes that are published in summative evaluation are rarely linked back with results and observations of what is happening in the school. It is not unreasonable for test scores attendance, standard courses and graduation to be used for measurement but it surely should not stand alone as a comparison between traditional and alternative schools. Those that seek to evaluate alternative high schools should seek to include more formative processes that account for differences between schools and contribute toward results.

\section{Alternative School History}

In order to understand and describe alternative high schools as they currently exist, a historical context and understanding of current policies is needed (Barr \& Parrett, 2001; Conley, 2002). This section on alternative school history provides an introduction 
of alternative (progressive) education at the national level, followed by a description and sample policies from alternative education history in Oregon. It is difficult to separate the historical context (practice) from policy, in part because policy has informed the history in the past three decades. Moreover, my role as a policy maker requires that I consider a historical context when I work with groups to develop or improve policy. Included in this section are previously adopted policies that have informed practice and recently revised policies that describe the history in Oregon. The section that follows provides additional literature and reference to alternative school policy that support the development of the Evaluation Toolkit. Figure 3 generally describes alternative school history over the past 100 years.

\section{Alternative Schools}

- Historical Context of Alternative Schools (100 years)

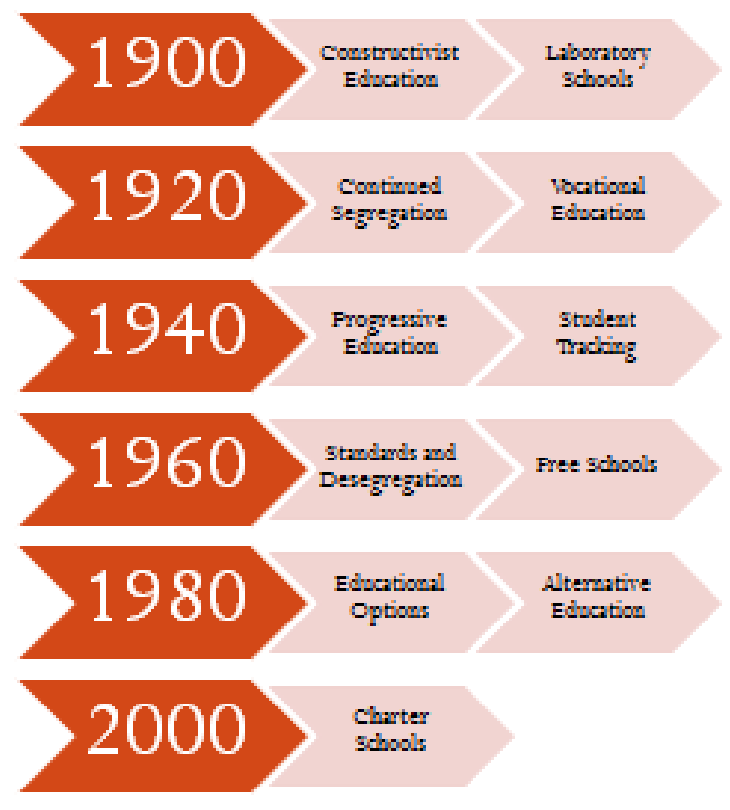

Figure 3. Historical Context of Alternative Schools Over the Last 100 Years. 
In the 1800 s it was not uncommon for children in the United States to attend church-sponsored schools, boarding schools, or private schools in their community. During that time, private school outnumbered public schools and variety of options existed for those able to pay the fees. Early in the nineteenth century, enrollment in public education surpassed home and private schooling when common neighborhood schools became an option (Conley, 2002; Mann \& Massachusetts Board of Education, 1957). Those who have studied the history of alternative education in America (Barr \& Parrett, 1997, 2001, 2010; Conley, 2002; Fowler, 2004) trace the development of alternative schooling back to the first part of the $20^{\text {th }}$ Century with the invent of progressive education theories of Dewey $(1909,1916,1938)$. Alternative schools in a broad sense are an integral part of the way the educational system has evolved in the United States: Early in our history we recognized that the needs of a few often mirror the needs of the many. From the establishment of Harvard College in 1636 originally intended for the education of Puritan ministers] to the magnet schools of today, American education is the collective result of countless alternative schools programs (Katsiyannis \& Williams, 1998).

School leaders trying to improve their schools seem to compulsively want to replicate currently successful models and try to apply those practices to local needs (Ravitch, 2010). One might assume that these practices might transfer across from successful alternative schools into traditional schools and in some cases they may. For example practices relating to credit by proficiency, acquisition of essential skills and personalized learning plans emerged from alternative education and those practices have 
been accepted in most states to support graduation. However, in some cases practices such as small learning communities (smaller traditional schools) have not been found to be better (Kopkowski, 2006; Shah, Mediratta, \& McAlister, 2009; Shaw, 2006) . This example serves as a warning that great caution should be taken to avoid implementing practices without first considering the context of the research generalizability (scalability of practices) of the findings and how they may or may not impact implementation of the learning theory (principles).

As mentioned previously, the learning principles applied in alternative education are frequently traced to early Twentieth Century socially progressive education theories of Dewey (1909), experiential (progressive) education and contextual learning. Dewey's (1916) belief in the unity of theory and practice argues that theory of experience in a democracy is what is needed to move from theory to practice. The knowledge and skills taught in alternative schools are among those essential skills and content standards required for high school graduation in traditional schools and are aligned with expectations for college and career. However the nature of student performance is sometimes significantly different in alternative schools.

Learning practices in alternative education settings may look different than those employed in more traditional learning environments. These differences are problematic when it comes to evaluating schools, in part because of the frequent lack of experience on the part of evaluators in working with alternative high schools. For example, the experience of Mrs. Refermer noted in the preface example of Crossroads Alternative 
School, has had experience with traditional schooling but did not fully understand what alternative school felt like until she spent significant time there.

Alternative schools include unique education subculture and include staff and students who are actively involved in educational innovation, often out of necessity (for survival). Learning practices in alternative education settings are often a mixed set of tools and innovations; often involving personalized learning; proficiency based progress monitoring, theme based instruction, authentic forms of assessment, student and teacher choice, and active learner engagement (Barr \& Parrett, 1997, 2010; Raywid, 1994). Learning principles applied into the subculture of alternative education described by Bruner (1996) also addressed theories of contextual learning. Bruner, applying the newly emerging "cultural psychology" to education, proposed that the mind reaches its full potential only through participation in the culture-not just its more formal arts and sciences, but its ways of perceiving, thinking, feeling, and carrying out discourse. By examining both educational practice and educational theory, Bruner explores new and rich ways of approaching many of the classical problems that perplex educators. The concept of knowing as doing is an attractive approach to learning in alternative education because of the relevance needed to motivate and engage students. For example, skills acquired in an inquiry science experiment (doing) might provide the background (knowing) and opportunity to capture a sample of expository writing.

Knowledge helps only when it descends into habit (Bruner, 1996). While some generalized learning principles are transferable to traditional learning environments, the teaching and learning practices in alternative education are often unlike those applied in 
traditional schools. These habits and norms are unique to each alternative learning environment and program. Successful alternative schools (Barr \& Parrett, 1997, 2001; Chalker, 1996; Leone \& Drakeford, 1999; NDPC, 2011) support students in learning the "grammar of school" (socially acceptable behaviors for academically civil settings) (Tyack \& Cuban, 1995). In essence they are learning to "play the game of school." Among the students who attend alternative schools are those who have not learned to "conform to socially acceptable norms" or play the game of school. Gardner (2000) suggested that it may be the job of schools to prepare students for life in a marketdominated world. Students who attend alternative schools are taught using approaches to both teaching and learning to which they can relate and to which they can engage. In this way students who have unique abilities or quirks that limit their skill in fitting in at a traditional school may thrive in an alternative learning environment. In a similar way, students who are very aware of their peers in large educational institutions may have found it difficult to express their voices and may flourish in an alternative setting.

Tomlinson and McTighe (2006) contended that differentiated instruction adjusts based upon a particular student's readiness, interest, and learning profile. Methods of “assessing for learning" allows for ongoing teacher feedback and adjustment for students via formative assessments as described by Rick Stiggins (Stiggins et al., 2005). Feedback and adjustments also need to be embedded into school design and evaluation and go beyond test scores, attendance and graduation rates. Benjamin Bloom (as cited in Guskey, 2012) described that schools should develop programing that include approaches 
to student development in affective domain and develop students ability to function and even thrive in a school community.

These methods of assessing often take into account multiple intelligences, such as those described by Gardner (2000), who has researched and demonstrated that intelligences include linguistic, logical-mathematical, special, bodily-kinesthetic, musical, interpersonal and naturalist. Assessment of readiness and intelligence has to do, generally, with learners' preferred styles of learning as well as their levels of proficiency with knowledge, understanding, and skill (zone of proximal development). Social and educational psychologist, Bandura (1997) has generally recognized the value of studentcentered learning and contextual learning as promoting intrinsic motivation for all kinds of learners. Researched based practices commonly used in traditional schools may also be applied generally in alternative settings where student-centered learning is supported as long as caution is taken in customizing practices for specific student populations (Marzano, 2003). Alternative school evaluation accounts for these learning principles by observing practices over time and involving stakeholders in the evaluation process.

Before alternative schools, the prevailing belief was that everyone learned in the same way and that one curriculum was sufficient for all students (Conley, 2002, p. 5). At its deepest core, alternative education, sometimes referred to as progressive education, could be described as an attitude, a movement, a belief in experimentation, and a commitment to the education of all children in the American schools (Conley, 2002). Also considered as core would be a commitment to social justice and anti-centralized systems. The four dominant themes of progressive education are represented in Table 8 . 
Table 8:

Dominant Themes of Progressive Education

1. A broadening of the school to include a direct concern for health, vocation and the quality of community life

2. The application in the classroom of more humane, more active and rational pedagogical techniques derived from research in philosophy, psychology and the social sciences

3. The tailoring of instruction more directly to the different kinds of classes of children who have been brought within the purview of school

4. The use of more systematic and rational approaches to the administration and management of the school

Source: (Conley, 2002, p. 1)

The origin of the alternative schools that exist today seem rooted in the civil rights movement of the late 1950s and early 1960s (R. Barr, personal communication, August 2011), when some perceived the traditional public school system as racially prejudiced. A variety of new schools generated educational options outside the neighborhood school. With respect to alternative schools, the 1960s might be considered the period of innovation. The number of public school alternatives grew exponentially, in just a decade growing from approximately 100 to more than 10,000 (Raywid, 1981). The 1970s might be referred to as the age of accountability and improvement; the 1980s, the period of excellence and quality and the reporting of A Nation at Risk (National Commission on Excellence in Education, 1983), which lead to educational reform and restructuring in the 1990s. In this series, the twenty-first century might be referred to as the era of competition, school choice and re-privatization (Aron, 2006; Barr \& Parrett, 2001; Conley, 2002; Lange \& Sletten, 2002).

Growing in numbers alongside various forms of alternative schools in the 1980s and 1990s a new kind of alternative school emerged as progressive schools began to 
decline. These alternative schools focused on behavioral reform and academic remediation of disruptive youth at risk of failing school (Barr \& Parrett, 2010).

Alternative schools increasingly focused on basic skills and less on innovations such as democratic decision-making by staff and students (Raywid, 1981). As an example, the John Adams High School in Portland, Oregon, which was organized as schools-within-aschool and designed around students' interests, opened in 1969 but was closed in 1981, because of difficulties associated with its unconventional approach to education (Tyack \& Cuban, 1995).

Oregon has a history of state laws and policies that allow local school districts to establish alternative education programs and requires their annual evaluation. In 2012 Oregon school districts reported that 384 alternative education programs were serving 15,328 students that year (ODE, 2006b, pp. 69-71). State law, ORS 336.640(1), requires districts to maintain learning situations that are flexible with regard to environment, time, structure and pedagogy. Such options provide innovative ways of educating students within the public school system. For the purpose of state laws (policy), the term program includes school and alternative education program means a school or separate class group designed to best serve students' educational needs and interests and assist students in achieving the academic standards of the school district and the state (ORS 336.615). Statutes are carried out through administrative rules and OAR 581-022-1350 provides standards for districts in operating alternative schools and programs.

OAR 581-022-1350(3) requires that "School districts must adopt policies and procedures for the approval and at least annual evaluation for public and private 
alternative education programs under ORS 336.615-336.665 that receive public funds." In addition to approval and at least annual evaluation, this rule sets other requirements. Commonly in Oregon, samples of policy required by state law are drafted by the Oregon School Boards Association (OSBA) for adoption by local school boards of education. Sample OSBA policy is developed and distributed to school districts through updates that require membership with the OSBA organization (OSBA, 2008). OAR 581-022-1350 was amended in 2006 and in 2007 I met several times with OSBA staff and composed revisions to sample policy but the project never was fully completed and the policies were not distributed formally to districts. Table 9 analyzes the standards described for alternative education in OAR 581-022-1350 and makes comparison of sample OSBA policy and selected school districts in Oregon that have historically adopted such policies. 
Table 9:

Comparative Analysis of State Law and Sample District Policies

\begin{tabular}{|c|c|c|c|c|c|c|c|}
\hline $\begin{array}{l}\text { Policies and } \\
\text { Procedures } \\
\text { Required in } \\
\text { OAR } \\
581-022-1350\end{array}$ & $\begin{array}{l}\text { OSBA } \\
\text { Sample } \\
\text { Policy }\end{array}$ & $\begin{array}{l}\text { Portland } \\
\text { SD }\end{array}$ & $\begin{array}{l}\text { Eugene } \\
\text { SD }\end{array}$ & $\begin{array}{l}\text { Hillsboro } \\
\text { SD }\end{array}$ & $\begin{array}{l}\text { Hermiston } \\
\text { SD }\end{array}$ & $\begin{array}{l}\text { North } \\
\text { Santia } \\
\text { m SD }\end{array}$ & $\begin{array}{l}\text { Forest } \\
\text { Grove } \\
\text { SD }\end{array}$ \\
\hline $\begin{array}{l}\text { Adopted: } 1996 \\
\text { Revised: } 2008\end{array}$ & Unknown & $\begin{array}{l}1990 \\
2005\end{array}$ & $\begin{array}{l}2006 \\
2008\end{array}$ & $\begin{array}{l}1996 \\
2008\end{array}$ & $\begin{array}{l}1996 \\
2004\end{array}$ & 2002 & 1999 \\
\hline $\begin{array}{l}\text { (3) "Must adopt" } \\
\text { For Approval of } \\
\text { (with provisions) }\end{array}$ & $\begin{array}{l}\text { "Annually" } \\
\text { (not in law) }\end{array}$ & $\begin{array}{l}\text { Approval } \\
\text { of new } \\
\text { "Ed. } \\
\text { Options" }\end{array}$ & OSBA & OSBA & $\begin{array}{l}\text { "List....ad } \\
\text { opted." }\end{array}$ & $\begin{array}{l}\text { No } \\
\text { policy }\end{array}$ & $\begin{array}{l}\text { No } \\
\text { policy }\end{array}$ \\
\hline $\begin{array}{l}\text { (3) "Must adopt" } \\
\text { For Annual } \\
\text { Evaluation of } \\
\text { (with provisions) }\end{array}$ & $\begin{array}{l}\text { "In } \\
\text { accordance } \\
\text { with } \\
\text { ORS/OAR" }\end{array}$ & $\begin{array}{l}\text { "On an } \\
\text { establish } \\
\text { ed cycle" }\end{array}$ & OSBA & OSBA & OSBA & $\begin{array}{l}\text { No } \\
\text { policy } \\
\text { (evalua } \\
\text { tion } \\
\text { criteria } \\
\text { only) } \\
\end{array}$ & $\begin{array}{l}\text { No } \\
\text { policy } \\
\text { (evaluat } \\
\text { ion } \\
\text { criteria } \\
\text { only) } \\
\end{array}$ \\
\hline $\begin{array}{l}\text { (5) "Shall adopt" } \\
\text { Placing students } \\
\text { in "must ensure" }\end{array}$ & $\begin{array}{l}\text { Yes, but } \\
\text { needs } \\
\text { revision to } \\
\text { conform to } \\
\text { current law }\end{array}$ & $\begin{array}{l}\text { Yes, } \\
\text { "Assist } \\
\text { students } \\
\text { and } \\
\text { families } \\
\text { to make } \\
\text { choices" }\end{array}$ & OSBA & OSBA & OSBA & $\begin{array}{l}\text { No } \\
\text { policy }\end{array}$ & $\begin{array}{l}\text { No } \\
\text { policy }\end{array}$ \\
\hline $\begin{array}{l}\text { (6) "Must adopt" } \\
\text { For notification } \\
\text { of students and } \\
\text { parents } \\
\text { of (a) the law, } \\
\text { (b) availability, } \\
\text { and (c) } \\
\text { procedures to } \\
\text { request } \\
\text { establishment of } \\
\text { new programs }\end{array}$ & $\begin{array}{l}\text { “...dedicate } \\
\mathrm{d} \text { to } \\
\text { providing } \\
\text { educational } \\
\text { options for } \\
\text { all } \\
\text { students." } \\
\text { (a) and (b) } \\
\text { not } \\
\text { addressed, } \\
\text { and (c) only } \\
\text { in terms of } \\
\text { program } \\
\text { approval }\end{array}$ & $\begin{array}{l}\text { General } \\
\text { supports } \\
\text { availabili } \\
\text { ty and } \\
\text { new } \\
\text { programs } \\
\text {, but not } \\
\text { specific } \\
\text { to these } \\
\text { areas }\end{array}$ & OSBA & OSBA & OSBA & $\begin{array}{l}\text { No } \\
\text { policy }\end{array}$ & $\begin{array}{l}\text { No } \\
\text { policy }\end{array}$ \\
\hline $\begin{array}{l}\text { (8) "Must have" } \\
\text { For making } \\
\text { claims for state } \\
\text { school funds } \\
\text { (with provisions) }\end{array}$ & $\begin{array}{l}\text { Refers to } \\
\text { only private } \\
\text { alternative } \\
\text { programs }\end{array}$ & $\begin{array}{l}\text { No } \\
\text { policy }\end{array}$ & OSBA & OSBA & OSBA & $\begin{array}{l}\text { No } \\
\text { policy }\end{array}$ & $\begin{array}{l}\text { No } \\
\text { policy }\end{array}$ \\
\hline $\begin{array}{l}\text { (9) "Must have" } \\
\text { data for each } \\
\text { student in } \\
\text { district } \\
\text { reporting } \\
\text { "ensure" }\end{array}$ & $\begin{array}{l}\text { Not in } \\
\text { current } \\
\text { sample } \\
\text { policy }\end{array}$ & $\begin{array}{l}\text { No } \\
\text { policy }\end{array}$ & OSBA & OSBA & OSBA & $\begin{array}{l}\text { No } \\
\text { policy }\end{array}$ & $\begin{array}{l}\text { No } \\
\text { policy }\end{array}$ \\
\hline
\end{tabular}

Source: Edwards (2012). 
The information in the previous table substantiated the need to update and clarify state law through sample policy, especially as it relates to the design and evaluation of alternative education programs designed to meet the needs of students at risk of educational failure. Appendix B describes current OSBA sample policy and includes a marked version with recommended changes I drafted with Mr. Chet Edwards (Mr. Edwards) in 2011. The marked version was further updated to include references to teacher effectiveness, online and blended learning as a part of the research, information collecting and learning activities conducted. District adoption and use of the proposed changes to policies may contribute toward improved results and student outcomes.

Oregon has a rich history with a variety of alternative education programs, and its future will likely be influenced heavily by Oregon's current Governor, chair of the Oregon Educational Investment Board (OEIB) and 12 educators and community leaders in their effort to create a seamless, unified system for investing in and delivering public education from early childhood through high school and college. Oregon's goal is that by the year 2025, 100\% of Oregonians will earn a high school diploma or its equivalent, $40 \%$ will earn a postsecondary credential, and $40 \%$ will obtain a bachelor's degree or higher (OEIB, 2012).

Recently, school districts, regional education service districts and postsecondary institutions were asked to submit "achievement compacts" that are being closely reviewed by stakeholders (Hammond, 2012a). Among these achievement compacts, institutions were invited to submit information, reports and evidence of their commitment to setting high goals for academic achievement, especially as it relates to high school 
graduation and postsecondary degrees. The rich history of educational innovation by Oregon educators and stakeholders and new state leadership provide great promise for improved performance, positive results that may impact generations of students and positive outcomes for Oregon. Alternative high schools serve as alternatives to suspension and expulsion and seek to serve students at risk of educational failure, enabling public schooling experiences to meet the needs of more students.

\section{Alternative School Policy}

Policies relating to alternative high schools vary across states and differences exist between school districts (Barr \& Parrett, 2001; Chalker, 1996; Conley, 2002; Fowler, 2004). Educational leaders need to be literate about policy and the policy process (Fowler, 2004, p. xi). Relevant to the Evaluation Toolkit are the policy topics of federal influence on school accountability and rating systems, school choice and local accountability measures. As mentioned earlier, large comprehensive traditional schools represent the method by which most students experience high school but these schools often educate thousands of students and operate different educational programs. Quality indicators for traditional high schools include characteristics of schools, teachers, classrooms and students at the high school level, and are designed to enroll one thousand students (Quality Education Commission, 2012). Comprehensive traditional high schools offer instruction in all academic standards, courses, and services that intend to support students in graduation from high school and preparation for postsecondary education. For some students, different types of schools provide educational options within their public schooling experience. In Oregon and nationwide, there is a growing population of 
students with alternatives options besides their traditional neighborhood public school (Barr \& Parrett, 2001; Raywid, 1994).

Public policy polls relating to the satisfaction of neighborhood schools consistently find that adults rate their neighborhood school higher than the nation's schools (Gallup \& Newport, 2009). With access to data and information more open than ever before, parents quickly become informed consumers about where their children will get the best forms of education. In the past, determining the quality of neighborhood schools was left to the stories representing the organization and the perception portrayed in the local news media. Summative reports noted a schools' progress toward targets set by the state and the school themselves. School and teacher evaluations were largely left alone by the general public. In this way, the quality of schooling was largely locallydriven and school accountability was left primarily to local citizenry to determine, maintain and report.

Innovations in summative test-based assessment and data systems for tracking program results lead to further questions and additional information about public education outcomes of schooling as well as alternative schooling. In 2001, measures for holding schools accountable for AYP were included in new federal policy in the United States, setting the trajectory for school report cards and state-established rating systems to hold schools accountable for their results and student outcomes. The trouble with testbased accountability is that it imposes consequences on children and schools on the basis of scores that may reflect measurement error, statistical error, random variation or a host of environmental factors or student attributes (Ravitch, 2010, p. 166). For the most part 
these data systems were limited to results relating to attendance, high school graduation and academic assessment but attempted to also determine characteristics of quality teachers and safe and drug free schools. While policies and implementation created a space for innovation, primarily in academic assessment, the result was the narrowing of the curriculum and a focus on a narrow set of academic-centered outcomes.

School report card and rating systems are, for the most part, still limited to results associated with attendance, graduation rate and state-wide academic achievement tests. There are no penalties or consequences for failing to reach established goals and achievement compacts, nor rewards for doing so (Hammond, 2012c). While the ratings serve the purpose of identifying schools with successful outcomes, these ratings are summative and do little to indicate how a school would improve. The school ratings are useful in predicting real estate and home prices but have done little to improve student learning. The ratings have been found to be inadequate for determining characteristics such as effectiveness of teachers (Ravitch, 2010) and administrators and fall short of measuring characteristics of quality curriculum or school culture (Barr \& Parrett, 2010; Barr \& Yates, 2010).

A recent innovation proposed by the federal government, "Race to the Top" attempts to develop more locally-driven accountability and a statewide system of support (ODE, 2012). Some of these policies appear to intend to reduce the federal role in school accountability while others make a clear reach for influence on local-level decision making. Federal support of College and Career Ready Standards also indicate an example of federal support for State-adoption and implementation of Common Standards. 


\section{School Accountability and Rating Systems}

In 2001 the federal No Child Left Behind (NCLB) (USED, 2001) bill was signed into law. The law called for standardized measures of rating school performance but did not account for complex typologies of schools. This version of the Elementary and Secondary Education Act (ESEA) also included more measuring "stick" than "carrot" reward. The USDE labels approximately $10 \%$ of schools failing and $30 \%$ schools as not meeting AYP (USED, 2001). States were called upon to refine the criteria that determine AYP as measured by state, district and school report cards. The data included are disaggregated by subgroups such as English Language Learners and Special Education as well as Race and Gender but did not account for many of the complex student characteristics that make up alternative schools serving the most vulnerable populations of students. In addition, the descriptive statistics and ratings were a primitive effort at school evaluation and did little to help improve schools themselves.

Despite the new policies for school accountability under NCLB, little was done to address alternative school programming or evaluation during this period (Aron, 2006; Cable \& Spradlin, 2009; Milliken, 2007; Smink \& Schargel, 2004). Few studies exist that identify general characteristics of successful alternative schooling and demonstrate valid methods to identify if they are present or not. As a result, my observation has been that public policy has traditionally either disregarded information relating to alternative schools or unjustifiably included them in comparisons with traditional schools. Also as a result of the lack of attention to programing and accurate evaluation school districts have 
used alternative programs and schools to remove low performing students from traditional schools to improve AYP measurements of the traditional school.

Considerable time and resources have been spent by State Education Agencies (SEAs) in improving accountability systems and the accuracy of instruments that measure student performance and adequate progress of traditional schools. Figure 4 demonstrates accountability lenses presented by NCLB (state, district, and school). The figure lacks program-level reporting which illustrates the lack of attention paid to the complex interactions between different types of districts, schools and programs. Figure 4 demonstrates that state, district and school organizations are held accountable through state report cards and school ratings without attention to their environmental differences. Types of schools are not accounted for in the ratings, yet all are compared with one another and given school ratings.

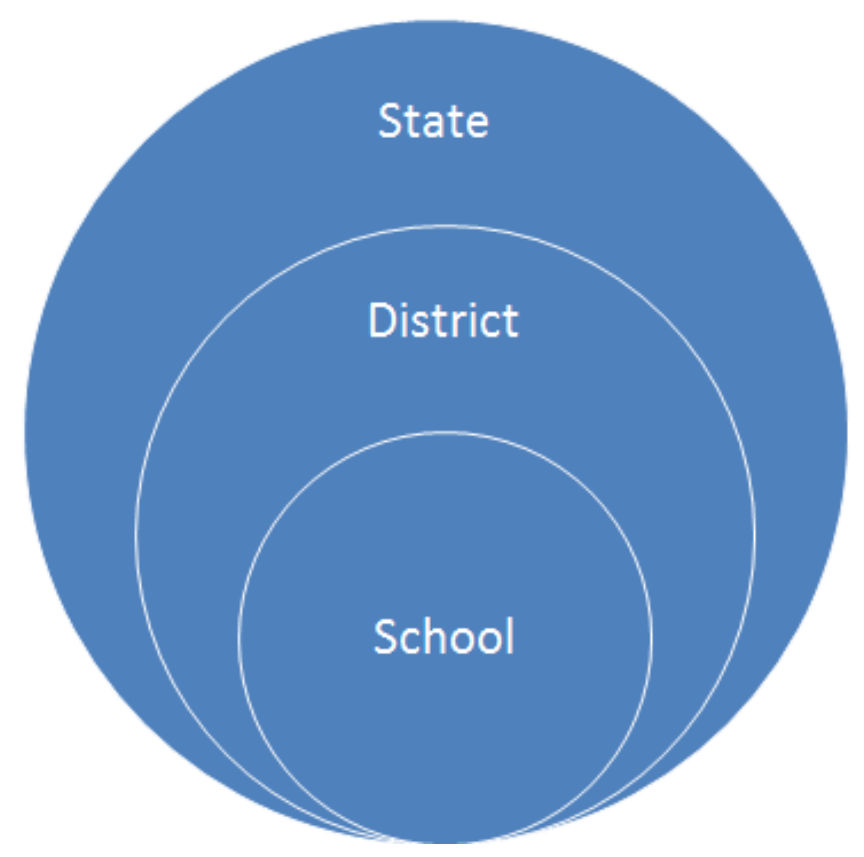

Figure 4. School Accountability System Under NCLB. 
Members of the school community sometimes disagree with the school ratings. For example, $90 \%$ of local citizens describe their school as successful (Gallup \& Newport, 2009) but that is far from the case in actual school ratings (ODE, 2012). Members of the community might hesitate to call their school failing and are likely not objective stakeholders in the determination. School communities strongly resist the negative rating. They may demonstrate this bias because their own children go to the school they are referring to and they participate as stakeholders in that school's success. Ratings are determined quantitatively at the state-level and are based on statistical measures using reported data. Few, if any, from the community are involved in establishing the school rating which leaves a lack of understanding about how these ratings may be used. Federal and state policy would indicate that they are used in school improvement monitoring (ODE, 2012). Researchers and program evaluators often distinguish between "insiders" who have a firm stake in the organization's success and “outsiders" who do not have as much difficulty establishing an objective viewpoint (Spaulding, 2008; Wholey, 2010). Program evaluators also suggest comparison between the effectiveness in context to the community and should include both insiders and outsiders in the evaluation process (Patton, 2011)

Those who set out to measure schools and hold schools accountable do so with any number of reasons. Some hold agendas that have a specific intent of social policy change. Others are in pursuit of some objective viewpoint that will help them determine if they should consider placing their children in the school. Still others are tasked by federal or state laws to hold schools accountable for students' academic performance. 
The purpose of school evaluation is essential in understanding how to use the resulting information. The purpose of school rating systems is, in most part, not clear to the schools or the communities where those schools are located. In my experience representing the state of Oregon, these rating systems are misused more than they are used for improvement or fully understood. Absent of the expressed purpose, school ratings are of little use to members of the community in improving their alternative schools. In the example describe in the preface, Crossroads had not met AYP for several years and had been designated as a failing school, yet the students attending the school described it as a positive place to learn and achieve credits toward graduation.

The NCLB provided funding and resources to incentivize states to develop state accountability systems to measure AYP. Comparisons among schools were accomplished by states in a number of ways and with a variety of intended and unintended outcomes. Debates arose regarding what was adequate progress and state definitions differed in this area depending upon the context of policies in that state. Some scholars now argue that school report cards are not an adequate form of measurement of school performance and schools are better off measuring themselves (Ravitch, 2010).

Critiques of school report cards have concluded that American school report cards may be a better measure of average student profiles and socioeconomic status than school performance (Figlio \& Lucas, 2004; Harris \& Herrington, 2006). Some now suggest that a growth model ought to be used to account for differences in student growth from year to year. Such comparisons in student growth make a logical argument but lack practical application when states account for student mobility between schools and districts (ODE, 
2012). This is especially true in alternative schools where the average length of stay could be as short as a few weeks and as long as a few years. Many alternative schools that currently receive report cards do not have an adequate data sample to result in a grade and those that have a population large enough to be measured are identified as some of the worst schools in the state of Oregon as determined in AYP calculations (ODE, 2006b).

The field of program evaluation has a lot to offer alternative schools as well as traditional schools, including standards to support evaluations that are useful in the improvement process. While determining quality in alternative schools is more difficult than it might seem, there are widespread research studies that include descriptions of quality alternative schools which serve as a basis for the evaluation of these types of schools. Traditional schools were never designed to serve all students; alternative school design, redesign and evaluation begin with needs assessment and evaluation that will provide ongoing feedback about how the school is doing.

Traditional forms of school accountability, such as school report card comparison are not adequate for alternative schools because they do not account for differences in student population over a like amount of time. Alternative schools typically serve students for shorter periods of time after those students have demonstrated (sometimes several times), that their needs were not being met in the traditional school. One urban area school district student service director referred to alternative schooling as an expensive undertaking that was her districts' sixth tier of intervention (referring to the Response to Intervention (RTI) Program which only describes three tiers of progressively 
intensified instructional treatment) (Urban School District Director, personal communication, February 18, 2011). Alternative high school evaluation and public policy should be derived from needs of the local classroom teacher and school leaders and serve to support them in increasing student achievement (Elmore, 2004). This review of literature and study were designed to ground the Evaluation Toolkit in previous work related to the determination of degrees of quality in alternative schools.

\section{Policy Involving School Choice}

The historical context of educational policy relating to alternative education in the past 40 to 50 years helps in understanding the complex interactions between and among state and federal stakeholder groups. Fowler (2004, p. 336) suggested three historical periods relating to educational policy; the "Young Republic" (1783-1830), the "Rise of the Common School" (1831-1900) and the "Scientific Sorting Machine (1900-1982). These time periods help to categorize transitions in types of schooling that were occurring during the first two periods. Alternative schools and charter schools have emerged as innovations to serve students who were sorted out by the "Scientific Sorting Machine." Some describe the emersion of public charter schools as a disinvestment of public education (Murphy, Louis, \& American Educational Research Association, 1999).

Milton Friedman (1962), professor of economics at the University of Chicago, first described "school choice" as an idea that would allow successful schools to emerge and thrive, creating competition in public education. In the early 1970s, school choice continued to move forward and educational options continued to emerge in many different forms. In the 1970s and early 1980s, continued to criticize the "Scientific 
Sorting Machine" and there was concern expressed by a number of groups about a growing number of students who were "at-risk" and did not appear to be successful in traditional schools.

As described earlier in this review of literature, a report titled "A Nation at Risk" suggested that there was "widespread public perception that something is seriously remiss in our educational system" (National Commission on Excellence in Education, 1983, p. 1). The report authors warned that the public school system in the United States was failing to prepare their graduates adequately for the competitive global economy and suggested reforms that they felt were necessary to address the needs of an endangered nation. These studies are included the agendas relating to school choice, which included the creation of alternative, charter and magnet schools. Many authors use the "Nation at Risk" juncture as a breakpoint in history because what has followed in the current policy environment is a seemingly endless stream of policy proposals for education reforms from politicians, business people, think tanks, and universities (Fowler, 2004).

In a series of events such as school choice are described by Gladwell (2000) as a "tipping point" in education policy; a set of events that, considered together, represent substantial change. The definitions of school choice and alternative schools emerged through the chronological stages described by Fowler (2004), from definition and agenda setting to policy formulation, policy adoption, implementation and evaluation. My role at the ODE, in part, is to determine the extent to which the alternative school policies are effective and use research and information to propose policy that improves programs. 
This has been a frustrating effort the past five years, largely because of the lack of research on school choice and processes for designing and evaluating alternative schools.

Few "policy proposals" ever make it to the point where they are defined at the federal, state and local levels. Policies that are skillfully defined and likely to move toward becoming "policy agendas" include several key characteristics. The defined policy proposal needs to include claims made about the problem, evidence to support the claims, a realistic solution for the problem, broad appeal, and powerful language that links the issues to deeply held values, hopes, fears and aspirations (Fowler, 2004). In the case of "school choice" the issue included all of these characteristics along with 20 years of research, and in the 1980s became policy agendas at the federal and state levels (Morken \& Formicola, 1999; Viteritti, 2001). While the policies gained solid momentum and became law, practitioners at the state and local levels continued to struggle in developing and replicating successful innovative schools based upon the research evidence. This process was and continues to be a mixture of experimentation and innovation with a wide array of approaches involving a variety of student populations enrolled in alternative schools. Developing exemplary programs to address educational programs at the local level is among the most effective things practitioners can do to influence policy agenda setting (Barr \& Parrett, 1997). I spend months every year visiting alternative schools in order to identify exemplary characteristics and support policies and procedures to support improvements.

There are a variety of stakeholder groups that agree in the claims made in the educational agenda of school choice. Among these claims is that students are more likely 
to succeed if they have choice in what school they attend. There is 50 years of evidence that suggests students thrive in schools where their individual needs and interests are addressed. Raywid (1994) suggested that quality alternative schools are the clearest example we have of what a restructured school might look like. They represent our most definitive departure from the programmatic, organizational and behavior regularities that inhibit school reform. Moreover, many of the reforms currently pursued in traditional schools (downsizing the high schools, pursuing a focus or theme, student and teacher choice, making the school a community, empowering staff, active learner engagement, authentic assessment) are practices that alternative schools pioneered. Given such assets and advantages, it is important to ask why alternative schools have not been more widely adopted. In the case of Crossroads Alternative High school, describe in the preface, leaders at the comprehensive high school and a few innovative educators were given the autonomy (ability to innovate) to begin a school that was designed to serve all students educational needs and engaging them in attaining credits toward graduation.

Raywid (1994) surfaced a very important policy question, "Why have alternative schools not been more widely adopted?", and admits that alternative schools pose some fundamental challenges to the way we organize and coordinate common schools. They call for diversity in preferences to common standards and uniformity. They challenge coordination, control arrangements, and what has been a conservative approach to school improvement. These important questions are part of the "how" and "why" of alternative education. Alternative education seeks to exist as a counter to traditional schooling; in essence, it exists because traditional schools have found that one size does not fit all. 
Stage models of policy processes begin with issue definition and progress chronologically continuing with agenda setting, policy formulation, policy adoption, implementation and evaluation (Fowler, 2004). Alternative school choice policies have been formed and adopted but methods of evaluation were neglected and put upon the local districts without support or guidance. The variances in programs and student populations have presented a challenge in the stages of both implementation and evaluation. It is clear that there is research needed in the area of evaluating alternative schools and it is also clear that school report card ratings, under NCLB, are not an adequate accountability system for that evaluation.

\section{Local Policies for Good Schools}

Cuban (2003) wrote that he has wrestled with the concept of "good schools" for many years and contended that just three criteria are needed to measure schools: are they democratic? Are they meeting their goals? And are stakeholders involved? Cuban contended that "good" is a common term that is in everyday use by top policymakers, educators, business leaders, parents, and taxpayers. A good school also could be described as "great," "excellent," "first-rate," or by other similar terms. Common as these terms are, there is no agreed-upon meaning to the word or phrases. Moreover, the words and phrases encompass several notions of "goodness" including Effective Schools, Core Knowledge Schools, Accelerated Schools, Coalition of Essential Schools, Success for All Schools, and dozens of other designs for a good school (Cuban, 2003).

Until present-day reformers openly recognize that parents, principals, and teachers have already made a variety of good schools, and until they develop explicit 
criteria that go beyond the training of students for the workplace to include the nourishing of civic virtue, the official orthodoxy will prevail. The tyranny of a one-best-school model that largely seeks to prepare individual students for an information-based workplace ultimately weakens public schooling in a democracy because it ignores the fundamental purpose of public schooling as revitalizing democratic practices and building a strong sense of common good in each generation while ensuring that the young are prepared for productive labor.

Cuban (2003) warned that in the late 19th century market-driven reformers steered public schools toward a progressive version of good schools through vocational education and in the past quarter century, business-minded reformers have urged all student a traditional academic schooling. There is a truth about democratic politics buried in the cliché: "when the nation has a cold, public schools sneeze." In the case of Crossroads Alternative High School, described in the preface, the local community services and urban resources are overburdened with request from the public and many of the students who are at risk of dropout out of school have been at risk for quite some time, due to economic, personal and academic challenges experienced.

Whether it is state or local policy, policy that is good for students needs to be the focus of program evaluations conducted at alternative high schools seeking to serve students at risk of academic failure. In order to lead in processes of improvement that are focused on students, State and district policy makers need to be able to understand what is going on, make sense of what is happening and have the processes and tools to inform decisions of what to do next. The Evaluation Toolkit suggests a process of evaluation that 
begins from where the school is and formatively considers what is best for those involved with the school.

\section{Evaluation Studies and Reports on Effective Alternative Schools}

While 50 years of research on alternative schools exists, representing exploration and evidence of successful forms of alternative schooling (Barr \& Parrett, 2001; Conley, 2002; Milliken, 2007; Smink \& Schargel, 2004), much of this research can be described as normative and a-theoretical. Most are based upon observations gleaned from traditional schools. These observations serve to only superficially benefit the evaluation of alternative schools. In addition, evaluation studies and reports have resulted in seemingly endless lists of generalized characteristics (frameworks) that appear to describe all effective schools. Researchers who have looked at what was happening in different types of schools have come up with different solutions (Conley, 2002, p. 12).

\section{School Evaluation Studies-Traditional Schools}

Well established quality characteristics for traditional (standard) high schools include specific descriptions of schools, teachers, and classrooms at the high school level that were designed to serve students in the "prototype" schools. These schools were intended to be comprehensive and include their own educational settings that serve as an alternative to suspension or expulsion (Quality Education Commission, 2012). These descriptions depict schools that were intended to serve thousands of traditional students who may not have the same characteristics of vulnerability, described earlier in this dissertation. Other examples of established quality characteristics include regional accreditation standards which include frameworks, rubrics and indicators that address 
school mission, leadership, curriculum, instruction, assessment and provide resources, including school visitation and monitoring, for continuous improvement (AdvancED, 2012a, 2012b, 2012c, n.d.; Northwest Accreditation Commission, 2011).

As described earlier, few research studies dig deeper into the characteristics and strategies of successful (effective) alternative high schools and as a result, valid program evaluation methods to identify successful alternative school practices are "hit and miss" (infrequently described in the literature reviewed for this dissertation). Valid evaluation requires trained evaluators equipped with complex and easy to use tools who operate with a common understanding of Standards for Educational Evaluation described earlier in this dissertation. There are a few notable examples of such evaluation studies and reports that describe, in greater detail, what is going on in traditional schools and in some cases alternative schools.

A notable example of a valid evaluation and comparison is the intensive 7-year study John Goodlad completed that resulted in the publication of A Place Called School, originally published in 1983 and again in 2004. The study encompassed 13 school districts, 38 schools, intensive classroom observations, central data gathering and interviews or surveys with 27,000 teachers, parents and students. His research and writings work from the premise (belief) that an understanding of schools must precede attempts to improve them and he seems to describe what the nation should consider as it designs new and better schools. Although Edmonds (1979) and Goodlad (2004) primarily focused on elementary schools, they described improvement as a school-by-school process, enlightened by the degree to which those associated with each school are trying 
to improve, having the information (data) required for building useful agendas for improvement. Put on one pair of glasses and our schools appear to be the worst of places. Put on another and they appear to be the best (Goodlad, 2004, p. 10).

Another research study by Edmonds (1979). described characteristics consistently found in effective schools such as a safe and orderly environment, clear and focused school mission, instructional leadership and high expectations While both Goodlad (2004) and Edmonds appear to take a very scientific and careful approach to establishing themes from rigorous observations made in traditional schools, neither specifically addressed differences between certain types of alternative high schools or the populations of students they serve.

The Washington State Office of Superintendent of Public Instruction (Shannon, 2007) has published the second edition and resource list of Nine Characteristics of HighPerforming Schools which include a clear and shared focus, high standards and expectations for all students, effective school leadership, curriculum, instruction and assessments aligned with State Standards and focused professional development . Others have sought to benchmark similar effectiveness indicators with research and rubrics (Dunsworth \& Billings, 2009). Further investigation reveals that many such indicators were never intended to address the needs of evaluating alternative schools (M. Dunsworth \& D. Billings, personal communication, February 25, 2010). NWREL described research which resulted in identifiable schooling practices and characteristics associated with measurable improvements in student achievement and behavior such as 
school time is used for learning, discipline is firm and consistent and there are high expectations for quality instruction (Cotton \& Paglin, 1995).

Oregon has its own conceptual framework (Standards) for continuous improvement planning and district accountability (ODE, 2011) which include indicators for curriculum, instruction, culture, family and community engagement, leadership and integrated systems and structures. At one point Oregon's Standards were used to conduct standardization visits (audits) including school and district monitoring and curriculum audits (English, 1999; Jacobs, 2010) but are now primarily used as a framework for submitting school improvement plans in a State accountability system that is primarily limited to state, district and school report cards, recently reinvented as achievement compacts. Recent changes in Oregon state policy has involved increased state and regional involvement with the lowest performing schools, identified as "Focus" and "Priority" Schools. Independent contractors conducted student, parent, and teacher surveys combined with protocol-driven classroom observations and reported on what was happening at focus and priority schools. These data are contributing to the development of statewide systems of support described by Sam Redding and others at the Center on Innovation and Improvement (Redding, 2006; Redding \& Walberg, 2008).

As mentioned previously, such research studies and reports on effective schools are not generalizable for use in alternative high schools, which serve a specified population of vulnerable students. Even with the help of multiple librarians, education experts, researchers, staff from the USDE and the support of the NWREL (now called Education Northwest) Compressive Center (Education Northwest Staff Researcher, 
personal communication, February 24, 2011), it was difficult to find studies that focused more narrowly on the topic of evaluating alternative high schools. In reaching out to my own professional network, as Alternative Education Specialist at ODE, I received more questions than answers in response.

\section{School Evaluation Studies-Alternative Schools}

The Accelerated Schools Project, since its inception in 1986, has been focused on transforming schools with high populations of students at risk of dropping out into schools with high expectations of students (Finnan, St. John, McCarthy, \& Slovacek, 1996; Hopfenberg, 1993). The project studied a systematic school-restructuring process, employed the work of trained accelerated school facilitators and was focused on unity of purpose (student achievement), empowerment coupled with responsibility (accountability) and building on strengths (design and evaluation planning). Trained facilitators used an inquiry-action framework to support improvement. Teachers and school stakeholders learned that inquiry played a vital role in the change process (Finnan et al., 1996, p. 73).

The Accelerated Schools Project in 1986 (Finnan et al., 1996) and the study of more traditional schools in 1983 (Goodlad, 2004) both described a school-by-school approach to school evaluation and improvement. The school-by-school approach included research (inquiry-action approach) and had a very rigorous mixed method (value added) research design; including training for those that sought to use the developed processes and tools. In both cases, trained facilitators contributed to the success of the project and the impact was felt throughout the literature of that decade and even decades 
to come. Both these evaluation studies and reports accounted for elements of humanity in the process of evaluating schools; recognizing that schools are made up of people (students, parents and members of the community, teachers, and administrators). As described earlier in this dissertation, schools improve as their students improve and are impacted by skilled teachers and communities that hold high expectations for them.

Another research study seeking to support schools with high concentrations of students that are at risk of dropping out is the Coalition for Community Schools (CCS) Project, which has defines a community school as both a place and set of partnerships between the school and other community resources (Shah, Brink, London, Masur, \& Quihuis, 2012). A community schools' mission is carried out through an integrated focus on academics, health and social services, youth and community development and community engagement that lead to improved student learning, stronger families and healthier community schools (CCS, 2012). The CCS project is similar to the Schools Uniting Neighborhoods (SUN) Community Schools in Multnomah County, Oregon which are full-service neighborhood hubs where the school and partners from across the community come together to make sure kids and families have what they need to be successful-in school and in life (Multnomah County, 2012). There SUN Community Schools (Service Systems) in Centennial, David Douglass, Gresham-Barlow, Parkrose, Portland and Reynolds School Districts and each maintain annual profiles, complete with logic model outputs (results) and outcomes described from the previous year. While Crossroads Alternative High School, described in the preface, is not a SUN Community 
School, Mr. Lovall and Mrs. Refermer may benefit from networking with other school and district leaders in Multnomah County who support these schools.

The Institute for Educational Leadership (2012) is currently working with the John W. Garner Center at Stanford University (JGC Stanford, 2012) on the CCS Project. CCS resources include national models, research publications, a Scaling up Guide and Community Schools Evaluation Toolkit. The Evaluation Toolkit was designed to help community schools evaluate their efforts so they learn from successes, identify challenges and plan future efforts. It provides a step-by-step process for planning and conducting an evaluation of community school site and includes a logic model, results (inventory), and corresponding indicators (for quality) for evaluation planning and design with clear descriptions of the evaluation process.

The NWREL published Alternative Schools: Approaches for Students At Risk that describes schools and programs targeting students who are unsuccessful in the traditional school environment. The report described certain features (characteristics) of alternative schools including a clear mission, small enrollment, more personal relationships between students and teachers, clear rules, high standards and a flexible schedule (NWREL, Paglin, \& Fager, 1997). Though this research appears to identify valid indicators of effective alternative schools beyond elements of successful alternative schools (Barr \& Parrett, 1997, 2001) the publication was intended only to briefly describe concerns and issues (NWREL et al., 1997, Foreword).

Throughout the research and information collecting in the R\&D Cycle (Borg \& Gall, 1989; Bridges \& Hallinger, 1995), I corresponded with state policy analysts in 
several states, policy analysts and administrators in: Georgia, 2006; California, 2007, 2010; Iowa, 2008; Idaho, 2009; Pennsylvania, 2009; New Jersey, 2009, 2010, 2011;

Tennessee, 2010; Wyoming, 2009; Massachusetts, 2010; Washington, DC, 2010;

Michigan, 2011; Arkansas, 2011. I have personally interacted with other researchers and graduate students that asked permission to cite Oregon law, policy and practices in their own research, personal communication with researchers and graduate students at: Lewis and Clark, 2006; Clemson, 2006; Stanford, 2007; University of Tennessee at Chattanooga, 2007, George Fox University, 2008; Portland State, 2009. Among those I consulted was James Witty, Board Member of the NAEA (2009) who was developing the headings for Exemplary Practices in Alternative Education: Indicators for Quality Programing described in Table 10.

Table 10:

Exemplary Practices in Alternative Education
1. Mission and Purpose
2. Leadership
3. Climate and Culture
4. Staffing and Professional Development
5. Curriculum and Instruction
6. Student Assessment
7. Transitional Planning and Support
8. Parent/Guardian Involvement
9. Collaboration
10. Program Evaluation

Source: NAEA (2009)

The alternative education practices (indicators) described by the NAEA may prove to be useful in small-scale testing and preliminary field testing of the product as a 
part of school observations, especially if they are included with school and student information (inventory) with a step-by-step Toolkit resources used by trained evaluators. However, the indicators are of little use at the state or regional levels, for holding schools accountable, without an agreed upon typology of alternative high schools and subgrouping of student population (based on vulnerability) that results in easily describable program outputs (results) and outcomes.

As previously described, the differentiation between different types of schools (typologies) benefit those who seek to identify schools based upon generalized school or student characteristics but such categorization only supports in determining their likeness and fall short of determining the quality of their programing (Aron, 2006; Barr \& Parrett, 2001; Conley, 2002; Raywid, 1981, 1994). Previous research studies and reports have introduced Elements of Successful Alternative Schools (Table 1) such as a strong mission and sense of purpose, high expectations for student achievement, low teacher/student ratio, individualized learning, varied instructional strategies, high standards, holistic services, caring staff and a flexible schedule (Aron, 2003; Barr \& Parrett, 1997, 2001; Harris \& Herrington, 2006; R. Morley, 1996; Raywid, 1994).

\section{Reports-Alternative Schools}

The National Center for Education Statistics (NCES) has twice published reports based on school district survey data that describes alternative schools and programs for students at risk of educational failure. The NCES report provided information about alternative schools and programs that are specifically designed to address the educational needs of students who are at risk of school failure in a setting apart from that of the 
regular (traditional) public school. Schools depicted in the report, as described by school districts, may be administered by the district (public) or an entity other than the district (private). The survey includes information on the availability and number of alternative schools and programs, the number of students enrolled in alternative schools, and programs, and district policy on returning students to regular school (NCES, 2002b, 2010). While the two reports are not directly comparable, their review and comparison provided information about federal perceptions of the value alternative schools have.

The survey conducted by the NCES reported that $39 \%$ of public school districts administered at least one alternative school or program for at-risk students during the 2000-2001 school year (NCES, 2002b). According to the NCES survey, 612,900 students, (or $1.3 \%$ of all public school students), were enrolled in public alternative schools or programs for at-risk students. Overall, 10,900 public alternative schools and programs in the nation served at-risk students during the 2000-2001 school year (NCES, 2002a). According to the survey, urban districts, (large districts with 10,000 or more students) and districts with high minority student enrollments, and districts with high poverty concentrations were more likely than other districts to have alternative schools and programs for at-risk students. Among other things, this information demonstrated that alternative education had become a viable policy option, especially in urban areas, for districts and more specifically for students at risk of academic failure. Though, alternative schools were still often not explicitly considered in state accountability systems that were designed under the guidance of NCLB. 
In addition to the evaluation studies and reports previously referenced (Barr \& Parrett, 2001; Finnan et al., 1996; Goodlad, 2004; Hopfenberg, 1993; NAEA, 2009; Shah et al., 2012), the ODE (2006b) produces an annual report on the status of alternative education programs and in 2006, produced a Summary of Exemplary Alternative Programs in Oregon (ODE, 2006a). The most recent annual Oregon State Report on Alternative Programs (referenced earlier in this review of literature) is included in Appendix $\mathrm{G}$ and reports on the types and numbers of students and alternative programs statewide. This information is based upon estimates submitted by districts in the Spring of each school year and are not reported publically for any purpose accept state-level reporting of alternative programs. Recent changes in federal, state, and district reporting have left questions about the future of state-level reporting of this information but up until now, ODE staff has maintained that the general reporting is useful to the Legislature, ODE and Districts despite law changes.

As described earlier in this dissertation, 50 years of research on alternative schools exists, representing exploration and evidence of successful forms of alternative schooling (Barr \& Parrett, 2001; Conley, 2002; Milliken, 2007; Smink \& Schargel, 2004), but much of this research can be described as normative and a-theoretical. Most are based upon observations gleaned from traditional schools and these observations serve to only superficially benefit the evaluation of alternative schools. Researchers who have studied what was happening in alternative schools have come up with different solutions (Conley, 2002, p. 12). The evaluation studies and reports included are representative of the literature available at the time of review. 
Among other steps in the process, developing and an evaluation plan is essential in the design of an alternative school (Barr \& Parrett, 1997; Chalker, 1996; Conley, 2002; Kellmayer, 1995; Mottaz, 2003). The next section reviews the literature relating to alternative school evaluation processes and tools.

\section{Alternative School Evaluation Processes and Tools}

Program evaluation is an essential component to an alternative school's effectiveness (Aron, 2006; Barr \& Parrett, 2001; Conley, 2002; Finnan et al., 1996; Leone \& Drakeford, 1999; Milliken, 2007; Mottaz, 2003; NAEA, 2009; NDPC, 2011; Raywid, 1994; Schargel \& Smink, 2001; Schargel, 2005; Shah et al., 2012; Smink \& Schargel, 2004, 2004; Thomas \& Thomas, 2008; Tyack \& Cuban, 1995). Many school district leaders today are involved in developing and evaluating new kinds of schools and are in need of simple and easy-to-use research-based tools and evaluation protocols (processes) to accomplish their work. The inventory of school policies that impact alternative high school student graduation is essential (R. E. Morley, 2002; R. Morley, 1996). Evaluations need to focus on observable indicators of successful alternative high schools (Barr \& Parrett, 1997; Cotton \& Paglin, 1995) to determine exemplary practices (indicators of quality programing) (NAEA, 2009). Compliance with federal and state laws continue to be one indicator for quality (compliance) that seek to maintain safe learning environments and provide students and parents with clear expectations regarding certain assurances (ODE, 2006b). The evaluation process that involved Crossroads, in the preface, would have benefited from a clearly design program evaluation process and tools described in this literature. 
In my work at ODE over the past six years, I have personally reviewed hundreds of program applications for alternative schools. The program applications include annual program evaluations, sample documentation and statements of expenditures reported by the organizations. Although it might be a cliché, "programs that fail to plan, plan to fail" Alternative schools that demonstrate thoughtful design with respect to evaluation appear to be more successful and are perceived by others to be delivering quality educational programing. I have personally observed increased issues and concerns expressed about schools that lack a clear vision/mission, leadership, financial resources and planning, in comparison with those that submit complete and polished applications. Although documentation and registration is just one indicator, failure to meet deadlines for registration and required annual program evaluation, are often valid indicators that the school is in leadership transition or having other problems.

\section{Accreditation Standards as Framework for the Evaluation Process}

The process of regional school accreditation provides a useful framework for looking at both quality school design and evaluation and is perceived as more useful than school report cards or compliance check lists. Accreditation for schools and school systems involve regular site visits combined with planning, regular reporting and assurances that are based upon commonly held standards for quality such as purpose and direction, governance and leadership, teaching and assessing for learning, resources and support systems, and using results for continuous improvement (AdvancED, 2012a, 2012b, n.d.). 
Accrediting organizations have traditionally maintained processes for regular mixed-method evaluations that attend to commonly agreed upon quality standards that are accompanied by indicators and rubrics that address school mission, leadership, curriculum, instruction and assessment, provide resources for continuous improvement. Accreditation of schools that serve a "special purpose" or that serve students "online" utilize indicators specific to that type of school and typically involve an evaluation team made up of stakeholders with experience in that particular type of school. Accreditation teams include stakeholders from inside and outside the school in an evaluation process.

In Oregon, public schools are not required to maintain regional accreditation but many choose to undergo the process anyway as it serves a purpose in school and system improvement. In some cases, especially smaller or private alternative schools, regional accreditation assures academic credits and certificates will be recognized by accepting institutions and organizations. Not all schools are accredited and most states do not require full accreditation as a prerequisite to serving alternative high school students. These accreditation standards and indicators are expanded upon in the context of evaluation in this dissertation. They offer a useful framework for consideration when evaluating alternative (special purpose) schools.

Some Oregon districts pursue regional accreditation as a part of contract arrangements to serve high school students. This assurance provides evidence of a standard quality of school and assures their traditional high school or community college will accept credit awarded by the alternative school. From their inception (design), highquality alternative schools should consider how they will communicate their evaluation 
results both internally and externally to stakeholders in the local community, district, and state. National recognition, regional accreditation, state registration and organizational memberships can improve public perception and allow avenues for public disclosure of evaluation results that positively reflects on the school.

In addition to being a contributory framework for program evaluation, accreditation standards may be used in designing new alternative schools (Edwards, 2012). School evaluation is embedded in this design process and occurs formatively throughout, providing a context for the inventory and evaluation of quality results and outcomes from a schools inception. Edwards suggests that there are four key areas of school development: Assessment of student needs, school design, school and educational program implementation and development, and continuous school improvement (program evaluation). We have worked together to refine continuous improvement to a formative evaluation process that begins with the end in mind. The results of this process include a program description that depicts the school vision and an evaluation plan that puts in place methods of formatively measuring and reporting on results and outcomes.

Throughout working with Chet Edwards the past several years, in reference to alternative school program evaluation, I have referenced the need to establish educational context through inventory and reporting, determine "quality" based upon established standard tools with indicators and monitor for "compliance" with federal and state laws. We have found in preliminary field testing that starting from accreditation standards and essential elements produces a quality program description (vision) and formative 
evaluation planning results in schools that better understand their mission and desired student outcomes.

To make the link between what school administrators know about traditional school improvement I strived to use generalizable terms such as curriculum, instruction, and assessment to describe the tools in the Toolkit. In my experience as the alternative school specialist at the department of education, I have had the opportunity to participate in hundreds of evaluation visits and have assembled dimensions of alternative high school program evaluation in a way that traditional high school administrators, teachers, teachers and students may contribute.

Following the visit to Crossroads, described earlier in the preface, I reached out to and corresponded with Bob Barr, author of several books that I had been reading about alternative education. Bob offered insights and historical context that no one else had referenced about alternative education and we met together and talked several times and interacted at various national meetings over the course of three years and remain in regular contact today. His personal narrative and stories provided me alternative school context to school segregation, free schools and introduced me to a whole new way of looking at charter schools, alternative schools and other forms of school choice. Upon further review of the literature and Bob's writings, I began to understand more about the context and history of alternative schools within the context of school choice. Bob's recent book was a self-guided audit for school improvement and was based upon tools used in Europe and Australia and were constructed with rubrics and indicators (Barr \& Yates, 2010). The tools described in the book combined with our conversations heavily 
influenced my design of the first version of Toolkit that included a rubric without indicators that described the framework. Further work (on the Toolkit) is needed to develop valid indicators and more reliable instruments for the Toolkit.

The last few years, I served on the Board for the Oregon Program Evaluation Network (OPEN), a professional organization for networking among program evaluators. I had come to believe the notion of "assessing impact" and auditing alternative schools was worth pursuing in the context of program evaluations required under Oregon law. A "logic model" is a tool used most often by evaluators of programs to determine the effectiveness of a program. Logic models are usually a depiction of the logical relationships between the resources, activities, outputs (results) and outcomes of a program. At a "logic model" workshop at the Oregon Museum of Science and Industry (OMSI) I interacted with professional program evaluators struggling to design methods to measure the impact of museums exhibits (OMSI Staff, personal communication, March 16, 2010). If a workable method of program evaluation was possible with museum visitors that were only present for a few hours, I asked a colleague, "Why are we not keeping better record of the results and outcomes of students attending alternative high schools, who often attend the school for the majority of a school year?"

\section{Evaluators' Objective Determination of Quality}

Failing to properly train the evaluation team can have serious negative effects on the outcome of the data collection process in evaluating an alternative school (Reimer \& Cash, 2003, p. 36). The involvement of outsiders and insiders in a program evaluation process, as a part of an evaluation team, impacts the measurements that determine 
alternative school effectiveness. Insiders are those who are directly impacted by the school rating, such as the school administrator, teachers, students, parents and members of the local community. Outsiders might include newspaper reporters, external program evaluators, contractors, government officials, and staff from state education agencies, regional education laboratories or the USDE.

In order to assess "quality" in alternative schools, in addition to compliance, evaluation team members must be competent (Russ-Eft, 2008) and take into account the perspectives of stakeholders from both inside and outside the organization (Chalker, 1996; Fowler, 2004; Russ-Eft, 2008; Spaulding, 2008; Yarbrough et al., 2011)

While it is impossible to be completely free of bias, evaluators must be expected to act ethically and adhere to propriety standards. For this purpose, the evaluation should be conducted by a team of professionals assembled from both inside and outside the organization. The evaluation team must consider fidelity (alignment) of the observed and noted school practices with the alternative school's mission and the school's effect on student learning (Barr \& Yates, 2010; Chalker, 1996; Goodman, 1999; Leiding, 2008; Mottaz, 2003; Reimer \& Cash, 2003; Slavin, 1989; Thomas \& Thomas, 2008; Yarbrough et al., 2011). The program evaluation should seek to evaluate fidelity to the program's design and assess its impact on student engagement and learning.

In many cases an alternative school looks nothing like a comprehensive school but a similar set of terms may be used in evaluation. In other cases the unit of analysis (school) looks more like a program that supports a comprehensive school. Either way, an alternative education setting may intimidate educational evaluators who are more familiar 
with traditional school settings, activities and assessments. Any process of measuring school performance is difficult without commonly understood categories of indicators such as curriculum, instruction, culture, engagement, leadership, systems and structures (ODE, 2011). As it turns out these categories are already the basis for many comprehensive school evaluation processes and make it easier for stakeholders not familiar with alternative schools to transfer the lexicon of terms required to discuss subject areas in evaluating alternative schools. In essence, these categories are commonly understood and provide a scaffold for alternative school evaluation training.

District evaluation of quality among their alternative schools necessitates (a) tools to focus attention on characteristics of quality and (b) qualified people involved in the evaluation team (inspectorate). These teams of people should account for what is present in context with the population of students who attend and the resulting outcomes accounted for that are relevant to the mission and goals. The team should be perceived as helpful in presenting accommodations, criticism and recommendations for improvement. In this way these evaluation teams should be utilized somewhere between a state consolidated monitoring and standardization visit and the school accreditation process with the overall intended outcome being continuous school improvement.

\section{Evaluating the Organizational Leadership in Alternative High Schools}

Leaders may build a commitment from those involved in their organizations, implement with fidelity, sustain the program, and assess and evaluate progress (Chenoweth \& Everhart, 2002). Designing with the end in mind is absolutely essential in the process of designing alternative high schools. Alternative high schools with strong 
educational leaders are more effective (AdvancEd, 2012a; Barr \& Parrett, 2001; Chalker, 1996; R. Morley, 1996; NAEA, 2009; NDPC, 2011). Educational leaders such as Mr. Lovall and Mrs. Refermer, described in the preface that involved Crossroads Alternative High School, were strong leaders and both had much to offer this unique school, however transition was not easy for students or staff because the school is such a unique setting.

Skilled organizational leaders and managers develop the skillset required to read situations with scenarios in mind and forge actions that seem most appropriate (Morgan 2006). Looking for this kind of organizational leadership in program evaluation and improvement is perhaps the most challenging of all the sections addressed in this paper because of the variance in organizations that make up alternative education. This is largely because the features of alternative schools are shaped to a large extent by the needs and characteristics of the students they serve as well as the philosophy of the staff. Compared with traditional schools, alternative schools vary widely in terms of how they are organized, as well as in their customized approach to instruction and support.

As mentioned in the introduction and policy sections of this paper, an agreed upon typology of alternative high schools does not exist. Alternative education can refer to any non-traditional educational service, but is often used to indicate a program provided for at-risk children or youth (Aron, 2006). As described earlier, programmatic characteristics are suggested as essential in alternative schools. These characteristics include (a) small class size and small school, (b) choice, (c) a personalized educational environment, (d) high expectations for success, (e) students included in the decision making process, (f) 
specialized teacher training and teaching arrangements, $(\mathrm{g})$ family involvement, (h) effective classroom management, and (i) transition support (Tobin \& Sprague, 1999).

Similarly to alternative schools, a lack of a workable typology with which to describe results and classify charter schools has contributed to the lack of quantitatively examined studies of schools (Carpenter, 2005). Carpenter conducted a two-dimensional typology (school type) that classifies these schools by their theme and the population the school is designed to serve. His typology is based on a study of documentation and "Common Core of Data" that described more than a thousand charter schools in Arizona, California, Florida, Michigan, and Texas and determined that the data represented could be consolidated into only five types of charter schools: traditional, progressive, vocational, general, and alternative delivery.

As mentioned earlier, Raywid (1994) suggested there are three types of schools ranging from innovative school to what she and others call "soft jail" based upon the severity of intervention services as well as the student population. Defining what alternative schools are is absolutely essential as one considers evaluation processes for the landscape of innovative educational organizations. It is difficult to advise leaders in alternative schools because there is so much variety in schools.

A particular alternative school may have a rich tradition and be in operation autonomously for decades while others may operate as a school within a school, having been opened and closed in a single school year. There are a growing number of virtual (online) educational programs and blended learning (blend of online and face-to-face) programs that are designed for at-risk students (International Association for K-12 Online 
Learning [iNACOL], 2012). The variety of size, mission, methods and purpose of such programs has made identifying the unit of analysis (alternative school) a constant challenge to both federal and state regulators attempting to reliably compare outcomes from such programs. As a result, public policy has traditionally either disregarded information relating to diverse schools or unjustifiably included them in comparisons with traditional schools. Both of these policies, as described, have devastating effects on such organizations and the attending students.

Alternative schools require additional resources to serve at-risk (vulnerable) populations of students and include smaller classes, specialized instruction, counseling, transition and career services, before and after school programs, and intervention planning. A National Longitudinal Study found that more students with emotional and behavioral disorders were attending school in alternative settings than any other disability group (Ennis, Jolivette, Swoszowski, \& Johnson, 2012). Fifty to 80 of incarcerated youth, many of whom are attending some type of alternative school, are reported to have educational disabilities or diagnosed mental health conditions (Quinn \& Poirier, 2006; Quinn, Rutherford, Leone, Osher, \& Poirier, 2005). These diagnosed, as well as undiagnosed conditions require that alternative schools customize versions of functional behavioral assessment and pyramids of intervention.

One example of a tiered intervention system is Positive Behavioral Intervention and Support (PBIS). PBIS implementation requires high levels of support to implement (Sagai et al., 2000). PBIS implementers are provided blueprint and evaluation tools (Algozzine et al., 2010) and caution that PBIS implementation with fidelity requires (a) 
establishing a leadership team to actively coordinate implementation efforts (b) adequate funding, visibility, and consistent political support; (c) building a cadre of individuals who can provide training and coaching support for local implementation, (d) a system for on-going evaluation and provision of performance-based feedback to implementers; and (e) a small group of initial implementation sites that demonstrate the viability of the approach within the fiscal, political and social climate of the state or system.

Customizing behavior and academic intervention systems such as PBIS requires a sophisticated level of organizational leadership and includes assisting program staff in organizing evidence-based behavioral interventions that enhance behavioral outcomes for all students (Sailor, Dunlap, Sugai, \& Horner, 2009). Logic models and blue print evaluation templates are supplied to support PBIS implementation that seeks to establish fidelity in efforts to scale up the program. The evaluation tools combined with best practices and recommendations for alternative education settings (Tobin \& Sprague, 1999, 2000) provide alternative educators implementation tools.

It has been my observation that educators and policy makers who do not have experience with alternative schools sometimes contend that alternative schools should be able to just get these kids and "fix" them. What these individuals fail to recognize, is that these students are vulnerable (at-risk) and simply addressing their current individual needs takes tremendous resources. Many at-risk students can be identified as early as third grade, while others have experienced some sort of educational interruption that has resulted in them falling behind in achieving the knowledge, skills or credits required to graduate. Some alternative educators describe what they do as "raising the dead." In a 
study from ODE titled "Student Voices: Why School Works for Alternative High School Students, the authors include direct quotes from students enrolled in alternative schools from throughout Oregon. Students were interviewed who attend Alternative High Schools and found that these students struggled due to personal, academic or school issues (Brush \& Jones, 2002). In my experience the past few years in working with both design and evaluation of alternative high schools, I have found the direct quotes in this report repeated by other vulnerable (at-risk) students.

The narrow set of indicators (attendance, graduation rate, and test scores) prescribed under NCLB, known as AYP, required that all schools that fail to meet target proficiency levels for two or more consecutive years are required to undergo the same series of prescriptive federal interventions. The law also required that states issue school report cards and school ratings without consideration of differences between schools or the populations of students they served. This one-size-fits-all accountability system rates the performance of schools and does not account for differences in school and program mission. A handful of states promptly adjusted state policies to increase standards, adjust for differences between schools and even altered monitoring schedules to include diverse programs such as alternative schools. Other states structured accountability systems to attend to units of analysis (only district and school, not program) that maintained an intact group and set of indicators that were mostly reliable from year-to-year. Complying with NCLB and accounting for the most vulnerable students in alternative schools has been a significant challenge for educational leaders and our communities over the past decade. Recent innovations by state and local educational organization with growth 
models, personalized learning, educator effectiveness, program evaluation, and modified grading systems that separate out academic achievement and behavior may be the focus of policy in the next decade.

Policy levers (tools to incentivize organizational behavior) in public organizations are limited primarily to money and accountability (Fowler, 2004) and these levers impact school and program accountability and systems to support improvement. An attention to students' well-being and choice must remain at the center of policy and program implementation if student outcomes (accountability) are to be impacted. Policies that lack attention to students, as well as educational practitioners who support student learning, will likely lack clear results or practical outcomes. Adult agendas are sometimes described as adult systems and organizations that hold them and are sometimes perceived as not having enough interest in students. Accountability and money, primarily recognized by school leaders, are two large moving parts in that organizational structure and cannot be ignored in evaluating alternative high school programs.

\section{Elements of the Evaluation Process}

School evaluation tools and self-evaluation audits are often used in school and university accreditation and seek to gather evidence and evaluate the institution based upon established professional standards (Barr \& Yates, 2010, p. 8). Tools are needed that (a) conduct an inventory and report on the educational options the district maintains for students (b) include indicators that assist in identifying levels of quality in specified variable areas such as curriculum, instruction, assessment, engagement, leadership, and structures and should (c) include checklists to assure compliance with state and federal 
laws that assist in maintaining student safety, equity, and access. Checklists to assure compliance with state and federal laws already exist and are required in most states in at least annual evaluation of their programs.

Tool elements. The tools need to be detailed enough to account for complexity in handling the varied types of results and outcomes targeted by alternative schools. These tools need to be detailed enough to support evaluator reliability (comparable determinations made between schools) and simple enough to maintain validity (indicators accurately describe what is happening in the school) among review teams. Terms must be described and used in context with observable indicators that make sense to the evaluation team and to the school district and greater community.

Strong teams. Building a strong team is important in moving a school from good to great (J. C. Collins, 2005; James Collins, 2001; Jim Collins, 2006; Cuban, 2003). For some, evaluating schools is routine and has become an internal process of accounting for where a school is in comparison to where it has been and where it is described to be going. These evaluation team members are exceptional and often have a position where they regularly visit different types of school as the lead on accreditation visits or has a role in the state or region where they interact with a more generalized (district or state level) set of policies. Evaluation tools should seek to support these determinations made by all members of the evaluation team.

The focus of this literature review is to ground the Evaluation Toolkit in methods that accurately and helpfully describe characteristics of the impact made by alternative high schools. There are widespread descriptions of quality alternative schools, and as 
many standards and toolkits as there are purposes to evaluate quality in alternative schools. Districts, schools and programs themselves, may identify useful tools that serve a specified purpose such as needs assessment, school designation, district approval, school distinction, the awarding of financial contracts or achievement compacts.

Program evaluation methods. The professional field of "Program Evaluation" has a lot to offer the field of "Educational Evaluation" as reflected by the revised Joint Committee on Standards for Educational Evaluation (Yarbrough et al., 2011). Program evaluation researcher Michael Patton describes a customized set of methods for applying complexity concepts to enhance innovation and use and suggests the use of a mix of internal and external members of an evaluation team rather than a single individual (Patton, 2011). For those fortunate enough to visit different types of schools regularly, characteristics of quality are complex but identifiable. Unfortunately, without experience as a school parent, teacher, school administrator, or program evaluator, the characteristics of quality may take much more time to identify and the resulting assessment of school quality would likely not be reliable across different schools.

Professional program evaluators are innovating to serve both public and private organizations and the research field benefits from international comparisons. Donaldson (2013) identified innovations professional program evaluators should look for in the coming years and recently presented at the Oregon Program Evaluator's Network (OPEN). A portion of the information he shared and cited in Table 11. 
Table 11:

Trends and Innovations Likely to Impact Your Evaluation Practice

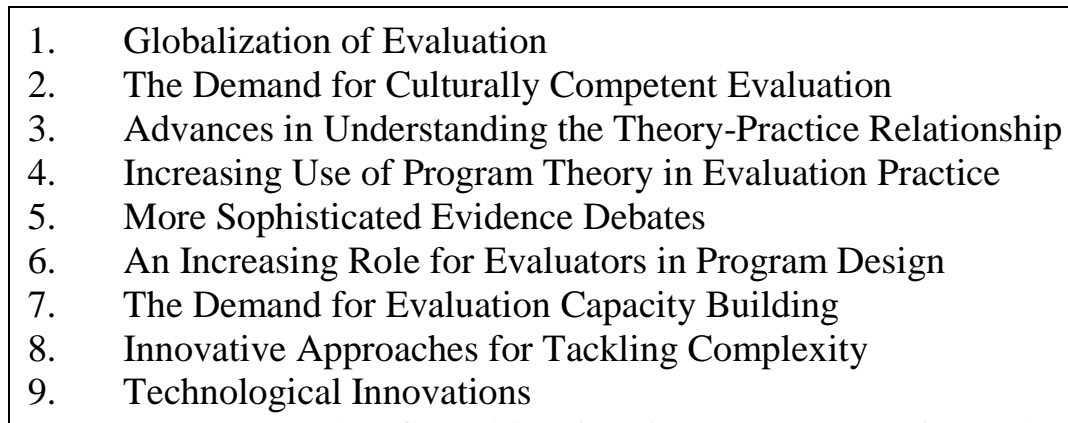

10. New Approaches for Addressing the Human Factor in Evaluation Practice

Source: OPEN presentation by Donaldson (2013)

\section{Characteristics of the Alternative High School Program Evaluation Process}

The Evaluation Toolkit needs to be detailed enough to be reliable, but yet simple enough to maintain validity between review teams and different types of schools (S. Noor, personal communication, February, 2011). The R\&D Steps were conducted as a researcher in combination with experience working to evaluate alternative high schools throughout Oregon and the Northwest Region of the United States. The 10 characteristics describe potential improvements to the existing forms of evaluation (old evaluation toolkit-compliance checklist) that is traditionally used with alternative high schools in Oregon. Table 12 contains a list of Toolkit Characteristics developed as a result of Steps 1-4 of the R\&D Cycle (research and information collecting, Planning objectives, learning activities, and small-scale testing, Develop preliminary form of the product, and Preliminary field testing). 
Table 12:

Alternative High School Program Evaluation Toolkit Characteristics

\section{Who (Members of the evaluation team):}

1. Toolkit effectively supports an evaluator (preferably from outside the school) who facilitates active participation of both internal and external stakeholders working in evaluation team to evaluate the alternative high school with the support of others in their community.

2. Toolkit supports the formation of an evaluation team that is knowledgeable about the school's mission, purpose and policies, leadership, curriculum, instruction and assessment, support systems and planning.

\section{Why (Establishing a clear purpose for the evaluation):}

3. Toolkit supports the evaluator and evaluation team in developing a program evaluation with a clear purpose and objectives that "begin with the end in mind" (S. R. Covey, 2004, p. 97) and thoroughly and accurately portrays the school.

4. Toolkit provides protocol, guidance and tools that support a mix of formative (ongoing and informative) and summative (school visit and summary) approaches to evaluation.

\section{What (Decide upon evaluation protocols, methods and metrics):}

5. Toolkit supports the evaluator and the evaluation team in a program evaluation process with a clear timeline and supportive learning activities (data collection, information gathering, reflection and reporting).

6. Toolkit includes valid tools (tools that measure what they intend to) for assessment, curriculum, engagement, instruction, leadership and structures that support those at the school in learning from their successes, identifying current challenges, planning for improvement and more effectively telling their story.

7. Toolkit includes tools that provide for program evaluation planning, survey of initial observations, indicators that portray school progress and a process that assists in formative program evaluation planning that is perceived by members of the community, school, district and state as generally useful in determining the schools' impact on students.

8. Toolkit includes an assurance of established school mission and goals addressing student attitude, academic performance, effective student learning and behavior, future job success, and parent/community engagement is required; program evaluation validates that the Toolkit is perceived as useful to the school, district and state. Determining the school's impact on academic and non-academic growth is essential.

9. Toolkit and program evaluation process includes consideration of school context variables such as: challenges students bring to the school (student demographic data, focus groups and interviews), what the school and district does that contributes to student failure (inventory of district and school policies) and assurance the district and school policies and practices are compliant with the law.

10. Toolkit includes tools that are designed to: inventory (profile) the school's context through policy and practice, determine a level of quality using approaches that may be referred to as a value-added or mixed-method and assure compliance with current laws. 
As described previously in this dissertation, I have observed and experienced various forms of evaluation and have attempted to incorporate principles and strategies I found generally helpful in the process of evaluating alternative high schools. The Characteristics described in the previous table represent research-based implications and theoretical positions (assumptions) about an effective alternative high school evaluation and used as a framework for program evaluation in the research study. The framework and Toolkit were designed to support a facilitator and evaluation team in determining the impact of an alternative high school. Gay, Mills, and Airasian (2009) described "an assumption is an assertion presumed to be true but not actually verified" (p. 109).

In addition to interviews and focus groups, I have formally presented the above list of characteristics as well as early drafts of the Toolkit with school district leaders, alternative high school principals and colleagues and several have expressed excitement about what the Toolkit might be able to offer both school districts and the alternative programs they are required to evaluate. Collaborating with fellow researcher Mr. Edwards, we found many uses for the Essential Elements (Barr \& Parrett, 1997; Reimer \& Cash, 2003) and Special Purpose Regional Accreditation Standards (AdvancED, 2012b) in both designing and evaluating alternative high schools. Edwards (2012) has developed four assumptions about alternative school design that are related to this research study: Consider all of the "essential elements" of alternative schools, deploy organizational leadership strategies that cause designers to "start over" when designing a new alternative school, use school accreditation standards as a framework for design, and weave program evaluation throughout the design process (Edwards, 2012, p. i). As I have 
contrasted my experiences with current district program evaluation practices, my own experience with various program evaluation methods in other fields of study and participation on different types of school accreditation teams I have found that there is considerable value in using accreditation standards and essential elements in the design process that results in a strong vision for the organization. Following the development of a strong vision, the school is likely ready to consider the development of mission, goals and planning methods of formatively measuring results and outcomes in their school.

\section{Summary}

The most effective methods of alternative high school evaluation are expensive and time-consuming (Barr \& Yates, 2010; Chalker, 1996; Goodlad, 2004; Reimer \& Cash, 2003); requiring detailed planning, the use and development of refined tools (Chalker, 1996; Dunsworth \& Billings, 2010; Redding, 2006; Redding \& Walberg, 2008; Slavin, 1989; Thomas \& Thomas, 2008) and the training of professional facilitators (Finnan et al., 1996; Goodlad, 2004; Hopfenberg, 1993; Redding \& Walberg, 2008; Shah et al., 2012). They include evaluation that is based upon localized context, determines compliance through consensus-building (AdvancED, 2012a) with stakeholders from both inside and outside the school or program (Donaldson, Azzam, \& Conner, 2013; Patton, 2011) with intent of accurately describing what is happening. This kind of evaluation requires resources beyond what is offered in the scope of work for a summative (reportstyle) program evaluation (Barr \& Yates, 2010; Spaulding, 2008). Effective program evaluation involves a formative (ongoing) process that includes goals, tasks and 
deliverables that utilize multiple site visits and tools in an approach similar to the methods utilized in the field of school anthropology.

As described in this review of literature, the accountability framework for NCLB was and one-size-fits all in its approach to holding state, districts and schools accountable and failed to recognize differences of school mission, student population and their local community. The policy focus on nationalization has resulted in the ability for states and districts for focus on improvement rather than compliance. Innovations in program evaluation are able to move to a more localized form of impact-determination, rather than a one-size fits-all solution. This new system will require trust building and (J. C. Collins, 2005; S. M. R. Covey, 2008; Redding \& Walberg, 2008; Senge, 2006)

Previously in Figure 1 Alternative, Charter and Traditional School types and their missions were depicted as being separate with some overlap. Figure 5 suggests that more customized (mix of formative and summative) lenses be considered when schools are held accountable for student achievement (more broadly defined as cognitive and noncognitive skills). The description in Figure 5 accepts the federal and state involvement and use of blunt instruments but suggests a bi-focal lenses be used in prescribing more formative evaluations for alternative schools. The enlarged circle encompasses alternative and charter schools due to expanded national policy agendas involving Common Core Standards, consolidation of regional accreditation to a single national commission, nationalized performance tasks and common assessments and Common Data elements required across all states in order to participate in federal grant funding and Race to the 
Top Initiatives. Figure 5 is a revised framework for alternative accountability School Typology Alternative Accountability Framework.

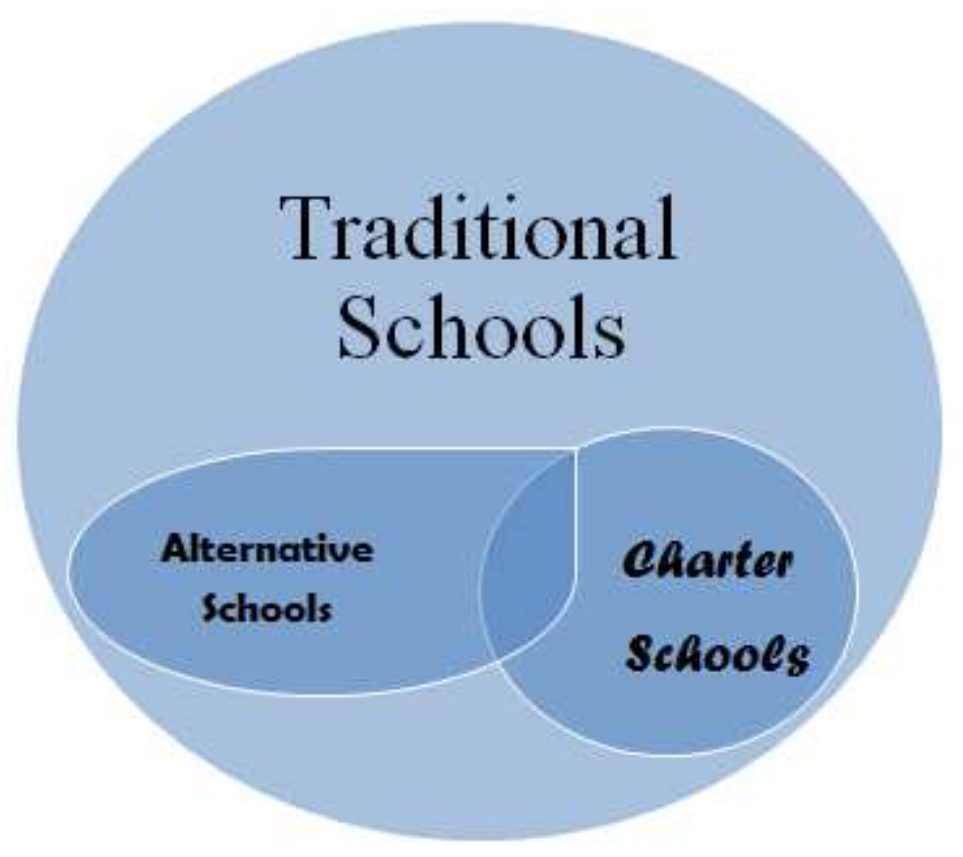

Figure 5. School Typology Alternative Accountability Framework.

This review of literature grounded the Evaluation Toolkit in research and prepared it for the main field testing of the product. The review included types and purposes of alternative schools, history and policy of alternative education, evaluation studies and reports on effective alternative schools and evaluation processes and tools. During the past several years I was very fortunate to have direct access to colleagues and references that supported this study. In many cases those colleagues lived through the era or policy period which I was seeking to learn about. The references listed represent professional reading, research and information collected over several years, including personal communications, references cited and Toolkits requested from organizations. 


\section{CHAPTER 3}

\section{RESEARCH METHODOLOGY}

Research is for the good of the public. If you want simple answers to educational questions, it would be better to stop reading and look elsewhere. (Eisner, 1985)

\section{Introduction}

This dissertation studies the research question: What tools support leaders in planning a thorough and accurate program evaluation of an alternative high school? According to The Joint Committee on Standards for Educational Evaluation a thorough and accurate educational program evaluation includes standard elements of utility, feasibility, propriety, accuracy and accountability (Yarbrough et al., 2011). These standard elements were included as organizers in the Literature Review (chapter 2), are the basis of small-scale testing, were used as the organizers of secondary (guiding) research questions presented in this chapter and are used in the analysis chapter that follows (chapter 4). Among all the frameworks described in chapter 2 these standards are best suited to accomplish my primary research question and address the issue of how best to evaluate alternative high schools. Data collection procedures for this research are theoretically and practically grounded in Bridges and Hallinger's (1995) PBL and Borg and Gall's (1989) R\&D Cycle. The study involves school leaders in the R\&D Cycle and resulted in the field testing and revision of an educational product, the Alternative High School Program Evaluation Toolkit. 


\section{Elements, Characteristics and Assumptions of the Evaluation Toolkit Recipe}

The Evaluation Toolkit could be thought of as a "recipe" for a thorough and accurate evaluation involving both tangible Tools and Characteristics of a process for evaluating alternative high schools. The first part of the recipe includes ingredients (Seven Tools) and describes "what to collect." The second part of the recipe is the instructions (Ten Characteristics) and describes "how to collect."

Both Tools and Characteristics contain features of the Standard Elements (Yarbrough et al., 2011) such as utility, feasibility and others. The Standard Elements developed by the Joint Committee on Standards for Educational Evaluation could be considered a "cookbook" with standard elements organized as a reference for different types of recipes. The Alternative High School Program Evaluation Toolkit is a specific type of recipe with a set of ingredients (tools) and instructions (characteristics). As is the case with most recipes there may be a degree of variance between one dish and another but the elements are the similar.

As an alternative school evaluator, I have developed and tested many of my own assumptions (seasoning in the recipe) such as three Evaluation Dimensions of reporting, compliance and quality assurance described by the funnel in Figure 9 presented later in this chapter. This method of formative program evaluation is further supported by the notion, derived from Covey (2004), that evaluation should begin with the end in mind. "Beginning with the End in Mind" is a way of describing the formative evaluation of an alternative school with the use of a previously developed vision, mission and goals. Additional assumptions about Tools and Processes are described later in this section. The 
focus of this research methodology is to further develop the Toolkit and describe the efficacy of the Recipe. Chapter 4 describes the results and the efficacy of the Evaluation Toolkit based on data from in depth interviews, focus groups and survey data collected during the main field. Data collection methods are described in this chapter.

\section{Evaluation Toolkit Elements}

The purpose of this research is to develop and field test the Elements of the Toolkit and Characteristics of the Process used by a facilitator and the evaluation team in the evaluation of an alternative high school. Toolkit Elements are tangible tools that support a Facilitator and the evaluation team in the process of evaluating an alternative high school. These Toolkit Elements include training materials, protocols and worksheets and are further described in this section, in Figure 6 and the tools themselves are included in the Appendix A. Participants in the main field test were asked to rank Toolkit Elements in a survey conducted at the conclusion of the main field test. This information was combined with qualitative data collected from interviews, focus groups and field journal entries about elements of an effective Toolkit and later used to discuss efficacy.

Original versions of the Toolkit Elements were developed over the course of the past six years as part of my responsibilities as the Alternative Education Specialist at ODE and lead evaluator in numerous types of evaluations. The initial survey was generally useful in getting an evaluation team aligned with the evaluation purpose. The indicators for alternative school improvement assisted in identifying potential areas of growth for the school community. The evaluation planning matrix (simplified logic model) went through several iterations before it was simplified to a left-to-right 
navigation that could be simply described as, "Where are you at? Where are you going? How will you know when you get there?" Research and information collection have been ongoing and I have collected hundreds of evaluation tools and the research frameworks that supports them. Many of these frameworks were examined and summarized in the review of literature and for the purpose of this research methodology are condensed down to the Standard Elements for Educational Evaluation developed by the Joint Committee on Standards for Educational Evaluation (Utility, Feasibility, Propriety, Accuracy and Accountability). Toolkit Elements are the actual tools that make up the Toolkit described in the following figure and the Tools themselves are included in the Appendix A.

\section{Seven Evaluation Toolkit Elements}
1. Evaluation Training Materials

2. Evaluation Planning Worksheet

3. Evaluation Protocols

4. Initial Survey Questions

5. School Progress Indicators

6. Six Evaluation Tools for Evaluation Teams (Curriculum, Assessment, Engagement, Instruction, Organizational Structures and Leadership)

7. Evaluation Planning Matrix

Figure 6. Seven Evaluation Toolkit Elements.

\section{Evaluation Process Characteristics}

The intent of this research is to develop and field test the Elements (tools) of the Alternative High School Program Evaluation Toolkit and Characteristics of the Process. 
For the purpose of this research, Process Characteristics are descriptions of effective evaluations processes such as "Begins with the end in mind" and "Involves internal and external stakeholders" and others provided in Figure 7. Process Characteristics are less tangible than Toolkit Elements but as described previously may be depicted by the standard elements of utility, feasibility, propriety, accuracy and accountability (Yarbrough et al., 2011). Characteristics of an effective process are further described later in this section through the standard elements including utility, feasibility, propriety, accuracy and accountability (Yarbrough et al., 2011). The result of the R\&D is demonstration of the efficacy of the Evaluation Process Characteristics. Additional research methodologies are presented later in this chapter to describe each Step in the R\&D Cycle in greater detail. Process Characteristics are described in Figure 7.

\section{Ten Evaluation Process Characteristics}

1. Begins with the end in mind.

2. Considers established school vision, mission or goals (program description)

3. Involves internal and external stakeholders

4. Supports the formation of an evaluation team

5. Uses a mix of both formative (informative) and summative (summary) approaches.

6. Is practical or realistic (feasible)

7. Is contextualized and produces value (accountable)

8. Is generally useful (utility)

9. Is proper and fair (propriety)

10. Accurately conveys analysis (accuracy)

Figure 7. Ten Evaluation Process Characteristics 
During the main field test (alternative school evaluation), I collected data while serving as Facilitator in the evaluation process. My role as the Facilitator and Researcher required that I act as a member of the evaluation team while collecting data about the evaluation process. To counteract potential bias as a participant in the research, interview and focus group data were compared with field journal entries and anonymous survey data collected at the conclusion of the main field test. During the survey, participants in the main field test were asked to rank Process Characteristics in an online survey. This information was compared with qualitative data collected from in-depth interviews, focus groups and field journal entries about effective Process Characteristics and scrutinized to determine efficacy. Methods employed during each Step in the R\&D Cycle (Borg \& Gall, 1989) are explained in greater detail later in this chapter.

\section{Assumptions about Program Evaluation}

The intent of this research is to develop and field test the Elements of the Evaluation Toolkit and Characteristics of the Process to determine their efficacy. As previously described, Toolkit Elements are tangible tools that support a Facilitator and the evaluation team in the process of evaluating an alternative high school and are described in Figure 6. Process Characteristics are descriptions of effective evaluations processes such as "Begins with the end in mind" and "Involves internal and external stakeholders" and others provided in Figure 7. My own personal Assumptions about alternative high school program Evaluation were derived from experience as an evaluator and are represented in Figure 8. These assumptions were also included in the survey as Likert 
Scale items that asked main field test participants "How essential are each of the following statements to evaluating an alternative high school?" The survey items were developed to explore these assumptions and their contribution to the efficacy of the product. These assumptions address both Elements (tools) and Process described in the Alternative High School Program Evaluation Toolkit.

\section{EightAssumptions about Program Evaluation that Begins With the End in Mind}

1. Planning for a program evaluation from the beginning of the design process with the full development of the new school in mind

2. Advocating for a formative evaluation of educational program quality that goes beyond standardized test scores

3. Compiling an inventory of school practice and policy

4. Complying with federal and state laws

5. Maintaining a checklist of quality indicators for alternative schools

6. Encouraging creative thinking about what an alternative school can be within the constraints of program evaluation

7. Considering the context and circumstance under which the alternative school was designed to be established for program evaluation

8. Establishing the outcomes for which the alternative school will be held accountable in the future when fully implemented

Figure 8. Eight Assumptions About Program Evaluation.

The eight assumptions are addressed and further described later in this section through the standard elements including utility, feasibility, propriety, accuracy and accountability (Yarbrough et al., 2011) and 15 guiding questions that are the basis of efficacy responses in the analysis of produce efficacy. The result of the R\&D was an improved product and the analysis provided a description of efficacy based on data 
collected from in depth interviews, focus groups, field journal entries and the survey items. As described the survey asked main field test participants to rank the 7 Elements and 10 Characteristics and provide a Likert scale response for the eight Assumptions. The Eight Assumptions are depicted in the Figure 8 and are described in analysis in chapter 4 of this dissertation.

\section{Online Survey Design}

An online survey was given to the evaluation team in Zeeland School District at the conclusion of the design and evaluation process. Demographic data were collected and summarized and only relevant questions are reported on in the analysis. A naturalistic qualitative examination of the data and text is used to analyze data. Survey questions 1 to 10 request background (demographic) information of participants and the environments they work in but may not be relevant to the efficacy discussed in the analysis thus it is not be included. Questions 11, 12, and 13 are simple yes or no answers which most importantly are asking for textual responses. Question 21 is a Likert type 4-point scale measuring "how essential" a series of statements is to Program Evaluation and is included in the analysis. A section is also provided for respondent comments. The 4-point scale used a 1 to indicate a statement is "not essential" or there is no support for the

provided statements. The 4-point scale used a 4 to indicate a statement is "absolutely essential."

Question 22 focuses on providing necessary feedback (rankings) on the level of importance of the Evaluation Process (Characteristics) statements. Participants were asked to rank order the 10 Evaluation Process statements with 1 being most important 
and 10 being less important. Question 23 asks participants to comment on the Evaluation Toolkit. Participants were asked to rank order the seven Evaluation Toolkit "elements" with 1 being most important and 10 being less important. For graphic display, the ranked characteristics were given numeric values of 1 to 10 (or 7) corresponding with the rank placement. So the number one ranked characteristic of most import were given a value of 1 , second rank value a 2 , through the seventh or tenth rank which was given a value of 7 or 10. By adding the numeric values in a given "row" and dividing by the total $n$, an average number is displayed.

\section{Approach to Program Evaluation and Research Design Explained}

It is necessary to clearly distinguish evaluation and research for the purpose of the methods used in this research study. The following seven sections of this chapter are critical to the readers understanding about the new approaches and assumptions being made in this research study about an effective alternative school evaluation. The Research Design Section follows this description of the Toolkit. As discussed previously a workable typology for evaluating alternative schools does not exist for alternative high schools in Oregon so early versions of the product generated such a structure based on dimensions, elements and characteristics described in this chapter and analyzed in chapter 4. These sections are followed by a section titled of research design.

This chapter also discusses the research design and questions used to evaluate the need for this product (utility) and its effectiveness (accuracy and accountability) in helping school leaders evaluate an alternative high school (Program Evaluation). The chapter then explains the data collection method used in this research study. The data 
analysis section explains how the researcher safeguarded the research process from bias and assured the validity of the study (Research Design). Lastly, this chapter describes the $R \& D$ Steps used in researching and field testing the product.

This chapter analyzes the results of a R\&D Cycle (Borg \& Gall, 1989) used to improve an educational product, in this case the Elements of the Alternative High School Program Evaluation Toolkit and Characteristics of a process for evaluating an alternative high school. It also reviews the primary and secondary research questions and the general design of the PBL project. It then reviews the development and implementation (field testing) of the research based on experiences and Steps 1-7 of the R\&D Cycle. The analysis concludes with discussions of challenges encountered during field testing and recommendations accounted for in the final product revision.

\section{Dimensions of an Effective School Program Evaluation}

The result of developing the Evaluation Toolkit within the R\&D Cycle is a more useful educational product (Evaluation Toolkit). Early in the research and information collecting (Step 1) I observed trends in accountability narrowly defined under NCLB that were mirrored by the compliance checklist ODE provided school districts in evaluating their alternative schools. The preliminary form of the product (Step 3) was designed from the observations described in Figure 9; that the dimensions of Alternative High School Program Evaluation Toolkit are Reporting, Compliance and Quality Assurance. These dimensions presuppose evaluations with a process that involves an evaluation team participating in planning and carrying out the evaluation that addresses all three dimensions. This type of planning has not traditionally been considered with program 
evaluations in Oregon. Program evaluation practices vary from an administrator with a clipboard to an external contracted professional program evaluator. It is my belief that evaluation planning informs the process by which an evaluation team will learn what they need to know to determine the impact of the identified alternative high school.

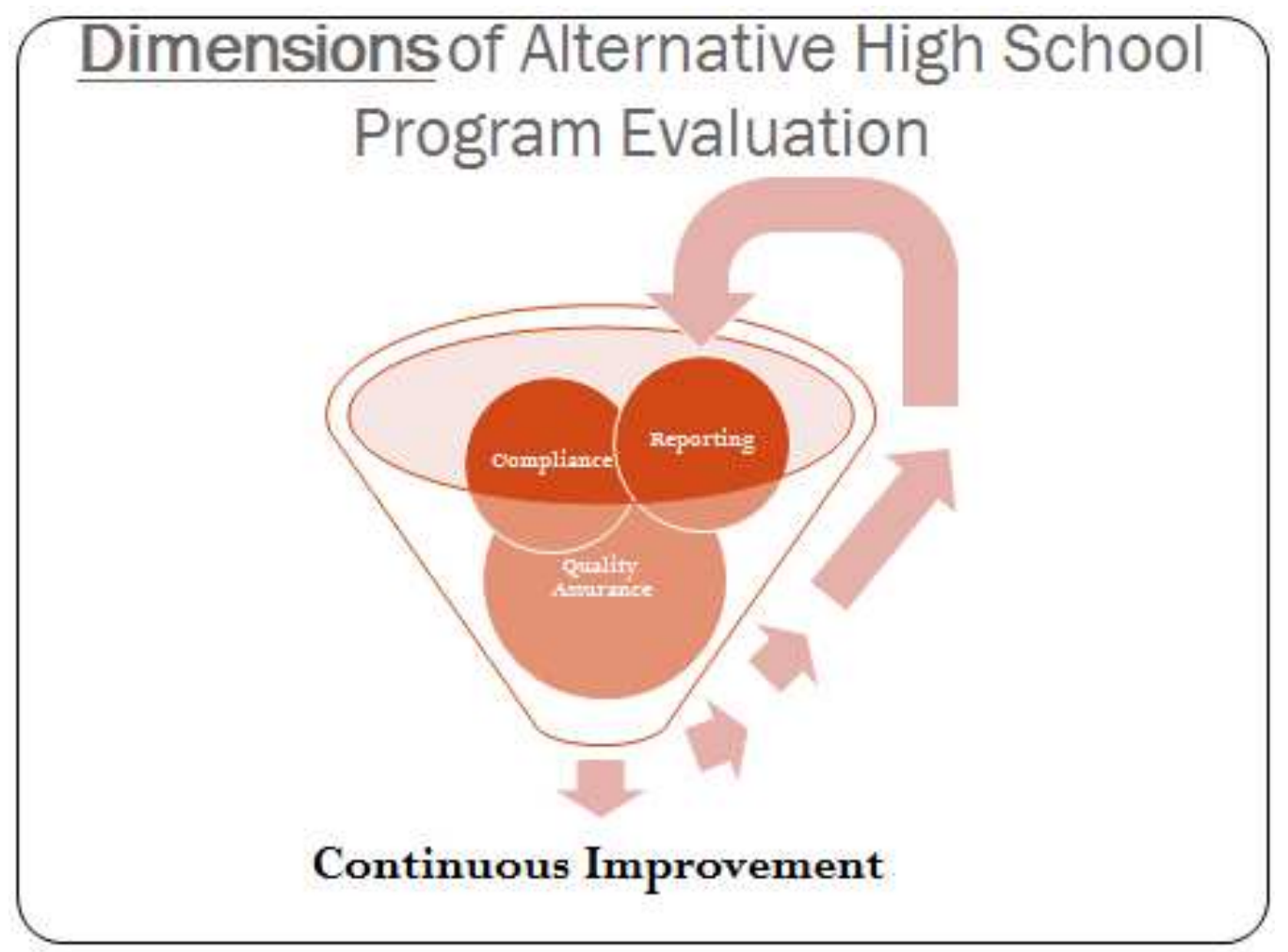

Figure 9. Dimensions of Alternative Aaccountability and Evaluation.

Figure 9 describes the dimensions of alternative school program evaluation as they contribute to continuous improvement. Dimensions of alternative school evaluation are described by three spheres labeled reporting, compliance, and quality assurance. The funnel illustrates a narrowing of information for the purpose of for consideration and continuous improvement. The arrows represent an interactive and ongoing process that illustrates ongoing (formative) program evaluation methods. 


\section{Differences Between Research and Evaluation}

The terms "research" and "evaluation" are sometimes referred to synonymously but are very different in purpose, especially in the case of the "research methodology" and "program evaluation" methodology described in this education study. "Educational research" is a formal and systematic application of the scientific method to the study of educational problems (Gay, Mills, \& Airasian, 2006). "Educational evaluation" is less formal but still often employs systematic application of scientific methods to study educational problems.

Program evaluation is conducted for a variety of reasons (sometimes to reduce or increase funding, illustrate needed changes, or at times to close a low performing school) and often is not conducted with the intent to continue the study of more generalized educational problems. Program evaluation is usually directed at a single school or program with the purpose of determining its impact on students and understanding what is going on at the school. Retired state administrator and researcher, Moreley (2012) suggested decision makers consider student-centered questions when evaluating schools.

Distinguishing between "research" and "evaluation" is essential in describing the methods used in this study because the two are similar. For the purpose of this study program evaluation relates to the evaluation of educational programs. A program is a set of specified activities designed for an intended purpose with quantifiable goals and objectives (Spaulding, 2008, p. 5). Spaulding (2008) contended that although a research study could certainly examine a particular program, most research tends to be interested 
in either generalizing findings back to wider audiences (quantitative research) or discussing how the study's finding relate back to the literature (that is qualitative research). Evaluation is a systematic collection of information about activities, characteristics, and outcomes of programs in order to make judgments about the program, to improve its effectiveness, an/or to inform decisions about future programming (Patton, 2011)

\section{Research Design}

The research design in this dissertation includes Steps 1-5 of the R\&D Cycle (Borg \& Gall, 1989) and involves research and information collecting, planning objectives, learning activities, and small-scale testing, developing a preliminary form of the product, preliminary field testing and main product revision. The main field test of the Evaluation Toolkit and evaluation process took place at an actual alternative school. The researcher served as a participant-facilitator in order collect information throughout the main field testing that informed the operational product revisions. Main field testing (Step 6) is discussed in chapter 4 in the analysis of the data collected from the in depth interviews, focus groups, field journal entries and survey questions regarding the Toolkit Elements, Process Characteristics and Assumptions about Program Evaluation. This research design is grounded in a product development process justified and linked to the R\&D Cycle described by Borg and Gall (1989). Table 2 described the R\&D Cycle in which the methods in this dissertation research are grounded. As previously described in the introduction and research methods sections of this dissertation, Borg and Gall (1989) identify 10 steps in an R\&D Cycle. 


\section{Product Efficacy}

This dissertation studies the research question: What tools support leaders in planning a thorough and accurate program evaluation of an alternative high school? The Toolkit Elements, Process Characteristics and Assumptions described in the previous section describe a thorough and accurate evaluation of an alternative high school. Secondary (Guiding) Questions Organized by Element is included in Table 21 and is used as the organizers for discussing product efficacy in chapter 4.

\section{Research Site}

The main field testing occurred at an alternative high school near an urban area of Oregon. The site was selected as a result of careful comparison of school district size and alternative schools within regions of Oregon that are accessible to the researcher. The alternative school is located in a region of Oregon that represents the majority of the population and is similar to many other districts in the state. For sake of anonymity this research site is referred to as Whyroads Alternative High School in Zeeland School District [pseudonyms]. Zeeland school district is generally representative of half the school districts in Oregon, having one high school, an alternative high school option, several middle schools and several elementary schools in the feeder system.

\section{Research Participants}

The Whyroads Principal has worked in the district and this school site for several years and the previous Zeeland Superintendent, with the support of those on her Cabinet, expressed a need to evaluate student placement procedures and investigate as to the outcomes of students attending the district alternative high school option. A series of 
development and evaluation team meetings were facilitated to inform the product revision and focused on the effectiveness of the product rather than participants. An example scope of work (included in the Appendix A) further describes the goals, tasks, deliverables and intended outcomes of the evaluation process with a team of internal and external stakeholders that included staff from both Zeeland and Whyroads. It is generally recognized that a control and experimental group method is not strictly adhered to in this study. The research sought to inform the product revision and focused on the effectiveness of the product rather than participants.

Facilitating the evaluation team in Zeeland allowed more in-depth access, observations, exploration and field testing intended to revise the Toolkit. As part of the participation in this study, the researcher (facilitator) provided a prototype of the Evaluation Toolkit that described a process and evaluation. Initial design meetings and trainings were conducted by another researcher, Edwards (2012), in the development of a design process with the intended result of a new alternative high school. The alternative high school evaluation included the involvement of the researcher (facilitator), essential to investigating the challenges involved in using the Toolkit. Early in the R\&D Cycle (small-scale testing and preliminary product development) Mr. Edwards and I developed a conceptual framework to build a more detailed process. This framework was necessary to assure the alignment of our collaborative field testing and future product revision. Figure 10 is a draft of the conceptual framework Mr. Edwards and I developed for purpose of aligning our research projects. A more elaborate framework is presented in chapter 5. 


\section{Research Project}

\section{New Alternative School Development} Need $\rightarrow$ Design $\rightarrow$ Implement $\rightarrow$ Improve Evaluation Process

\section{Develop a Program Description 2. Design and Evaluation Plan}

Figure 10. Framework for the Design and Evaluation Process.

Great attention and caution was taken in the research design to care for the subjects involved and the methods described in the Toolkit product revision. While participating in this study, it was possible that subjects could have been inconvenienced due to using their time to participate. In order to safeguard against this risk, the researcher limited the focus group time and attempted to write the survey so that it could be completed in less than 30 minutes; making the entire commitment to participating in the study as under one hour. In addition, an informed consent noted that research participants may discontinue the study at any time, for any reason, and that participation is not required. The Consent Form also noted that any information that is obtained in 
connection with this study that can be linked to them or identify them will be kept confidential. Research activities and field testing is intended to inform the product revision and focus on the effectiveness of the product rather than participants.

\section{Toolkit Prototype Descriptions}

The Inventory of school characteristics intends to support the profiling of the school in the context of its broader community; it provides information about the school that reaches beyond the school report card data (attendance, test scores and graduation information) and seeks to include information such as growth in attendance, credit and obtainment of a high school equivalency certificate (GED) and postsecondary enrollment. The Alternative High School Evaluation Planning Worksheet (included in Appendix A) asks the evaluation facilitator and members of the evaluation team to each identify the school name, purpose of the evaluation and determine who will be using the results. The form includes a place for members of the evaluation team to share their name, phone and email contact information as well as a place for them to describe what they perceive their role to be with the alternative high school evaluation. The Worksheet also describes resources needed for the evaluation (described in Table 13). 
Table 13:

Materials and Resources Needed for the Program Evaluation

Materials and Resources Needed:

- Facilitator (Preferably not associated with the organization)

- Room/Uninterrupted space for discussion

○ Easel Pad \& Markers, Post-It Notes, Computer

○ Documents: Plans, contracts, budgets, requirements and standards

○ Data: Program descriptions, reports, profiles, portfolios

Among the tasks identified for the first meetings of the program evaluation planning team is to determine the timeline for the evaluation. The timeline and purpose for the evaluation recorded during that first meeting should be referred to throughout the evaluation. The Alternative High School Evaluation Planning Worksheet includes questions that intend upon capturing a Timeline for Evaluation (described in the following table) and asks the team to designate (come to consensus on) how many times the group was willing to meet, who was responsible for taking the group's work and making electronic draft (s) available, when we needed a finished product and when additional evidence or results would be provided and when the next evaluations will occur. The Timeline for Evaluation is included Table 14.

Table 14:

Timeline for Evaluation for the Program Evaluation

Timeline for Evaluation:

$\checkmark$ How many times is the group willing to meet?

$\checkmark$ Who will be responsible for taking the group's work and making electronic draft(s)?

$\checkmark$ When do we need a "finished" product?

$\checkmark$ When will additional evidence of results be provided?

$\checkmark$ When will the next evaluations occur? 
The front page of the Tools for Evaluation Teams includes Initial Survey Questions and includes room for Comments made by individuals working alone or in workgroups. The tools on the front side of these evaluation tools are simple and could be used with minimal discussion and documentation to substantiate claims made about the level of agreement or practices. The Quality indicators included in the Tools for Evaluation Teams are each intended to support a team of evaluators by themselves or in workgroups to identify both successes and areas of challenge. Initial Survey Questions, Comments and School Progress Indicators are included on the first page of the six tools and are specific to that tool. Each of the six Tools for Evaluation Teams is briefly described in Table 15.

Table 15:

Six Tools for Evaluation Teams

Tools for Evaluation Teams (Six Tools):

1. Assessment: Assessment for learning and assessment of learning - The school maintains methods of tracking student performance and growth.

2. Curriculum: Aligned, managed and monitored curriculum - Both teachers and students know what is taught and assessed.

3. Engagement: Engaged in relevant learning activities - Students attend and participate.

4. Instruction: Sustainable instructional capacity - Effective learning and instruction is used in the teaching and learning process

5. Leadership: Effective leadership

- Guidance is provided in assuring teacher effectiveness and student performance

6. Structures: Integrated systems and structures

- Systems of student support assure programs are achieving results and outcomes

The backside of each of the Tools for Evaluation Teams includes the Evaluation Planning Matrix (Simplified Logic Model) that requires a different level of 
sophistication, care and attention on the part of the facilitator in order to use it as an evaluation planning tool (not a program evaluation tool). Teams must discuss various audiences and the purpose for formative (ongoing) evaluation and logic model planning in order to understand how results and outcomes are best described. Teams should plan to revisit the written timeline and purpose of the evaluation process (Worksheet) at least quarterly to determine the schools impact on students. In addition to the Evaluation Planning Matrix is a simplified Evaluation Plan based upon the determinations of measurement and accountability agreed upon in the Matrix.

The evaluation planning sections (on the second page of each of the six tools) are included to assist the team in better understanding characteristics of more accurate and formative program evaluations. The Evaluation Planning Matrix is a simplified logic model that has the generalizable characteristics of a logic model (left to right progression including requested descriptions of inputs, results and outcomes) but designates the granularity of the logic discussed that leads backwards (right to left) from desired outcomes. A series of questions was used to guide the evaluation planning team workgroups through thinking about the kinds of things they wanted to know (objectives), how they would know it (feedback tools) and when they would know it (timelines for results). In program evaluation logic model work, this planning process is sometimes referred to "beginning with the end in mind," a principle of effectiveness borrowed from Covey (2004). The granularity in the logic model is described as students, teachers and community and is further depicted by Table 16. 
Table 16:

Evaluation Planning Matrix (Assessment Evaluation Workgroup Example)

\begin{tabular}{|c|c|c|c|}
\hline \multicolumn{4}{|c|}{$\begin{array}{l}\text { Evaluation Planning Matrix - Assessment Evaluation Workgroup } \\
\text { Instructions: Discuss possible objectives of your evaluation process and determine how you will } \\
\text { know those objectives were met, what feedback tools you plan to use and when they will be } \\
\text { reassessed. }\end{array}$} \\
\hline $\begin{array}{l}\text { Assessment Evaluation } \\
\text { Objectives } \\
\text { What do you want to } \\
\text { know? }\end{array}$ & $\begin{array}{l}\text { Stakeholder } \\
\text { Groups } \\
\text { Who? }\end{array}$ & $\begin{array}{l}\text { Tool, Data or } \\
\text { Instrument (Feedback } \\
\text { tools) } \\
\text { How will you know } \\
\text { it? }\end{array}$ & $\begin{array}{l}\text { Design Timeline \& } \\
\text { Results } \\
\text { (Start and restart dates) } \\
\text { When will you know it? }\end{array}$ \\
\hline 1. & Students & & \\
\hline 2. & Students & & \\
\hline 3. & Teachers & & \\
\hline 4. & Community & & \\
\hline
\end{tabular}

The Evaluation Plan was designed to narrow the evaluation team - workgroup thinking, from the broader Evaluation Planning Matrix, toward a single objective (a word or two) that describe what they want to know and when they would know it (formative or summative evidence). This tool also engages members of the evaluation team in applying, what may be new understandings about different forms of program evaluation and planning. As described earlier in this dissertation, evaluation planning can be 
complex, time consuming and expensive. The Evaluation Plan section seeks to simplify the evaluation teams planning process and build consensus about objectives that seek to serve the students, teachers and community (see Table 17).

Table 17:

Evaluation Plan (Assessment Evaluation Workgroup Example)

\begin{tabular}{|c|c|c|c|}
\hline \multicolumn{4}{|c|}{$\begin{array}{l}\text { Evaluation Plan - Assessment Evaluation Workgroup } \\
\text { Instructions: Further discuss objectives for the evaluation and summarize the objectives in a } \\
\text { shorter statement from above. Further consider the formative or summative reporting periods } \\
\text { and update status. }\end{array}$} \\
\hline $\begin{array}{l}\text { Assessment Evaluation } \\
\text { Objectives } \\
\text { (From above but more } \\
\text { concise) }\end{array}$ & $\begin{array}{l}\text { Stakeholder } \\
\text { Groups }\end{array}$ & $\begin{array}{l}\text { Formative and Summative } \\
\text { Evidence }\end{array}$ & Status \\
\hline 1. & Students & & \\
\hline 2. & Students & & \\
\hline 3. & Teachers & & \\
\hline 4. & Community & & \\
\hline
\end{tabular}

As described earlier in this dissertation, the previously developed Alternative Education Program Evaluation Toolkit (Compliance) (ODE, 2006c) is a checklist intended to assure compliance with state and federal laws. The checklist continued to serve as a useful instrument in determining compliance and was necessary in supporting the work of an evaluation team because many of the required laws address characteristics of school safety. For the purpose of this research study, this compliance tool was considered part of the Evaluation Toolkit. The Toolkit also includes a description of 
purpose (Reporting, Compliance and Quality Assurance) described earlier in this dissertation and depicted in Table 18.

Table 18:

Dimensions and Underlying Purpose of the Evaluation Toolkit for Teams

The Purpose of the Toolkit is for evaluation teams to learn about planning and conducting evaluation.

- Reporting - Seeks to understand the context of the school and its programs in order to account for its unique purpose and student population. The reporting inventories policies and practices related to student failure and dropping out, use new and existing data sources to learn from success, identify areas in need of improvement and effectively tell the schools story.

- Compliance - Assures the alternative high schools are following laws that promote the safety of students and a minimum level of quality and predictability among educational schooling systems.

- Quality Assurance - Regularly gather information, observations and evidence that help in identifying challenges and informing future planning and decisions.

The Toolkit includes instructions and protocols that describe six simple steps (protocol) for Facilitating Evaluation Team Planning that include the following (summarized from the actual protocol provided in the Appendix A):

1. Use and Update Evaluation Planning Worksheet

2. Review and Discuss Tools for Evaluation Teams

3. Respond to the Initial Survey Questions

4. Identify level in the School Progress Indicators

5. Fill out the Evaluation Planning Matrix

6. Fill out the Evaluation Plan

As previously mentioned, the main field testing involved the evaluation of an alternative high school located near an urban area of Oregon. This school site was 
carefully selected because of its size, student populations, staff, leadership and current relationship with the district and community. While the use of the Toolkit at a single site may limit the generalizability of the research findings, the size and scope of the field testing location allowed for operational product revisions to be made that will inform future research studies. The determination of the toolkit's effectiveness was considered with support of the professional standards on educational evaluation in the areas of utility, feasibility, propriety, accuracy and accountability (Yarbrough et al., 2011). Secondary (guiding) research questions are included in this section to further support the determination of the efficacy of the Evaluation Toolkit. The accuracy and accountability questions are included below:

Accuracy Questions (adequately conveys analysis):

1. Are the Tools (assessment, curriculum, engagement, instruction, leadership and structures) valid (measure what they intent to measure)?

2. What obstacles (challenges) have leaders (evaluation facilitators and evaluation team members) experienced when attempting to evaluate an alternative school? How well does the process and tools address those challenges?

3. How useful are the Alternative High School Program Evaluation Toolkit Characteristics in the evaluation process? Are there other frameworks intended for use with alternative high school program evaluation and tooldevelopment?

Accountability Questions (contextualized and produces value): 
1. How does using an evaluation team impact the school evaluation process and results?

2. What impact can this Toolkit have on students at risk of high school failure?

3. Do the Tools for Evaluation Teams support those at the school in learning from their successes, identifying current challenges, planning for improvement and more effectively telling their story?

\section{Steps in the Research Design}

PBL is a product development process justified and linked to the R\&D cycle described by Borg and Gall (1989). Table 2 described the R\&D Cycle in which the methods in this dissertation research are grounded. As previously described in the introduction and research methods sections of this dissertation, Borg and Gall (1989) identify ten steps in an R\&D cycle. This dissertation describes the problem-based approach that seeks to improve the functionality of the Evaluation Toolkit.

The Evaluation Toolkit has been developed to support evaluation teams in identifying current challenges, planning for improvement and more effectively telling their story. The Toolkit describes a process for planning and tools for data collection and information gathering that support the evaluation team in conducting a thorough and accurate evaluation. As mentioned previously, the research includes a focus group and survey information collection that field testing and product revision outlined by Borg and Gall (1989) in steps two through six, ending with operational product revision. Future research will involve operational field testing with samples of more diverse alternative high schools and the training of evaluation facilitators. This work will involve operational 
field testing, final product revision, dissemination and implementation and is discussed in the final recommendations section of this dissertation.

Step 1. (Research and information collecting.) This step was accomplished through the research and information collected for the review of literature and has been a vital part of my day-to-day activities in my position at ODE. I interact regularly with state and national leaders who have served in positions similar to mine at ODE and many have decades of experience in the process of developing and implementing alternative educational policy. As discussed previously, this step was also accomplished through information and feedback collected while presenting on alternative school design and evaluation at state, regional and national conferences. These interactions were reflected in previous sections and presentations are listed in Table 19.

Table 19:

Conference Presentations on Alternative School Evaluation

\begin{tabular}{|l|l|l|l|}
\hline Title of Presentation & Event & Location & Date \\
\hline $\begin{array}{l}\text { Designing and Evaluating } \\
\text { Alternative Schools }\end{array}$ & $\begin{array}{l}\text { Northwest Innovative Schools } \\
\text { Conference }\end{array}$ & $\begin{array}{l}\text { Gervais, } \\
\text { Oregon }\end{array}$ & $\begin{array}{l}\text { October } \\
2012\end{array}$ \\
\hline $\begin{array}{l}\text { An Innovative School } \\
\text { Design Process }\end{array}$ & $\begin{array}{l}\text { Oregon Association for Comprehensive } \\
\text { Education }\end{array}$ & $\begin{array}{l}\text { Seaside, } \\
\text { Oregon }\end{array}$ & $\begin{array}{l}\text { January } \\
2012\end{array}$ \\
\hline $\begin{array}{l}\text { PBIS and Data Teams in } \\
\text { Alternative Education }\end{array}$ & $\begin{array}{l}\text { Northwest Innovative Schools Network } \\
\text { Webinar Series }\end{array}$ & Webinar & $\begin{array}{l}\text { March and } \\
\text { May } 2012\end{array}$ \\
\hline $\begin{array}{l}\text { Designing and Evaluating } \\
\text { Innovative Schools }\end{array}$ & $\begin{array}{l}\text { Podcast, National Dropout Prevention } \\
\text { Center/Network }\end{array}$ & $\begin{array}{l}\text { Oregon } \\
\text { Public Radio }\end{array}$ & $\begin{array}{l}\text { November } \\
2011\end{array}$ \\
\hline $\begin{array}{l}\text { Designing and Evaluating } \\
\text { Innovative Schools }\end{array}$ & $\begin{array}{l}\text { Northwest Innovative Schools } \\
\text { Conference }\end{array}$ & $\begin{array}{l}\text { Gervais, } \\
\text { Oregon }\end{array}$ & $\begin{array}{l}\text { October } \\
2011\end{array}$ \\
\hline $\begin{array}{l}\text { Designing and Evaluating } \\
\text { Innovative Schools }\end{array}$ & $\begin{array}{l}\text { National Dropout Prevention } \\
\text { Center/Network Annual Conference }\end{array}$ & $\begin{array}{l}\text { Chicago, } \\
\text { Illinois }\end{array}$ & $\begin{array}{l}\text { October } \\
2011\end{array}$ \\
\hline
\end{tabular}


Table 19 (continued)

\begin{tabular}{|c|c|c|c|}
\hline Title of Presentation & Event & Location & Date \\
\hline $\begin{array}{l}\text { Design and Evaluation of } \\
\text { Innovative Alternative } \\
\text { Programs }\end{array}$ & $\begin{array}{l}\text { Confederation of Oregon School } \\
\text { Administrators (COSA) Annual } \\
\text { Conference }\end{array}$ & $\begin{array}{l}\text { Seaside, } \\
\text { Oregon }\end{array}$ & June 2011 \\
\hline $\begin{array}{l}\text { Designing Innovative } \\
\text { Schools }\end{array}$ & $\begin{array}{l}\text { Washington Association for Learning } \\
\text { Alternatives (WALA) Annual Conference }\end{array}$ & $\begin{array}{l}\text { Ocean } \\
\text { Shores, } \\
\text { Washington }\end{array}$ & March 2011 \\
\hline $\begin{array}{l}\text { Design and Evaluation of } \\
\text { Alternative Programs }\end{array}$ & $\begin{array}{l}\text { Oregon Association for Comprehensive } \\
\text { Education Conference (OACE) }\end{array}$ & $\begin{array}{l}\text { Seaside, } \\
\text { Oregon }\end{array}$ & $\begin{array}{l}\text { January } \\
2011\end{array}$ \\
\hline $\begin{array}{l}\text { Program Evaluation in K- } \\
12 \text { Schools }\end{array}$ & $\begin{array}{l}\text { Oregon Program Evaluators Network } \\
\text { (OPEN) Annual Conference }\end{array}$ & $\begin{array}{l}\text { Portland, } \\
\text { Oregon }\end{array}$ & $\begin{array}{l}\text { September } \\
2010\end{array}$ \\
\hline $\begin{array}{l}\text { Alternative Education } \\
\text { Programs: Review Teams } \\
\text { and Evaluation }\end{array}$ & $\begin{array}{l}\text { Confederation of Oregon School } \\
\text { Administrators (COSA) Annual } \\
\text { Conference }\end{array}$ & $\begin{array}{l}\text { Seaside, } \\
\text { Oregon }\end{array}$ & June 2010 \\
\hline $\begin{array}{l}\text { Tools for District Review } \\
\text { of Alternative Education } \\
\text { Options }\end{array}$ & $\begin{array}{l}\text { Washington Association for Learning } \\
\text { Alternatives (WALA) Annual Conference }\end{array}$ & $\begin{array}{l}\text { Ocean } \\
\text { Shores, } \\
\text { Washington }\end{array}$ & March 2010 \\
\hline $\begin{array}{l}\text { Effective Evaluation of } \\
\text { Alternative Education } \\
\text { Programs in Oregon }\end{array}$ & Superintendent's Summer Institute & $\begin{array}{l}\text { Eugene, } \\
\text { Oregon }\end{array}$ & July 2009 \\
\hline $\begin{array}{l}\text { Alternative School } \\
\text { Evaluation }\end{array}$ & Alternative School Leaders Training & $\begin{array}{l}\text { Portland, } \\
\text { Oregon }\end{array}$ & April 2009 \\
\hline $\begin{array}{l}\text { Dropout Prevention } \\
\text { Programs }\end{array}$ & Oregon Diploma Summit & $\begin{array}{l}\text { Portland, } \\
\text { Oregon }\end{array}$ & March 2009 \\
\hline Alternative Schools & $\begin{array}{l}2008 \text { Governor's Youth Summit - } \\
\text { Eliminating DMC in the Juvenile Justice } \\
\text { System }\end{array}$ & $\begin{array}{l}\text { Portland, } \\
\text { Oregon }\end{array}$ & $\begin{array}{l}\text { November } \\
2008\end{array}$ \\
\hline $\begin{array}{l}\text { Accountability for } \\
\text { Confirming Success }\end{array}$ & Superintendent's Summer Institute & $\begin{array}{l}\text { Portland, } \\
\text { Oregon }\end{array}$ & August 2008 \\
\hline $\begin{array}{l}\text { Alternative Education } \\
\text { Workgroup }\end{array}$ & $\begin{array}{l}\text { Alternative Education Workgroup - } \\
\text { Secretary of State Audit }\end{array}$ & $\begin{array}{l}\text { Salem, } \\
\text { Oregon }\end{array}$ & $\begin{array}{l}\text { June-August } \\
2008\end{array}$ \\
\hline $\begin{array}{l}\text { Alternative Education } \\
\text { Programs }\end{array}$ & Oregon Data Collection Training & Webinar & $\begin{array}{l}\text { Fall 2007- } \\
2012\end{array}$ \\
\hline $\begin{array}{l}\text { Types of Schools and the } \\
\text { Laws that Apply }\end{array}$ & $\begin{array}{l}\text { Confederation of Oregon School } \\
\text { Administrators (COSA) Annual Special } \\
\text { Education Conference }\end{array}$ & $\begin{array}{l}\text { Eugene, } \\
\text { Oregon }\end{array}$ & $\begin{array}{l}\text { October } \\
2007\end{array}$ \\
\hline $\begin{array}{l}\text { Alternative School } \\
\text { Evaluation Toolkit }\end{array}$ & $\begin{array}{l}\text { Oregon Closing the Achievement Gap } \\
\text { Conference }\end{array}$ & $\begin{array}{l}\text { Salem, } \\
\text { Wilsonville }\end{array}$ & $\begin{array}{l}\text { September } \\
2008\end{array}$ \\
\hline $\begin{array}{l}\text { New Alternative Education } \\
\text { Policies }\end{array}$ & $\begin{array}{l}\text { Alternative Education Regional Technical } \\
\text { Assistance Workshops }\end{array}$ & $\begin{array}{l}13 \text { OR } \\
\text { Regional } \\
\text { Locations }\end{array}$ & Fall 2006 \\
\hline
\end{tabular}


As previously discussed, I have and will continue to use speaking engagements and conference presentations as opportunities to gather feedback on topics I'm studying and consider those who attend my presentations at conferences to be among my target audience for the subject. I meet regularly with Oregon alternative school leaders and other state alternative education specialists from around the country as well as ODE staff working with traditional school statewide systems of support and will continue to seek feedback on my perceptions and observations. I typically distribute and collect cards with questions or suggestions as a part of conference presentations and informally collect questions attendees have about the topic. I involve local practitioners and researchers to add creditability and relevance to the sessions and this has generated great opportunities for me to grow and maintain my professional network with innovative educators and educational leaders from the state, regional and federal levels. During many of the conferences mentioned that include "design" in the title of the presentation, I copresented with Mr. Edwards, who is also a member of my doctoral program cohort at Portland State University. Our research is similar as he is studying the design of new and innovative schools. Further information regarding the coordination of our research is presented later in this chapter. Research and formative information collection will continue to be used in the R\&D Cycle that intends to improve the Toolkit.

Step 2. (Planning, objectives, learning activities and small scale testing.) Step 2 took place as a part of my role at the ODE where, among other things, I have the responsibility of monitoring and evaluating many alternative high schools for a variety of purposes. Having helped in the development and implementation of new alternative 
education policies, I understand what the dissemination and implementation will take. In the process of presenting information and evaluating schools, the research problem of how best to evaluate alternative high schools emerged. The primary and secondary (guiding questions) reported later in this section was developed during this step in the planning process. The majority of current evaluations take place in isolation from the schools' vision, mission and goals many are conducted by staff with no formal training in program evaluation. Through conference presentations and visits to alternative high schools, I will continue to grow an understanding of the challenges and will continue to take time to collect and conduct small-scale testing of high quality examples of tools that are intended to support teams of evaluators seeking to determine the impact of their alternative high school.

Step 3. (Develop a preliminary form of the product.) The seven sections that precede this step-by-step account of the research methods include a detailed account of the process whereby I developed a preliminary form of the Evaluation Toolkit. Portions of the Toolkit are described throughout that section and distinguished from the research methodology described in this section. It is safe to say that the R\&D process around the development, testing and analysis of Toolkit effectiveness has taken on a unique meaning in and outside my role at ODE. I have collected and reviewed hundreds of evaluation frameworks, toolkits and instruments used in school evaluation and several years ago was challenged by my advisor to write a research proposal and create a prototype of the Toolkit I was envisioning. At the time I had developed the list of toolkit elements and characteristics of an effective evaluation from the research I was immersed in that year. I 
wanted to make the tool short, front and back, and use terms familiar to most educators. It started out on a yellow pad of paper and sketches in my research journal.

I presented a matrix of the terms and tools I was collecting at the Washington Alternative Learning Association (WALA) Conference. I had begun to employ the practice of handing out notecards at the start of a conference sessions to collect the thoughts and questions from attendees interested in my topic. I will never forget the comment one gentleman wrote and read aloud when asked to share. He noted several of the frameworks I had described and the historical context that occurred in large part before I was born and said, "it's all been done before." I asked him to elaborate and he shrugged and responded in the same way my parents did at the fast-food dinner table at the midpoint of both their careers as educators (my mom a second grade teacher and my dad a middle school math and science teacher). This man was a caring teacher and simply didn't understand how these frameworks and the interrelated standards and policy initiatives impacted his classroom and students. He was refreshingly cynical about what this meant to him and had no interest in any of it if it did not make a difference with students. I have found that alternative educators are very honest and open about the challenges they face supporting students that have, for one reason or another, not fit in at the traditional high school. The alternative education serves as an alternative to the traditional school that differs in both curriculum and pedagogy.

The Tools for Evaluation Teams include research based Initial Survey Questions (Strongly Disagree to Strongly Agree) and a place for Comments. The comments sections were added at the request of participants in small-scale testing an provides the 
opportunity to put their concerns or compliments in writing. I had originally wanted a quick survey to get a picture of the school but the narrative provides room for a story. On the same page are School Progress Indicators (Exemplary Practices to In Need of Improvement). The different tools and scoring structures allow for customization and require a certain level of flexible interpretation by evaluation team members regarding common terms used to represent some school activities such as staff meetings, data teams or professional learning communities which may be used interchangeably. Once the team gets past the nomenclature, the discussion that ensues is rich and focused around the topic on the front and back of that page. The tools include clear and open direction intended to move from simple to more narrow and focused.

Step 4. (Preliminary field testing.) During the preliminary field testing, I conducted a mixed method study involving a focus group of leaders who had demonstrated interest in evaluating alternative high schools. After presenting and discussing evaluation process with participants in alternative school evaluation session, I asked those who could to stay after to discuss the topic. Participants were engaged in discussion about alternative accountability metrics developed for use in holding alternative schools accountable for student performance. I shared the Alternative Accountability Metrics, as well as the Toolkit Elements, Process Characteristics, and Assumptions about Program Evaluation during the breakout session I facilitated with Mr. Edwards. All participants had already planned to attend the conference and, other than my own field notes, no formal data were collected. 
In the research, I proposed working with an Oregon Alternative Accountability Taskforce seeking to develop methods of program evaluation and accountably for alternative schools in Oregon. The Taskforce is not legally called for but the approach of stakeholder engagement is called for in effective educational policy (Fowler, 2004). This Taskforce served as a focus group made up of evaluators, researchers, district and school leaders and alternative educators representing regions from throughout Oregon and allowed me to distribute the tool more widely than had been done in the small-scale field testing. Addressing the issue of Alternative School Accountability is needed and a part of my responsibilities at ODE. Leadership at ODE is aware of my research and has been supportive of my research project, as it may benefit Oregon Alternative High Schools.

As described, research study and evaluation of Whyroads Alternative High School took place with the involvement of an evaluation team made up of stakeholders from both inside and outside the Zeeland school district with support of others in their educational community. While my direct involvement, as facilitator of the evaluation planning process may present some difficulty in separating my views as a participant observer (bias), this role (Program Evaluation Facilitator) with the evaluation team in the main field testing is necessary at this early stage in the R\&D of the product. I need to experience using the tools with the evaluation team in order to make improvements at this stage of development and field testing. This active involvement and inquiry-action framework to support improvement because this inquiry plays a vital role in the R\&D process (Borg \& Gall, 1989; Bridges \& Hallinger, 1995; Finnan et al., 1996, p. 73). 
Observations and quotations will allow for more objective observations as well as learning activities and reflection as a part of the main product revision.

Step 5. (Main product revision.) The main product revision will use the notes from my professional field journal, combined with notes and questions from presentations and preliminary field testing to refine and improve the tools included in the Evaluation Toolkit. Some of the descriptions in this section were updated as a direct result of preliminary field testing and main product revision steps in the R\&D Cycle. Final product adjustments were made in preparation to the main field testing, and involved the development of annotated agendas (with notes to the facilitator), activities (that involved the design and evaluation team in active participation), and the development of presentation slides to support the main field testing.

Step 6. (Main field testing.) The main field testing was conducted, in coordination with Mr. Edwards' research on alternative school design, at Whyroads Alternative School in Zeeland School District. Our goal was to design and evaluate a new and innovative alternative high school. Main field testing resulted in the development of a new alternative high school program guide and plan for evaluating the school. The methods used in the main field testing were documented with field journal entries, meeting agendas, annotated agendas, activities and presentation slides. Following design and evaluation meetings, Chet and I regularly communicated by email and phone to further reflect and explore the field testing process together. I conducted informal phone interviews with the superintendent, student services director, curriculum director, traditional high school principal, alternative school principal and lead teachers to collect 
additional insights and information. The results are described in the data collection section of this chapter and a scope of work and evidence from the meetings (agendas, activities and presentations) are included in Appendix A.

Issues of objectivity and validation are addressed in a variety of ways. First the co-researcher, Mr. Edwards will take field notes during the evaluation portions of the training which were compared with observations and reflections made in my own field journal. Second, input and suggestions from in depth interviews and focus groups were be used to develop observations about the product efficacy. Third, members of the evaluation team involved in the study were asked to reflect on the process, assumptions, Toolkit Elements and Process Characteristics as well as the post-process survey instrument itself.

Step 7. (Operational product revision.) The result of operational product revisions included refined Characteristics of a process for evaluating an alternative high school. The Evaluation Toolkit Elements were each refined and an example evaluation report template, for use in dissemination, is included in Appendix A. As a participant observer and evaluation facilitator, I was afforded the opportunity to experience and receive feedback about the tools in combination with my skills as a program evaluator. While my focus is on product revision I learned a lot about the needs of an evaluator (evaluator competencies) and evaluation team which further informed R\&D. The product revision will be published in the form of an electronic and printed notebook that will be edited, refined and made ready for dissemination (Bridges \& Hallinger, 1995). The R\&D Cycle 
has provided the information needed to create, refine and improve the educational product that is needed and beneficial to Oregon alternative high schools.

Steps 8-10. As mentioned earlier, future research will involve operational field testing with a larger sample of more diverse alternative high schools with trained facilitators and expand on the evaluation training. Operational field testing, final product revision, dissemination and implementation are further discussed in the recommendations section of this dissertation.

\section{Research Questions}

\section{Primary Research Question}

My research is guided by a central issue of how best to evaluate alternative high schools. My central research question is: What tools support leaders in planning a thorough and accurate program evaluation of an alternative high school? For the purpose of this research question, "leaders" include program evaluation facilitators as well as members of an evaluation team with the task of evaluating an alternative high school. For the purpose of this research product and the central research question, "accurate" should also include elements of utility, feasibility, propriety, accuracy, and accountability (Yarbrough et al., 2011) discussed in the literature review and later to structure the guiding questions for this dissertation.

The broader research question (long version) is: What tools support evaluation teams in planning a program evaluation with a clear purpose and objectives (learn from successes, identify current challenges and plan for improvement) that result in a thorough and accurate portrayal of the impact an alternative high school is making on students? As 
described earlier in this dissertation, current evaluations, in Oregon, often include a single leader in an effort to evaluate an alternative high school using a compliance checklist. The checklist is not an adequate tool for program evaluation and is expanded upon in this R\&D process by a toolkit of tools to support an evaluation team in evaluating a school.

\section{Secondary (Guiding) Research Questions}

Related research questions that help consider how best to evaluate an alternative high school are included below. These research questions were developed based on questions important to the R\&D cycle (Borg \& Gall, 1989) combined with standards and guidelines developed by the Joint Committee on Standards for Educational Evaluation (2011) to improve usefulness and accuracy of the educational product (Evaluation Toolkit) for alternative school evaluation. The 15 guiding questions included in Table 20 are organized in five headings (3 Questions Each) based upon the elements described by the Joint Committee on Standards for Educational Evaluation (Utility, Feasibility, Propriety, Accuracy and Accountability) and were the organizers used in data analysis and conclusions sections of this dissertation. 
Table 20:

Secondary (Guiding) Questions Organized by Element

Utility Questions (useful or purposeful)

1. Is the Toolkit an effective (useful) tool for formatively (ongoing) and summatively (summary) determining the impact of alternative high schools?

2. Are the tools in the Toolkit supportive to evaluation teams in developing a program evaluation with a clear purpose and objectives that "begin with the end in mind" (S. R. Covey, 2004, p. 97) and thoroughly and accurately portray the school?

3. Do the Protocols and Tools support facilitators in involving both internal and external stakeholders working with an evaluation team to evaluate the alternative high school?

Feasibility Questions (practical or realistic)

4. What learning activities (data collection, information gathering, reflection, reporting etc.) are needed to support the facilitator and members of the evaluation team in using the Tools for Evaluation Teams: Initial Survey Questions, Comments and School Progress Indicators?

5. Do the School Progress Indicators provide an opportunity for members of the evaluation team (in workgroups) to come to consensus on what is meant by "Exemplary", "Effective" and "In Need of Improvement" in the Tools for Evaluation Teams: Assessment, Curriculum, Engagement, Instruction, Leadership and Structures.

6. Do the Initial Survey Questions and Comments provide an opportunity for members of the evaluation team (in workgroups) to convey thoughts, observations and the evidence?

Propriety Questions (proper or fair)

7. How should a school district or school go about selecting an evaluation team?

8. Does the Evaluation Planning Worksheet adequately support the initial communication of an evaluation purpose with a timeline, supportive learning activities and explanation of how the results will be used?

9. What learning, reflection and planning activities are needed to support the facilitator and members of the evaluation team in utilizing the Evaluation Planning Matrix and Evaluation Plan?

Accuracy Questions_(adequately conveys analysis)

10. Are the Tools (assessment, curriculum, engagement, instruction, leadership and structures) valid (measure what they intent to measure)?

11. What obstacles (challenges) have leaders (evaluation facilitators and evaluation team members) experienced when attempting to evaluate an alternative school? How well does the process and tools address those challenges?

12. How useful are the Alternative High School Program Evaluation Toolkit Characteristics in the evaluation process? Are there other frameworks intended for use with alternative high school program evaluation and tool-development?

Accountability Questions (contextualized and produces value)

13. How does using an evaluation team impact the school evaluation process and results?

14. What impact can this Toolkit have on students at risk of high school failure?

15. Do the Tools for Evaluation Teams support those at the school in learning from their successes, identifying current challenges, planning for improvement and more effectively telling their story? 
Using feedback from the research and guiding questions above, I will refine and more fully develop the Toolkit Elements, Process Characteristics and reconsider my Assumptions about program evaluation in alternative high schools. As discussed previously, operational product revision and field testing will add to my knowledge of what leaders (facilitators and members of the evaluation team) need to know and how to assist them in obtaining that knowledge.

My hope is alternative high school evaluation teams will use the process and the tools (Toolkit) to support those at the school in learning from their successes, identifying current challenges, planning for improvement and more effectively telling their story; intending to result in more thorough and accurate evaluation of their schools and their ability to better meet the educational needs and interests of all students. The preliminary data, combined with main product revision and testing provided enough information to generate improvements and multiple iterations of field testing will provide further opportunities to improve the process and tools.

\section{Data Collection Procedures}

It is important to consider what kinds of data will be useful to addressing the problem statement and answering the research questions. Multiple methods of data collection to overcome the limitations of each (Gay et al., 2006). Triangulation (the use of three of more sources of data) enables the researcher to gain multiple perspectives, thereby increasing the validity of the data. Since the Evaluation Toolkit is a resource for school leaders (facilitators and other members of the evaluation team) qualitative data were collected from school leaders in the form of meeting documentation, evidence of 
planning, as well as the focus group reflections and survey responses. My own reflection on the facilitation of a program evaluation and team leadership was documented through my field journal in order to consider the effectiveness (usefulness) of the Toolkit and its elements.

The primary data collection procedures will include focus group and survey data triangulated with field journal and notes from in depth interviews with participants. The survey will ask main field test participants to rank Toolkit Elements and Process Characteristics and score Assumptions about program evaluation with alternative high schools. As described previously, alternative education settings vary in both mission and goals but researchers have identified elements of successful alternative schools. Early Steps of the R\&D process have assisted in developing new characteristics and elements of thorough and accurate alternative high school evaluations. The purpose and methods used (data collection) in alternative high school program evaluation are grounded in research, and seeks to improve the educational product. Data collection procedures for this research study were theoretically and practically grounded in Bridges and Hallinger's (1995) PBL and Borg and Gall's (1989) R\&D Cycle. The study involved school leaders and external program evaluators in the product revision and field testing in order to improve an Evaluation Toolkit.

Research on successful alternative schools characterized by typology of alternatives schools that have been used throughout 50 years of research by (Barr \& Parrett, 1997, 2001; R. Morley, 1996; Raywid, 1981, 1994; Schargel \& Smink, 2001; Schargel, 2003; Smink \& Schargel, 2004). Reimer \& Cash (2003, p. 15) describe 
characteristics (elements) of successful alternative schools as a synthesis of previous research and similar elements of successful alternative schools have been identified and validated by others (Leiding, 2008; NWREL et al., 1997; ODE, 2006a; Schargel \& Smink, 2001). As described earlier, the methods for applying these elements of successful alternative schooling in program evaluation are not explored in the literature so characteristics and elements of alternative high school program evaluation were developed and expanded upon in previous sections.

The research and data collection procedures included a mix of qualitative and quantitative methods. The central focus of qualitative research was to provide an understanding of an activity from the perspective of research participants (Gay et al., 2006). Qualitative data that school districts may collect include reviews of literature transcripts of in-depth interviews or focus group discussions, notes from observations, open-ended surveys, personal statements, diaries/journals, minutes from meetings, official reports, legal documents, books and materials and photographs (Fowler, 2004, p. 311). As described previously active involvement and inquiry-action framework to support improvement because this inquiry plays a vital role in the $R \& D$ process (Borg $\&$ Gall, 1989; Bridges \& Hallinger, 1995; Finnan et al., 1996, p. 73).

The methods described in this section (participant-facilitator) allowed me access to experienced school leaders so as to gain the information needed to improve the effectiveness of the Toolkit under development in the field testing. The primary focus of the main field testing and pilot was to facilitate evaluation using the Toolkit and work with an evaluation team. This allowed me to further understand how leaders (facilitator 
and other members of the evaluation team) perceive and use the Toolkit. Field notes taken during the meetings, focus groups and semi-private conversation between meetings were summarized as data for further analysis and triangulation.

Participants signed an informed consent form before participation in the program evaluation team and study which explains the intended use of their comments and assures them confidentiality and participation at no risk during every step of the R\&D cycle. A copy of the consent forms will be kept for two years and destroyed in accordance with university policies.

Fowler (2004, p. 311) also describes other types of research data (quantitative) and were primarily used in Step 5: Main Field Testing. Types of quantitative research data collected will include group surveys, confidential edited record of phone conversations and discussions between meetings, kept in the form of a research journal. Other types of quantitative information for district/state policy-level program evaluation include state and local assessment scores, retention rates, attendance figures, dropout rates, per-pupil expenditure, teachers' salaries, teacher-pupil ratios, percentages of students on free and reduced lunch, enrollment figures and percentages of teachers with masters degrees (Fowler, 2004, p. 311).

Focus group data were used to collect information, generalizations, themes and direct anonymous quotes about the alternative high school program evaluation. Survey data are analyzed in the following chapter and used with a large sample of participants in future steps (operational field testing, final product revision, dissemination and implementation). 
The sections that pertain to school, participant and program evaluation are included in the analysis. This research contributes to Steps 4 and 5 of the Borg and Gall's (1989) R\&D cycle, discussed previously in this chapter. Specific research and evaluation instruments are discussed later in this section and included in Appendix A. Research focus group and survey information derived from the field test and survey of the design process were analyzed, but are not included in this dissertation as they do not pertain directly to evaluation process or operational product revisions to the Evaluation Toolkit.

Step 6 of the R\&D Cycle is main field testing and during this step further evaluation of the product's efficacy is made. Main field testing took take place with an alternative high school evaluation leadership team that used the process to evaluate an actual school. Main field testing was done in collaboration with Chet Edwards, who is researching methods of designing alternative schools in Oregon. Edwards (2012) conducted quantitative surveys of design team members that were used to evaluate the efficacy of the design process during the implementation of the process. When conducting this research, I served as a researcher-facilitator. In this role I acted as a participant-observer in the research, the facilitator and member of the evaluation team. The role allowed me access to the evaluation team and staff at the school site who were involved in using the process and tools; however; involvement in the research generated challenges that are discussed later in this section.

To the extent possible, a single evaluation team will utilize the Toolkit while observing the Toolkits usefulness from start to finish in the process. In future study it will likely be useful for the researcher to remove themselves from the role of facilitator in 
order to maintain a more objective perspective. The main field testing will include the evaluation of one alternative high school and will be guided by the facilitator and an evaluation team that will represent both internal and external stakeholders. It will be valuable for the researcher to make observations, personal field journal notes and observations that will inform future product revisions. In future research study multiple diverse school sites might be carefully selected in an attempt to represent the variety of mission, location and student population as well as differing instructional strategies used by alternative high schools statewide.

Efforts were made to select an alternative school with characteristics similar to others in the state, the data collection in the main field testing will not be designed to represent different types of alternative high schools in the state and this is among the limitations of the research study and this issue will be discussed further in this section and the next. Other limitations exist in the research, such as the experience and background of the leaders (facilitators and other members of the evaluation team) involved in the main field testing. Because of these limitations, the research findings and conclusions discussed later may only be generalized with the school studied or possibly with schools that are similar, based upon geographic location, mission, staff and student population. As a result, the conclusions from this study will not be broadly generalizable to all types of alternative programs and will likely demonstrate the need for additional research in this area.

The Evaluation Toolkit includes both compliance and quality indicators and characteristics that could be described as both formative (ongoing) and summative 
(summary). The Evaluation Toolkit resulted in the team composing and contributing toward an evaluation plan. The study of the Toolkit and its elements involved a mix of methods including a focus group that contributed toward the main product revision, followed by main field testing with an actual alternative high school evaluation. The evaluation included ordinal and observational information as not to be skewed toward a single determination of "good" or "bad" school or program elements that could limit the credibility and usefulness of the program evaluation as well as the research findings. To do otherwise would serve to jeopardize the ethical and political ramifications that must be considered with any formal evaluation (Reimer \& Cash, 2003).

Facilitating the program evaluation involved the analysis of local data, on-site interviews and planning meetings with leaders (facilitator and other members of the evaluation team) and observations that were managed through evaluation teams consisting of internal stakeholders (unique to the alternative high school) as well as external members from the state, region and/or broader community. As is typically done by external program evaluators, I provided the school a final report that described the method, steps taken, results and recommendations (Appendix A). The R\&D Cycle required data and information from a variety of sources (described in Table 21) contributing toward the development and improvement of the Evaluation Toolkit. 
Table 21:

Sources of Data Used in This Study

Preliminary Field Testing (Step 4 in the R\&D Cycle):

- Qualitative focus group involving members of the Alternative Accountability Taskforce, who were in attendance at the Northwest Innovative (Alternative) Schools Conference and demonstrated interest in alternative school evaluation tools (approximately 50 in attendance at three sessions and the afternoon meeting and all received a copy of the Toolkit)

- Quantitative pilot survey of educational leaders in sessions on Design and Evaluation of Alternative High Schools (approximately 20 in session)

- Field notes from in depth interviews and school visits with participants and day-to-day observations as the alternative education specialist at ODE.

Main Field Testing (Step 6 in the R\&D Cycle):

- Field notes and written communication collected in my role as program evaluation facilitator and from in depth interviews with main field test participants and day-to-day observations as the alternative specialist at ODE.

- Qualitative focus group and in depth interviews of leaders (evaluation team) who participated in the evaluation process (approximately 10 participants).

- Quantitative survey of educational leaders participating in the evaluation process and main field test (approximately 10 participants)

Source: Steps 4 and 7 are based upon the R\&D Cycle (Borg \& Gall, 1989)

The main field testing research included 10 educational leaders who have had experience with alternative high school evaluation. All participants were assured that their participation was completely voluntary. In addition, they were assured that the decision to participate would not have any effect on their relationship with me as a researcher, their school, or school district. The participants were not offered financial compensation, but pizza and refreshments were provided by the district at every team meeting. The participants were advised that they could withdraw from the study at any time without any negative effect on their relationship with the researchers, their school, 
or school district. The participants were assured that their responses and the information gathered would be kept confidential and comments be generalized so as not to identify the participant uniquely.

The focus of this work was to develop an educational product which is a process for designing new and innovative alternative high schools and not evaluating participants or their work. The data collection process $(\mathrm{R} \& \mathrm{D})$ methods that have been covered in this section are all methods that contribute to creating a quality process for the product users.

\section{Data Analysis Strategies}

Collecting and analyzing the data necessary to conduct a reliable (repeatable) study requires using valid (measure what it intends to measure) research methods. Essential to effective data analysis is the focus on the primary research issue of how best to evaluate alternative high schools. The purpose of the research is to improve the Toolkit and my central research question was: What tools support leaders in planning a thorough and accurate program evaluation of an alternative high school? As described in this chapter, Toolkit Elements and Process Characteristics were considered along with Assumptions in the analysis.

The focus of the analysis is on determining if the efficacy of the Toolkit Elements and Process Characteristics supports consideration of the Assumptions about program evaluation used to determine the impact of alternative high schools. The 15 guiding questions presented previously in this chapter (Table 21) are comprehensive enough to give a broad perspective and were used in the focus groups and field testing. 
The focus group conducted during Step 4 (preliminary field testing) and information collected in Step 6 (Main field testing) of the R\&D process makeup the primary components of the research design in this study. In analyzing the data, I used field notes from Alternative Accountability Taskforce Meetings, Design and Evaluation Meetings and responses to the survey to summarize and code (mark similar comments and phrases to discover themes and possible conclusions) the results and gather information such as participant contributions and quotations.

During main field testing, I facilitated an alternative high school evaluation with the support of the district leadership and evaluation team. At the conclusion of team meetings, a survey was conducted to collect data that were analyzed and used to guide the improvement of Alternative School Program Evaluation Toolkit (product, not people). My experience and role at ODE may have had a tendency to influence team members, but I am unable to determine how much their behavior was affected and what to do to mitigate the consequences of my involvement as a facilitator and member of the evaluation team. As a result, it must be considered among the limitations of this study. If the study was repeated and the researcher was also a state alternative programs coordinator, I believe the documentation and methodology I have provided would provide enough information to repeat the study.

The surveys described previously in Step 4 (preliminary field testing) was provided in print format (included in Appendix F) which allowed close interaction, observation and quick modifications in preparation for main production revision (Step 5). Step 6 (Main field testing) of the R\&D process, was given using an internet service 
website called "Survey Monkey." To analyze the data, I exported the survey data from Survey Monkey and imported it into spreadsheet software to summarize and graph the results, gather and report on information such as participant ratings, rankings and comments. The results of this process are included in the analysis section of this dissertation.

There were three main sections of the survey: school and participant information, school design and program evaluation. The school and participant information is described later in graphic detail in the analysis section of this dissertation. The school design section asked participants to use a numerical rating statement: 1="Not Essential," 2=“Somewhat Essential," 3="Moderately Essential," and 4="Absolutely Essential" to respond to statements about the four assumptions. Mr. Edwards developed three of the four questions in this second section and I developed the fourth based on our collaboration over the course of this research study. Scores and comments were analyzed to improve the evaluation process based on participant ratings and a mix of other data and observations. The final survey question in the second (Design) section asked participants to reflect on program evaluation that begins with the end in mind and linked $\mathrm{Mr}$. Edwards' research in design with mine, evaluation. The intent of the questions in the second section is for process refinement.

The final two questions in the third section of the survey relate directly to program evaluation and ask participants to rank Toolkit Elements and Process Characteristics of the evaluation process as to their importance and value. The intent of this section of the survey is to discover the value that participants have for one Toolkit 
Element and Process Characteristics in comparison with the other elements listed. Participant responses and comments reflected an understanding about evaluation and an awareness of the elements in the Toolkit. This information is described in the analysis of this dissertation and used to determine characteristics and elements that were revised in the operational product revision.

\section{Work Plan}

This research plan was submitted to Portland State University's Human Subjects Department along with the informed consent form, focus group guiding questions and survey questions. In this section, more detailed information on the work plan and timeline is described. A Research Timeline Table is provided that describes activities (see Table $22 ?)$.

It is important to note that research and information collecting for this research project began in 2003 with my experiences as a district administrator with the responsibility of supervising staff in a variety of alternative education settings (before/after programs, summer school, treatment programs and alternative school). These experiences exposed me to some of the tools and processes used to address the needs of these diverse educational programs. As previously discussed, I currently serve as the Alternative Education Specialist at ODE and have the opportunity to frequently work with school and district leaders exploring the need to evaluate their alternative schools.

In July 2009, planning objectives, learning activities and small scale testing became more formalized as I chose alternative school evaluation as a research topic I was engaged as a consultant, with Mr. Edwards, by three small school districts in the South 
Coast region of Oregon to help design and evaluate a new alternative high school. In October 2012, Mr. Edwards and I co-presented at a Conference of Oregon alternative school leaders. As part of Step 5 (main product revision) of the R\&D cycle, voluntary participants in my sessions (approximately 50 alternative school leaders) were engaged in sessions that described the Metrics for Alternative Accountability and the Alternative School Program Evaluation Toolkit (both included in the Appendix A).

Table 22:

Research Timeline

\begin{tabular}{|l|l|l|}
\hline Season & Activity & Action \\
\hline Fall 2012 & $\begin{array}{l}\text { Present at conferences and collect question } \\
\text { cards, develop Toolkit elements }\end{array}$ & $\begin{array}{l}\text { Pilot the survey instrument } \\
\text { and gather feedback on tools }\end{array}$ \\
\hline Fall 2012 & Analyze data & Make product revisions \\
\hline Winter 2012 & Request data from successful evaluators & $\begin{array}{l}\text { Collect question responses \& } \\
\text { in depth interviews }\end{array}$ \\
\hline Winter 2012 & Analyze data & Make product revisions \\
\hline Winter 2012 & $\begin{array}{l}\text { Facilitate Zeeland School District - Whyroads } \\
\text { Alternative High School Evaluation Team }\end{array}$ & $\begin{array}{l}\text { Group and in depth } \\
\text { interviews with leaders } \\
\text { (participants), in depth } \\
\text { interviews and field notes }\end{array}$ \\
\hline Spring 2013 & Analyze Data & Main Product Revision \\
\hline
\end{tabular}

Participants in the main field test (Step 6) were asked to sign informed consent forms, had the opportunity to experience the evaluation process from start to finish and were asked to respond to survey and focus group questions (guiding questions). The intentions of the research described began with communicated expectations with the team and in writing through the use of a Scope of Work (example included in Appendix A). Contact information was provided to participants in case any of them wanted to revoke 
consent. Participants were notified that their identities would be held in confidence and that their responses would be reported in a generalized manor so as not to identify them.

From February 2013 through April 2013, research (Main Field Testing) was conducted at Whyroads Alternative High School in Zeeland School District. The main field testing consisted of facilitating the alternative high school program evaluation of an actual school located near an urban area of Oregon. The focus group on alternative accountability and surveys for team members were conducted and the Evaluation Toolkit and was revised through each step in the R\&D Cycle: preliminary field testing, main field testing and operational product revision.

\section{Summary}

This chapter described the product revision, the process of PBL and the steps in the R\&D cycle (Borg \& Gall, 1989; Bridges \& Hallinger, 1995). As discussed previously in this dissertation, 50 years of evidence exist in what works in alternative schools but much of that research has not yet been applied in processes of evaluating alternative schools. Moreover, alternative school evaluation characteristics or elements have not been previously developed or field tested. The R\&D method facilitates the further development of the Evaluation Toolkit in the context of a new process for evaluating alternative high schools. The evaluation protocols were used to support the researcherfacilitator and the evaluation team in conducting a thorough and accurate evaluation of an actual alternative high school, Whyroads Alternative School. Chapter 4 includes an analysis of the efficacy of the Evaluation Toolkit Elements and Process Characteristics of the Process in addition to a method to reflect upon Assumptions about evaluation. 


\title{
CHAPTER 4
}

\begin{abstract}
ANALYSIS
"It seems that the necessary thing to do is not to fear mistakes, to plunge in, to do the best that one can, hoping to learn enough from blunders to correct them eventually." Abraham Maslow (1970)
\end{abstract}

\section{Overview}

This study was guided by the central issue of how best to evaluate alternative high schools. The purpose of the research was to design, field test and revise an Evaluation Toolkit. The primary research question: What tools support leaders in planning a thorough and accurate program evaluation of an alternative high school?

\section{Standard Elements}

For the purpose of considering the efficacy of this research product, "accurate" includes Standard Elements for Educational Evaluation (Yarbrough et al., 2011) developed by the Joint Committee on Standards for Educational Evaluation. Those Standard Elements include:

- Utility (useful and purposeful)

- Feasibility (practical or realistic)

- Propriety (proper or fair)

- Accuracy (adequately conveys analysis)

- Accountability (contextualized and produces value) 
The research methodology and product revisions have supported the exploration of the primary research question and further supported guiding questions organized by element. These guiding or secondary research questions are analyzed in future sections of this chapter.

\section{Process Characteristics}

This chapter analyzes the results of a R\&D Cycle used to develop and improve an educational product, in this case the Elements of the Alternative High School Program Evaluation Toolkit and Characteristics of a process for evaluating an alternative high school. These Characteristics were described in previous chapters and include:

- Generally useful: Utility

- Practical, realistic: Feasible

- Proper, fair: Propriety

- Accurately conveys analysis: Accurate

- Contextualized produces value: Accountable

- Begins with the end in mind

- Considers established school vision, mission and goals

- Involves internal, external stakeholders

- Uses a Mix of formative and summative evaluation

- Supports formation of evaluation team

This chapter also reviews the primary and secondary (guiding) research questions and the general design of the PBL project. It then reviews the development and implementation (field testing) of the research based on experiences and Steps 1-7 of the R\&D Cycle. The analysis concludes with discussions of challenges encountered during field testing and considerations accounted for in product revision. 
As a part of this research, participants in the product development, revision and field testing were educational leaders with extensive background and experience in public alternative high school education. The main field test site (Whyroads Alternative School in Zeeland School District) and research participants were selected based upon a careful analysis of the different types of districts and schools in Oregon. To the extent possible, research objectives and goals were communicated clearly to participants. Great care was taken to listen, observe and record throughout the R\&D Cycle with intention of improving the usefulness of the product (Evaluation Toolkit). The Alternative High School Program Evaluation Toolkit was grounded in the research literature on effective alternative schooling and elements described by the Joint Committee on Standards for Educational Evaluation which include Standards of utility, feasibility, propriety, accuracy and accountability (Yarbrough et al., 2011).

The analysis in this chapter explains Steps 1-7 of the R\&D process, describing what was done and what was learned during each Step. Research questions that guided this study were then reviewed and reflected upon as a part of the field testing of the Evaluation Toolkit. Finally, this section explains the results and findings of the first seven R\&D steps. The following section outlines the research design (Steps 1-7) and research questions. As previously mentioned, the research questions involve Elements of alternative high school evaluation and Characteristics of the alternative high school evaluation process. 


\section{Evaluation Toolkit Description}

The Alternative High School Program Evaluation Toolkit is included in Appendix A and begins with a list of contents. The Toolkit is made up of tangible Elements (tools) and less tangible evaluation Process Characteristics and should be thought of as a recipe described previously in the introduction to chapter 3 . The Evaluation Toolkit includes an introduction and description of the three dimensions of alternative school evaluation (reporting, compliance and quality assurance) and the five Standard Elements of Educational Evaluation (Utility, Feasibility, Propriety, Accuracy and Accountability), as well as instructions (protocols) for Evaluation Facilitators (Yarbrough et al., 2011). In addition, the Toolkit provides pre-process support documents such as agendas, a Needs Assessment Template and an example Scope of Work to support evaluation planning.

Following the pre-process materials and introduction, the Toolkit includes agendas, annotated agendas and multimedia presentations to support the Design Team described by Edwards (2012). The multimedia presentations for Design include the topics of innovative schools, essential elements, school accreditation, evaluation training and planning. Next, the Toolkit provides evaluation training and planning support materials including agendas, annotated agendas and multimedia presentations to support evaluation training and planning. Evaluation Tools are also provided (Assessment, Curriculum, Instruction, Engagement, Leadership and Structures) that include Initial Survey Questions, Indicators for School Success and an Evaluation Planning Matrix. The development process that resulted in the Evaluation Toolkit Elements and the Characteristics was described in chapter 3. An example program description and 
evaluation report are provided to give team members a model to reference throughout the process of designing and evaluating alternative high school.

\section{Research Questions and General Design}

\section{Research Question}

The purpose of the research was to improve the Toolkit and to focus on the primary research question of: What tools (Elements and Characteristics) support leaders in planning a thorough and accurate program evaluation of an alternative high school? Responses were logged in my field journal, focus group notes and survey responses that are reported on in this analysis. Steps 1-7 of the research design (Borg \& Gall, 1989) informed the research process that resulted in operational product revisions and to the final product (included in Appendix A).

For the purpose of this research analysis, "accurate" includes Standard Elements of utility, feasibility, propriety, accuracy and accountability (Yarbrough et al., 2011). These standard elements describe an effective program evaluation and were introduced and reinforced with the evaluation team at Whyroads Alternative School early in the main field testing and provided a framework for the evaluation. The secondary (guiding) research questions mentioned above were the basis for the data gathered and were instrumental in making operational product revisions to the Evaluation Toolkit (See Appendix A). The secondary (guiding) research questions are provided in Table 23 as a reference. These questions are responded to later in this chapter as a part of discussion relating to the efficacy of the Toolkit Elements, Process Characteristics as well as Assumptions about program evaluation in alternative schools. 
Table 23:

Secondary (Guiding) Questions Organized by Standard Element

Utility Questions (useful or purposeful)

1. Is the Toolkit an effective (useful) tool for formatively (ongoing) and summatively (summary) determining the impact of alternative high schools?

2. Are the tools in the Toolkit supportive to evaluation teams in developing a program evaluation with a clear purpose and objectives that "begin with the end in mind" (S. R. Covey, 2004, p. 97) and thoroughly and accurately portray the school?

3. Do the Protocols and Tools support facilitators in involving both internal and external stakeholders working with an evaluation team to evaluate the alternative high school?

Feasibility Questions (practical or realistic)

4. What learning activities (data collection, information gathering, reflection, reporting etc.) are needed to support the facilitator and members of the evaluation team in using the Tools for Evaluation Teams: Initial Survey Questions, Comments and School Progress Indicators?

5. Do the School Progress Indicators provide an opportunity for members of the evaluation team (in workgroups) to come to consensus on what is meant by "Exemplary", "Effective" and "In Need of Improvement" in the Tools for Evaluation Teams: Assessment, Curriculum, Engagement, Instruction, Leadership and Structures.

6. Do the Initial Survey Questions and Comments provide an opportunity for members of the evaluation team (in workgroups) to convey thoughts, observations and the evidence?

Propriety Questions (proper or fair)

7. How should a school district or school go about selecting an evaluation team?

8. Does the Evaluation Planning Worksheet adequately support the initial communication of an evaluation purpose with a timeline, supportive learning activities and explanation of how the results will be used?

9. What learning, reflection and planning activities are needed to support the facilitator and members of the evaluation team in utilizing the Evaluation Planning Matrix and Evaluation Plan?

Accuracy Questions (adequately conveys analysis)

10. Are the Tools (assessment, curriculum, engagement, instruction, leadership and structures) valid (measure what they intent to measure)?

11. What obstacles (challenges) have leaders (evaluation facilitators and evaluation team members) experienced when attempting to evaluate an alternative school? How well does the process and tools address those challenges?

12. How useful are the Alternative High School Program Evaluation Toolkit Characteristics in the evaluation process? Are there other frameworks intended for use with alternative high school program evaluation and tool-development?

Accountability Questions (contextualized and produces value)

13. How does using an evaluation team impact the school evaluation process and results?

14. What impact can this Toolkit have on students at risk of high school failure?

15. Do the Tools for Evaluation Teams support those at the school in learning from their successes, identifying current challenges, planning for improvement and more effectively telling their story?

Source: Standard Elements (Yarbrough et al., 2011) were used to organize questions. 
The basis of the Evaluation Process Characteristics used as headings in Table 23 were the Standards for Educational Evaluation and were developed by the Joint Committee on Standards for Educational Evaluation (Yarbrough et al., 2011).

Using feedback from the research questions, modifications were made to the Elements of the Evaluation Toolkit and Characteristics of the evaluation process along with basic assumptions were reconsidered. In depth interviews, focus groups and survey data triangulated the research findings in order to make improvements. Data collection and application of the product added to the existing knowledge about what makes up an effective alternative high school evaluation in Oregon. Benefits of the evaluation process were noted in my field journal as well as the report prepared for and presented to the school in the form of a final report and recommendations (see Appendix A).

\section{General Design}

The dissertation research included R\&D that resulted in the development and revision of the Alternative High School Program Evaluation Toolkit and followed field testing guidelines outlined by Borg and Gall (1989) in steps one through six, ending with operational product revision (Step 7). Future research will involve field testing with a larger sample of more diverse alternative high schools and will follow final product revision (Step 9) to prepare the Toolkit for dissemination (Step 10). Borg and Gall's Steps provide a framework included in the introduction (Table 2) is useful for considering next steps in a R\&D Cycle that produce educational products. The general research design focused on the Toolkit Elements and Process Characteristics that support leaders in planning a thorough and accurate program evaluation of an alternative high 
school and carefully followed Steps 1-7 of the R\&D Cycle. The Toolkit Elements and Process Characteristics were considered alongside Standard Elements of utility, feasibility, propriety, accuracy and accountability (Yarbrough et al., 2011) in order to further analyze Toolkit efficacy.

\section{Research Design}

The research design utilized to improve the Evaluation Toolkit included PBL and the R\&D Cycle designed to help solve problems of practice in the field or workplace. Borg and Gall (1989) depict educational R\&D as "a process used to develop and validate educational products" (p. 782). Researchers customize the R\&D Cycle and use results to create a product that is ready for dissemination and implementation in real world educational applications. The entire R\&D Cycle includes a 10-step process leading to full implementation of the educational product of the R\&D. For the purposes of this dissertation, the first seven steps in the R\&D Cycle are followed to develop, field test and refine the Elements of the Evaluation Toolkit and the Characteristics of the process for evaluating an alternative high school. The first seven steps in the R\&D Cycle were utilized to ensure that the product is ready to assist evaluation teams in the field. The next section of this chapter provides information on the researcher's experience in the development, main field testing and refinement of the product throughout each of the seven steps in the process. Steps 8-10 are also presented and are further addressed in conclusions and recommendations provided in chapter 5 of this dissertation. As shown previously in Table 2, Steps in the R\&D Cycle include: 
1. Research \& information collecting

2. Planning, objectives, learning activities, and small scale testing

3. Develop preliminary form of the product

4. Preliminary field testing

5. Main product revision

6. $\quad$ Main Field testing

7. Operational product revision

8. Operational field testing

9. Final product revision

10. Dissemination and implementation

\section{Development and Implementation}

\section{Step 1: Research and Information Collecting}

Determining the impact of an alternative high school that serves mostly at-risk students presented a significant research problem. Fortunately, 50 years of research on alternative schools existed, representing evidence of successful forms of alternative schooling (Aron, 2003, 2006; Barr \& Parrett, 1997, 2001, 2010; Morley, 1996, 2012; Raywid, 1981, 1994; Reimer \& Cash, 2003; Schargel \& Smink, 2001; Smink \& Schargel, 2004).

The focus of the research and information collection was on a primary research question: What tools support leaders in planning a thorough and accurate program evaluation of an alternative high school? I spent the greater part of a year collecting evaluation tools from international, national, regional, and other U.S. and state 
organizations that were seeking to evaluate diverse schools such as alternative schools. The information included a broad range of checklists, inventories, protocols, standards, needs assessments, several types of audits and examples of program evaluations. The process of research and information collecting exposed me to a wide array of assessments and evaluations seeking to accurately describe what is going on at a school and describe what it could do to improve; simply put, "Where is your school and where is it going?"

The literature reviewed served to demonstrate that few studies exist that dig deeper into the elements of the tools or characteristics of a process that would describe valid program evaluation methods that identify successful alternative schools. Few had sought to apply sets of elements and fewer had published or described the field testing of the tools themselves. I encountered several for-profit and not-for-profit organizations that agreed to share their evaluation tools with me if I agreed not to cite them in my research study or make them publically available. There were other organizations that had previously published information about indicators and processes to identify them NWREL (Cotton \& Paglin, 1995) and others (Barr \& Parrett, 1997; Leiding, 2008; ODE, 2006a; Schargel \& Smink, 2001) have recorded the observation of evaluation tool elements. Reimer and Cash (2003, p. 15) described the characteristics (elements) of successful alternative schools as a synthesis of previous research and include a portion of their tool for evaluating what they call "Tier 1" and "Tier 2" levels of evaluation. In addition, I have reviewed documents that sought to apply standard tools with evaluating alternative schools (Moreley, 2012; ODE, 2006c; Witty, 2009). 
Additionally, the literature reviewed from the professional field of program evaluation offered best practices in evaluation and characteristics of a thorough and accurate program evaluation. The work by the Joint Committee on Standards for Educational Evaluation provided a framework for the structuring of the evaluation in this research study as well as questions and meta-evaluation (evaluation of the evaluation). For the purpose of this analysis efficacy should include consideration of elements of utility, feasibility, propriety, accuracy and accountability (Yarbrough et al., 2011).

\section{Step 2: Planning, Objectives, Learning Activities, and Small-Scale Testing}

The review of literature described previously in this dissertation exposed a lack of a workable typology for alternative high schools as well as elements of the Evaluation Toolkit used in the process evaluating alternative high schools. Planning, learning activities and small-scale testing occurred over the past six years in my position at ODE as well as the better part of a year spent gathering and reflecting on components of different types of tools. That year allowed me to conceptualize what an effective tool would look like as well as visit diverse types of alternative schools with the tools themselves. Serving as an evaluation facilitator and specialist at ODE allowed me access and opportunities for small-scale testing that contributed toward multiple interactions of a variety of evaluation tools used in alternative high school visits.

The initial development of the Toolkit Elements and small-scale testing followed the research and information collecting. During this period, I developed the secondary (guiding) questions described earlier in this dissertation and used them as the basis for the reporting of results in this analysis. I developed the list of seven toolkit elements and 10 
characteristics of the evaluation process as well as the three dimensions of alternative high school evaluation (the funnel from Figure 9), six evaluation protocol steps for facilitators and eight assumptions about alternative school evaluation that begins with the end in mind. I have shared these tools informally with colleagues, alternative educators, educational leaders and others who expressed interest in alternative school evaluation. Throughout the small-scale testing, the Toolkit elements continued to evolve, some elements were removed, revised, and elements were added. Primary to this effort was making the tools simple enough to understand but complex enough to reliably and validly determine the impact an alternative high school is making through a thorough and accurate evaluation.

\section{Step 3: Develop Preliminary Form of the Product}

The preliminary forms of the product included rough checklists, rubrics, audit templates and various forms of logic models but I knew from experience in the learning activities and small-scale testing that these tools wouldn't be much use to a team made up of individuals with diverse backgrounds and experiences. I was asked by several small school districts in the South Coast region of Oregon to assist them in designing and evaluating a regional alternative high school. I involved my research colleague, Mr. Edwards and we initiated a pilot (out of town tryouts). As the small-scale testing concluded, this was an opportunity to further develop a preliminary form of the product in preparation for preliminary field testing. Mr. Edwards and I met several times with superintendents in the South Coast who had already conducted a thorough needs assessment and were aware of the needs of out-of-school youth in the region. However, 
they were not confident about where to begin with school design and were unsure about how to thoroughly and accurately measure their progress.

Planning, learning activities and small-scale testing over the past several years had prepared me to quickly compile an original workable product (Evaluation Toolkit). I used the list of Elements and Characteristics previously described in Step 2 to compile a set of instructions (later called protocols), initial questions, indicators, and an evaluation planning matrix (simplified logic model). Around this same time a colleague from the Oregon Program Evaluation Network (OPEN) invited me to a workshop at the Oregon Museum of Science and Industry (OMSI) where I learned more about logic models and rubrics being used in museums. At the logic model workshop I interacted with program evaluators struggling to design methods to measure the impact of museum exhibits and came to the belief that if a workable method of program evaluation was possible with museum visitors that were only present for a few hours, I asked a colleague, "Why are we not keeping better record of the results and outcomes of students attending alternative high schools who often attend the school for the majority of a school year?"

Following the OMSI workshop and further development of the preliminary form of the product, I applied an approach online course developers call "rapid-prototyping" (developing multiple versions of a product very quickly). This is essentially a less elaborate version of the R\&D Cycle (Borg \& Gall, 1989). I also continued to share the early versions of the Evaluation Toolkit with educational leaders, alternative educators, other state alternative program coordinators, and others who expressed an interest. I eventually came to a point where I felt the Toolkit was ready to share with my colleagues 
in Oregon's South Coast. The Elements and Characteristics, although largely unique, they were representative of the Standard Elements.

During this same time period, Mr. Edwards and I had begun working on the first of four objectives in support of those South Coast superintendents by assisting in the formation of a local design and evaluation leadership team composed of what program evaluators Donaldson (2013) and Patton (2011) call internal and external stakeholders. Design and evaluation team members included superintendents, principals, teachers, parents, students and other local community members with interest in out-of-school youth. Toward the end of the design process the local team also served as the Evaluation Team and considered preliminary forms of the Toolkit Elements and Characteristics of the evaluation process. I noted their suggestions, comments and suggestions in my field journal and responded with almost daily additions to the preliminary form of the Evaluation Toolkit during that period.

The second objective was to create learning activities that would benefit the team in understanding how to design and evaluate their new innovative alternative to their local traditional high schools. These took the form of agendas, reference materials and multimedia presentations used in both the preliminary and main field testing in the R\&D Cycle. Mr. Edwards worked with the lead district and the new alternative school principal to create a "program description" that served as a "blueprint" for the new school. The program description (vision) would be used to form a school mission, goals and methods of formative evaluation for the school and used to communicate to the local community and news media as well as potential external supporters. 
It has been my experience that schools that don't have a strong vision, have a very difficult time with recommendations, and are especially difficult to evaluate. In short, "If a school does not know who they are it is going to be difficult to contribute to where they are going." Subsequent to the design process began the fourth objective of planning for a formative (ongoing) evaluation. This required the team and educators to think differently about accountability and accurate evaluations (Yarbrough et al., 2011) as well as student performance and assessment. I used and referenced Stiggins et al.'s (2005) work in the area of assessment for (rather than of) learning in the trainings to help bridge the gap between educators' understandings about different types of assessment (formative and summative) and its linkage to how the terminology is used in program evaluation.

During the process in the South Coast, some components of the Evaluation Toolkit were introduced as part of the evaluation planning, initial questions, indicators and logic modeling. In reflection, there was a lot to learn from the procedures used in that pilot. I had spent the entire previous year collecting and reflecting on the elements of the Evaluation Toolkit and found it difficult to communicate what I was talking about with anyone, including Mr. Edwards. I found conversations with fellow program evaluators and experts in this field most helpful during this Step in the R\&D Cycle and appreciate ODE, OPEN and the State Instructional Materials Review Administrators (SIMRA) for providing regular professional learning opportunities where I was able to reflect as the preliminary form of the product took shape. The four objectives previously discussed included the formation of a team who participated in learning activities to support the development of a school vision and were introduced to the Elements of the Evaluation 
Toolkit and Characteristics of an effective process for determining the impact of an alternative high school.

New innovative methods of program evaluation. I was also supported in the product development by research emerging from the literature supported by professional organizations like the American Evaluation Association and the American Educational Research Association. Specifically, a new form of qualitative research in the field of program evaluation known as Developmental Evaluation (Patton, 2011), described earlier in the review of literature section of this dissertation. "Developmental evaluation supports innovation development and $R \& D$ to guide adaptation to emergent and dynamic realities in complex environments" (p. 1). Developmental evaluation seeks to involve characteristics of complex adaptive systems, like alternative schools, in the process of evaluation. Patton draws distinctions between traditional evaluation methods and complexity-sensitive developmental evaluation (p. 23). Such methods include accounting for dynamic and difficult-to-measure variables and require collaboration with those engaged in the change effort to co-create an evaluation that is useful and matches the innovation process philosophically and organizationally (p. 25). In contrast, alternative school evaluations in Oregon typically focus on observable and easy-tomeasure variables and involve a single evaluator that results in a completed checklist or evaluation report.

In effective program evaluations quantitative and qualitative data need to be collected as a part of an alternative school evaluation. Depending on the purpose of and the audience for the evaluation, an evaluation team should employ methods of evaluation 
that are quantitative or qualitative (mixed-method). Depending upon time and available resources, such an evaluation may not be feasible or cost effective. The evaluation research suggests that an evaluation should provide summative (summary at the end) and formative (forming along the way) evaluation within a project (Spaulding, 2008). The evaluation should involve multiple approaches to determining the impact the program is making with the students. Schools making use of program evaluation should become familiar with Standard Elements of educational evaluation (Yarbrough et al., 2011) and consider evaluator competencies (Russ-Eft, 2008) in the development and evaluation process.

Evaluation process. Evaluation teams and educational leaders in alternative schools who want to design or improve innovative schools will do well to consider the role of both localized program evaluation and more general educational evaluation research. Research may help an alternative school leader overcome organizational barriers to education reform (Chenoweth \& Everhart, 2002) and program evaluation may give school leaders the tools to make program improvements. School improvement requires that leaders attend to best practices in school leadership and make use of program evaluation. Major assumptions about change reflected by Chenoweth and Everhart (2002) asserted that change must be focused on improved student learning, must be comprehensive, demand shared leadership, include all relevant stakeholders and mean change in school cultures. In a book titled The Self Renewing School, Joyce, Wolf, and Calhoun (1993) also noted that the centrality of student learning must be the purpose of improvement activities. 
The evaluation is best conducted with the involvement of both internal and external stakeholders in a process where practitioners and stakeholders come to consensus about the schools strengths and needed improvements. The outcomes and process should be agreed upon and contextually designed to meet the needs of the school so that school staff may make use of the evaluation. The Alternative High School Program Evaluation Process Characteristics, described in previous Tables 12, further define the characteristics of an effective evaluation process and what should be considered when developing a program evaluation for an alternative high school.

Evaluation tools. The tools used in the evaluation process must be complex enough to capture identified characteristics of quality but simple enough to make those tools valid. Alternative school program evaluation tools need to be detailed enough to account for many different types of alternative schools and the evaluation process needs to include both internal and external stakeholders and be facilitated by someone outside the organization. The Alternative High School Program Evaluation Toolkit Elements are described in greater detail in this section with justification and descriptions that depict specific elements of the tools and their contribution toward Toolkit efficacy.

Tools for evaluation teams need to address assessment, curriculum, engagement, instruction, leadership and organizational structure (Barr \& Parrett, 1997, 2001; Barr \& Yates, 2010; Chalker, 1996; R. Morley, 1996, 1996; R. E. Morley, 2002; NAEA, 2009; NDPC, 2011). The evaluation needs to meet recognized standards for program evaluation such as utility, feasibility, propriety, accuracy and accountability (Yarbrough et al., 2011) and address the dimensions of reporting, compliance, and quality assurance. 
The competent evaluator as a tool. Not all evaluators will have had diverse experiences in school settings. An evaluator may not appreciate being called a "tool" but a skilled program evaluator makes a difference. As noted earlier in this dissertation, credible evaluators communicate effectively, attend to multiple problems at once, and manage multi-dimensional projects successfully (Russ-Eft, 2008, p. 34). The evaluation facilitator can dramatically impact the overall success of the program evaluation (Donaldson et al., 2013; Patton, 2011; Spaulding, 2008) and contribute toward building a strong team (J. C. Collins, 2005; James Collins, 2001; Jim Collins, 2006; Cuban, 2003) that will evaluate an alternative high school. In most alternative school evaluations there is flexibility in who conducts the determination of the impact the school is making. The Evaluation Toolkit is only as good as the evaluation team that is using it. Training materials and protocols were included in the Toolkit to support the training and development of the evaluation team.

\section{Step 4: Preliminary Field Testing}

The purpose of preliminary field testing was to obtain an evaluation of the effectiveness of the initial product (Borg \& Gall, 1989). My primary research question was: What tools support leaders in planning a thorough and accurate program evaluation of an alternative high school? Experienced leaders who regularly evaluate alternative high schools often have a set of tools they are comfortable using. These tools often vary from the Oregon Compliance Checklist (previously described) to a professional evaluator's toolset that might include student, parent, teacher surveys and 
rubrics with defined indicators of quality to assist in the identification and recognition of policies and practices that support in a thorough and accurate program evaluation.

Analysis from these data sources revealed that the educational leaders who responded would have benefited from additional experience and training. The Toolkit Elements and Characteristics of the facilitated Alternative School Evaluation Process are described in the Main Product Field Testing (Step 6). As described previously in the methods section of this dissertation, the preliminary field testing (Step 4 in the R\&D Cycle) involved the assembly of qualitative focus groups. This focus group was made up of alternative education leaders interested in alternative accountably metrics and program evaluation as a means to demonstrate that alternative schools were held to account for student performance (Alternative Accountability Taskforce). The members of the Taskforce were also in attendance at the annual Oregon alternative schools conference (Northwest Innovative Schools Network Conference) and demonstrated interest in alternative school evaluation tools. Mr. Edwards and I presented at the conference and enlisted participant feedback. As their responses were analyzed, themes and suggestions emerged that are described below in the main product revision (Step 5). Their suggestions resulted in the inclusion of Alternative Accountability Metrics being included as examples of ways to reliably measure school by something other than test scores, attendance and graduation. These metrics suggested broader methods of determining student growth based upon performance, attendance growth and the earning of individual credits and certificates and were used by the evaluation team in the main field testing to 
report back to the school district and community stakeholders regarding the school performance. These metrics are included in the final version of the product.

The Alternative High School Program Evaluation Toolkit was continuously developed through presentations to various professional audiences described previously in the list of Conference Presentations on Alternative School Evaluation (Table 19) and also depicted in the Research Timeline (Table 22). During the preliminary field testing I carried several copies of the Evaluation Toolkit and Guiding Questions in my backpack to share with others at ODE or in school sites conducting audits, investigations and evaluations. I shared the Tool as a reference (clearly marked DRAFT with a note to email me with additions) in state and national meetings, alternative school visits, school district monitoring visits, interviews, lunch and dinner meetings and with groups of students in the lunchroom while I was on school visits. One of those copies was always labeled "Drew's Edits" and I used it to make corrections and write notes that contributed toward main product revisions (Step 5). Every few weeks I would incorporate my edits into the most recent version of the Toolkit. I collected suggestions from colleagues, experienced educational evaluators, college professors, program evaluators and even an educational anthropologist that recently moved to Oregon from the Midwest.

I shared the Evaluation Toolkit with the Whyroads Principal a year before I received a call from the Zeeland Superintendent inquiring about the new evaluation process with a request that Zeeland would be the first to pilot it. When sharing the Toolkit I provided the Guiding Questions to shape the conversations around my primary research question and Standard Elements (Yarbrough et al., 2011) of program evaluation. As it 
worked out Zeeland and Whyroads are reasonably representative of alternative high schools throughout Oregon in size and mission and their commitment afforded Mr. Edwards and me the opportunity to move forward with a Main Field Test at the site.

\section{Step 5: Main Product Revision}

Main product revisions to the Evaluation Toolkit were directly linked to the R\&D Cycle and the focus on the primary research question of: What tools support leaders in planning a thorough and accurate program evaluation of an alternative high school? The framework for establishing a thorough and accurate evaluation was the Standard Elements for Educational Evaluation which included utility, feasibility, propriety, accuracy and accountability. Main product revisions were made based upon exploration of secondary research questions and were triangulated with data analysis that is expanded upon in this section. Changes made to the toolkit were iterative (flying the plane while building it) and some of the training and evaluation materials were developed and customized to meet the specific needs of Whyroads Alternative School in Zeeland School District. These changes were also based on experiences in the South Coast and previous experience with alternative school program evaluation. As an example, the Whyroads Evaluation Report (included in Appendix A) was developed during the Main Field Test.

I learned and reinforced my thinking about curriculum review and implementation (Elmore, 2004) and how methods for more traditional schools should be applied in alternative educational settings. I was also reminded that trust saves time (S. M. R. Covey, 2008) and benefited from the buy-in and commitment to Toolkit improvement exhibited by the Zeeland Superintendent, Whyroads Alternative School Principal and 
members of the evaluation team. The sections that follow begin with the Standard

Indicator, guiding research questions and a response that contribute toward the demonstration of Toolkit efficacy. Table 24 describes the Utility Guiding Research Questions.

Table 24:

Utility Guiding Research Questions

\section{Utility Questions (useful or purposeful)}

1. Is the Toolkit an effective (useful) tool for formatively (ongoing) and summatively (summary) determining the impact of alternative high schools?

2. Are the tools in the Toolkit supportive to evaluation teams in developing a program evaluation with a clear purpose and objectives that "begin with the end in mind" (S. R. Covey, 2004) and thoroughly and accurately portray the school?

3. Do the Protocols and Tools support facilitators in involving both internal and external stakeholders working with an evaluation team to evaluate the alternative high school?

1. It was observed that the Evaluation Toolkit's utility (usefulness) was largely dependent upon the experience and buy-in of the evaluation team and program evaluator. One evaluation team member commented, "The facilitator is important to the process." The data demonstrated that participants valued the Toolkit indicating that it was supportive to evaluation teams. The data collected from in depth interviews, focus groups and the survey and field journal entries indicated that the Toolkit did a better job than the Compliance Checklist in determining the impact of Whyroads Alternative High School in Zeeland School District. However, it was not found that the Toolkit met the Standard Element of being effective for formative and summative evaluation. Data are not 
conclusive about whether the Toolkit is an effective tool in formatively and summatively determining the impact of alternative high schools.

2. The agendas, annotated agendas, protocols and evaluation planning worksheet were helpful to me in facilitating the meetings with a clear purpose, especially because I was trying to write notes in my field journal while acing as a facilitator. In the survey conducted of the evaluation team at Whyroads in Zeeland, participants ranked the formative and summative item second to last in comparison with other Characteristics, indicating that it was not the strongest element. As one participant put it, "A six-category tool, using multiple stakeholders as links through which to assess the school's success."

3. The Protocols and Tools were found to be helpful to the facilitator and members of the team but the protocols themselves were not specifically called out in the survey. Reflecting upon this, the research would have benefited from a survey item that requested responses about the Protocols. This could indicate that the protocols were in essence not visible and were used to support the process or it could indicate that they were not attended to at all and were useless. The six protocol steps are summarized below for consideration in this analysis and the full version description of the protocols are included in the introduction to the Toolkit located in Appendix A.

1. Use and Update Evaluation Planning Worksheet

2. Review and Discuss Tools for Evaluation Teams

3. Respond to the Initial Survey Questions

4. Identify level in the School Progress Indicators

5. Fill out the Evaluation Planning Matrix

6. Fill out the Evaluation Plan 
The district leadership was involved purposefully in the evaluation from the beginning and approached me as a possible site for the main field testing of the Toolkit and evaluation process. Based upon experiences in the preliminary (Step 4) and main field testing (Step 6), the district needs assessment assists in establishing the purpose. Table 25 describes the Feasibility Guiding Research Questions.

Table 25:

Feasibility Guiding Research Questions

\section{Feasibility Questions (practical or realistic)}

4. What learning activities (data collection, information gathering, reflection, reporting etc.) are needed to support the facilitator and members of the evaluation team in using the Tools for Evaluation Teams: Initial Survey Questions, Comments and School Progress Indicators?

5. Do the School Progress Indicators provide an opportunity for members of the evaluation team (in workgroups) to come to consensus on what is meant by "Exemplary", "Effective" and "In Need of Improvement" in the Tools for Evaluation Teams: Assessment, Curriculum, Engagement, Instruction, Leadership and Structures.

6. Do the Initial Survey Questions and Comments provide an opportunity for members of the evaluation team (in workgroups) to convey thoughts, observations and the evidence?

Feasibility refers to the time and resources available for the evaluation. As shared previously, alternative schools in Oregon have traditionally used a compliance checklist rather than a process for thorough and accurate evaluation. The compliance checklist method required one or more people to visit the alternative school every year, review documents and make observations with a clipboard. The demonstration of efficacy relating to feasibility of the Evaluation Toolkit likely relies on the ability to conduct a process with little to no expense (cost), time or disruption in school activities. To this I 
would say, "You get what you pay for." That is to say that a better evaluation process will cost more money and require additional staff time to complete.

4. The program evaluation of Whyroads Alternative School in Zeeland School District will took place over five 2-hour meetings, and involved students, parents, teachers, school and district administrators. The entire process took only 12 total hours of meeting time commitment with a few assignments between meetings. The first two meetings were designated for the design process conducted by Mr. Edwards. The next two meetings allowed me to facilitate the evaluation team in common learning activities related to training and planning a thorough and accurate evaluation. Agendas were distributed electronically prior to meetings to assist participants. Working groups were established to support progress toward the completion of work products during and between meetings such as the mission and goals, program guide, evaluation planning worksheet and tools. The result of the process was presented during the fifth meeting as a finalized program guide (vision for the school) and evaluation report.

5. The use of Indicators for School Success provided an opportunity for selfreflection by the evaluation team. The Toolkit provided an opportunity for members of the evaluation team (in workgroups) to come to consensus on what is meant by "Exemplary," "Effective," and "In Need of Improvement" in the Tools for Evaluation Teams: Assessment, Curriculum, Engagement, Instruction, Leadership and Structures. 6. As a participant-observer and program evaluation serving as a researcherfacilitator I had the responsibility to make sure those members of the team understood program evaluation (training) and conducted a thorough and accurate program evaluation 
(planning). The Initial Survey Questions and Comments were filled in by participants while working with a partner in a subgroup. These drafts were used in the analysis and informed product revision. School staff was paired with central office staff to identify different points of view needed in the evaluation planning. Ten hours of meetings with district and school community stakeholder was inexpensive (feasible) in comparison with the cost and work associated with a full external professional program evaluations. Table 26 describes the Propriety Guiding Research Questions.

Table 26:

Propriety Guiding Research Questions

\section{Propriety Questions (proper or fair)}

7. How should a school district or school go about selecting an evaluation team?

8. Does the Evaluation Planning Worksheet adequately support the initial communication of an evaluation purpose with a timeline, supportive learning activities and explanation of how the results will be used?

9. What learning, reflection and planning activities are needed to support the facilitator and members of the evaluation team in utilizing the Evaluation Planning Matrix and Evaluation Plan?

7. In the main field test the Zeeland School District superintendent and the District Office Student Services Director suggested the names of the design and evaluation team and the Whyroads Principal provided the parents and students who participated with the design and evaluation teams. The evaluator continuously reinforced the benefit and need to include external stakeholders resulting in the involvement of another alternative high school principal from the region, parents and racially diverse students who attended the school. 
8. The new Evaluation Toolkit and process represents a significant time and resource investment to establish an evaluation team, consider the proper purpose (propriety) of the evaluation in using a needs assessment (was added during the final product revision) or Program Evaluation Planning Worksheet. The result of the planning and main field testing demonstrated positive results as described in the data collected and the analysis that continues in this section. As facilitator, I provided the evaluation team a copy of the Scope of Work agreed upon by the District Superintendent and a draft of the Evaluation Planning Worksheet that clearly identified the evaluation purpose. The Scope of Work and the purpose were used in the recommendations included in the final report.

9. One administrator reported previously in this analysis responded that, "all the tools were valuable [including the Evaluation Planning Matrix and Evaluation Plan] and it is difficult to rank things that are so reliant on one another." Another remarked, "These tools are much better than what we have." A third said "I like how simple the tools are, now that I understand them." Though many on the team had experienced program evaluation before (see survey data in the section that follows the guiding questions), it did not appear any of them knew what to expect out of the design and evaluation process. Table 27 describes the Accuracy Guiding Research Questions. 
Table 27:

Accuracy Guiding Research Questions

\section{Accuracy Questions (adequately conveys analysis)}

10. Are the Tools (assessment curriculum, engagement, instruction, leadership and organizational structures) valid (measure what they intent to measure)?

11. What obstacles (challenges) have leaders (evaluation facilitators and evaluation team members) experienced when attempting to evaluate an alternative school? How well does the process and tools address those challenges?

12. How useful are the Alternative High School Program Evaluation Toolkit Characteristics in the evaluation process? Are there other frameworks intended for use with alternative high school program evaluation and tool-development?

As described earlier in this dissertation, the current tools for program evaluation are inadequate and the school report cards have been described as, "doing more harm than good in closing the achievement gap." As described in the review of literature and methods sections of this dissertation the Elements of the toolkit and the Characteristics of the evaluation process are grounded in research.

10. The evaluation team appeared to have felt very comfortable approaching the Tools (assessment, curriculum, engagement, instruction, leadership and organizational structures). A teacher said, "I know what those things are." A district office student service director said, "It's not these things I am concerned about, it's if it actually happening at the school." These comments indicate that the Toolkit instruments are approachable and understood by these participants in the process. Unfortunately, the parents and students were not able to participate in the survey but experiences during the field test and observations in my field journal would indicate that parents and students generally understood that we were trying to understand how the school was doing. 
11. The set of evaluation objectives described on the Scope of Work and the Final Report (See Appendix A) was not developed by the current superintendent (developed by the previous superintendent) and while the superintendent referenced experience in performance auditing it did appear that the district was not sure what they wanted out of the evaluation. That is not to say that the purpose was not clear just that the evaluation team was unsure about how to support staff at the school. This lack of intentionality was detected early on in the evaluation and an emphasis was put on early drafts of the evaluation planning worksheet and drafts of the report recommendations that would be finalized at the conclusion of the evaluation team meetings. Contributions were invited from all evaluation team members and were considered or included in the final report.

12. The facilitators met the needs of the design and evaluation team, resulting in products that will benefit the school and district and perhaps the attending students, although that claim is not made in this analysis. Further descriptions of accuracy are described later in this analysis with regard to the ranking survey questions. Overall, the accuracy could be improved through additional methods of collecting data about the school perhaps through a coordinated site visit, and consideration of student, parent or teacher survey information. Evaluation participants described the process as being much better than what they had been using (compliance checklist). Table 28 describes the Accountability Guiding Research Questions. 
Table 28:

Accountability Guiding Research Questions

\section{Accountability Questions (contextualized and produces value)}

13. How does using an evaluation team impact the school evaluation process and results?

14. What impact can this Toolkit have on students at risk of high school failure?

15. Do the Tools for Evaluation Teams support those at the school in learning from their successes, identifying current challenges, planning for improvement and more effectively telling their story?

As described in this dissertation, perspective matters. Accountability requires context and in the case of alternative schools a comparative group to accurately compare and hold a school accountable may not exist. Absent a comparative group, any accountability system or statewide system of support (Redding \& Walberg, 2008) will struggle to be contextualized or produce value (Yarbrough et al., 2011). The best state school systems could do for schools might be to pair like alternative schools but as described earlier in the introduction and review of literature a workable typology does not exist for alternative high schools. What is left is the need for a customized program evaluation (often expensive) of alternative high schools.

13. The use of an evaluation team and facilitator mostly utilizes existing resources in support of the district in achieving an evaluation that has is useful, feasible, fair, accurate and produces value (Yarbrough et al., 2011). The various contributions of an evaluation team described in this research study demonstrate the importance of getting the right people on the bus (J. C. Collins, 2005; Jim Collins, 2006).

14. The question of what impact the Toolkit will have on students at risk of school failure was not specifically asked for during the evaluation but was included in the design 
process facilitated by Mr. Edwards. These meetings share the same members and survey but is reported by Edwards (2012) in demonstrating the need for new and innovative school design. The question asked "What impact can this process potentially have on students at-risk of high school failure?" The analysis reported that among the eight participants in the survey, three $(37.5 \%)$ responded positively, three $(37.5 \%)$ responded negatively, and two (25\%) made no response. Those who responded positively commented, "Allowed for parent and student voices to be heard." "I believe it is possible. In my years working with at-risk youth, I have found alternative schools are the last hope for the disenfranchised." "Potentially, yes. To be determined."

15. If done properly the program evaluation provides establishes trust (S. M. R. Covey, 2008) with internal and external stakeholders (Donaldson et al., 2013; Patton, 2011) and increases accountability (produces value). The result was observable and transparent recommendations for alternative high school improvement (Barr \& Parrett, 2001; Barr \& Yates, 2010; Moreley, 2012; Redding \& Walberg, 2008; Reimer \& Cash, 2003; Smink \& Schargel, 2004; Tobin \& Sprague, 1999)

The above analysis has contributed a lot to the determination of Toolkit efficacy but additional analysis is needed, such as analysis that would specifically informed Evaluation Toolkit revisions in preparation for main field testing.

Comment boxes on the Toolkit Elements. One of the Elements in the Toolkit focuses in on curriculum, assessment, instruction, engagement, organizational structures and leadership. The intent during the design of that particular tool was to make it quick and simple to fill out, having boxes for yes and no. However, indicators suggest that the 
focus group and pilot survey results recommend adding a place for comments on the front page of all of the tools for evaluation teams. The six tools for evaluation teams are also included in Appendix A.

Rubric, indicators and logic models. Logic models are graphic organizers for systems-level thinking and when applied to schools often include language like program results and student outcomes. It was determined during the small-scale testing and validated during the preliminary field testing of the toolkit that educators and community members have generally had limited experience with organizational theory and evaluation methodology and logic models. They do not have a working framework to apply when using logic models as a form of program evaluation. Feedback collected in preliminary field testing led to clarifications of the title "simplified logic model" on each of the six tools designed for evaluation team use. Due to lack of understanding about logic models, the title was changed to "evaluation planning matrix" to clarify the purpose of the tool (evaluation planning).

The term "rubric" was also considered in place of "matrix" because there is an existing context and format for the term rubric in education. A rubric is commonly used as a scoring guide with common verbs and activities judged on a four or six point scoring guide. Rubrics are generally used for scoring student work or teacher performance. The term matrix was used with several groups who reflected that the term made sense for the purpose of the Tools (Formative Evaluation Planning). This challenge is expanded upon later in the context, issues, and challenges section and the description of additional tools 
(presentation slides and learning activities) that were developed to train the evaluation team in the field testing.

Granularity in the logic model. As a result of feedback, the logic model was broken into two parts, as depicted in Tables 16 and 17, and further described in the research methods section of this dissertation. The two part (rather than one) logic model assisted in defining the target group (students, teachers and members of the community). This challenge of grain-size is a known challenge in the use of logic models with application in social sciences. The two (rather than one) logic models also serves to further isolate and refine the dimensions of reporting, compliance and quality assurance depicted previously in Figure 9. The separated portions of the revised Evaluation Planning Matrix further reflect the school improvement funnel-approach described in the Toolkit Elements and characteristics of the alternative high school program evaluation process described in the Evaluation Toolkit Description.

Introduction and protocols. The feedback collected also identified the lack of a clear organizer which led to the development of an introduction section that was later added which described activities and protocols to support leaders in planning a thorough and accurate program evaluation. Educational leaders often lack time for an in-depth analysis and tools must be simple to understand and use. To address the need to train the evaluation leadership team, the researcher went to the extent of developing an entire online course on program evaluation for educators that are referenced further in chapter 5 in discussion of Steps 8-10 of the R\&D Cycle (Operational Field Testing, Final Product Revision, Dissemination and Implementation). 
As discussed previously in the research methods, limitations exist in this research study. One of those limitations is the involvement of the researcher as a facilitator in the use of the Evaluation Toolkit and process for evaluating alternative high schools. It is recognized that the introduction and protocols will need to be improved in future versions of the Toolkit to support external facilitators (other than the researcher) in understanding, using and communicating the Toolkit and evaluation process.

Indicators for school success. Feedback collected indicated that the researchbased indicators at the bottom of the first page of the six tools for evaluation teams also needed work. Some of the indicators were not clear to groups of educational leaders depending on their experience and training in professional learning communities, instructional coaching and knowledge about effective teaching strategies. In some cases it was just language (semantics) and the educators had not heard a more recent term for a practice they had learned about long ago and had been using for years. This is often the case with educational ideas that are resurfaced in cycles of 6 to 10 years as there is teacher-turnover, retirement and new formats of previous ideas. Examples of this include professional learning communities, differentiation, assessment, and various uses of data to inform instruction.

The Evaluation Toolkit terminology, without context or accompanying indicators leaves some ambiguity in the conclusion of performance-level being asked for by the evaluation team participant in filling out the tool. In short, "If you don't know what you are measuring, you will not know how well it is occurring." As previously mentioned, the 
value of the tool is in its simplicity but the tools simplicity caused confusion and frustration among a few who considered the Tools for Evaluation Teams.

Teamwork in program evaluation. Previous sections of this dissertation have discussed the characteristics of the evaluation process used to evaluate alternative high schools, which included the assembly of a team made up of both internal and external stakeholders. Leaders who participated in the focus groups, in depth interviews and initial surveys expressed a value to the team or committee approach used to evaluate alternative high schools. General composition of the teams should be generally aligned with the educational program being evaluated. For example, an alternative high school with a focus on "the arts" should have art and music educators or a school with a focus on manufacturing and apprenticeship should have members of trade organizations in that sector in addition to members of the community, parents, students, teachers and administrators. It was also expressed that team members should be afforded the opportunity to learn and work together in evaluation development.

Time constraints. In addition, participants expressed concern about the lack of adequate time to conduct a thorough and accurate evaluation in just two 2-hour meetings. Some suggested a more thorough audit of school practices, additional student, parent or teacher surveys, and classroom observations as a part of a coordinated site visit. Based on my experience as a program evaluator and school audit facilitator, I would concur that the limitation of time is a challenge but it always is. Comprehensive evaluations generally spend days or even weeks in a setting and use the Standard Element terms described by the Joint Committee on Standards for Educational Evaluation (2011), that may not be 
"feasible." As previously described in this dissertation, the Joint Committee framework also provides professional standards and clear descriptions of utility, propriety, accuracy and accountability as it pertains to conducting a thorough and accurate educational program evaluation.

\section{Step 6: Main Field Testing}

The main field test involved implementation of the new product and collection of data concerning its application and efficacy (Bridges \& Hallinger, 1995, p. 122). The process involved obtaining an evaluation of the effectiveness of the initial product (Borg \& Gall, 1989). Zeeland School District in Oregon was selected as our field site. It had an existing alternative high school, Whyroads School that expressed interest in using our school design and evaluation processes. Zeeland School District is a mid-sized, suburban district representative in demographic composition of many other Oregon school districts. The Zeeland School District superintendent understood and hoped that going through the design process would clarify the vision and purpose of Whyland School. It also increased communication between central office, the traditional high school and Whyroads leadership and staff. Finally, it fulfilled the requirement of an annual evaluation required by law.

Initial meetings resulted in the development of a Scope of Work (Appendix A) that further described the goals, tasks, deliverables and intended outcomes of the evaluation process with a team of internal and external stakeholders that include staff from both Zeeland and Whyroads. Under the leadership of the Zeeland School District 
superintendent and central office Student Services Director, a design team for Whyroads alternative school was identified for the main field testing of the Evaluation Toolkit.

Development of the design and evaluation plan for Whyland School was the result of a series of five 2-hour meetings held in collaboration with myself, Mr. Edwards, staff from the Zeeland School District and external team members representing the parents of Whyland School. The first two meetings were led by Mr. Edwards and devoted to the design process, and the third and fourth meetings were led by me and used to develop an evaluation plan. The fifth meeting was used jointly by both Mr. Edwards and me to conclude this application of our design and evaluation processes and to collect final focus group and survey research data from the team.

The first team meeting was used to create a common vocabulary (lexicon) that would be useful in future discussions among design and evaluation team members with different backgrounds. The second session of the Design Leadership Team was conducted two weeks after the first session and subsequent meetings were within a few weeks of each other. The second session was used to create a shared district vision for Whyroads School, based on knowledge gained by team members during the first session. That revised vision, mission and goals were incorporated into the sample evaluation planning worksheet (Appendix A) and were used as the basis for the evaluation process. I facilitated sessions three (evaluation training) and four (evaluation planning) to field test the Evaluation Toolkit and further develop characteristics the alternative high school evaluation process. Agendas, annotated agendas, handouts and presentation slides are 
included in Appendix A and these tools references are all considered part of the Evaluation Toolkit for implementation.

During those sessions the team learned about elements of effective alternative schools, accreditation standards, the dimensions (reporting, compliance and quality assurance) participated in training on Evaluation Toolkit elements and characteristics of effective program evaluation (Yarbrough et al., 2011). During the time between sessions three and four, the Whyroads school principal worked with Mr. Edwards to draft a program description that was presented to the design team at the conclusion of session four. Also between meetings, I worked with the evening coordinator, teacher and the school principal to apply the use of the Tools for Evaluation Teams that was previously presented to the evaluation team. The principal developed several additional documents, data sets and graphics to present to the evaluation team that offered information for team discussion and consideration as the evaluation planning. Table 29 reports the attendance pattern of the evaluation team in the main field test meetings.

The Facilitator-Researcher (Evaluation Consultant) is me and the FacilitatorResearcher (Design Consultant) was Mr. Edwards. As facilitators, we were careful not to participate in the discussion or respond to our own research survey. As noted in the table, two minority students provided support to the evaluation team by answering questions but did not submit survey responses. As described in chapter 3, a method of data triangulation is being used to validate and address some of the issues of bias in the study. A survey was conducted of design and evaluation team (8 members) who participated in the main field test (Step 6). The data and results are explained below and are woven into 
responses to the issue of the Toolkit's efficacy in this chapter. The leadership team was critical to the success of the evaluation process and members of the Leadership Team their role and attendance at the each of the five meetings is described Table 29.

Table 29:

Participants, Roles and Meeting Attendance

\begin{tabular}{|c|c|c|c|c|c|c|c|}
\hline & \multirow[b]{2}{*}{ Description } & \multirow[b]{2}{*}{ Role } & \multicolumn{5}{|c|}{ Meetings } \\
\hline & & & \#1 & \#2 & \#3 & \#4 & \#5 \\
\hline 1. & $\begin{array}{l}\text { Facilitator- } \\
\text { Researcher }\end{array}$ & Evaluation Consultant & $\mathrm{X}$ & $\mathrm{X}$ & $\mathrm{X}$ & $\mathrm{X}$ & $\mathrm{X}$ \\
\hline 2. & $\begin{array}{l}\text { Facilitator- } \\
\text { Researcher }\end{array}$ & Design Consultant & $\mathrm{X}$ & $\mathrm{X}$ & $\mathrm{X}$ & $\mathrm{X}$ & $\mathrm{X}$ \\
\hline 3. & $\begin{array}{l}\text { Alternative School } \\
\text { Principal }\end{array}$ & $\begin{array}{l}\text { Whyroads Alternative School } \\
\text { Principal }\end{array}$ & $\mathrm{X}$ & $\mathrm{X}$ & $\mathrm{X}$ & $\mathrm{X}$ & $\mathrm{X}$ \\
\hline 4. & Superintendent & $\begin{array}{l}\text { Zeeland School District } \\
\text { Superintendent }\end{array}$ & $\mathrm{X}$ & $\mathrm{X}$ & $\mathrm{X}$ & $\mathrm{X}$ & $\mathrm{X}$ \\
\hline 5. & Administrator & $\begin{array}{l}\text { Zeeland District Curriculum and } \\
\text { Assessment Director }\end{array}$ & $\mathrm{X}$ & $\mathrm{X}$ & & $\mathrm{X}$ & \\
\hline 6. & Director & $\begin{array}{l}\text { Zeeland District Student Services } \\
\text { Director }\end{array}$ & $\mathrm{X}$ & $\mathrm{X}$ & $\mathrm{X}$ & $\mathrm{X}$ & $\mathrm{X}$ \\
\hline & Principal & $\begin{array}{l}\text { Zeeland Traditional High School } \\
\text { Principal }\end{array}$ & $\mathrm{X}$ & $\mathrm{X}$ & & $\mathrm{X}$ & $\mathrm{X}$ \\
\hline 8. & Teacher & Teacher (Leadership Team) & $\mathrm{X}$ & $\mathrm{X}$ & $\mathrm{X}$ & $\mathrm{X}$ & $\mathrm{X}$ \\
\hline & Teacher & $\begin{array}{l}\text { Teacher (Evening Program } \\
\text { Coordinator) }\end{array}$ & $X$ & $\mathrm{X}$ & $X$ & $X$ & $X$ \\
\hline 10. & Principal & $\begin{array}{l}\text { Other Alternative High School } \\
\text { Principal }\end{array}$ & $\mathrm{X}$ & $\mathrm{X}$ & $\mathrm{X}$ & $\mathrm{X}$ & $\mathrm{X}$ \\
\hline & Parent & Parent/Community Member & $\mathrm{X}$ & $\mathrm{X}$ & $\mathrm{X}$ & & \\
\hline 12. & Parent & Parent/Community Member & $\mathrm{X}$ & $\mathrm{X}$ & $\mathrm{X}$ & & \\
\hline & Student & $\begin{array}{l}\text { Whyroads Academy Program } \\
\text { Student (Hispanic Male) }\end{array}$ & & $\mathrm{X}$ & $\mathrm{X}$ & & \\
\hline 14. & Student & $\begin{array}{l}\text { Whyroads Option Program Student } \\
\text { (Asian Female) }\end{array}$ & & $\mathrm{X}$ & $\mathrm{X}$ & & \\
\hline
\end{tabular}


Online survey of design and evaluation team from the main field test. The survey (Appendix G) was developed as a part of the R\&D Cycle and given to the evaluation team in Zeeland School District at the conclusion of the design and evaluation process. The prototype print version of the survey that was used in planning objectives, learning activities, and small-scale testing (Step 2) is also included in Appendix H. Demographic data is summarized and only relevant questions are reported in this analysis. As described in chapter 3, a naturalistic qualitative examination of the data and text was used to analyze data. Survey questions 1 to 10 provide important background (demographic) information of participants and the environments they work and this this information is summarized later to understand the makeup of the evaluation team who experienced the process in Zeeland at Whyroads School.

Questions 11, 12 and 13 are simple yes or no answers which most importantly are asking for textual responses. Question 21 is a Likert type 4-point scale measuring "How essential" a series of statements are to program evaluation. A section is also provided for respondent comments. The 4-point scale used a 1 to indicate a statement is "not essential" or there is no support for the provided statements. The 4-point scale use a 4 to indicate a statement is "Absolutely Essential."

Questions 22 focused on providing necessary feedback (ratings) on the level of importance of the Evaluation Process statements. Participants were asked to rank order the 10 Evaluation Process statements with 1 being most important and 10 being less important. Question 23 asked participants to comment on the Evaluation Toolkit. Participants were asked to rank order the seven (7) Evaluation Toolkit "elements" with 1 
being most important and 10 being less important. For graphic display the ranked characteristics were given numeric values of 1 to 10 (or 7) corresponding with the rank placement. So the number one ranked characteristic of most import was given a value of 1 , second rank value a 2, through the seventh or tenth rank which was given a value of 7 or 10. By adding the numeric values in a given "row" and dividing by the total $\mathrm{n}$, an average number is displayed. Thus in the visual display the lower bar on the graph is the first and most important characteristic.

Summary of survey participant information. A survey was given to the evaluation team at the conclusion of the design and evaluation process in Zeeland School District. The following survey data findings and quotations were collected from the evaluation planning team that met over the course of 4 months during the main field testing period. The makeup of the evaluation team and their respective roles on the evaluation team are described previously in this section and a table is included that reflects their attendance at the design and evaluation meetings.

At the conclusion of the fifth of five 2-hour sessions on designing and evaluating alternatives to traditional high schools team members were surveyed to collect data regarding the process. Eight of $10(80 \%)$ team members were present for the fifth meeting. As noted later in the analysis, Mr. Edwards and I, as researcher-facilitators and participants did not participate in the survey. The two students who participated briefly in the sessions were not included in the pool of 10 potential survey participants.

Unfortunately, the two parent team members were unable to attend the fifth session, during which the survey was conducted. Effort was made to request their 
participation in the survey remotely but after several weeks with no response the effort was abandoned so the data could be analyzed and reported on. During the first hour of the fifth session the design and evaluation processes were reviewed, followed by an hour for the team members present to complete the survey. An internet-based online survey tool called Survey Monkey was used to administer the survey and collect quantitative and qualitative data and was later exported to a format that could be opened in spreadsheets and other statistical analysis software.

Among the eight design team members who responded to the survey:

- All (100\%) were from the Portland Metro-Area

- All (100\%) were professionally involved with high schools (Grades 9-12)

- All (100\%) were experienced with small schools (enrollment approx. 150)

- All $(100 \%)$ were experienced with schools housed in their own building

- All (100\%) were experienced in working with small teaching staffs (10-15 FTE)

- All $(100 \%)$ were familiar with alternative and traditional school environments

- Two were teachers, two alternative high school principals, two central office directors, one a traditional high school principal, and one was a superintendent

- All eight had a combined total of 119 years of administrative experience

- Six of eight (75\%) held administrative licenses

- Six of eight (75\%) had had some prior participation in a design process leading to a vision statement and program description

Note: All participants did not participate in every research question or item so the tables below the data are provided that reflect the "Response Count" of 8 or less survey participants for research questions and results of the survey taken at the conclusion of the main field testing. In the case where there are no tables, all participants (8) responded. 
Participant responses were all collected within the Portland Metro-Area which consists of a three county urban region which houses approximately $70 \%$ of the State of Oregon's total student population. All but one of the survey participants was affiliated (internal stakeholders) at Zeeland School District and more than half worked at Whyroads Alternative High School.

Participants indicate that grades 6 through beyond grade 12 are involved in current alternative programs. Grade 12 consists of students 19 and over who did not graduate with their class within 4 years. $100 \%$ of respondents indicated grade 8-12 are taught at their alternative school, reflecting the middle school program at Whyroads.

With the urban district involved participants indicate that student enrollment numbers in alternative programs is 150 to 165 students. Total enrollment was one of the issues that the central office had questions about along with the number of full time and part time students being reported in attendance and claimed for average daily membership (ADM) from ODE.

Participants indicate that alternative programs are placed in their own buildings, rather than a room or facility shared with the traditional high school. This question has to do with school autonomy. Schools with a separate building are more likely to have characteristics of a comprehensive school such as their own administrator, office staff, curriculum, library, and institution number for separate accounting and purposes relating to school accountability in comparison with traditional high schools.

Participants indicated estimate of 10-15 full-time equivalent (FTE) facility. There was disagreement between the traditional and alternative high school principal on class 
size and the determination of need for FTE positions at Whyroads in Comparison to Zeeland School District where they needed to cut positions and reduce FTE. In response to questions surfaced by the Zeeland High School and central office questions about how FTE, the Whyroads Principal developed a spreadsheet and graphic that generally described the population and class sizes in the various programs at Whyroads. It was generally agreed upon and noted in my field journal that enrollment and staffing information should have been a part of a comprehensive needs assessment and considered in the evaluation training to provide context to the Alternative Accountability Metrics presented (included in Appendix A).

Participants indicated the school is alternative rather than other types of schools. This survey item indicates that at the conclusion of the design and evaluation process all participants know and understand that they are considered a public alternative school. There were a few on the team that did not fully understand the differences between these types of schools at the beginning and 8 out of 8 now know what they are.

I have had hundreds of phone conversations and presented in front of hundreds of alternative school leaders that did not know their school type. As previously discussed in this analysis, it has been my experience that a school with a strong vision (knows who it is and the students it serves) is more likely to benefit from program evaluation (knows where it is going).

Participants indicate a variety of titles and roles. This survey question demonstrates that the evaluation team is almost entirely internal stakeholders. Despite Mr. Edwards and my best efforts and the efforts of the alternative school principal to 
recruit parents and community members to participation, we were left with the people, for the most part, that were "being paid to be there" (employed by the district or Regional Education Service District). As discussed earlier in this analysis, additional methods were used to increase student, parent, and teacher participation in the future with reliable tools such as student, parent and teacher surveys and classroom observation tools.

Participants indicated they have a considerable number of years (119) involved as school leaders (administrator or teacher leader) in any settings. The design and evaluation team that participated in the evaluation process at Whyroads was a very experienced group of individuals, knowledgeable and thoughtful about the practices and strategies being used at the school. Participants also indicated they have a considerable number of years involved as school leaders (75) in alternative educations settings. It was also my observation during site visits and through the review of their staff roster that the entire staff at Whyroads is very experienced and many have decades of experience working with students at risk of not graduating on time with their peers. Table 30 and Figure 11 describe the results of the survey question that followed questions about general demographic participant information and their experience using the Toolkit. 
Table 30:

Survey Data Table Question 12

\begin{tabular}{|l|c|c|}
\hline $\begin{array}{l}\text { Question 12: Have you participated in a School Evaluation Process that resulted in the } \\
\text { development of an evaluation plan using the Alternative School Evaluation Toolkit? }\end{array}$ \\
\hline Answer Options & $\begin{array}{c}\text { Response } \\
\text { Percentage }\end{array}$ & $\begin{array}{c}\text { Response } \\
\text { Count }\end{array}$ \\
\hline Yes & $75.0 \%$ & 6 \\
No & $25.0 \%$ & 2 \\
\hline If yes, please briefly describe the school's evaluation plan: \\
\hline Response Text: If yes, please briefly describe the school's evaluation plan: \\
\hline A six-category tool, using multiple stakeholders as links through which to assess the school's \\
successes. \\
Part of the district process. \\
Looked at components of a quality evaluation, program components (curriculum, leadership, \\
etc.)
\end{tabular}

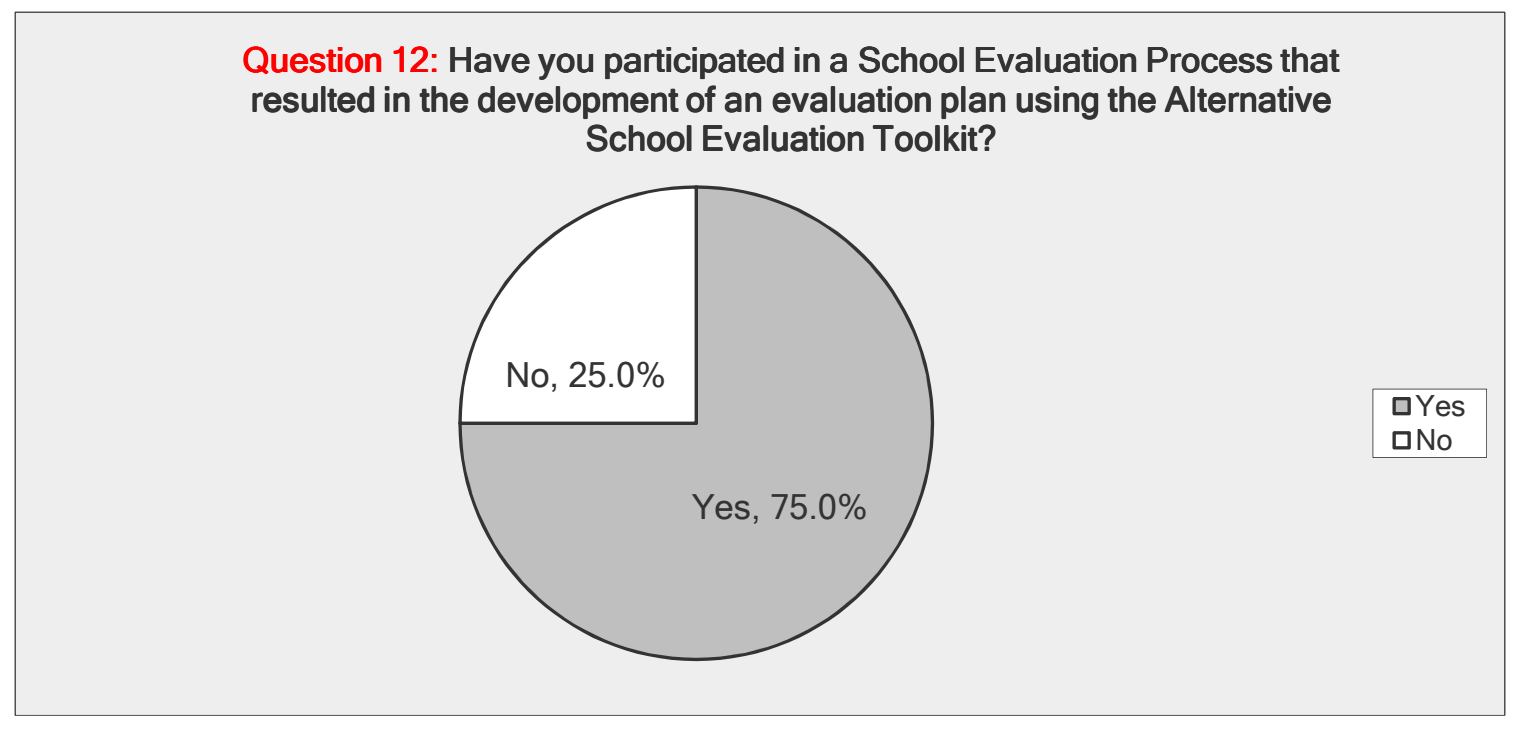

Figure 11. Survey Data Figure Question 12 (Participation in Evaluation Process).

Assumptions about Alternative School Program Evaluation. Evaluation team

Participants indicated that 75\% (6) had participated in the School Evaluation Process using the Toolkit. One person was absent and one did not respond to this survey question. Survey questions 13-20 pertain only to the School Design process facilitated by Mr. 
Edwards and will not be analyzed in this dissertation. Question 21 collected data from participants regarding their reflections about formative program evaluation that "begins with the end in mind" and are analyzed in this chapter. One survey participant said, "A six-category tool, using multiple stakeholders as links through which to assess the school's success." Another participant said, "Part of the district process." Another participant said, "Looked at components of quality evaluation, program components (curriculum, leadership etc.).”

Beginning with the end in mind implies that those who work with the school would know and understand how improvement will be formatively (continuously) measured. Overall the assumptions were validated and the data and statements made by the evaluators indicated that the characteristics presented in the assumptions should be considered for including in the Toolkit where possible. Table 31 and Figure 12 report on data from the Likert scale survey items where participants were asked to respond to assumptions about alternative school program evaluation. Figure 12 reports that members of the Evaluation Leadership Team believed that all eight of my assumptions about program evaluation that begins with the end in mind were either moderately or absolutely essential. Seven of the eight assumptions resulted in the majority of the Leadership Team responding that the item was absolutely essential. Results from item a (planning for a program evaluation from the beginning of the design process with the full development of the new school in mind) were consistent with other information gathered throughout the study and reflects the teams resistance to disregard the existing school and "start over" in the design process. 
Table 31:

Survey Data Table Question 21

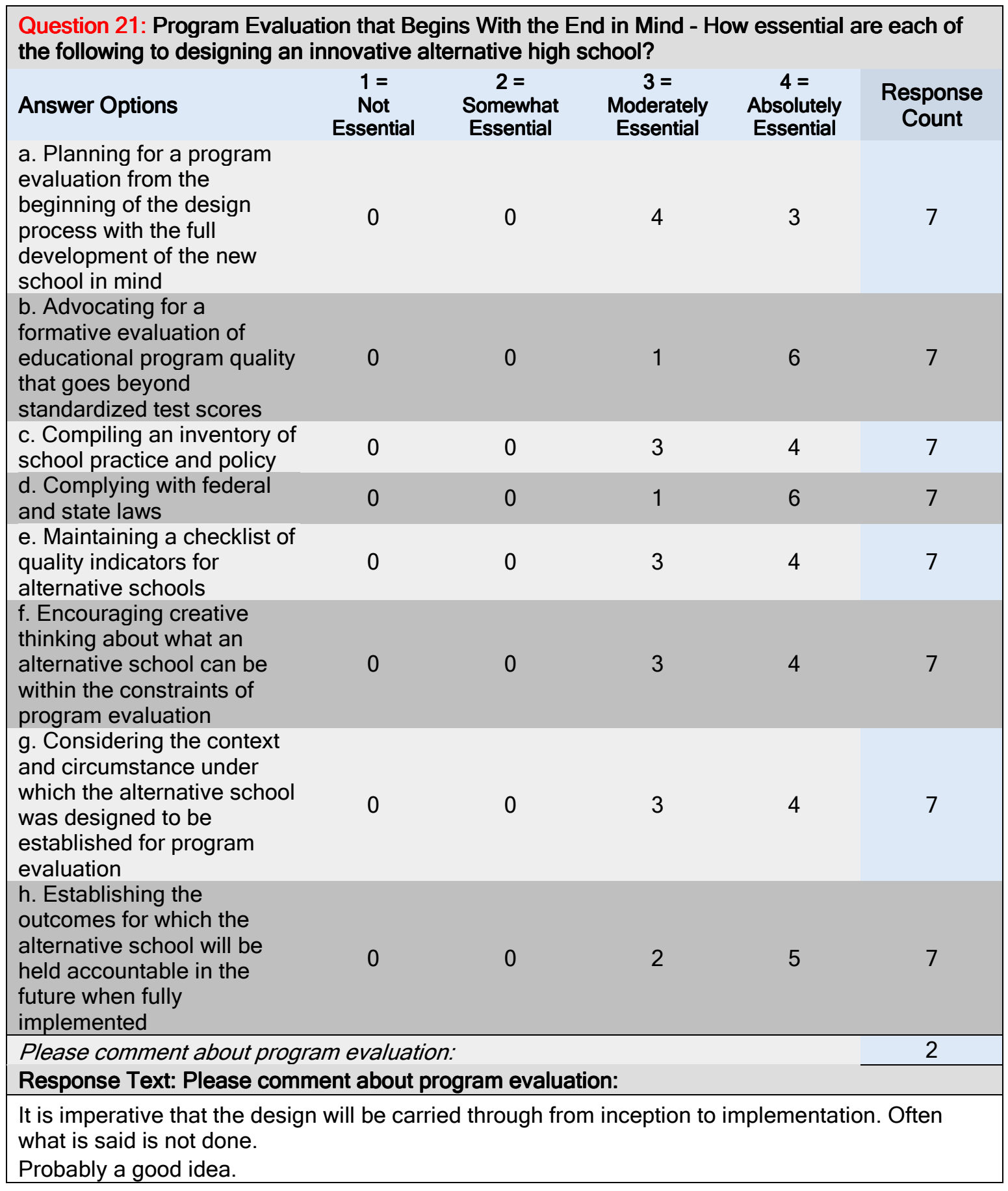




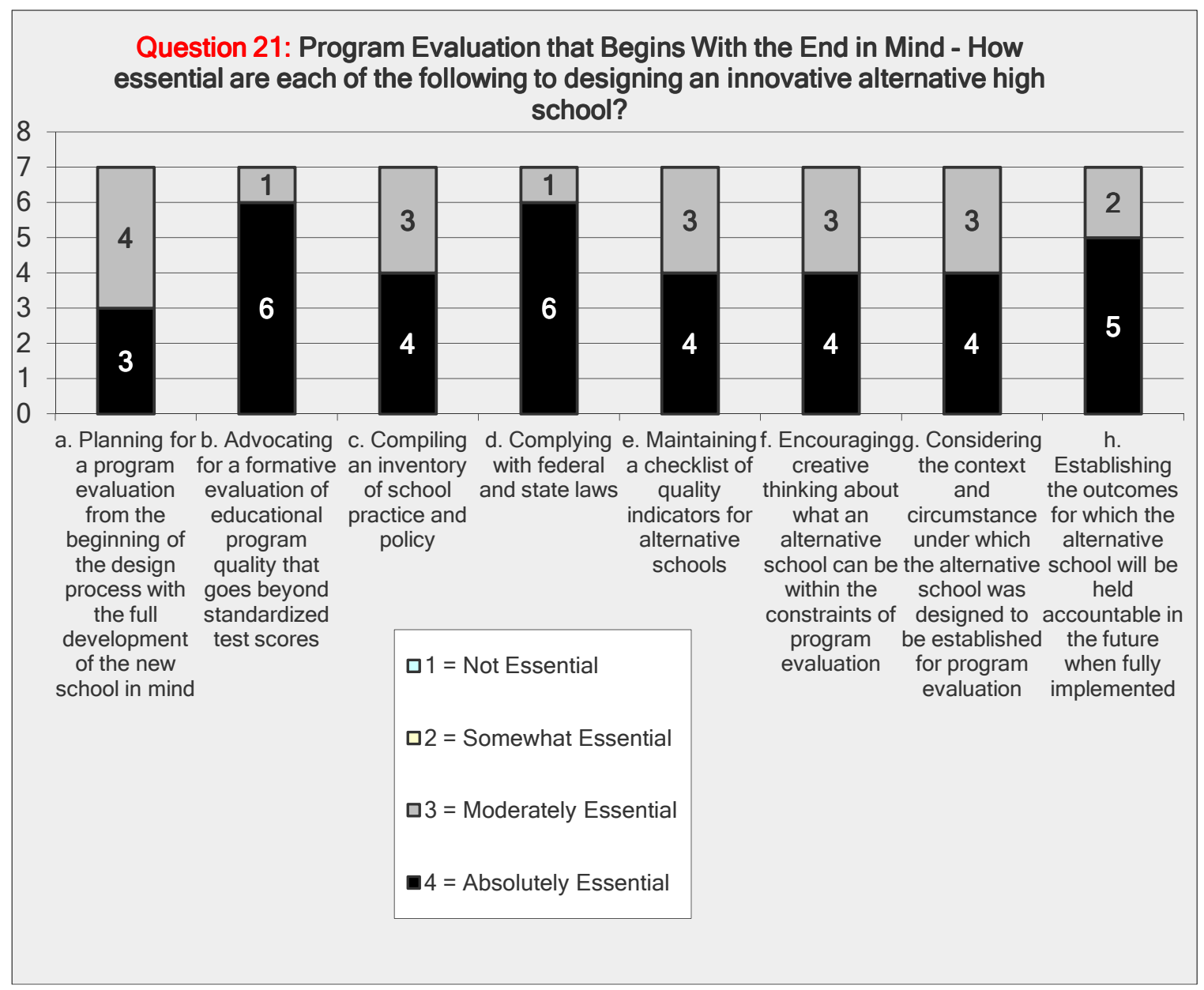

Figure 12. Survey Data Figure Question 21 (Assumptions About Evaluation Process).

Six of seven participants identified criteria (b.) and (d.) as "Absolutely Essential" to designing an innovative alternative school program. One of seven identified criteria (b.) and (d.) as "Moderately Essential." Combining the scores indicates that (b.) and (d.) are of most essential criteria on the list. Five of seven participants identified criterion (h.) as "Absolutely Essential" to designing an alternative school program.

Two of seven identified criterion (h.) as "Moderately Essential. Combining the scores indicates that (h.) is the third most essential criterion on the list. Four of seven participants identified criterion (c., e., f., and g.) as "Absolutely Essential" to designing 
an innovative alternative school program. Three of seven identified criteria (c., e., f., and g.) as "Moderately Essential. Combining the scores indicates that (c., e., f., and g.) are essential criteria. Three of seven participants identified criteria (a.) as "Absolutely Essential" to designing an innovative alternative school program. Four of seven identified criterion (a.) as "Moderately Essential. Combining the scores indicates that (a.) is a less then "Absolutely Essential" criterion.

Survey participants scored this section between moderately and absolutely essential, indicating agreement with the assumption, made by Mr. Edwards and me that consideration of program evaluation throughout the design process is probably important. Survey participants reported, "It is imperative that the design will be carried through from inception to implementation. Often what is said is not done." Another participant responded, "Probably a good idea." These comments are in agreement with the overall score as well. The second comment suggests congruence with the evaluation plan, as it was developed during the alternative high school design and evaluation planning processes with the support of sample design guides and the Evaluation Toolkit.

Ranking the Evaluation Process Characteristics. As discussed previously, the concept of beginning with the end in mind resonated with members of the team when $\mathrm{Mr}$. Edwards and I shared with them information about the design and evaluation process and the item was ranked first among other items listed. Most of the survey participants were administrators and on multiple planning and budget committees so the concept of planning ahead likely resonated with them in the process of evaluating alternative high schools. There is a lot of work being done in the area of accountability (alternative 
accountability) and it's generally accepted that most alternative schools should not be compared with large traditional high schools. However, I wonder if that is an area that needs reconsideration because the Joint Committee on Standards and Educational Evaluation defines accountability as contextualized and produces value, which is not the same way NCLB and AYP define the term. Table 32 reports the data from the evaluation team and their reflections on the Evaluation Process Characteristics.

For graphic display the ranked characteristics were given numeric values of 1 to 10 corresponding with the rank placement. Accordingly, the number one ranked characteristic was given a value of 1 , second rank value a 2 , through the tenth rank which was given a value of 10. As respondents selected a characteristic's order all corresponding numeric values were added. For example, characteristic one was selected as first by three respondents, third by 1,5 th by 1,7 th by 1 and 8 th by 1 . Correspondingly, the values added were, $1+1+1+3+5+7+8=26$. By adding the numeric values in a given "rows" and dividing by the total n, an average number is displayed, $26 / 7=3.714$ (note: The electronic system automatically rounded to 3.7). Thus on the visual display the lower bar on the graph is the first and could be described as the most important characteristic. 
Table 32:

Survey Data Table Question 22

\begin{tabular}{|c|c|c|c|c|c|c|c|c|c|c|c|c|}
\hline \multicolumn{13}{|c|}{ Question 22: Ranking the Characteristics of the Alternative High School Evaluation Process } \\
\hline Answer Options & 1 & 2 & 3 & 4 & 5 & 6 & 7 & 8 & 9 & 10 & $\begin{array}{c}\text { Rating } \\
\text { Average }\end{array}$ & $\begin{array}{c}\text { Response } \\
\text { Count }\end{array}$ \\
\hline $\begin{array}{l}\text { begins with the end in } \\
\text { mind. }\end{array}$ & 3 & 0 & 1 & 0 & 1 & 0 & 1 & 1 & 0 & 0 & 3.7 & 7 \\
\hline $\begin{array}{l}\text { is contextualized and } \\
\text { produces value } \\
\text { (accountable). }\end{array}$ & 2 & 1 & 0 & 1 & 0 & 2 & 1 & 0 & 0 & 0 & 3.9 & 7 \\
\hline $\begin{array}{l}\text { is practical or realistic } \\
\text { (feasible). }\end{array}$ & 1 & 0 & 2 & 1 & 1 & 1 & 1 & 0 & 0 & 0 & 4.1 & 7 \\
\hline $\begin{array}{l}\text { accurately conveys } \\
\text { analysis (accuracy). }\end{array}$ & 0 & 3 & 1 & 1 & 0 & 0 & 0 & 0 & 0 & 2 & 4.7 & 7 \\
\hline $\begin{array}{l}\text { is generally useful } \\
\text { (utility). }\end{array}$ & 0 & 0 & 2 & 1 & 1 & 0 & 1 & 1 & 1 & 0 & 5.6 & 7 \\
\hline $\begin{array}{l}\text { considers established } \\
\text { school vision, mission } \\
\text { or goals (program } \\
\text { description). }\end{array}$ & 0 & 2 & 0 & 1 & 0 & 0 & 1 & 2 & 1 & 0 & 5.7 & 7 \\
\hline $\begin{array}{l}\text { involves internal and } \\
\text { external stakeholders. }\end{array}$ & 1 & 0 & 1 & 0 & 1 & 0 & 2 & 0 & 2 & 0 & 5.9 & 7 \\
\hline $\begin{array}{l}\text { is proper or fair } \\
\text { (propriety). }\end{array}$ & 0 & 0 & 0 & 1 & 1 & 2 & 0 & 1 & 1 & 1 & 6.9 & 7 \\
\hline $\begin{array}{l}\text { uses a mix of both } \\
\text { formative } \\
\text { (informative) and } \\
\text { summative } \\
\text { (summary) } \\
\text { approaches. }\end{array}$ & 0 & 0 & 0 & 1 & 0 & 2 & 0 & 2 & 2 & 0 & 7.1 & 7 \\
\hline $\begin{array}{l}\text { supports the } \\
\text { formation of an } \\
\text { evaluation team. }\end{array}$ & 0 & 1 & 0 & 0 & 2 & 0 & 0 & 0 & 0 & 4 & 7.4 & 7 \\
\hline \multirow{2}{*}{\multicolumn{12}{|c|}{$\begin{array}{l}\text { answered question } \\
\text { skipped question }\end{array}$}} & 7 \\
\hline & & & & & & & & & & & & 1 \\
\hline \multicolumn{13}{|c|}{$\begin{array}{l}\text { Is there a way to make sure or check-in on what has been done with the recommendations } \\
\text { from the evaluation? } \\
\text { Good to look at a variety of criteria as well as components. }\end{array}$} \\
\hline
\end{tabular}

Ranking questions in the electronic system used to collect the survey data (Survey Monkey) are automatically calculated and reported in the manor reported above in Table 42, however, in an effort to be accurate in reporting, the researcher has also chosen to 
report the "ranking of ranks" which is a statistical calculation that more accurately reflects the collected data in the items from question 22 (see Figure 13).

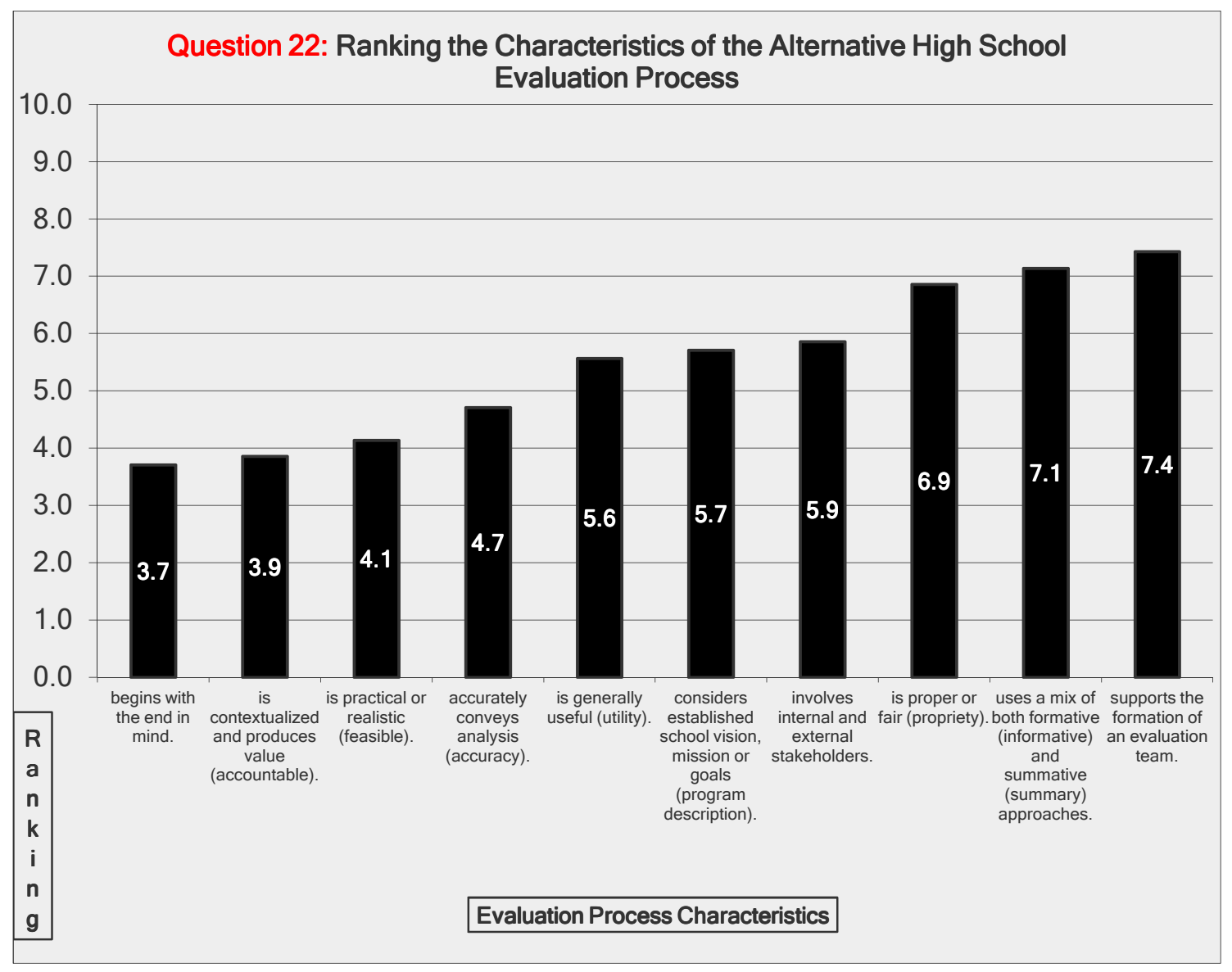

Figure 13. Survey Data Figure Question 22 (Ranking of Process Characteristics).

I was surprised that the item "uses a mix of both formative (informative) and summative (summary) approaches" did not end up with a higher value among main field test participants and this may be an area where the team needs additional training. Table 33 reports the data from the evaluation team and their reflections on the Evaluation Process Characteristics in rank order based on average ranking method. 
Table 33:

Characteristics in Rank-Order Based on Average Ranking Method

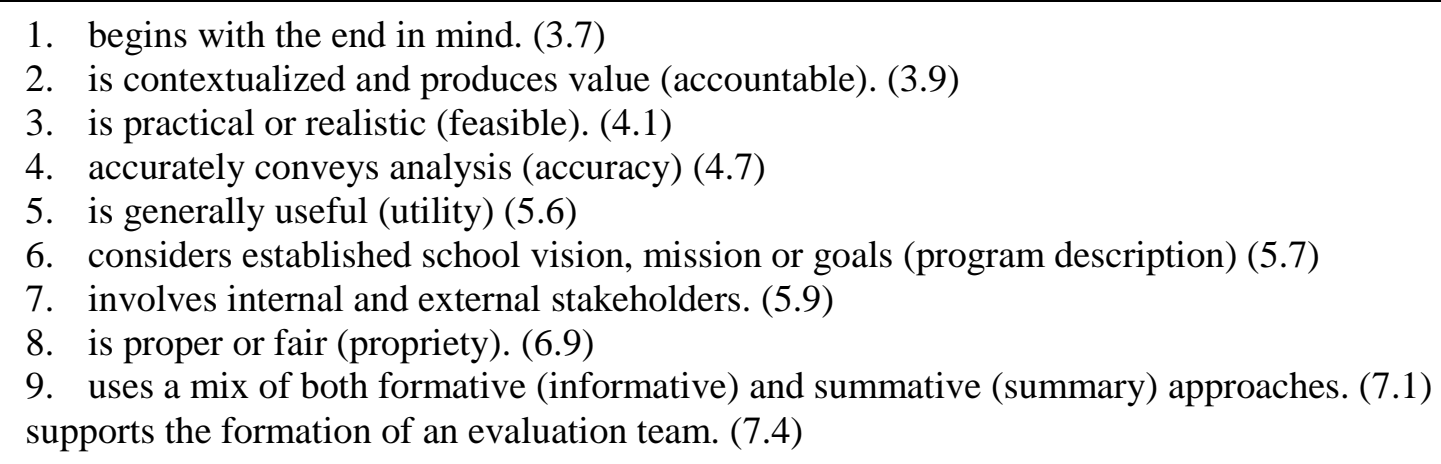

Table 33 reports rearranged item descriptions in ascending order of "rating average" to report how the sample of 7 participants valued each item. While all of the 10 Characteristics are important to the Evaluation Process, I now have an idea of which of the items the sample group considered important. For example, one of the premises of all five meetings was that the design team work to develop a program guide to develop an understanding (context) of the school and begin with the end in mind (S. R. Covey, 2004, p. 97). Participants' high ranking of "produces value (accountable)" also did not surprise me because the basis for my research problem is that most educational leaders understand alternative schools should not be held accountable based on comparison with traditional schools.

One participant asked, "Is there a way to make sure or check-in on what has been done with the recommendations from the evaluation?" Another reported, "Good to look at a variety of criteria as well as components." Both these comments reflect the evaluation teams new learning about the importance of formative (ongoing) evaluation. 
The Toolkit was designed to support an evaluation team in conducting a thorough and accurate evaluation however I did not account for the need for district to continually check-in with the school to assure progress has been made. To be honest, I assumed that would be common practice but it may not be. The Toolkit may demonstrate efficacy and adequately support the evaluation team for the five meetings but does not appear to adequately support the intentional planning of future meetings of the team (other than indirectly through the Evaluation Planning Matrix and Evaluation Plan).

This means that at the close of the final evaluation team meeting there should be meeting dates established to check-in with those responsible for the information included in the evaluation. While it appears that this is a good idea I'm not sure how to operationalize it within the Toolkit Elements or Process. It is clear that if a more formative (ongoing) evaluation is the goal then the evaluation plan produced should include dates to follow-up on what was agreed upon as a team. This could mean that operationalizing the process would mean a more contextualized approach to follow-up.

Table 34 reports the data from the evaluation team and their reflections on the Evaluation Process Characteristics in rank order based on mean rank of rank method (same data with a different calculation method). The smaller number means higher importance (value). There are statistical advantages of using ranking items such as those presented in question 22 and 23 , such as the contextual comparison with other items in the list and the ability to compare each participant's reported ranking with others who ranked the items. One survey participant asked, "Is there a way to make sure or check-in on what has been done with the recommendations from the evaluation?" Another 
participant said, "Good to look at a variety of criteria as well as components." It is generally accepted and even reflected by written comments made in the survey that is difficult for participants to rank items (characteristics) that are interrelated. All the characteristics listed are considered to be important and a rank item question asks the participant to consider their perceived value in the ranking of each item. For this reason the data has also been reported in a format that reflects ranking of ranks (Table 34).

Table 34:

Characteristics in Rank-Order Based on Mean Rank of Rank Method

\begin{tabular}{|rc|}
\hline Characteristics of the Evaluation Process & Mean Rank of Rank \\
\hline Begin with end in mind & 23 \\
Contextualized, produces value: Accountable & 24 \\
Practical, realistic: Feasible & 26 \\
Accurately conveys analysis: Accuracy & 30 \\
Generally useful: Utility & 36 \\
Considers established school vision, mission, goals & 37 \\
Involves internal, external stakeholders & 38 \\
Proper, fair: Propriety & 45 \\
Uses mix of formative and summative evaluation & 47 \\
Supports formation of evaluation team & 49 \\
\hline
\end{tabular}

Ranking items such as Question 22 should not be simply averaged in order to generate a summation of the description. A statistical procedure (Sharp, 1979) was used to produce a value of each item in comparison with others in the list for participants that responded. The more accurate data is presented in Table 34 (rather than Table 33). The above table gives a true (mean rank of rank) because there are "ranks of ranks," but there are not "average ranks."

Context and lessons learned. A tremendous amount of study and experience contributed toward the research and information collecting (Step 1) and learning 
activities (Step 2) that resulted in the development of a preliminary form of the product (Step 3) and initial set of Process Characteristics. As a part of further development I had recorded my thoughts on tools and process in my field journal. This separation between the tools used and the professional competencies I was developing in experiences as a program evaluator helped distinguish Toolkit Elements from the Evaluation Process Characteristics. Upon further research study I ran across the Standard Elements (Yarbrough et al., 2011) which helped me collapse my longer list to the list of 10 items that remain on this survey and as a part of the primary and secondary research questions in this study. The result from Step 1-3 in the R\&D (Borg \& Gall, 1989) were formalized planning and field testing objectives (and Characteristics) that participants valued as reported previously in this chapter.

At the time I was working through my comprehensive exams and in an effort to decrease my own procrastination re-read "Seven Habits of Highly Effective People" and noted the phrase "begin with the end in mind" (Covey, 2004, p. 97) in my field journal. There in my journal I had 15 other characteristics recorded on the list and I added "begins with the end in mind" which later was narrowed to 10. During conversations with Mr. Edwards I described what I was learning and suggested that it be applied to our collaborative research in the South Coast. It was combined with another one of our assumptions that a school needed to know who it was before we could make recommendations about how it could determine success (considers established school vision, mission and goals). I had recently heard leading program evaluation researcher, Michael Patton speak in Portland at an OPEN event which is where the "formation of an 
evaluation team" and "involves internal and external stakeholders" came from. Together with the Standard Elements it was a list that encompassed most of what I knew to be effective program evaluation Characteristics.

The survey ranking completed by evaluation team participants indicated that "begin with the end in mind" resonated with them in comparison with the other Characteristics ranked. Second ranked was "Contextualized, produces value: Accountable), which was not a surprise for me because Zeeland had expressed a particular interest in participating in the research study. In my role at ODE, just over a year ago I received a call from the Whyroads Principal asking about how they were going to be held accountable under the proposed changes in Oregon education al policy. The principal was asking to be held accountable in a process that would produce value in a period of leadership transition at Whyroads. Ranked last was "Supports formation of an evaluation team" and based upon data and reflections during the focus group that the team was already established when the processes started leaving it with little value.

Overall, the exercise of ranking presented significant challenge to the evaluation team because as several of participants noted in the survey, the Toolkit Elements are interconnected and all perceived to be valuable in supporting the evaluation team in planning and carrying out a thorough and accurate program evaluation. Table 35 presents information from evaluation team participants with regard to their ranking of seven Elements of the Evaluation Toolkit. Figure 14 describes the Elements across the bottom (x-axis) and the combined rank on the left side (y-axis). The Toolkit Elements in the Table and Figure have been ordered from lowest rank to highest rank for graphic display. 
Table 35:

Survey Data Table Question 23

\begin{tabular}{|c|c|c|c|c|c|c|c|c|c|}
\hline \multicolumn{10}{|c|}{ Question 23: Ranking the Elements of the Alternative High School Evaluation Toolkit } \\
\hline Answer Options & 1 & 2 & 3 & 4 & 5 & 6 & 7 & $\begin{array}{c}\text { Rating } \\
\text { Average }\end{array}$ & $\begin{array}{c}\text { Response } \\
\text { Count }\end{array}$ \\
\hline $\begin{array}{l}\text { Evaluation training, learning and } \\
\text { planning activities (data collection, } \\
\text { information gathering, reflection, } \\
\text { reporting etc.) that support the } \\
\text { evaluation team in using the Toolkit. }\end{array}$ & 2 & 2 & 0 & 2 & 1 & 0 & 0 & 2.7 & 7 \\
\hline $\begin{array}{l}\text { Evaluation Planning Worksheet that } \\
\text { supports communication of the } \\
\text { evaluation purpose, timeline, activities } \\
\text { and an explanation of how the results } \\
\text { will be used. }\end{array}$ & 1 & 1 & 2 & 2 & 1 & 0 & 0 & 3.1 & 7 \\
\hline $\begin{array}{l}\text { Protocols that support a facilitator in } \\
\text { involving a team of internal and } \\
\text { external stakeholders. }\end{array}$ & 1 & 0 & 2 & 3 & 0 & 0 & 1 & 3.7 & 7 \\
\hline $\begin{array}{l}\text { Tools for Evaluation Teams } \\
\text { (assessment, curriculum, } \\
\text { engagement, instruction, leadership } \\
\text { and structures) that support those at } \\
\text { the school in learning from their } \\
\text { success, identifying current } \\
\text { challenges, planning for improvement } \\
\text { and more effectively telling their story. }\end{array}$ & 0 & 2 & 2 & 0 & 2 & 1 & 0 & 3.7 & 7 \\
\hline $\begin{array}{l}\text { Evaluation Planning Matrix and } \\
\text { Planning Tool (simplified logic model) } \\
\text { that supports the facilitator and } \\
\text { members of the team in developing } \\
\text { and communicating an evaluation } \\
\text { plan. }\end{array}$ & 2 & 0 & 1 & 0 & 0 & 0 & 4 & 4.7 & 7 \\
\hline $\begin{array}{l}\text { School Progress Indicators Section of } \\
\text { the Tools for Evaluation Teams that } \\
\text { provide an opportunity for the } \\
\text { evaluation team to come to } \\
\text { consensus on what is meant by } \\
\text { "Exemplary", "Effective" and "In Need } \\
\text { of Improvement" as they make use of } \\
\text { the Tools for Assessment, Curriculum, } \\
\text { Engagement, Instruction, Leadership } \\
\text { and Structures. }\end{array}$ & 0 & 2 & 0 & 0 & 1 & 3 & 1 & 4.9 & 7 \\
\hline $\begin{array}{l}\text { Initial Survey Questions and } \\
\text { Comments Section of the Tools for } \\
\text { Evaluation Teams that provides an } \\
\text { opportunity for members of the } \\
\text { evaluation team (in workgroups) to } \\
\text { convey thoughts, observations and } \\
\text { evidence. }\end{array}$ & 1 & 0 & 0 & 0 & 2 & 3 & 1 & 5.1 & 7 \\
\hline & & & & & & & ippe & $\begin{array}{l}\text { question } \\
\text { question }\end{array}$ & $\begin{array}{l}7 \\
1\end{array}$ \\
\hline Response Text: Please comment abou & 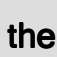 & $\Gamma_{1}$ & & & & & & & 2 \\
\hline
\end{tabular}




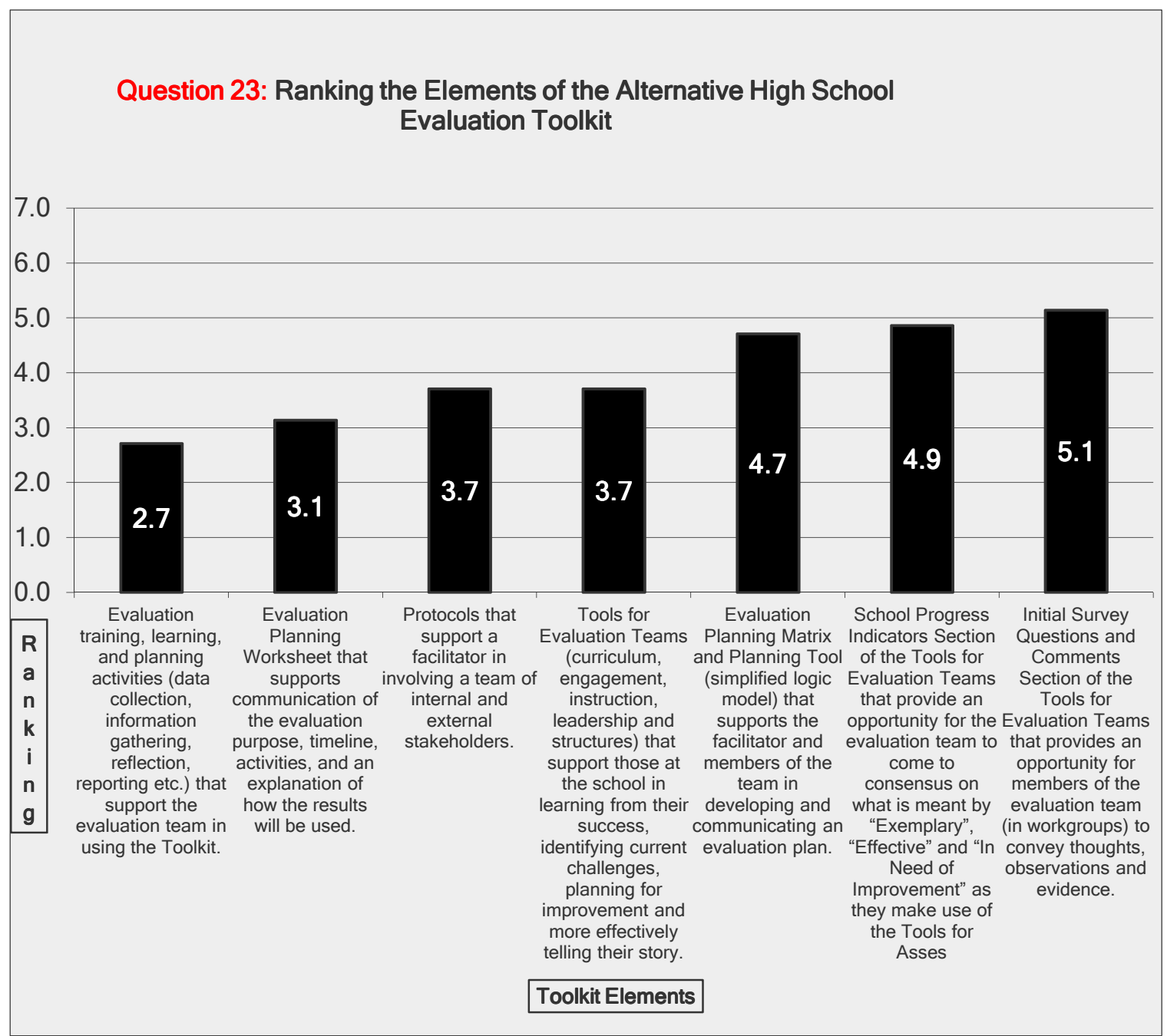

Figure 14. Survey Data Figure Question 23 (Ranking of Toolkit Elements).

Ranking the Elements of the Toolkit. For graphic display the ranked items were given numeric values of one to seven corresponding with the rank placement. So the number one ranked item of most import was given a value of 1 , second rank value a 2 , through the seventh rank which was given a value of 7 . By adding the numeric values in a given "row" and dividing by the total $n$, an average number is displayed. Thus in the visual display the lower bar on the graph is the first and most important item. As previously noted in this section, evaluation team participants found it difficult to rank 
items that were interconnected, as reflected by one participant that said, "It's difficult to rate things that don't stand alone well."

As I reflect on this I am left to wonder if any of the Toolkit Elements or Process Characteristics would stand alone as its own tool in evaluating an alternative school. Another participant remarked, "The opportunity to clarify meanings/expectations was valuable." This response was confirmed by field journal entries and by survey data that reported that the first and second highest rated items had to do with training, learning and planning activities and the evaluation planning worksheet.

Context and lessons learned. As Step 4 (preliminary field testing) began evaluation tools were collected along with their instructions (some of the tools called the instructions protocols) and frameworks (organizing terminology). These evaluation tools were compared with others collected and the work was presented at several conferences in the Northwest as frameworks for evaluating alternative schools. Reflecting on those presentations, I was excited about the topic but do not feel I had much to offer participants other than knowledge of the frameworks (in the form of a spreadsheet). I facilitated these sessions as a two-way conversation alongside presentation of the content, in hopes that it would make it useful for both me and the participants that attended.

I sometimes joke that I spent a year in the "Typology Forest" because around the same time I was challenged due to the lack of a workable typology needed to reference the tools or the indicators. I had hoped to determine a methodology to compare similar alternative schools with some sort of weighting based upon their mission, purpose and goals but in the end resulted with a simple Oregon School Typology Produced for the 
purpose of communicating the types of schools directly accountable through State-issued Report Cards (see Appendix K). This work of developing a typology is moving along with the support of Education Northwest and Portland Public Schools with the Alternative Accountability Taskforce described in this chapter as part of Step 4 (Preliminary Field Testing), and will continue through Step 8 (Operational Field Testing) was that year that I learned to read professional literature in my field and even bought the same book twice, confirming that I had saturated the literature. During Step 3 (product development) I attempted to use language that traditional school evaluators (school improvement staff) would understand on the spreadsheet of tools that the terms that organized the educational documents were all very similar to current terminology such as Assessment, Curriculum Instruction, Engagement, Leadership and Structures. In my work at ODE I have found it valuable to share educational knowledge common educational language Those who attended the sessions offered by Mr. Edwards and I were asked to informally share about a particular topic sessions offered insights on how the toolkit could be improved.

The Toolkit was developed and added to during the main field testing (Step 5) based upon data collected from a variety of organizations such as hospitals, private online education companies, private and public school districts and even a Fortune 500 multimedia-entertainment company. These in depth interviews and focus groups were recorded in my field journal and provided a basis for an understanding that went beyond my own experiences and ultimately helped me find a more comprehensive framework to the work of evaluating educational organizations. Tools from different fields and 
disciplines I began to observe the characteristics of the toolkits that were not contextually specific. That is to say they had to do with hospitals or other organizations rather than schools. As I continued to observe and gather information it became increasingly clear that the work done by the Joint Committee on Standards for Educational Evaluation was very accurate and agreed upon across the field of educational evaluation. The last set of Standards the Joint Committee published were only a few years old but the new version was recommended to me by one of my colleagues at OPEN as well as Amazon books (predictive book search (others who bought $\mathrm{x}$ bought $\mathrm{y}$ )

Focus groups and in depth interviews with colleagues at the Oregon Program Evaluation Network (OPEN), and initial data collected from my field journal entries aligned. Rather than generate a whole new framework, I assimilated for the most part with the Characteristics of the Evaluation Process. I believed there were common characteristics of quality evaluations. When I found the work conducted by the Joint Committee on Standards for Educational Evaluation, I had found it; they put terms and a framework with indicators and standards.

Table 36 presents the Toolkit Elements in Rank-Order based upon the Average Ranking Method. As described earlier in this section the lower numbers are the more important Elements as reflected on by the Evaluation Leadership Team. 
Table 36:

Toolkit Elements in Rank-Order Based on Average Ranking Method

1. Evaluation training, learning and planning activities (data collection, information gathering, reflection, reporting etc.) that support the evaluation team in using the Toolkit. (2.7)

2. Evaluation Planning Worksheet that supports communication of the evaluation purpose, timeline, activities and an explanation of how the results will be used. (3.1)

3. Protocols that support a facilitator in involving a team of internal and external stakeholders. (3.7)

4. Tools for Evaluation Teams (assessment, curriculum, engagement, instruction, leadership and organizational structures) that support those at the school in learning from their success, identifying current challenges, planning for improvement and more effectively telling their story. (3.7)

5. Evaluation Planning Matrix and Planning Tool (simplified logic model) that supports the facilitator and members of the team in developing and communicating an evaluation plan. (4.7)

6. School Progress Indicators Section of the Tools for Evaluation Teams that provide an opportunity for the evaluation team to come to consensus on what is meant by "Exemplary", "Effective" and "In Need of Improvement" as they make use of the Tools for Assessment, Curriculum, Engagement, Instruction, Leadership and Organizational Structures. (4.9)

7. Initial Survey Questions and Comments Section of the Tools for Evaluation Teams that provides an opportunity for members of the evaluation team (in workgroups) to convey thoughts, observations and evidence. (5.1)

As noted earlier with reference to question 22, ranking questions in the electronic system used to collect the survey data (Survey Monkey) are automatically calculated and reported in the manor reported above in Table 46, however, in an effort to be accurate in reporting, the researcher has chosen to report the ranking of ranks which is a statistical calculation that more accurately reflects the collected data in the items from question 22 . Table 37 reports on the evaluation team's rankings. All the elements listed are considered to be important and a rank item question asks the participant to consider their perceived value in the ranking of each item. For this reason the data has also been reported in a format that reflects ranking of ranks (same data with a different calculation method). 
Table 37:

Toolkit Elements in Rank-Order Based on Mean Rank of Rank Method

\begin{tabular}{|cc|}
\hline Elements of the Toolkit & $\begin{array}{c}\text { Mean Rank of } \\
\text { Rank }\end{array}$ \\
\hline Evaluation activities support team in using Toolkit & 16 \\
\hline Evaluation Planning Worksheet for communication and explanation & 19 \\
Protocols support facilitator with team internal, external stakeholders & 23 \\
Tools that support school learning, identifying, planning, telling story & 23 \\
Evaluation Planning Matrix and Tool for developing \& communicating plan & 30 \\
School progress Indicators for consensus on rating terms & 31 \\
\hline Initial survey questions, comments to convey thoughts, observations, evidence & 33 \\
\hline
\end{tabular}

As described previously in this analysis there statistical advantages of using ranking items such as those presented in question 22 and 23. A survey of participants reflected that "It's difficult to rate things that don't standalone well." Another participant said, "The opportunity to clarify meanings/expectations was valuable." It is generally accepted and even reflected by written comments made in the survey, that it is difficult for participants to rank items (Evaluation Toolkit Elements) that are interrelated. All the Evaluation Toolkit elements listed are considered to be important and a rank item question asks the participant to consider their perceived value in the ranking of each item. For this reason the data has also been reported in a format that reflects ranking of ranks.

Ranking items such as Question 23 should not be simply averaged in order to generate a summation of the description. A complex statistical procedure (Sharp, 1979) was used to produce a value of each item in comparison with others in the list for participants that responded. The more accurate data are presented in Tables 34 and 37; however the resulting order of the ranking did not change. The above table gives a true 
(mean rank of rank) because there are ranks of ranks, but there are not "average ranks". As noted earlier in this analysis, the smaller number means higher importance (value).

Overall the ranking of the toolkit elements also was difficult for members of the evaluation team who had begun using them. The justification for this was that the elements are so interconnected. The ranks provide good information to consider the perceived value of one element in comparison with others in the Toolkit. This information was used in the operational product revision (Step 7).

Field testing issues and challenges. This study was guided by a central issue of how best to evaluate alternative high schools. My central research question was: What tools support leaders in planning a thorough and accurate program evaluation of an alternative high school? The expressed purpose of this research was to improve the Toolkit and to focus on the primary research question and the issue of how best to evaluate alternative high schools.

The features of the Toolkit addressed the need for alternative school evaluation to be practical, useful, fair and accurate. The Evaluation Toolkit also included training materials, protocols, an evaluation planning worksheet and an evaluation planning matrix that supports the team in conducting the evaluation. Feedback received from the evaluation team, indicated Zeeland and Whyroads benefited from participating in the R\&D Cycle. Evidence that team members benefited from the design and evaluation process were expressed by the evaluation team and could be summarized by a comments made by the Whyroads Alternative School Principal, "How do you separate out these tools that are each so useful?" There may have been someone on the evaluation team (8 
members) who did not agree fully with the statement made by the Whyroads Principal but survey data presented in the previous sections and comments collected at during the final evaluation meeting indicated that they generally found the process useful (utility).

Alternative school leadership and experience. The Whyroads School principal was already familiar with regional accreditation standards and elements of effective alternative schools, having co-presented at conferences and facilitated regional alternative education leader meetings. While the principal was instrumental in leading the school up to this point, during the initial meetings, the principal's retirement was announced, causing uncertainty among the design and evaluation team about the future leadership at the school. This information created issues and challenges in design and redesign as well as the evaluation process.

The principal has served at Whyroads as alternative school principal and Zeeland as the student services director. However, the principal has provided strong leadership in the school and advocated within the district to maintain Whyroads as an educational option for students attending Zeeland High School. The Zeeland District Superintendent asked that he be able to contribute along with others to the final report. I solicited openly and even provided multiple deadlines to gather input from the evaluation team that was included in the recommendations section of the final report.

Facilitator-researcher. Throughout the main field test Mr. Edwards and I served as participant observers in the research study therefore generating potential bias and limiting the generalizations of this research study. The purpose of this study is on the product not the people and having a firsthand account in using the Toolkit with an 
evaluation team gave me more ways to know than other methods. That is we facilitated the design and evaluation process at the same time we were serving as researchers in the study. As participant-observers it was necessary that we reflect within the team and contribute little to nothing in the workgroups as to protect for bias to the extent possible. I worked and gathered data with an awareness of the research biases I held had and did the best I could to put them away. In the end, I gathered far more insight on how to support regional-facilitator training because I have actually conducted an entire 5 meeting design and evaluation process.

There were times during the main field test when Mr. Edwards and discussed methodology with the evaluation team. Examples of this include our discussion to include school research site visits, conducting a needs assessment and a needs assessment and worked to critique each other when bias occurred. While it was valuable to have firstperson access to the participants and make observations as a participant in the study, it was difficult at times to separate my role as a researcher and program evaluators, not to mention my role at ODE. In all honesty I probably ended up needing to compromise and didn't do as well of a job documenting and researching as I would have if I didn't have responsibly in both. However, through the experience, I now reflect differently on the role of preliminary field testing.

I believe my actions in and out of the evaluator role are above reproach and I did everything I could to contribute to the successful evaluation of the alternative school but I struggled to remain objective and not take criticism personally, even when it was regarding others in the research study or at the school. In the end, I believe I was able to 
gather much more information from the experience from a first person perspective. That said, it was a very difficult role to balance and I involved other facilitators in a strategic process of selection, training and commitment during the operational field testing phase over several months. This is the risk in this type of research method as I was both the participant and researcher presenting consistent challenge in systematically gathering data when I was also trying to facilitate evaluation training and planning. As described in chapter 3, this method was employed to assure direct access to reflections as a program evaluation facilitator and this perspective was very valuable in operational field testing and final product revisions (Steps 7 and 8).

I am looking forward to future steps in the R\&D Cycle such as Operational Field Testing (Step 8) and Dissemination and Implementation (Step 10) where I will be able to observe and more objectively and take notes on how to improve the product over time without a personal stake in the outcome. This would include training a small number of facilitators to fulfill that role (alternative schools program evaluation facilitator), perhaps in their region of the State. Operationalizing the product through product revision and another round of field testing will allow me to address other issues that surface with a broader sample of alternative school sites.

Team member attendance and participation. For the sake of the main field test in this study, the design team facilitators were also used as members of the evaluation team. However all team members did not attend all meetings. For example, while we had parents at the first several meetings, the 2-hour meeting commitment was just too much of a sacrifice in time during the evenings for them to reliably participate. 
Facilitators made multiple verbal and written requests to involve a community member and additional stakeholders that would contribute to the diversity of the team. The response by the Zeeland leadership was to make sure the students represented Hispanic and Asian descent. Future field tests should consider holding noon-hour parent focus groups, student and parent surveys to reliably collect information about the schools' performance. This data could be used in the design and evaluation process and included in the plans for a more formative (ongoing) evaluation.

Limited sessions and time for the design process: The full design process conducted by Mr. Edwards was truncated to the foundational steps of establishing a shared vision. A full design process would involve 6 to 10 sessions during which subgroups would more fully develop subsections of a program description that described the new school. The program description would have a description of the courses and activities offered at the school as well as the common characteristics of students who would be the schools target student population.

Although the design process was abbreviated in this field test, team members signed a consent form included in Appendix I and were made fully aware they were participating in a field test of the design and evaluation processes and also fully aware of the research questions being explored. Session five was used to debrief the design and evaluation team and involved a facilitated focus group among the members of the team..

After a brief focus group discussion, an online survey was given to team members and was followed by a brief focus group discussion about the survey itself. The results of the survey are presented in the later section. It was expressed from the beginning that $\mathrm{Mr}$. 
Edwards would like a truthful account of their participation in the planning process in their responses to the survey.

\section{Step 7: Operational Product Revision}

The assessment of the Evaluation Toolkit was made using both formative and summative evaluation methods. Formative purposes included the use of data that point the way toward improving the Evaluation Toolkit. Summative purposes included the use of data to shed light on the efficacy of the product (Bridges \& Hallinger, 1995, p. 122).

Operational revisions of the Evaluation Toolkit and evaluation process were based on the results of the main field test, which took place over a four month period at "Whyroads Alternative School in Zeeland School District. Feedback from the evaluation team participants was analyzed and taken into consideration to inform operational revisions. Data included quantitative scores and qualitative comments in response to research-based elements of the Evaluation Toolkit and characteristics of the evaluation process. The evaluation team was composed of a school district superintendent, district student services director, district curriculum director, traditional high school principal, alternative school principal, evening program coordinator, teacher and two parents. Students were interviewed by the team during the field test and there remarks contributed to the development of the program guide and evaluation planning. Revisions were made based on the researcher's field notes, in depth interviews with team members, focus group reflections, and participant's use of the Evaluation Toolkit and process used to evaluate the alternative high school. 
Needs assessment. Survey data, focus group discussion, personal interviews and discussions with Mr. Edwards suggest that a more thorough needs assessment is necessary to assure the school district is prepared for a process that is externally facilitated and involves more diverse mix of internal and external stakeholders. In the case of the main field study, the research site was an alternative school with strong leadership, existing structures, and a strong curriculum with strategies to promote best practice instruction and student engagement, and an established formative and summative assessment system that provided regular progress with regard to students. Based on the data collected, the school benefited from the design and evaluation process with a refined vision, mission, goals and an established plan for evaluation, but one could argue that they were in good shape when the facilitators arrived on site. While this benefited the evaluation toolkit and process by having measurable, documented evidence of existing structures, the sites strength and established structure made it difficult for Mr. Edwards to work the assumptions such as "start over" in a process that recommends starting over from scratch.

Alternative schools in future field testing. The field site in the Zeeland school district represented just one site, but it was selected based on its traditional size (fewer than 150 students) and population (similar to approximately half of the school districts in Oregon). The context of the research setting was suburban and it offered limitations with regard to generalizing the findings in the study. Selecting more sites during the same time period may not have been feasible in the main field test and evaluation study. Operational product revisions should take into account the capacity of the facilitators and new tools 
should be developed to support dissemination and implementation without the involvement of the facilitator-researcher.

Another possible modification should be to consider the publication of online course content and the offering of a hybrid of asynchronous and synchronous tools (webinars and video conferencing) to support evaluation facilitators. Many of these revisions have already been made and added to the online course posted on the Oregon Virtual School District Course Directory. This innovation is further discussed in the chapter 5 of this dissertation and imbedded in Steps 8-10 of the R\&D process described in that section.

\section{Summary}

The Alternative High School Program Evaluation Toolkit was researched and developed to provide Tools in support of leaders in a process of evaluating alternative high schools. The research was conducted to support a facilitator and evaluation teams in planning a program evaluation with a clear purpose and objectives (learn from successes, identify current challenges and plan for improvement) that result in a thorough and accurate portrayal of the impact an alternative high school is making on students. As described previously, current evaluations, in Oregon, often include a single evaluation facilitator (leader) in an effort to evaluate an alternative high school using a compliance checklist. As described previously in this dissertation and within this chapter the checklist is not an adequate tool for program evaluation. In future versions of the Toolkit the checklist will be replaced and expand upon in future Steps in the R\&D Cycle and validated by data described an analyzed in the proceeding sections. 
The R\&D Cycle resulted in research and development of the Alternative High School Program Evaluation Toolkit in support of leaders in a process of evaluating alternative high schools, and resulted in an Evaluation Toolkit ready for dissemination, implementation and application in alternative high school settings. Chapter 5 discusses additional conclusions, ideas about the Toolkit efficacy and expand upon possible future uses of the toolkit. 


\section{CHAPTER 5}

\section{CONCLUSIONS AND RECOMMENDATIONS FOR LEADERSHIP}

\section{Overview}

This final chapter addresses conclusions and ideas about efficacy and future use of the Alternative High School Program Evaluation Toolkit. This research was guided by a central issue of how best to evaluate alternative high schools. The R\&D has also contributed a tremendous amount to my own experience as a professional. The purpose of the research was to improve the Evaluation Toolkit and was based on the primary (central) research question of: What tools support leaders in planning a thorough and accurate program evaluation of an alternative high school? As mentioned previously, "accurate" includes elements of utility, feasibility, propriety, accuracy and accountability (Yarbrough et al., 2011). The R\&D Method (Borg \& Gall, 1989) resulted in multiple product revisions of the educational product have supported the exploration of the primary research question. The Toolkit development was supported by guiding questions organized by standard element (utility, feasibility, propriety, accuracy, and accountability) and was analyzed in in previous sections.

The R\&D Cycle included an extensive review of literature, an assessment of research need, small-scale testing, preliminary field testing and data collection, main field testing, in-depth interviews, focus groups and a group survey. During the main field testing the design and evaluation team provided valuable insights and information that were useful in product revision. These data and learning activities resulted in multiple 
product revisions, Toolkit validations, and the demonstration of the Toolkit's efficacy when the research questions were considered.

\section{Personal Reflections}

The theoretical basis for the R\&D and use of the product development cycle resonated with the core of who I am as an educator, administrator, practitioner, innovator, policy contributor and who I am becoming as a researcher and program evaluator. My research colleague Mr. Edwards used my assumptions and theoretical framework (Elements and Process Characteristics) in his work and dissertation research. Our dialogue enriched the R\&D Cycle at each Step. I am always evaluating something or sketching a rubric or tool. The research and information collecting funneled my efforts in a way I found to be very relevant and motivating throughout the process. As I reflect generally on the R\&D Cycle I would say that I have internalized the conceptual framework as a way of thinking about my day-to-day work in school and program improvement and policy development. The result of the process for me personally was meta-reflection on my professional role as a program evaluator and educational leader. Simply put the R\&D Cycle includes multiple loops of testing and revision with "intent to implement."

\section{Advisor and Committee Support}

I am so grateful for my doctoral advisor, Dr. Chenoweth for exposing me to a way of thinking about learning through R\&D. Sitting his office one day we were working through the methodology for my research when he simply suggested that I could learn a lot in a small research setting. This concept has become absolutely foundational to my 
approach to research. I am also grateful to members of my committee for their thoughtful responses such as Dr. Burk who suggested that accountability be local, Dr. Henry that suggested the evaluation recipe metaphor used to introduce the Evaluation Elements and Process in chapter 3 and Dr. Labissiere who described effective program evaluation as having bifocal lenses of analysis.

\section{Lessons Learned}

Throughout the R\&D experience I learned a number of lessons about the value of teamwork and time in the process of designing and evaluating alternative schools. In our small-scale testing in Oregon's South Coast Mr. Edwards and I spent 10 full sessions with the stakeholders who were seeking to design their new school as an alternative to the traditional high schools in the region. Understanding the time commitment from previous experience in starting new schools, the South Coast Superintendent's hired a full-time administrator to begin the planning process. The time commitment in the main field test at Zeeland was different. The Superintendent and leadership wanted to spend half that amount of time and complete both the design and evaluation in just five sessions over three months. The research provided the district a program guide, evaluation plan and evaluation at no cost and Mr. Edwards completed the process before the deadline and prior to the start of their district budget process. However, we accomplished less than half the work during that time, leaving much of the burden to complete the needs assessment, vision and mission, evaluation planning to the facilitators and working groups that met between sessions to complete the work. 


\section{Experiences Through the Process}

As I have considered the educational product (Evaluation Toolkit) more specifically I have been able to internalize the importance of simple descriptions and tools for use by facilitators and evaluation teams. There were significant challenges in developing tools that would be simple and valid (measure what they intent to measure). Of the hundreds of evaluation tools I collected over the last few years, fewer were less than six pages back to back. In the R\&D I sought out the most useful tools based on experience and understanding of the Standard Elements of utility, feasibility, propriety, accuracy, and accountability.

I am especially interested in developing a system of supports for alternative schools and further refining alternative accountably metrics that could contribute to more accurate descriptions of alternative school performance in comparison to other like schools. In addition to the need for more thorough and accurate descriptions, formative program evaluations should support districts and schools in determining the impact of their alternative high schools. As described in the literature review, local news reports have completely discounted (not included) alternative programs in reporting about the performance in urban districts and others have put an over-emphasis on low graduation rates in alternative schools rather than the dropouts and at-risk students they recovered. As one alternative school administrator put it, "You are blaming the shiny ambulance at the bottom of the cliff," referring to the low graduate rate at their alternative high school. Later in this section I have outlined other specific future uses of the Evaluation Toolkit. 


\section{Development}

This chapter discusses the overall assessment of the research experience; further discusses the results of the operational product revision (Step 7 of the R\&D Cycle); speculates about future field testing, dissemination and implementation of the Evaluation Toolkit (Steps 8, 9, and 10 of the R\&D Cycle). Lastly, this chapter provides recommendations for further study and recommendations for leadership. The intent of this study was to construct, field test, revise, and improve an educational product that addresses a real world problem in education. In this case the problem was the need to support leaders in planning a through and accurate program evaluation of alternative high schools. An Evaluation Toolkit and process was developed using the R\&D methodology recommended by Borg and Gall (Borg \& Gall, 1989). The R\&D method used to develop the school design process consisted of the first seven-steps of the R\&D Cycle (see Table 2). The Evaluation Toolkit development required extensive professional experience with program evaluation and alternative schools and a thorough review of the literature in several fields of study represented in chapter 2 of this dissertation. In depth interviews, focus groups, small-scale and field testing with school leaders, administrators from other state departments of education, superintendents and central office administrators also contributed to the development of the research study.

\section{Product Efficacy}

As to the efficacy and future use of the Toolkit, the R\&D Cycle provided a research-based process for the developing and improving the product. As described earlier in this dissertation, the current Oregon evaluation tool is a checklist often used by 
a single evaluator while the Evaluation Toolkit includes multiple elements (survey, indicators and a logic model) in combination with a process to support an evaluation team in conducting a thorough and accurate evaluation of an alternative high school.

\section{Step 8: Operational Field Testing}

Operational product revision and field testing is expanded upon in this chapter and involves alterations such as the incorporation of reliable tools to conduct site visits and collect data from students, parent, teacher surveys and protocol-driven classroom observations (Redding \& Walberg, 2008). Revisions will be guided by a larger group that includes the Oregon Alternative Accountably Taskforce described in reference to preliminary field testing and main product revision in chapters 3 and 4 of this

Dissertation. Operational field testing will involve a small number (5-7) of alternative high schools in a "pilot study" of the Toolkit with trained facilitators and evaluation teams equipped with the Evaluation Toolkit and protocols to support thorough and accurate evaluation processes involving alternative high schools in their region.

Facilitate a reliable site visit and collect data for planning. Operational product revisions indicated the need for reliable data sets to inform evaluation planning and school improvements. One example of this is described by in Redding's work (2008; 2006) described earlier in this dissertation and involves triangulation of student, parent and teacher surveys, combined with a classroom observation data that are compared and reported back to schools as a part of the statewide system of school support. Oregon is already using this method combined with Achievement Compact Descriptors (included in Appendix D) and school improvement indicators (included in the Appendix C) to support 
schools that have not met AYP for more than two years and been identified as Focus or Priority schools. The new Oregon Report Card (see Appendix E) will also contribute to a more formative method of evaluation offering a narrative format for high school principals and school leaders to portray a more accurate story of what is happening.

Check-ins on the results of planning. One survey participant asked, "Is there a way to make sure or check-in on what has been done with the recommendations from the evaluation?" These comments and other data from the main field test suggest that a schedule should be established to check-in on what has been done as a result of planning and any recommendations made as a part of the evaluation process. The evaluation training (2 hours) and planning ( 2 hours) resulted in a simple evaluation plan that describes how the school will tell their story. The result of the evaluation was summarized and resulted in a lengthy evaluation report that includes evaluation recommendations (Report included in Appendix A) that should be followed up on in some way. The superintendent, student achievement and curriculum director in Zeeland School District each separately asked me to visit and check-in to assure recommendations were carried out. In my role at ODE, I have often thought this would be a good idea with private alternative schools that register with ODE and contract with districts. Considering this idea with public alternative schools may involve stepping between districts and the schools they operate and may not be considered to be proper or fair (propriety).

This suggestion would require additional resources to disseminate and implement across the state but is worth considering in the chapter 5 recommendations. I was able to configure our internal operations at ODE to attend to program level performance and 
included randomized selection of private and public alternative schools that were directed to participate in desktop monitoring with the possibility of site visits if necessary. To contribute to this work and align it with work being done with Focus and Priority Schools, discussed in chapter 4, final product revisions (Step 9) should consider adding the school improvement indicators in place of the existing indicators for use with Focus and Priority schools and for use in identifying Model schools defined in Oregon's Next Generation Accountability System waiver (ODE, 2012).

One of the efforts made in product design (Step 3) was to align the alternative school evaluation terminology with traditional school terminology such as assessment, curriculum, instruction, engagement, organizational structures and leadership. As discussed in the methods section of this dissertation this effort was explicitly made to help the traditional school administrators feel comfortable with the organizers used in the Evaluation Toolkit as they participated in evaluations of alternative high schools.

My recent involvement with these initiatives grew as a direct result of lessons learned in Steps 1-7 of the R\&D Cycle. The work Oregon has done in developing weighted metrics for alternative accountability and a formative process for program evaluation has been recognized by ODE staff working with traditional school improvement and turnaround schools as well as staff at the USED. As a result of this R\&D and my role at ODE I have been asked to serve as a key research informant on three research studies involving alternative schools and have twice been asked to speak with USED Staff regarding common data elements for longitudinal data sharing.

\section{Step 9: Final Revisions}


Final product revisions will be made by a small subgroup of the Alternative Accountably Taskforce and involve leadership from the Oregon Educator Effectiveness Network, the School Improvement Team and other individuals or organizations perceived as key to successful implementation. Oregon's new Indicators for School Success will be incorporated in place of the current indicators and a post-revision trial will need to take place that incorporates these new elements and considers the efficacy of their use with alternative schools. The product will be generated in a more formal format with form field boxes and dropdown menus for easier and more reliable data entry and collection. Future revisions may involve the development of an online format to collect and use the information within Oregon's new Customized Improvement Planning Tool and Next Generation Accountability System.

\section{Step 10: Dissemination and Implementation}

Dissemination will involve the Evaluation Toolkit being posted as a prototype along with other district evaluation tools, student, parent and teacher survey instruments on the ODE Alternative Schools Evaluation Toolkit's webpage. Dissemination will also involve intentionally developed strategies for communication, regional facilitator training and supports. Depending upon funding, time and resources allocated to the project by ODE Leadership, these supports may include regular online professional learning community meetings, trainings, webinars and templates designed for communicating the new Alternative School Evaluation Toolkits with a variety of audiences. As described earlier in this dissertation in my role at ODE I have been asked frequently by school leaders and evaluators if there was something other than a compliance checklist to 
support the evaluation of alternative schools in Oregon. National, regional and state-level policy makers and news reporters have described the problems with holding alternative schools accountable and Oregon will step out as a national leader in thorough and accurate evaluations of alternative schools and their programs.

Following the operational field testing, final product revision, dissemination and implementation, the Alternative School Evaluation Toolkit will contribute alongside new forms of reporting (new school report card), compliance monitoring (new statewide system of support) as a tool to support the improvement of alternative programming and assure quality in the schools and programs that serve Oregon's most at risk youth. The Evaluation Toolkit implementation will coincide with Oregon's new metrics for education service district and school district achievement compacts and system for Next Generation Accountability. The dissemination and implementation of the Evaluation Toolkit will be facilitated by ODE in partnership with the Educator Effectiveness and School Improvement, and Northwest Innovative Schools Networks and will continue to support evaluation teams in thoroughly and accurately preforming evaluations and holding alternative schools accountable for the services provided to Oregon's students. Taking the Evaluation Toolkit to scale will require a network (team) of regional facilitators trained in using the Toolkit and methods of formative program evaluation.

Evaluation Toolkit released under a creative commons license. In order to encourage use of the educational product (Evaluation Toolkit) and facilitate dissemination, I released the Evaluation Toolkit under a "Creative Commons AttributionNon-Commercial-Share-Alike" (CC BY-NC-SA) License. This license lets others remix, 
tweak and build upon your work non-commercially, as long as they credit you and license their new creations under the identical terms (Creative Commons, 2013). In addition to dissemination and implementation through my work at ODE it is my intent to release Evaluation Toolkit that results from the final product revision under this same license in order to continue encouraging others to use the Tool.

\section{Overall Conclusions and Assessment of the Experience}

I learned a lot about myself through the process and was able to align my understanding and methods with experienced innovators in the field of education. My research was guided by a central issue of how best to evaluate alternative high schools. The purpose of my research was to improve the Toolkit. My primary research question was "What tools support leaders in planning a thorough and accurate program evaluation of an alternative high school?" Following an extensive review of the literature and smallscale testing, my research question was addressed by the development of the preliminary form of the product (Step 3).

Characteristics of efficacy were validated throughout the Cycle in R\&D field testing (Steps 4 and 6). The research cited and methods used in the preliminary and main field testing increased relevance for me personally and allowed me to focus on a smaller set of evaluators to improve the Toolkit and focused my attention on the efficacy of the product rather than a large number of people. The Alternative High School Program Evaluation Toolkit was developed to provide Tools in support of leaders in a process of evaluating alternative high schools and to support evaluation teams in planning a program evaluation with a clear purpose and objectives (learn from successes, identify current 
challenges and plan for improvement) that result in a thorough and accurate portrayal of the impact an alternative high school is making on students. It has been my intent all along to develop something that can be given away and supports alternative schools in Oregon to more accurately tell their story.

The main field testing was just the first step in giving away (dissemination and implementation) the product. The evaluation team at Whyroads Alternative School in Zeeland School District reflected in the focus group and survey that they found the process to be valuable and the Toolkit to be useful. The Team was surprised to find out during the process that the current Whyroads administrator is going to retire at the end of this school year disrupting the leadership continuity provided at the school for more than a decade. This announcement made the process and recommendations all the more relevant to the well-being of the school mission and the students that attend Whyroads. As mentioned previously several members of the leadership team requested that I come back to visit the school and assist, to the extent possible, in the establishment of new leadership at the school. Members of the leadership team thanked me personally for the objectivity and strong professional standard I adhered to during the evaluation.

\section{Conclusions about the Efficacy of the Evaluation Toolkit}

My research was guided by a central issue of how best to evaluate alternative high schools. My central research question is: What tools support leaders in planning a thorough and accurate program evaluation of an alternative high school? As previously described in the introduction, methods and analysis sections of this dissertation, for the purpose of this research question and guiding questions, "leaders" included program 
evaluation facilitators as well as members of an evaluation team with the task of evaluating an alternative high school. For the purpose of the research product and the central research question, "accurate" included elements of utility, feasibility, propriety, accuracy, and accountability (Yarbrough et al., 2011).

As described in the research methods section, the broader research question (long version) was: What tools support evaluation teams in planning a program evaluation with a clear purpose and objectives (learn from successes, identify current challenges and plan for improvement) that result in a thorough and accurate portrayal of the impact an alternative high school is making on students? As described earlier in this dissertation, current evaluations, in Oregon, often include a single leader in an effort to evaluate an alternative high school using a compliance checklist. The checklist is not an adequate tool for program evaluation and is expanded upon in this R\&D process by a toolkit of tools to support an evaluation team in evaluating a school.

The next section of this chapter describes future research and goals, development and implementation of the Evaluation Toolkit. The description requires a review of the current conceptual framework of the product and process experienced in the main field testing of the design and evaluation of alternative high schools. The current framework is represented in Figure 15. 


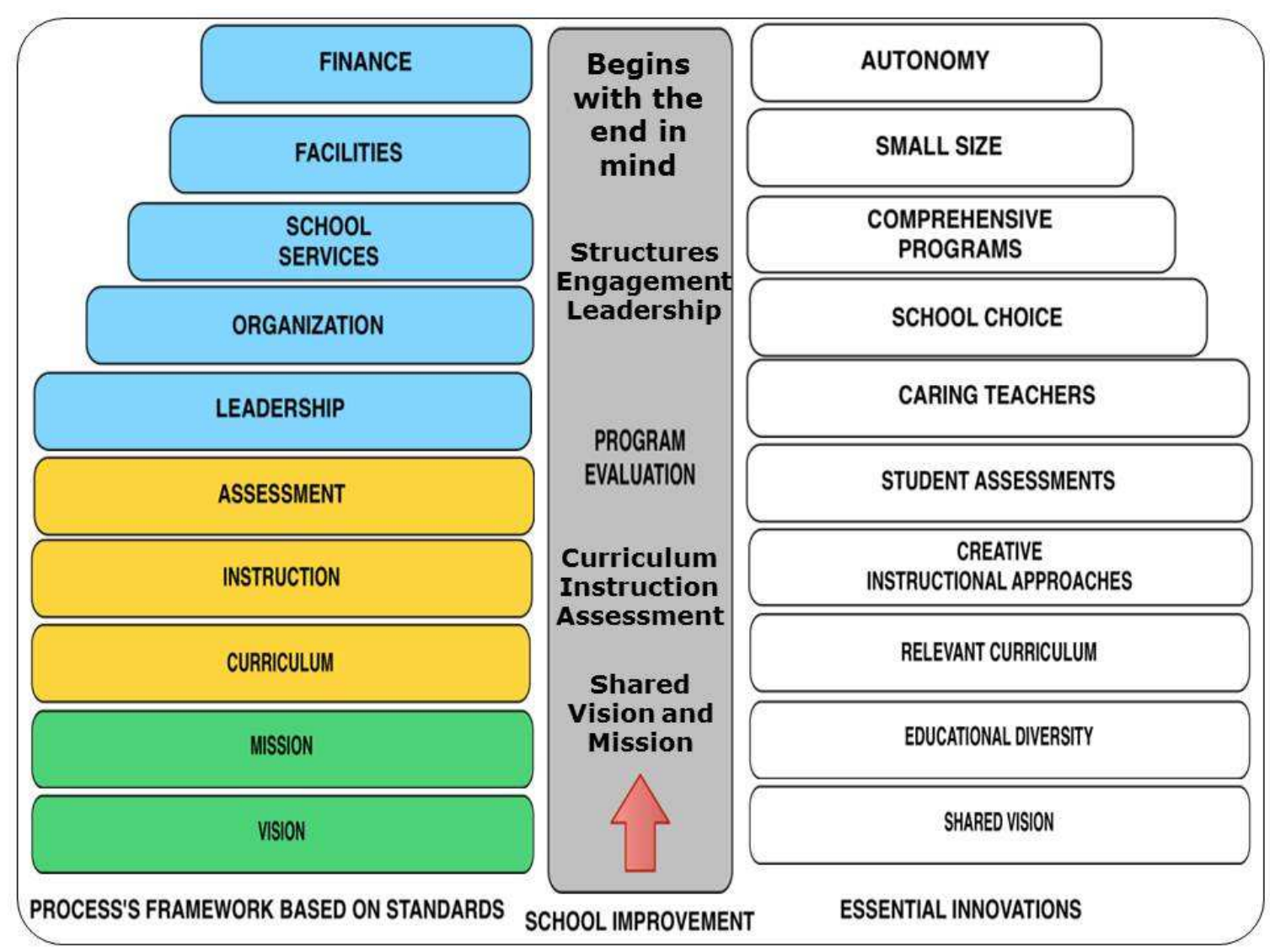

Figure 15. Framework for the Design and Evaluation of Alternative High Schools.

In Figure 15, Mr. Edwards' four assumptions about what leaders need to design innovative alternatives to traditional schools, in the form of accreditation standards that address the expectations, educational program and supports for learning (left) and elements of successful alternative schools (right) are combined with a formative evaluation (school improvement) process with subjects of the tools for evaluation teams. My colleague Mr. Edwards conducted concurrent and collaborative dissertation research that is also represented by the stair steps on either side of the "black box" in the middle that includes the Evaluation Toolkit and a process for evaluating alternative high schools. 


\section{Future Research and Goals}

Operational field testing of the Evaluation Toolkit is among the first applications of the new understandings I have about alternative school program evaluation. The Toolkit has been field tested and is ready to share with a broader audience that more accurately represents alternative schools in Oregon. I will seek to provide training to each region in the state as a part of the work currently being done in the educator effectiveness and school improvement networks.

For the past seven jubilee years I worked within a personal mission to, "Lead, listen to and develop rapport with educational leaders, parents, students and stakeholders in order to increase the relevancy of education, guide and encourage collaboration, support learning communities and increase strong cultural connections.” This mission has served me well but in some ways I have outgrown it and am ready for a new challenge. The next seven years will include goals for article and book publication and speaking engagements to discuss and debate about program evaluation in schools.

I have established and will continue to improve routines (disciplines) of writing by completing this dissertation that I will use to accomplish the submission of at least two book reviews, two professional articles in peer reviewed journals and one book in the next two years. I have been asked by three professionals to work with them on professional articles and Bob Barr has asked me to co-author a second version of his book titled "How to Create Alternative, Magnet and Charter Schools that Work." I have also met and began to foster relationships with persons at two research journals and two publishers in order to accomplish these goals. Future uses of the Evaluation Toolkit are 
presented in the following table and organized by Step with Operational Field Testing

(Step 8), Final Product Revision (Step 9), and Dissemination and Implementation (Step

10; Borg \& Gall, 1989).

Table 38:

Future Uses of the Evaluation Toolkit

Steps 8-10 in the R\&D Cycle

Operational Field Testing (Step 8) with a Wider Representative Sample of Schools:

1. Field test different types and forms of needs assessments

2. Field test tools for reliable methods of conducting site visits and data collection

3. Field test subgroup-work within the evaluation process

4. Field test measurements of the Evaluation Toolkit's impact on school climate

5. Field test methods of measuring the Evaluation Toolkit's impact on students

6. Field test methods of Evaluation Facilitator Training

7. Field test a System of Support for Alternative Schools (Urban-Suburban-Rural)

Final Product Revision (Step 9) with the Alternative Accountably Taskforce:

1. Finalize tools to support district-conducted Initial Needs Assessments

2. Finalize tools to support subgroup-work within the evaluation process

3. Finalize tools for reliable methods to conduct site visits and data collection

4. Finalize tools to determine the Evaluation Toolkit's impact on school climate

5. Finalize tools to determine the Evaluation Toolkit's impact on students

6. Finalize tools to support Evaluation Facilitator Training

7. Refine the Statewide System of Support for Alternative Schools

Dissemination and Implementation (Step 10) Through Regional Networks:

1. Conduct regional evaluation facilitator trainings (certification)

2. Employ the System of Support for Alternative Schools for Training

3. Collaborate with Oregon Educator Effectiveness Network (ODE)

4. Collaborate with Northwest Innovative Schools Network (ODE)

5. Collaborate with Oregon School Support Network (ODE)

6. Collaborate with Oregon Association of Education Service Districts (OAESD)

7. Collaborate with Oregon Leadership Network Districts (Education Northwest)

8. Consider other strategic collaborative partnerships (COSA, OSBA, OACOA)

9. Develop/pilot an Online/Blended Educational Program Evaluator Training

10. Publish 3-5 Articles as a Result of the Work in this Dissertation

11. Co-author 2nd Edition of a book with Bob Barr and William Parrett

12. Consult/Collaborate with Authors of PBIS and Community Schools Toolkits.

Source: Steps 8-10 of the R\&D Cycle (Borg \& Gall, 1989) 


\section{Summary}

This chapter included conclusions and ideas about the efficacy and future use of the Alternative High School Program Evaluation Toolkit. This research was guided by a central issue of how best to evaluate alternative high schools. The purpose of this research was to improve the Evaluation Toolkit in order to support leaders in planning a thorough and accurate program evaluation of an alternative high school. The Toolkit development was supported by guiding questions that were organized by the standard elements of utility, feasibility, propriety, accuracy, and accountability (Yarbrough et al., 2011). The research represented in this dissertation is theoretically and practically grounded in Bridges and Hallinger's (1995) PBL and Borg and Gall's (1989) R\&D Cycle. The product of the R\&D Cycle was the Evaluation Toolkit and a process for use by evaluation teams assigned the task of planning and carrying out alternative high school evaluations.

Students attending public school right now have more choice in their educational experiences than ever before and that trend does not appear be slowing. In fact new forms of online and blended learning will likely change school ecosystems dramatically. Like it or not, U.S. federalization (Increasing role of the federal government in the U.S.) combined with privatization (private for-profit schools operating public schools) are having an impact on the public schooling systems and this trend is also not likely to slow in the short term. Rather than fearing change, alternative school leaders in Oregon exhibit courage by innovating and challenging existing notions through a belief that all students can learn. Rather than fear competition, educational policy makers in Oregon are 
increasing school choice, opening district enrollment practices and have proposed funding educational organization with outcomes based methodologies. If student and family well-being is measured by school choice, Oregon students are in a good place.

Together with my colleague, Mr. Edwards, we have developed a promising educational product, a process for Designing and Evaluating Alternative Schools. However, we realize there is much more to learn. The true value of the R\&D Cycle and research process may be in further study of the benefits of the process on school culture and students who attend the school. We saw evidence of this on small-scale testing and field testing but did not have the ability to capture it in a reliable way so this is speculation. However, there are clearly demonstrated benefits of the process, such as improved community relations, development of administrative and teacher support for the school, and the use of resources more efficiently. Educational innovation is sure to continue and has been the result of generations of educational leaders that had the courage to innovate.

\section{Educational Imagination}

Eisner (1985) has indirectly contributed a great deal to the design and evaluation of alternative schools with works including his book "The Educational Imagination." His work accounts for historical and contemporary social forces that affect both schools and programs and pay particular attention to an artistic approach to what is usually regarded as a scientific activity. Eisner warns that the consequence of scientifically-based approaches to educational research in schools goes beyond the issues of what subject matters are emphasized or the methods used to teach. When combined with a reward 
structure to care for problems of student motivation and a set of minimum standards to ensure the public of good quality education, we have a complete system-at least in theory-for the management and control of school programs (Eisner, 1985, p. 15). Eisner's cynicism is warranted. There are few, if any, simple answers in the systematic evaluation of alternative schools and research in this area must take account for the complexity involved in these non-traditional environments.

The Black Box: To summarize and insightfully conclude this dissertation, I would like to cite educational leader and practitioner, Larry Cuban, who consistently contributed to literature about alternative education and school reform. Cuban has used metaphors to describe national educational policy reform efforts, which include state, district and school improvement efforts, accountability and multiple forms of evaluation. He uses the metaphor of the hurricane national educational reform efforts speeding across the ocean surface while fathoms below, stability in schools and classrooms reigns (Cuban, 2012). He mixes the hurricane metaphor with the image of the school or classroom as a "black box" referring to the term as used in systems engineering and economic production functions where input (e.g. funding, facilities, teacher qualifications) go into a box called "schools" or "classrooms" and outputs emerge (e.g. test scores, skilled, knowledgeable graduates).

He refers to the "black box" as a metaphor for what happens daily in schools and classrooms that remains out of the public sight but is seemingly known to all since every policymaker, researcher, parent and taxpayer experienced schooling in one form or another and may consider themself an expert on principles and practices of learning at 
school. Cuban states, that what occurs in classrooms remains mysterious to non-teachers because memories fade and children's reports of what they do in school are at best, laconic and hiding more than revealing what is occurring at school.

Cuban elaborates on the metaphor of the hurricane and the black box, that on that quiet ocean floor, where life is largely undisturbed by the roar of hurricane, rests the box of the school and classroom. Within the black box is another complex world filled with patterns of change and stability in interdependent relationships blended with unanticipated events and unpredictable responses. Not only do national education reformers have to parse the hurricane metaphorically but they also have to open up the black box and figure out what happens inside if they want to improve teaching and learning in U.S. classrooms (Cuban, 2012).

Because of my experience as a teacher, administrator and state specialist, I associate with those who seek to teach and lead alternative high schools as well as those seeking to evaluate and report on them. Members of school evaluation teams who seek to evaluate alternative high schools have a similar challenge to Cuban's Metaphor (be observant of the storm but focus on what is in the box - students). Educational policy makers sometimes refer to schools as if they didn't contain students, teachers and hardworking members of the community who volunteer their time. During my core examination and proposal for this dissertation research, a professor, intimately familiar with these and many other policy issues remarked, "I have come to the conclusion that alternative school accountability should be nothing but local." I believe there is tremendous wisdom in those words and in other words used to describe our schools. 
Often times, policy makers and educational leaders are burdened with influence from members of the school board, community and traditional schools and have little knowledge of what is actually happening at schools and programs in their own districts. Holding alternative high schools accountable, through program evaluation, will take courageous leadership, a supportive evaluation team, evaluation training and valid tools that seek to thoroughly and accurately portray the impact the school is making on students. Those at the local alternative school will learn from their successes, identify current challenges and plan for improvement that more effectively tells their story. 


\section{AFTERWORD}

The following is a sequel to the Preface based upon lessons learned from my research.

My visit to Crossroads, with the evaluation team, validated assumptions I had

about the Elements and Characteristics of the Alternative School Program Evaluation Toolkit. As a facilitator, the rapport I maintained with members of the evaluation team and administrators at the district and school allowed them to speak candidly about the current problems with the Evaluation Toolkit and a process to thoroughly and accurately evaluate the impact of their alternative high school. I am grateful for the opportunity to have had the opportunity to work with staff and administrators that were so willing to be evaluated and so eager to improve. The first steps in conducting a professional program evaluation is to conduct an evaluability assessment and examine the readiness of a program for evaluation and the last being a meta-reflection about the methods used. In five years of visiting and working with alternative high schools in Oregon, I have encountered very few that were unwilling to be candid and honest about their areas to improve and be willing to critique their services to students. Crossroads was no different.

On average students who attend Crossroads are at least one year behind academically but if they attend regularly for at least six months most will make twice the growth rate than traditional school students, based upon test scores, skills and credits obtained. Despite this growth with the intact group of students, for the past three years Crossroads has graduated less than $30 \%$ of its students and daily attendance averages less than $70 \%$. Graduation, attendance and state test scores are the outcome measures used to determine the school's AYP against all other high schools. AYP was designed under 
federal law (No Child Left Behind) to hold schools accountable and requires the State issue Report Cards annually that provide a summative measure of the school's performance. Over four years, Crossroads has had an intact group of about 20\%; that is to say that about 2 students out of every 10 begins and ends their four years of high school at Crossroads. The other 8 out of 10 students attend Crossroads for shorter periods of time. Despite these differences in the schools mission, purpose, goals and direction, the State and School Districts are required, under federal law (NCLB), to take prescriptive measures if any school fails to meet state-established levels of performance on a narrow set of indicators (test scores, attendance, and graduation). Schools are labeled "unsatisfactory" on the state report card if they failed to meet established summative performance targets.

Having been labeled "unsatisfactory" for three years and averaging student performance in the bottom 5\% among high schools, statewide, Crossroads was found to be eligible for a large multi-year federal School Improvement Grant (SIG), if only they adopt and implement one of four school turn around models; school closure, transformation, restart or turnaround. All four models would have required major staffing changes and replacing the current principal, Mr. Lovall. District administrators consulted with staff at the State agency about the requirements of the four models and decided not to accept the grant but subsequently, ended up replacing the principal anyway due to state budget shortfalls. The district office education director, Mrs. Refermer, a former comprehensive high school principal, was called upon to fill the position. 
Mrs. Refermer was familiar with Crossroads, having worked with Mr. Lovall on the Continuous Improvement Plan (CIP); although, she had not ever served as principal of an alternative high school. She had been involved in the school's recent 6-year site visit conducted by Northwest Accreditation Commission, now referred to as AdvancED. She had assisted in preparing for the accreditation visit by helping to fill out the SelfStudy Documentation and supported staff in reviewing their curriculum. The one-day onsite review, scheduled once every 6 years, is based upon established accreditation standards for special purpose schools and conducted by an evaluation team. Mrs. Refermer had helped the school prepare for the visit and presented information regarding the district role and documentation gathered during the self-study.

In addition to her participation in the Accreditation visit, the past four years Mrs. Refermer had been given the responsibility of conducting an annual program evaluation. Having no background in formal program evaluation, she utilized the Toolkit for program evaluation, which was essentially a checklist of laws and requirements that were required by the State such as fire inspections, highly qualified teachers, criminal background checks, plans to deal with lead-based paint and blood-borne pathogens. While she did not find the checklist particularly useful, Mrs. Refermer used it during the winter to evaluate the compliance of Crossroads School. In addition, she annually worked with the principal, Mr. Lovall to refine and repurpose Crossroad's School Improvement Plan, utilizing the same forms and Specific, Measurable, Attainable, Relevant and Time-bound (SMART) Goals required for traditional comprehensive high schools in the district. 
In the months leading up to the start of the school year at Crossroads, Mrs. Refermer began, as she had done in her previous years as a traditional high school principal, by preparing the building and staff, scheduling school events and assembling the instructional resources that would be available for teaching and learning. When the students arrived the first day of school and made their way into the school cafeteria for breakfast, she remembers thinking to herself that the setting looked more like the Star Wars Cantina than a high school. There were students in all shapes and sizes, with tattoos, piercings, spiked hair, worn-out clothing. Teen moms were busily feeding their young children while other students were lined up for breakfast and to take daily medications. She greeted each of the students as they arrived, making note of what she had learned about each student by reviewing their student profiles in the weeks preceding this first day of school. Feeling overwhelmed by the needs of the students, she sat down to consider what adjustments she and the staff needed to make as the school year started.

Mrs. Refermer realized that she needed something much more useful than a State Developed Checklist for Alternative School Compliance and SMART goals to meet the individual needs of the students at this school. She needed ways to monitor and determine the impact they were making with each and every student who attends Crossroads.

Lying awake at night after the first full day as Crossroads Alternative High School Principal, she began to formatively consider the following questions:

1. Who are these students? Where did they come from? How can we help them?

2. Reporting-What measurements would be useful in determining our success?

3. Compliance-What federal and state laws do we still need to follow?

4. Quality-What would success look like at our school?

5. How do we determine the impact that our school is making on each student?

6. What is the most effective way to tell our schools' story? 


\section{REFERENCES}

AdvancEd. (2012a). AdvancED. Retrieved May 27, 2012, from http://www.advanced.org/

AdvancEd. (2012b). Accreditation the advancEd way. Alpharetta, GA: AdvancEd. Retrieved from http://www.advanc-ed.org/resources/accreditation-support AdvancEd. (2012c). What is accreditation? Alpharetta, GA: AdvancEd. Retrieved from http://www.advanc-ed.org/what-accreditation

AdvancEd. (n.d.). We are advancEd. Alpharetta, GA: AdvancEd. Retrieved from http://www.advanc-ed.org/press-room

Algozzine, B., Horner, R., Sugai, G., Barrett, S., Dickey, S., Eber, L., \& Kincaid, D. (2010). Evaluation blueprint for school-wide positive behavior support. National Technical Assistance Center on Positive Behavior Interventions and Support. Retrieved from www.pbis.org

Aron, L. Y. (2003, July 31). Towards a typology of alternative education programs: a compilation of elements from the literature. Text. Retrieved September 20, 2012, from http://www.urban.org/publications/410829.html

Aron, L. Y. (2006, March 6). An Overview of Alternative Education. Text. Retrieved September 20, 2012, from http://www.urban.org/publications/411283.html

Bandura, A. (1997). Self-efficacy: the exercise of control. Macmillan.

Barr, R. D., \& Parrett, W. (1997a). How to Create Alternative, Magnet, and Charter Schools That Work. National Educational Service. 
Barr, R. D., \& Parrett, W. (1997b). How to create alternative, magnet, and charter schools that work. Bloomington, Ind.: National Educational Service.

Barr, R. D., \& Parrett, W. (2001). Hope fulfilled for at-risk and violent youth: K-12 programs that work. Allyn and Bacon.

Barr, R. D., \& Parrett, W. H. (2010). The kids left behind: catching up the underachieving children of poverty. Solution Tree.

Barr, R. D., \& Yates, D. L. (2010). Turning your school around $\square$ : a self-guided audit for school improvement. Bloomington, IN: Solution Tree Press.

Borg, W., \& Gall, M. (1989). Educational research $\square$ : an introduction (5th ed.). White Plains, New York: Longman Inc. Retrieved from http://www.eric.ed.gov/PDFS/ED400583.pdf

Bridges, E. M., \& Hallinger, P. (1995). Implementing problem based learning in leadership development. ERIC Clearinghouse on Educational Management, 5207 University of Oregon, Eugene, OR 97403-5207. Retrieved from http://www.eric.ed.gov/ERICWebPortal/contentdelivery/servlet/ERICServlet?acc no=ED400583

Bruner, J. S. (1996). The culture of education. Cambridge, Mass.: Harvard University Press.

Brush, C., \& Jones, B. (2002). Student voices: why school works for alternative high school students (Report, findings and quotations). Oregon: Oregon Department of Education. Retrieved from http://www.ode.state.or.us/data/reportcard/whyschworks.pdf 
Carpenter, D. (2005). Playing to type? mapping the charter school landscape (p. 24). Thomas B. Fordham Foundation \& Institute. Retrieved from http://www.eric.ed.gov/PDFS/ED489109.pdf

Chalker, C. S. (1996). Effective alternative education programs $\square$ : best practices from planning through evaluating. Lancaster: Technomic Pub.

Chenoweth, T. G., \& Everhart, R. B. (2002). Navigating comprehensive school change $\square$ : a guide for the perplexed. Larchmont, N.Y.: Eye on Education.

Coalition for Community Schools. (2012). Community schools evaluation toolkit. Retrieved September 23, 2012, from http://www.communityschools.org/resources/community_schools_evaluation_too lkit.aspx

Collins, J. C. (2005). Good to great and the social sectors: why business thinking is not the answer $\square$ : a monograph to accompany Good to great $\square$ : why some companies make the leap--and others don't. J. Collins.

Collins, James. (2001). Good to great $\square$ : why some companies make the leap--and others don't (1st ed.). New York NY: HarperBusiness.

Collins, Jim. (2006). Good to great and the social sectors: why business thinking is not the answer. Random House Business.

Conley, B. E. (2002a). Alternative schools $\square$ : a reference handbook. Santa Barbara, Calif.: ABC-CLIO.

Conley, B. E. (2002b). Alternative Schools: A Reference Handbook. ABC-CLIO. 
Cotton, \& Paglin. (1995). Effective schooling practices: a research synthesis (A Research Synthesis). Portland, Oregon. Retrieved from http://www.nwrel.org/scpd/esp/esp95.html\#1

Covey, S. M. R. (2008). The speed of trust: the one thing that changes everything (Reprint.). Free Press.

Covey, S. R. (2004). Seven habits of highly effective people. Simon and Schuster. Creative Commons. (2013). About the licenses. Retrieved April 22, 2013, from http://creativecommons.org/licenses/

Cuban, L. (1970). To make a difference; teaching in the inner city. New York: Free Press. Cuban, L. (1988). The managerial imperative and the practice of leadership in schools. Albany: State University of New York Press.

Cuban, L. (2003). Why is it so hard to get good schools? New York: Teachers College Press.

Cuban, L. (2012). Policy to Practice: An Abundance of Metaphors | Larry Cuban on School Reform and Classroom Practice. Retrieved June 1, 2012, from http://larrycuban.wordpress.com/2012/06/01/policy-to-practice-an-abundance-ofmetaphors/

Dewey, J. (1909). Moral principles in education, . Boston; New York [etc.: Houghton Mifflin Company.

Dewey, J. (1916). Democracy and education $\square$ : an introduction to the philosophy of education. New York: Macmillan.

Dewey, J. (1938). Experience and education. New York: Macmillan. 
Donaldson, S. (2013). Trends \& innovations likely to influence your evaluation practice. Portland, Oregon. Retrieved from http://oregoneval.org/dev/wpcontent/uploads/2013/01/Donaldson-Keynote-OPEN-Conference-3-15-13-1.pdf

Donaldson, S. I., Azzam, T., \& Conner, R. F. (Eds.). (2013). Emerging practices in international development evaluation. Information Age Publishing.

Dunsworth, M., \& Billings, D. (2010). The high-performing school $\square$ : benchmarking the 10 indicators of effectiveness. Moorabbin, Vic: Hawker Brownlow Education.

Edmonds, R. (1979). A discussion of the literature and issues related to effective schooling. Retrieved from http://www.eric.ed.gov/ERICWebPortal/detail?accno=ED170394

Edwards, C. (2012). Designing new and innovative alternative high schools: what leaders need to know (Unpublished dissertation proposal). Portland State University.

Eisner, E. W. (1985). The educational imagination $\square$ : on the design and evaluation of school programs. New York: Macmillan Publishing Company.

Elmore, R. F. (2004). School reform from the inside out: policy, practice, and performance. Harvard Education Press.

English, F. W. (Ed.). (1999). Deciding what to teach and test: developing, aligning, and auditing the curriculum. Corwin Press.

Ennis, R., Jolivette, K., Swoszowski, N., \& Johnson, M. (2012). Secondary prevention efforts at residential facility for students with emotional and behavioral disorders: 
function-based check-in, check-out. Residential Treatment For Children \& Youth, 29(2), 79-102.

Figlio, D., \& Lucas, M. (2004). What's in a grade? school report cards and the housing market. The American Economic Review, 94(3), 591-604.

Finnan, C., \& And Others. (1996). Accelerated Schools in Action: Lessons from the Field. Corwin Press, Inc., 2455 Teller Road, Thousand Oaks, CA 91320 (e-mail: order@corwin.sagepub.com). Retrieved from http://www.eric.ed.gov/ERICWebPortal/detail?accno=ED390180

Florida Department of Education. (1999, April). Quality standards for dropout prevention programs. Retrieved from http://www.manatee.k12.fl.us/staff_development/ace_web/Research\%20\&\%20Re sources/resources.pdf

Fowler, F. C. (2004). Policy studies for educational leaders $\square$ : an introduction. Upper Saddle River, N.J.: Merrill.

Friedman, M. (1962). Capitalism and freedom. University of Chicago Press.

Gallup, A. M., \& Newport, F. (2009). Gallup Poll: Public Opinion 2008. Rowman \& Littlefield.

Gardner, H. (2000). The Disciplined Mind: Beyond Facts and Standardized Tests, the K12 Education that Every Child Deserves. Penguin (Non-Classics).

Gay, L. R., Mills, G. E., \& Airasian, P. W. (2006). Educational research $\square$ : competencies for analysis and applications. Upper Saddle River, N.J.: Pearson Merrill Prentice Hall. 
Gay, L. R., Mills, G. E., \& Airasian, P. W. (2009). Educational research $\square$ : competencies for analysis and applications. Upper Saddle River, N.J.: Merrill/Pearson.

Gladwell, M. (2000). The tipping point: how little things can make a big difference. Hachette Digital, Inc.

Goodlad, J. I. (2004). A Place Called School. McGraw-Hill Professional.

Goodman, G. S. (1999). Alternatives in education $\square$ : critical pedagogy for disaffected youth. New York: P. Lang.

Guskey, T. R. (2012). Benjamin S. Bloom: Portraits of an Educator. R\&L Education. Hammond. (2012a, August 7). Oregon school officials set low goals, angering education chief Rudy Crew. The Oregonian - OregonLive.com. Retrieved September 2, 2012, from http://www.oregonlive.com/education/index.ssf/2012/08/oregon_school_officials _set_lo.html

Hammond, B. (2012b). Rudy crew says one third of Oregon school districts must rewrite goals, aim higher. The Oregonian - OregonLive.com. Retrieved September 23, 2012, from http://www.oregonlive.com/education/index.ssf/2012/09/rudy_crew_says_one_thi rd_of_or.html

Harris, D., \& Herrington, C. (2006). Accountability, standards, and the growing achievement gap: lessons from the past half-century. American Journal of Education, 209, 112. 
Hinds, D. (2010). Program brief on alternative education. Oregon department of education.

Hopfenberg, W. S. (1993). The Accelerated schools resource guide. Jossey-Bass.

IEL. (2012). IEL | Institute for Educational Leadership. Retrieved September 23, 2012, from http://www.iel.org/

iNACOL. (2012). International association for k-12 online learning (iNACOL) - national standards. Retrieved from http://www.inacol.org/research/nationalstandards/

Jacobs, H. H. (2010). Curriculum 21: essential education for a changing world. ASCD. JGC Stanford. (2012). California Alternative Education Research Project Report. Retrieved from http://gardnercenter.stanford.edu/our_work/alt-ed.html Joyce, B. R., Wolf, J., \& Calhoun, E. (1993). The self-renewing school. Association for Supervision and Curriculum Development.

Katsiyannis, A., \& Williams, B. (1998). A National Survey of State Initiatives on Alternative Education. Remedial and Special Education, 19(5), 276-284. doi:10.1177/074193259801900503

Kellmayer, J. (1995). How to establish an alternative school. Corwin Press.

Kelly E. Cable, \& Terry E. Spradlin. (2009). Alternative schools: What's in a name? (Center for Evaluation and Education Policy Education Policy Brief No. 4). Indiana: Indiana University. Retrieved from http://ceep.indiana.edu/projects/PDF/PB_V7N4_Winter_2009_EPB.pdf

Kohn, A. (1999). Punished by Rewards: The Trouble with Gold Stars, Incentive Plans, A's, Praise, and Other Bribes. Houghton Mifflin Harcourt. 
Kopkowski, C. (2006). NEA - is smaller better? Retrieved September 23, 2012, from http://www.nea.org/home/12214.htm

Koretz, D. M. (2008). Measuring Up: What Educational Testing Really Tells Us. Harvard University Press.

Lange, \& Sletten. (2002). Alternative education: a brief history and research synthesis. Alexandria VA: National Association of State Directors of Special Education.

Leiding, D. (2008). The hows and whys of alternative education: schools where students thrive. Rowman \& Littlefield Education.

Leone, \& Drakeford. (1999). Alternative education: from a "last chance" to a proactive model. The Clearinghouse, 3(2).

Mann, H., \& Massachusetts. Board of Education. (1957). The republic and the school $\square$ : Horace Mann on the education of free men. New York: Teachers College, Columbia University.

Maslow, A. H. (1970). Motivation and personality. Harper \& Row.

McDonald, J. P. (2007). The power of protocols $\square$ : an educator's guide to better practice. New York: Teachers College Press.

Milliken, B. (2007). The Last Dropout: Stop the Epidemic! Hay House.

Moreley, R. (2012). Alternative schools: questions for administrators and school board members when considering closing a school.

Morken, H., \& Formicola, J. R. (1999). The politics of school choice. Rowman \& Littlefield. 
Morley, R. (1996). Inventory of policies and practices related to student failure and dropping out. Iowa. Retrieved from http://www.iaae.net/site/files/PoliciesPracticesStudentFailure1.pdf

Morley, R. E. (2002). A framework for learning alternative environments in Iowa. Retrieved from http://learningalternatives.net/wpcontent/uploads/legacy/Framework.pdf

Mottaz, C. (2003). Quality High School Curriculum for Alternative Settings. Scarecrow Press.

Multnomah County. (2012). SUN Community Schools | Multnomah County. Retrieved September 23, 2012, from http://web.multco.us/sun/sun-community-schools

Murphy, J., Louis, K. S., \& Association, A. E. R. (1999). Handbook of research on educational administration: a project of the American Educational Research Association. Jossey-Bass Publishers.

NAEA. (2009). Exemplary Practices in Alternative Education. National alternative education association. Retrieved September 19, 2012, from http://thenaea.org/Exemplary_Practices_in_Alternative_Education/

National Commission on Excellence in Education. (1983). A nation at risk: the imperative for educational reform. Retrieved from http://datacenter.spps.org/sites/2259653e-ffb3-45ba-8fd604a024ecf7a4/uploads/SOTW_A_Nation_at_Risk_1983.pdf 
NCES. (2002a). Executive summary, public alternative schools and programs for students at risk of education failure: 2000-01. Retrieved from http://nces.ed.gov/surveys/frss/publications/2002004/index.asp

NCES. (2002b). Public alternative schools and programs for students at risk of education failure. Retrieved from http://nces.ed.gov/pubsearch/pubsinfo.asp?pubid=2002004

NCES. (2010a). Alternative schools and programs for public school students at risk of educational failure: 2007-08. Retrieved from http://nces.ed.gov/pubsearch/pubsinfo.asp?pubid=2010026

NCES. (2010b, March 23). Alternative Schools and Programs for Public School Students At Risk of Educational Failure: 2007-08. Retrieved May 27, 2012, from http://nces.ed.gov/pubsearch/pubsinfo.asp?pubid=2010026

NDPN/C. (2011). Effective strategies for dropout prevention. Retrieved September 16, 2011, from http://www.dropoutprevention.org/effective-strategies

NWAC. (2011). Northwest accreditation commission to join advanced. AdvancED. Retrieved from http://www.advanc-ed.org/press-room

NWREL, Paglin, C., \& Fager, J. (1997). Alternative schools: approaches for students at risk. Retrieved from http://educationnorthwest.org/webfm_send/456

O’Neill, J. (2006). The Power of SMART goals $\square$ : using goals to improve student learning. Bloomington, IN: Solution Tree. 
OEIB. (2012). Governor John Kitzhaber Oregon Education Investment Board Achievement Compact Template. Retrieved September 22, 2012, from http://www.oregon.gov/gov/pages/oeib/oregoneducationinvestmentboard.aspx

Oregon Department of Education. (2006a). 2006 Summary of Exemplary Oregon Alternative Education Programs. Retrieved from http://www.ode.state.or.us/teachlearn/specialty/alt/summary-of-specific-aspectsof-select-exemplary-programs.pdf

Oregon Department of Education. (2006b). Alternative Education - Oregon Department of Education. Retrieved May 27, 2012, from http://www.ode.state.or.us/search/page/?id=731

Oregon Department of Education. (2006c). Alternative Education: Toolkits for Districts Oregon Department of Education. Retrieved September 25, 2012, from http://www.ode.state.or.us/search/page/?id=731

Oregon Department of Education. (2011). Standards for district success: continuous improvement planning and district accountability conceptual framework. Retrieved from http://www.google.com/url?sa=t\&rct=j\&q=\&esrc=s\&source=web\&cd=1\&ved=0 CCIQFjAA\&url=http\%3A\%2F\%2Fwww.ode.state.or.us\%2Fschoolimprovement \%2Fcdip\%2Fstandardsfordistrictsuccess.rtf\&ei=hipeULXiFKjUigK_mICAAg\&u sg=AFQjCNGMLgmVQ2Wa5QKgHUoUR8JQX21vRg\&sig2=ZiJ6ZYDyLzZEuBA6WsNLw\&cad=rja 
Oregon Department of Education. (2012). Next generation of accountability - oregon department of education. Next generation of accountability. Retrieved September 19, 2012, from http://www.ode.state.or.us/search/page/?id=3475

OSBA. (2008). Board Policy for Alternative Education. Retrieved September 25, 2012, from http://www.osba.org/Resources/LeftNav/Board_Policy.aspx

Patton, M. Q. (2011). Developmental evaluation $\square$ : applying complexity concepts to enhance innovation and use. New York: Guilford Press.

Popham, W. J. (2001). The Truth About Testing: An Educator's Call to Action. ASCD. Quality Education Commission. (2012). Quality Education Commission Report. Oregon Department of Education.

Quinn, M., \& Poirier, J. (2006). Study of effective alternative education programs final grant report. Washington, D.C.: Office of Special Education Programs, U.S. Department of Education.

Quinn, M., Rutherford, R., Leone, P., Osher, D., \& Poirier, J. (2005). Youth with disabilities in juvenile corrections: a national survey.

Ravitch, D. (2010). The death and life of the great American school system $\square$ : how testing and choice are undermining education. New York: Basic Books.

Raywid, M. A. (1981). The First Decade of Public School Alternatives. Phi Delta Kappan, 62(8), 551-54.

Raywid, M. A. (1994). Educational leadership: the new alternative schools: synthesis of research / alternative schools: the state of the art. Retrieved September 20, 2012, from http://www.ascd.org/publications/educational- 
leadership/sept94/vol52/num01/Synthesis-of-Research- -Alternative-Schools@The-State-of-the-Art.aspx

Redding, S. (2006). The mega system: deciding. learning. connecting. a handbookfor continuous improvement within a community of the school. Academic Development Institute.

Redding, S., \& Walberg, H. (Eds.). (2008). Handbook on statewide systems of support. The Acadmic Development Institute and Information Age Publishing. Retrieved from www.centerii.org

Reimer, M. S., \& Cash, T. (2003). Alternative schools: best practices for development and evaluation. National Dropout Prevention Center/Network, Clemson University. Retrieved from http://www.eric.ed.gov/ERICWebPortal/contentdelivery/servlet/ERICServlet?acc no=ED481475

Russ-Eft, D. (2008). Evaluator competencies $\square$ : standards for the practice of evaluation in organizations (1st ed.). San Francisco: Jossey-Bass.

Sagai, G., Horner, R. H., Dunlap, G., Hieneman, M., Lewis, T., Nelson, C. M., ... Ruef, M. (2000). Applying positive behavior support and functional behavioral assessment in schools. Journal of Positive Behavior Interventions, 2, 131-143.

Sailor, W., Dunlap, G., Sugai, G., \& Horner, R. (2009). Handbook of positive behavior support. Retrieved from http://www.pbis.org 
Sanders, M. G. (2000). Schooling students placed at risk $\square$ : research, policy, and practice in the education of poor and minority adolescents. Mahwah, N.J.: L. Erlbaum Associates.

Schargel, F. P. (2003). Dropout prevention tools. Eye on Education.

Schargel, F. P. (2005). Best Practices to Help At-Risk Learners. Eye On Education.

Schargel, F. P., \& Smink, J. (2001). Strategies to help solve our school dropout problem. Larchmont, N.Y.: Eye On Education.

Senge, P. M. (2006). The fifth discipline: the art and practice of the learning organization. Random House Digital, Inc.

Shah, \& Brink etc. (2012). Coalition for community schools evaluation toolkit. Retrieved September 23, 2012, from http://www.communityschools.org/resources/community_schools_evaluation_too lkit.aspx

Shah, Mediratta, \& McAlister. (2009). Building a district wide small schools movement.

Shannon, G. S. (2007). Nine characteristics of high-performing schools second edition resource list. Retrieved September 22, 2012, from http://www.sos.wa.gov/library/docs/spi/9characteristicsRresourcelist_2008_0084 95.pdf

Sharp, V. F. (1979). Statistics for the social sciences. Boston, MA: Little, Brown.

Shaw, L. (2006). Foundation's small-schools experiment has yet to yield big results. Retrieved from http://seattletimes.com/html/localnews/2003348701_gates05m.html 
Slavin, R. E. (1989). Effective programs for students at risk. Boston: Allyn and Bacon. Smink, J., \& Schargel, F. P. (2004). Helping students graduate: a strategic approach to dropout prevention. Eye on Education.

Spaulding, D. (2008). Program evaluation in practice $\square$ : core concepts and examples for discussion and analysis (1st ed.). San Francisco: Jossey-Bass.

Stiggins, R. J., \& Assessment Training Institute. (2005). Classroom assessment for student learning $\square$ : doing it right -- using it well. Portland, Or.: Assessment Training Institute.

Thomas, R. G., \& Thomas, R. M. (2008). Effective Teaching in Correctional Settings: Prisons, Jails, Juvenile Centers, and Alternative Schools. Charles C Thomas Publisher.

Tobin, T, \& Sprague, J. (2000). Alternative education strategies: reducing violence in school and community programs. Journal of Emotional and Behavioral Disorders, 8, 177-186.

Tobin, Tary, \& Sprague, J. (1999). Alternative education programs for at-risk youth: issues, best practice, and recommendations. Oregon school study council bulletin, 42(4), n4.

Tomlinson, C. A., \& McTighe, J. (2006). Integrating differentiated instruction and understanding by design. ASCD.

Tyack, D. B., \& Cuban, L. (1995). Tinkering toward utopia $\square$ : a century of public school reform. Cambridge, Mass.: Harvard University Press.

USED. (2001). No child left behind. Retrieved from http://www2.ed.gov/nclb 
Viteritti, J. P. (2001). Choosing equality: school choice, the constitution and civil society. Brookings Institution Press.

Wholey, J. (2010). Handbook of practical program evaluation (3rd ed.). San Francisco: Jossey-Bass.

Witty, J. (2009). Exemplary practices in alternative education: indicators of quality programing. National Alternative Education Association. Retrieved from http://www.the-naea.org/NAEA/wpcontent/uploads/Documents/ExemplaryPracticesinAE.pdf

Yarbrough, D. B., Shulha, L. M., Hopson, R. K., \& Caruthers, F. A. (2011). The program evaluation standards $\square$ : a guide for evaluators and evaluation users (3rd ed.). Los Angeles: SAGE. 
APPENDIX A

THE EVALUATION TOOLKIT

\section{Contents:}

\section{Tools:}

Evaluation Toolkit Introduction and Protocols

Evaluation Planning Worksheet (blank)

Evaluation Tools:

Curriculum

Assessment

Instruction

Engagement

Structures

Leadership

\section{Meeting Agendas:}

Pre-Evaluation \#1 Agenda

Pre-Evaluation \#2 Agenda

Meeting \#1 Agenda (Design Team)

Meeting \#2 Agenda (Design Team)

Meeting \#3 Agenda and Annotated Agenda

Meeting \#4 Agenda and Annotated Agenda

Meeting \#5 Agenda and Annotated Agenda

\section{Examples:}

Example: Zeeland School District Alternative School Evaluation Scope of Work Example: Evaluation Planning Worksheet (completed)

Example: Alternative High School Accountability Metrics

Example: Whyroads Evaluation Final Report 


\section{Alternative High School Program Evaluation Toolkit}

Introduction: Welcome to the Alternative High School Program Evaluation Toolkit. This Toolkit is designed to help alternative high schools evaluate their efforts with the support of others in their community. Program evaluation teams are assembled to help alternative high schools learn from their successes, identify current challenges, plan for improvement and more effectively tell their story. This Toolkit describes a process for planning and tools for data collection and information gathering that support the evaluation team in conducting a thorough and accurate evaluation.

Alternative school evaluation process needs to be detailed enough to account for many different types of alternative schools. The process needs to include both internal and external practitioners and stakeholder and is preferably facilitated by someone outside the organization (Facilitator).

\section{$\underline{\text { Tools }}$ for Evaluation Teams (Six Tools):}

1. Assessment: Assessment for learning and assessment of learning - The school maintains methods of tracking student performance and growth.

2. Curriculum: Aligned, managed and monitored curriculum - Both teachers and students know what is taught and assessed.

3. Engagement: Engaged in relevant learning activities - Students attend and participate.

4. Instruction: Sustainable instructional capacity - Effective learning and instruction is used in the teaching and learning process

5. Leadership: Effective leadership - Guidance is provided in assuring teacher effectiveness and student performance

6. Structures: Integrated systems and structures - Systems of student support assure programs are achieving results and outcomes

Evaluation Teams are made up of both internal and external practitioners and stakeholders:

- Internal stakeholders (school leaders, teachers, students and members of the original school design team or board)

- External stakeholders (members of a regional accreditation association, education service district, members of the community or a trained program evaluator)

Evaluation Team Members include school leaders, i.e., principals, school directors, site coordinators, superintendents, local government leaders, foundations, site, curriculum planners, 
community organizations, higher-education faculty and member of the community with an interest and understanding about alternative high schools and programs.

Purpose of the Toolkit is for evaluation teams to learn about planning and conducting evaluation.

- Inventory - Seeks to understand the context of the school and its programs in order to account for its unique purpose and student population. Inventory policies and practices related to student failure and dropping out, use new and existing data sources to learn from success, identify areas in need of improvement and effectively tell the schools story.

- Quality - Gather information, observations and evidence that help in identifying challenges and informing future planning and decisions.

- Compliance - Assure the alternative high schools are following laws that assure the safety of students and a minimum level of quality and predictability among schools.

\section{Evaluation Protocol (Instructions for Facilitating Evaluation and Team Planning - Six Steps):}

1. Use the Alternative School Evaluation Planning Worksheet to discuss the purpose of the evaluation and collect information to discuss how the evaluation results will be used.

2. As a whole group, review and discuss the research-based principles that are included. Allow each team member, including the facilitator, to take a lead role in collecting evidence and observations to support determinations and further discussion regarding at least one of the six Tools for Evaluation Teams (briefly described above).

3. Review the Initial Survey Questions and Comments in workgroups, then as a whole group with time for evaluators to reflect on thoughts, observations and the evidence.

4. Proceed to the School Progress Indicators in small workgroups; record and come to consensus on what is meant by "Exemplary", "Effective" and "In Need of Improvement" in Assessment, Curriculum, Engagement, Instruction, Leadership and Organizational Structures. As workgroups, then in the whole group, reflect on the experience of using the six tools, initial survey questions, comments and school progress indicators of evaluation planning.

5. Proceed to the Evaluation Planning Matrix (Simplified Logic Model) and discuss various audiences and the purpose for formative evaluation and planning (Logic Model). Revisit the written purpose of the evaluation process and determine how you will know those objectives were met, what feedback tools are necessary to tell the school's story.

6. Further discuss objectives for the evaluation (described on the evaluation plan worksheet) and summarize the objectives in a shorter statement (one or two words) from the above section in the Evaluation Plan. Further consider the formative and summative evidence and reporting in order to update status regularly in a way the team and members of the community may continue to become informed on how the school is impacting students. 


\section{Alternative High School Evaluation Planning Worksheet}

Alternative School:

Type/Mission of the School (Briefly describe the school):

Organizations that support the school (List and describe):

Purpose of the evaluation (Briefly describe your understandings):

What is the timeline for the evaluation (See second page for guiding questions)?

How will the evaluation results be used and by whom? 
Key participants in the evaluation process:

\begin{tabular}{|c|l|l|}
\hline & $\begin{array}{l}\text { Name } \\
\text { Phone and Email Address }\end{array}$ & $\begin{array}{l}\text { Role with the Alternative School } \\
\text { Evaluation }\end{array}$ \\
\hline 15. & $*$ & \\
\hline 16. & & \\
\hline 17. & & \\
\hline 18. & & \\
\hline 19. & & \\
\hline 20. & & \\
\hline 21. & & \\
\hline 22. & & \\
\hline 23. & & \\
\hline 24. & & \\
\hline 25. & & \\
\hline
\end{tabular}

* Indicates that the evaluation team member who is also the facilitator.

\section{Timeline for Evaluation:}

$\checkmark$ How many times is the group willing to meet?

$\checkmark$ Who will be responsible for taking the group's work and making electronic draft(s)?

$\checkmark$ When do we need a "finished" product?

$\checkmark$ When will additional evidence of results be provided?

$\checkmark$ When will the next evaluations occur?

\section{Materials and Resources Needed:}

- Facilitator (Member of the evaluation team, preferably not associated with the school)

- Room/Uninterrupted space for discussion

- Easel Pad \& Markers, Post-It Notes, Computer(s)

- Documents: Plans, contracts, budgets, requirements and standards

- Data: Program descriptions, reports, profiles, portfolios 
Alternative High School Evaluation Tool: Assessment
"Assessment for learning and assessment of learning",

Initial Survey Questions and Comments - Assessment Evaluation Workgroup

Instructions: Read and consider the questions, check yes/no and expand your response with comments.

Research-Based Principle:

1. Do you believe that administrators, staff, students, parents and the community receive enough training to understand assessment?

[Strongly Disagree] [ Disagree] [ Neutral] [ Agree] [Strongly Agree] Comments and Evidence:

Research-Based Principle:

2. Do you believe that those involved in the process of teaching and learning regularly use data in decision making?

[Strongly Disagree] [ Disagree] [ Neutral] [ Agree] [Strongly Agree]

Comments and Evidence:

\section{Research-Based Principle:}

3. Do you believe that the curriculum and instruction use different kinds of assessments to evaluate student learning?

[Strongly Disagree] [ Disagree] [ Neutral] [ Agree] [Strongly Agree]

Comments and Evidence:

School Progress Indicators - Assessment Evaluation Workgroup

Instructions: Indicate how effectively the school has been in addressing each of the following issues.

\begin{tabular}{|l|l|l|l|}
\hline $\begin{array}{l}\text { "Exemplary" indicates that the school consistently } \\
\text { demonstrates practices described, "Effective" indicates } \\
\text { adequate and "In Need of Improvement" not at all. }\end{array}$ & $\begin{array}{l}\text { Exemplary } \\
\text { Practices }\end{array}$ & $\begin{array}{l}\text { Effective } \\
\text { Practices }\end{array}$ & $\begin{array}{l}\text { In Need of } \\
\text { Improvement }\end{array}$ \\
\hline 1. Uses data-based decision making & & & \\
\hline $\begin{array}{l}\text { 2. Uses student, classroom, school and program data } \\
\text { profiles }\end{array}$ & & & \\
\hline $\begin{array}{l}\text { 3. Uses multiple assessments to evaluate learning, } \\
\text { instruction and interventions }\end{array}$ & & & \\
\hline $\begin{array}{l}\text { 4. Uses the results of assessments to modify curriculum } \\
\text { and instruction }\end{array}$ & & & \\
\hline $\begin{array}{l}\text { 5. Establishes classroom and school goals of assessment } \\
\text { literacy }\end{array}$ & & & \\
\hline 6. Other: & & & \\
\hline
\end{tabular}




\begin{tabular}{|c|c|c|c|}
\hline $\begin{array}{l}\text { Assessment Evaluation Objectives } \\
\text { What do you want to know? }\end{array}$ & $\begin{array}{l}\text { Stakeholder } \\
\text { Groups } \\
\text { Who? }\end{array}$ & $\begin{array}{l}\text { Tool, Data or } \\
\text { Instrument (Feedback } \\
\text { tools) How will you } \\
\text { know it? }\end{array}$ & $\begin{array}{l}\text { Design Timeline \& } \\
\text { Results } \\
\text { (Start and restart dates) } \\
\text { When will you know } \\
\text { it? }\end{array}$ \\
\hline 1. & Students & & \\
\hline 2. & Students & & \\
\hline 3. & Teachers & & \\
\hline 4. & Community & & \\
\hline
\end{tabular}

\section{Evaluation Plan - Assessment Evaluation Workgroup}

Instructions: Further discuss objectives for the evaluation and summarize the objectives in a shorter statement from above. Further consider the formative or summative reporting periods and update status.

\begin{tabular}{|l|l|l|l|}
\hline $\begin{array}{l}\text { Assessment Evaluation Objectives } \\
\text { (From above but more concise) }\end{array}$ & $\begin{array}{l}\text { Stakeholder } \\
\text { Groups }\end{array}$ & Formative and Summative Evidence & Status \\
\hline 1. & Students & & \\
\hline 2. & Students & & \\
\hline 3. & Teachers & & \\
\hline 4. & Community & & \\
\hline
\end{tabular}

Completed by:

Date: 
Alternative High School Evaluation Tool: Curriculum "Aligned, managed and monitored curriculum"

Initial Survey Questions and Comments - Curriculum Evaluation Workgroup

Instructions: Read and consider the questions, check yes/no and expand your response with comments.

\section{Research-Based Principle:}

1. Do you believe that teachers in the school are involved in a process to develop/align curriculum to determine what students need to know, understand and be able to do?

[Strongly Disagree] [ Disagree] [ Neutral] [ Agree] [Strongly Agree]

Comments and Evidence:

Research-Based Principle:

2. Do you believe that instruction will be aligned with the expectations of the school district and state i.e., Diploma, Essential Skills, Performance Tasks and beyond?

[Strongly Disagree] [ Disagree] [ Neutral] [ Agree] [Strongly Agree] Comments and Evidence:

\section{Research-Based Principle:}

3. Do you believe that the classroom instruction at other schools in the grade level or subject have similar expectations for student performance? [Strongly Disagree] [ Disagree] [ Neutral] [ Agree] [Strongly Agree] Comments and Evidence:

\section{School Progress Indicators - Curriculum Evaluation Workgroup}

Instructions: Indicate how effectively the school has been in addressing each of the following issues.

\begin{tabular}{|l|l|l|l|}
\hline $\begin{array}{l}\text { "Exemplary" indicates that the school consistently } \\
\text { demonstrates practices described, "Effective" indicates } \\
\text { adequate and "In Need of Improvement" } \text { not at all. }\end{array}$ & $\begin{array}{l}\text { Exemplary } \\
\text { Practices }\end{array}$ & $\begin{array}{l}\text { Effective } \\
\text { Practices }\end{array}$ & $\begin{array}{l}\text { In Need of } \\
\text { Improvement }\end{array}$ \\
\hline $\begin{array}{l}\text { 1. Curriculum practices are aligned with standards, } \\
\text { assessments and desired student outcomes }\end{array}$ & & & \\
\hline $\begin{array}{l}\text { 2. Effective process of curriculum development, planning } \\
\text { and alignment of curriculum }\end{array}$ & & & \\
\hline $\begin{array}{l}\text { 3. Process of monitoring, evaluating and revising curriculum } \\
\text { to ensure successful student transitions }\end{array}$ & & & \\
\hline 4. Rigorous academic core curriculum for all students & & & \\
\hline $\begin{array}{l}\text { 5. Curriculum that provides coordinated opportunities for } \\
\text { career-related learning experiences }\end{array}$ & & & \\
\hline 6. Other: & & & \\
\hline
\end{tabular}




\begin{tabular}{|c|c|c|c|c|}
\hline \multicolumn{5}{|c|}{$\begin{array}{l}\text { Evaluation Planning Matrix - Curriculum Evaluation Workgroup } \\
\text { Instructions: Discuss possible objectives of your evaluation process and determine how you will know } \\
\text { those objectives were met, what feedback tools you plan to use and when they will be reassessed. }\end{array}$} \\
\hline $\begin{array}{l}\text { Curriculum Evaluation } \\
\text { Objectives } \\
\text { What do you want to know? }\end{array}$ & $\begin{array}{l}\text { Stakeholder } \\
\text { Groups } \\
\text { Who? }\end{array}$ & $\begin{array}{l}\text { Tool, Data or } \\
\text { Instrument (Feedback } \\
\text { tools) } \\
\text { How will you know it? }\end{array}$ & \multicolumn{2}{|c|}{$\begin{array}{l}\text { Design Timeline \& Results } \\
\text { (Start and restart dates) } \\
\text { When will you know it? }\end{array}$} \\
\hline 1. & Students & & & \\
\hline 2. & Students & & & \\
\hline 3. & Teachers & & & \\
\hline 4. & Community & & & \\
\hline \multicolumn{5}{|c|}{$\begin{array}{l}\text { Evaluation Plan - Curriculum Evaluation Workgroup } \\
\text { Instructions: Further discuss objectives for the evaluation and summarize the objectives in a shorter } \\
\text { statement from above. Further consider the formative or summative reporting periods and update status. }\end{array}$} \\
\hline $\begin{array}{l}\text { Curriculum Evaluation } \\
\text { Objectives } \\
\text { (From above but more concise) }\end{array}$ & $\begin{array}{l}\text { Stakeholder } \\
\text { Groups }\end{array}$ & \multicolumn{2}{|c|}{ Formative and Summative Evidence } & Status \\
\hline 1. & Students & & & \\
\hline 2. & Students & & & \\
\hline 3. & Teachers & & & \\
\hline 4. & Community & & & \\
\hline
\end{tabular}

\begin{tabular}{|l|}
\hline Completed by: \\
\hline Date: 1
\end{tabular}




\section{Alternative High School Evaluation Tool: Engagement "Engaged in relevant learning activities"}

Initial Survey Questions and Comments - Engagement Evaluation Workgroup Instructions: Read and consider the questions, check yes/no and expand your response with comments.

\section{Research-Based Principle:}

1. Do you believe students are engaged in core academic achievement and growing?

[Strongly Disagree] [ Disagree] [ Neutral] [ Agree] [Strongly Agree]

Comments and Evidence:

Research-Based Principle:

2. Do you believe there is continuous two-way communication with students and their families?

[ ]SD [ ]D [ ]N [ ]A [ ]SA

[Strongly Disagree] [ Disagree] [ Neutral] [ Agree] [Strongly Agree]

Comments and Evidence:

Research-Based Principle:

3. Do you believe that parents and community members are welcomed partners in supporting student achievement?

[Strongly Disagree] [ Disagree] [ Neutral] [ Agree] [Strongly Agree]

Comments and Evidence:

School Progress Indicators - Engagement Evaluation Workgroup

Instructions: Indicate how effectively the school has been in addressing each of the following issues.

\begin{tabular}{|l|l|l|l|}
\hline $\begin{array}{l}\text { "Exemplary" indicates that the school consistently } \\
\text { demonstrates practices described, "Effective" indicates } \\
\text { adequate and "In Need of Improvement" not at all }\end{array}$ & $\begin{array}{l}\text { Exemplary } \\
\text { Practices }\end{array}$ & $\begin{array}{l}\text { Effective } \\
\text { Practices }\end{array}$ & $\begin{array}{l}\text { In Need of } \\
\text { Improvement }\end{array}$ \\
\hline $\begin{array}{l}\text { 1. Students are able to identify what they need to know, be } \\
\text { able to do and understand }\end{array}$ & & & \\
\hline $\begin{array}{l}\text { 2. Teachers are able to identify what they need to teach and } \\
\text { what the students need to know, be able to do and } \\
\text { understand }\end{array}$ & & & \\
\hline $\begin{array}{l}\text { 3. Students participate in self-directed learning and are able } \\
\text { to demonstrate proficiency in activities where they are } \\
\text { progressing and know where to get help if they need it }\end{array}$ & & & \\
\hline $\begin{array}{l}\text { 4. Administrators encourage and support teachers in } \\
\text { maintaining communication with staff and their families }\end{array}$ & & & \\
\hline $\begin{array}{l}\text { 5. School policies, programs and organization engage } \\
\text { students and their families as active partners with the school }\end{array}$ & & & \\
\hline 6. Other: & & & \\
\hline
\end{tabular}




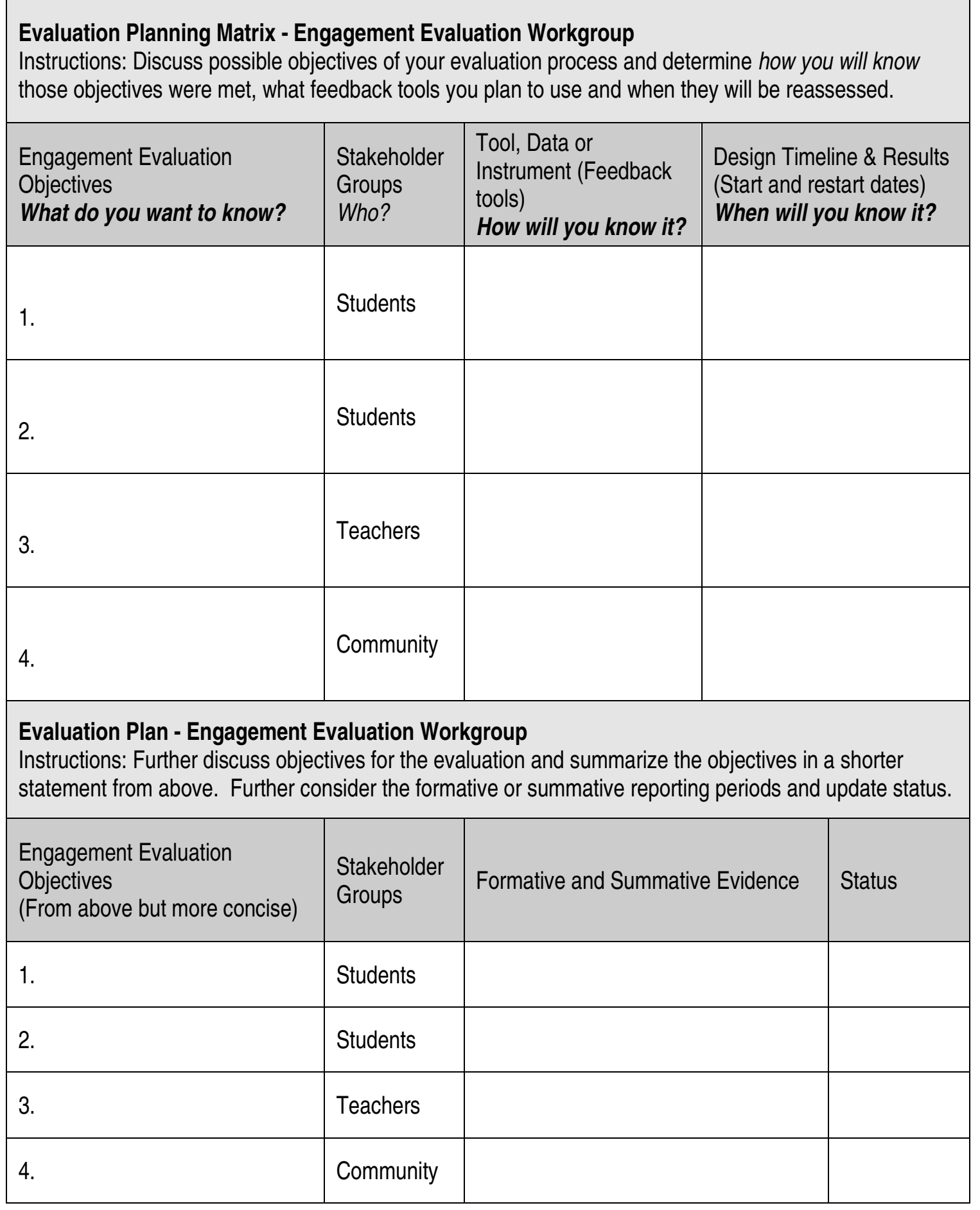

\section{Completed by:}

Date: I_ I




\section{Alternative High School Evaluation Tool: Instruction "Sustainable instructional capacity"}

Initial Survey Questions and Comments - Instruction Evaluation Workgroup

Instructions: Read and consider the questions, check yes/no and expand your response with comments.

\section{Research-Based Principle:}

1. Do you believe that the school will provide time for teachers to meet regularly and review curriculum and information about how students are doing?

[Strongly Disagree] [ Disagree] [ Neutral] [ Agree] [Strongly Agree] Comments and Evidence:

Research-Based Principle:

2. Do you believe that the school is consistently monitoring classroom instruction to ensure that there is alignment with state and local standards? [Strongly Disagree] [ Disagree] [ Neutral] [ Agree] [Strongly Agree] Comments and Evidence:

\section{Research-Based Principle:}

3. Do you believe that the school is providing instructional coaching, professional mentoring or other ongoing classroom supports to ensure high levels of student achievement?

[Strongly Disagree] [ Disagree] [ Neutral] [ Agree] [Strongly Agree] Comments and Evidence:

\section{School Progress Indicators - Instruction Evaluation Workgroup}

Instructions: Indicate how effectively the school has been in addressing each of the following issues.

\begin{tabular}{l|l|l|l|}
\hline $\begin{array}{l}\text { "Exemplary" indicates that the school consistently } \\
\text { demonstrates practices described, "Effective" indicates } \\
\text { adequate and "In Need of Improvement" not at all. }\end{array}$ & $\begin{array}{l}\text { Exemplary } \\
\text { Practices }\end{array}$ & $\begin{array}{l}\text { Effective } \\
\text { Practices }\end{array}$ & $\begin{array}{l}\text { In Need of } \\
\text { Improvement }\end{array}$ \\
\hline $\begin{array}{l}\text { 1. Teachers are provided time and encouraged to meet } \\
\text { regularly to examine student work in a way that informs } \\
\text { instructional practices }\end{array}$ & & & \\
\hline $\begin{array}{l}\text { 2. Teachers are encouraged and supported in classroom } \\
\text { action research, evaluation and informal assessment }\end{array}$ & & & \\
\hline $\begin{array}{l}\text { 3. Administrators provide targeted interventions for low- } \\
\text { performing teachers in using research-based instruction } \\
\text { that is aligned with state and local standards and } \\
\text { assessments }\end{array}$ & & & \\
\hline $\begin{array}{l}\text { 4. Administrators and Teachers use student assessment } \\
\text { data to guide professional development of both teachers } \\
\text { and administrators }\end{array}$ & & & \\
\hline $\begin{array}{l}\text { 5. Administrators and teachers are provided targeted } \\
\text { professional development in content, pedagogy and } \\
\text { diversity }\end{array}$ & & & \\
\hline 6. Other: & & & \\
\hline
\end{tabular}




\section{Evaluation Planning Matrix - Instruction Evaluation Workgroup}

Instructions: Discuss possible objectives of your evaluation process and determine how you will know those objectives were met, what feedback tools you plan to use and when they will be reassessed.

\begin{tabular}{|l|l|l|l|}
\hline $\begin{array}{l}\text { Instruction Evaluation Objectives } \\
\text { What do you want to know? }\end{array}$ & $\begin{array}{l}\text { Stakeholder } \\
\text { Groups } \\
\text { Who? }\end{array}$ & $\begin{array}{l}\text { Tool, Data or } \\
\text { Instrument (Feedback } \\
\text { tools) } \\
\text { How will you know it? }\end{array}$ & $\begin{array}{l}\text { Design Timeline \& Results } \\
\text { (Start and restart dates) } \\
\text { When will you know it? }\end{array}$ \\
\hline 1. & Students & & \\
\hline 2. & Students & & \\
\hline 3. & Teachers & & \\
\hline & Community & & \\
\hline
\end{tabular}

\section{Evaluation Plan - Instruction Evaluation Workgroup}

Instructions: Further discuss objectives for the evaluation and summarize the objectives in a shorter statement from above. Further consider the formative or summative reporting periods and update status.

\begin{tabular}{|l|l|l|l|}
\hline $\begin{array}{l}\text { Instruction Evaluation Objectives } \\
\text { (From above but more concise) }\end{array}$ & $\begin{array}{l}\text { Stakeholder } \\
\text { Groups }\end{array}$ & Formative and Summative Evidence & Status \\
\hline 1. & Students & & \\
\hline 2. & Students & & \\
\hline 3. & Teachers & & \\
\hline 4. & Community & & \\
\hline
\end{tabular}

Completed by:

Date: 


\section{Alternative High School Evaluation Tool: Leadership "Effective leadership"}

Initial Survey Questions and Comments - Leadership Evaluation Workgroup

Instructions: Read and consider the questions, check yes/no and expand your response with comments.

\section{Research-Based Principle:}

1. Do you believe that the school has a vision and mission that is widely supported by teachers and administrators?

[ ]SD [ ]D [ ]N [ ]A [ ]SA

[Strongly Disagree] [ Disagree] [ Neutral] [ Agree] [Strongly Agree]

Comments and Evidence:

Research-Based Principle:

2. Do you believe that the school has focused attention and support for identifying, discussing and dealing with serious problem areas?

[ ]SD [ ]D [ ]N [ ]A [ ]SA

[Strongly Disagree] [ Disagree] [ Neutral] [ Agree] [Strongly Agree]

Comments and Evidence:

Research-Based Principle:

3. Are teachers provided with scheduled time for ongoing collaboration with grade-level or subject-like groups?

[Strongly Disagree] [ Disagree] [ Neutral] [ Agree] [Strongly Agree]

Comments and Evidence:

\section{School Progress Indicators - Leadership Evaluation Workgroup}

Instructions: Indicate how effectively the school has been in addressing each of the following issues.

\begin{tabular}{|l|l|l|l|}
\hline $\begin{array}{l}\text { "Exemplary" indicates that the school consistently } \\
\text { demonstrates practices described, "Effective" indicates } \\
\text { adequate and "In Need of Improvement" not at all. }\end{array}$ & $\begin{array}{l}\text { Exemplary } \\
\text { Practices }\end{array}$ & $\begin{array}{l}\text { Effective } \\
\text { Practices }\end{array}$ & $\begin{array}{l}\text { In Need of } \\
\text { Improvement }\end{array}$ \\
\hline $\begin{array}{l}\text { 1. Demonstrated determination through a clear vision of } \\
\text { excellence in policies, newsletters, press releases, news } \\
\text { stories and other forms of communication }\end{array}$ & & & \\
\hline $\begin{array}{l}\text { 2. Publicized student performance of all required } \\
\text { subgroups, even if the information reflects low school or } \\
\text { subgroup performance }\end{array}$ & & & \\
\hline $\begin{array}{l}\text { 3. Time provided for teacher collaboration and support for } \\
\text { the development and maintenance of professional learning } \\
\text { communities }\end{array}$ & & & \\
\hline $\begin{array}{l}\text { 4. Systemic efforts in place to monitor, evaluate and sustain } \\
\text { student achievement progress }\end{array}$ & & & \\
\hline $\begin{array}{l}\text { 5. Regularly monitored progress toward the established } \\
\text { goals and publicly reported results }\end{array}$ & & & \\
\hline 6. Other: & & & \\
\hline
\end{tabular}




\begin{tabular}{|c|c|c|c|c|}
\hline \multicolumn{5}{|c|}{$\begin{array}{l}\text { Evaluation Planning Matrix - Leadership Evaluation Workgroup } \\
\text { Instructions: Discuss possible objectives of your evaluation process and determine how you will know } \\
\text { those objectives were met, what feedback tools you plan to use and when they will be reassessed. }\end{array}$} \\
\hline $\begin{array}{l}\text { Leadership Evaluation } \\
\text { Objectives } \\
\text { What do you want to know? }\end{array}$ & $\begin{array}{l}\text { Stakeholder } \\
\text { Groups } \\
\text { Who? }\end{array}$ & $\begin{array}{l}\text { Tool, Data or } \\
\text { Instrument } \\
\text { (Feedback tools) } \\
\text { How will you } \\
\text { know it? }\end{array}$ & \multicolumn{2}{|c|}{$\begin{array}{l}\text { Design Timeline \& Results } \\
\text { (Start and restart dates) } \\
\text { When will you know it? }\end{array}$} \\
\hline 1. & Students & & & \\
\hline 2. & Students & & & \\
\hline 3. & Teachers & & & \\
\hline 4. & Community & & & \\
\hline \multicolumn{5}{|c|}{$\begin{array}{l}\text { Evaluation Plan - Leadership Evaluation Workgroup } \\
\text { Instructions: Further discuss objectives for the evaluation and summarize the objectives in a shorter } \\
\text { statement from above. Further consider the formative or summative reporting periods and update status }\end{array}$} \\
\hline $\begin{array}{l}\text { Leadership Evaluation } \\
\text { Objectives } \\
\text { (From above but more concise) }\end{array}$ & $\begin{array}{l}\text { Stakeholder } \\
\text { Groups }\end{array}$ & $\begin{array}{l}\text { Formative and Su } \\
\text { Evidence }\end{array}$ & native & Status \\
\hline 1. & Students & & & \\
\hline 2. & Students & & & \\
\hline 3. & Teachers & & & \\
\hline 4. & Community & & & \\
\hline
\end{tabular}

Completed by:

Date: ___ I




\section{Alternative High School Evaluation Tool: Structures "Integrated systems and structures"}

Initial Survey Questions and Comments - Structures Evaluation Workgroup

Instructions: Read and consider the questions, check yes/no and expand your response with comments

\section{Research-Based Principle:}

1. Does the school provide teachers with low-performing students' adequate assistance and support?

[ ]SD [ ]D [ ]N [ ]A [ ]SA

[Strongly Disagree] [ Disagree] [ Neutral] [ Agree] [Strongly Agree]

Comments and Evidence:

Research-Based Principle:

2. Are there classroom instructional coaches, professional mentors, or other ongoing classroom supports that are intended to ensure high levels of student achievement?

[Strongly Disagree] [ Disagree] [ Neutral] [ Agree] [Strongly Agree]

Comments and Evidence:

Research-Based Principle:

3. Does the school maintain transition plans to help ease the transition of students between schools, programs and onto the world of work and/or post-secondary education?

[Strongly Disagree] [ Disagree] [ Neutral] [ Agree] [Strongly Agree]

Comments and Evidence:

\section{School Progress Indicators - Structures Evaluation Workgroup}

Instructions: Indicate how effectively the school has been in addressing each of the following issues.

\begin{tabular}{|l|l|l|l|}
\hline $\begin{array}{l}\text { "Exemplary" indicates that the school consistently } \\
\text { demonstrates practices described, "Effective" indicates } \\
\text { adequate and "In Need of Improvement" not at all. }\end{array}$ & $\begin{array}{l}\text { Exemplary } \\
\text { Practices }\end{array}$ & $\begin{array}{l}\text { Effective } \\
\text { Practices }\end{array}$ & $\begin{array}{l}\text { In Need of } \\
\text { Improvement }\end{array}$ \\
\hline $\begin{array}{l}\text { 1. Provided ongoing targeted professional development and } \\
\text { training in content, pedagogy and diversity }\end{array}$ & & & \\
\hline $\begin{array}{l}\text { 2. Provided time and encouragement for teachers to meet } \\
\text { regularly to examine and discuss student work collaboratively } \\
\text { and use this information to inform the learning process }\end{array}$ & & & \\
\hline $\begin{array}{l}\text { 3. Extended the school year or reorganized/extended the } \\
\text { school day to support student achievement }\end{array}$ & & & \\
\hline $\begin{array}{l}\text { 4. Provided effective transition between grades, to } \\
\text { postsecondary education or the world of work }\end{array}$ & & & \\
\hline $\begin{array}{l}\text { 5. Integrated school and behavioral systems with other state } \\
\text { and regional services to support students and their families } \\
\text { with both formal and informal interventions }\end{array}$ & & & \\
\hline 6. Other: & & & \\
\hline
\end{tabular}




\section{Evaluation Planning Matrix - Structures Evaluation Workgroup}

Instructions: Discuss possible objectives of your evaluation process and determine how you will know those objectives were met, what feedback tools you plan to use and when they will be reassessed.

\begin{tabular}{|l|l|l|l|}
\hline $\begin{array}{l}\text { Structures Evaluation Objectives } \\
\text { What do you want to know? }\end{array}$ & $\begin{array}{l}\text { Stakeholder } \\
\text { Groups } \\
\text { Who? }\end{array}$ & $\begin{array}{l}\text { Tool, Data or } \\
\text { Instrument (Feedback } \\
\text { tools) How will you } \\
\text { know it? }\end{array}$ & $\begin{array}{l}\text { Design Timeline \& Results } \\
\text { (Start and restart dates) } \\
\text { When will you know it? }\end{array}$ \\
\hline 1. & Students & & \\
\hline 2. & Students & & \\
\hline 3. & Teachers & & \\
\hline & & & \\
\hline
\end{tabular}

\section{Evaluation Plan - Structures Evaluation Workgroup}

Instructions: Further discuss objectives for the evaluation and summarize the objectives in a shorter statement from above. Further consider the formative or summative reporting periods and update status.

\begin{tabular}{|l|l|l|l|}
\hline $\begin{array}{l}\text { Structures Evaluation Objectives } \\
\text { (From above but more concise) }\end{array}$ & $\begin{array}{l}\text { Stakeholder } \\
\text { Groups }\end{array}$ & Formative and Summative Evidence & Status \\
\hline 1. & Students & & \\
\hline 2. & Students & & \\
\hline 3. & Teachers & & \\
\hline 4. & Community & & \\
\hline
\end{tabular}

\section{Completed by:}

Date: 1


Example: Meeting Agendas

\section{SCHOOL DISTRICT}

Steering Committee for Design and Evaluation Process

[Date]

[Time] @ District Office

\section{Agenda - Pre-Process Meeting \#1}

- Introductions

- Needs and Purpose of Design and Evaluation Process - Superintendent

- Description of the Framework and Process - Facilitators

- Description of the Design and Evaluation Team - Facilitators

- Draft Scope of Work - Facilitators

- Next Meeting:

- Needs Assessment Template - Facilitators

- Need for Data and/or Reporting - Facilitators

- Close and confirm the date for next meeting 


\author{
SCHOOL DISTRICT \\ Steering Committee for Design and Evaluation Process \\ [Date] \\ [Time] @ District Office \\ Agenda - Pre-Process Meeting \#2
}

- Welcome

- Clarify and Process "The Charge" - Superintendent

- Finalize the Design and Evaluation Team - Steering Committee

- Report the formalized Needs Assessment - Director

- Report the Data and Previous Reporting - Principal

- Propose the Customized Framework and Process - Facilitators

- Finalized Scope of Work - Facilitators

- Next Meeting - School Design and Evaluation Team:

- The Charge - Superintendent

- Needs Assessment - Director

- Data and/or Reporting - Principal

- Close and confirm the date for next meetings 


\author{
SCHOOL DISTRICT \\ School Design Leadership Team \\ [Date] \\ [Time]@ The Alternative School \\ Agenda - Design Meeting \#1
}

- Introduce and Welcome the Team - Design Facilitator

- Charge - Superintendent

- Needs Assessment - School Principal

- School Design Process - Design Facilitator

- Discuss "School Standards" and Guiding Principles - Team Members

- "10 Essentials of Effective Alternative Schools" - Design Facilitator

- Preview: Creating an Alternative School Vision Statement

- Suggested Reading - Design Facilitator

- Meeting Dates - Design and Evaluation Facilitators

$\circ \quad$ Next Meeting $-[$ Date $]$ 


\section{SCHOOL DISTRICT \\ School Design Leadership Team \\ [Date] \\ [Time] @ The Alternative School \\ Agenda - Design Meeting \#2}

- Introduction - Design and Evaluation Facilitators

- Review of Charge - Superintendent

- Student Voices - Students, Staff and Principal

- Brief Review of Standards, Elements, and Assumptions about Alternative School Design - Design Facilitator

- Development of Shared School Vision - Design Facilitator

- Closure and Next Steps - Design and Evaluation Facilitator

$\circ \quad$ Next Meeting $-[$ Date $]$ 


\section{SCHOOL DISTRICT \\ School Evaluation Leadership Team \\ [Date] \\ [Time]@ The Alternative School \\ Agenda - Evaluation Meeting \#3}

- Revisit Shared School Vision from the Design Process - Design Facilitator

- Revisit Alternative School Evaluation Worksheet - Evaluation Facilitator

- Alternative School Evaluation Training Activity - Evaluation Team

- Alternative School Evaluation Toolkit - Evaluation Team

- Alternative Accountability Metrics - Evaluation Facilitator

- Closure and Next Steps - Evaluation and Design Facilitators

$\circ$ Next Meeting - [Date] 


\author{
SCHOOL DISTRICT \\ School Evaluation Leadership Team \\ [Date] \\ [Time] @ The Alternative School \\ [Annotated] Agenda - Evaluation Meeting \#3
}

- Revisit Shared School Vision from Design Process - Design Facilitator

[Review DRAFT Vision from the past two meetings: Beliefs, Access, Outcomes and

Expectations, Culture, Teaching and Learning]

Handout Presentation Slides and Research Questions (Design and Evaluation)

20 minutes

- Revisit Alternative School Evaluation Worksheet- Evaluation Facilitator

[Revisit Sam's Charge and compare/contrast mission with shared school vision]

Handout Updated Evaluation Worksheet

10 minutes

- Alternative School Evaluation Training Activity - Evaluation Team

[Brainstorm Activity - In pairs or small groups of 2-3, use the agreed upon design characteristics as the basis for completing the phrase: "I think Look for" to determine what are the appropriate things to measure. Later on tonight and next week we will be discussing how we measure those things at the Alternative School as a part of the evaluation planning process. On the draft mission and characteristics paper, record at least one phrase with regard to - beliefs, access, outcomes and expectations, culture, teaching and learning]

20 minutes

BREAK and dinner - 10 minutes

Handout instructions, paper-clipped sets of terms, descriptions and definitions.

[Program Evaluation Team Training (Introduction to Program Evaluation) - In small groups of 3-4, match the terms with the descriptions and definitions provided that describe program evaluation.

Brief introduction of the five terms and asks for short application i.e., Utility (utility belt is actually useful), Feasibility (college savings plan that is feasible), Propriety (Proper evaluation of a school goes beyond just walking into the office of the school or meeting in the library), Accuracy (An accurate evaluation tells the true story of the school), Accountability (allows the local community to hold the school accountable):

1. Utility (useful and purposeful)

2. Feasibility (practical or realistic)

3. Propriety (proper or fair)

4. Accuracy (adequately conveys analysis)

5. Accountability (contextualized and produces value)]

20 minutes

- Alternative School Evaluation Presentation - Evaluation Facilitator

Handout presentation slides and Alternative Education Evaluation Toolkit

20 minutes

- Alternative Accountability Metrics - Evaluation Facilitator

Handout presentation slide - Alternative Accountability Metrics

[Revisit the "Purpose of the evaluation" on the Evaluation Planning Worksheet]

10 minutes

- Closure and Next Steps - Evaluation and Design Facilitator

[Next meeting date, work products - Design Guide and Evaluation Plan etc.]

10 minutes 


\author{
SCHOOL DISTRICT \\ School Evaluation Leadership Team \\ [Date] \\ [Time]@ The Alternative School
}

\title{
Agenda - Evaluation Training Meeting \#4
}

- Revisit Accountability and Program Evaluation - Evaluation Facilitator

- Alternative School Evaluation Worksheet - Evaluation Facilitator

- Alternative School Evaluation Toolkit - Evaluation Team

- Alternative School Evaluation Planning - Evaluation Team

- School Description Review - Design Facilitator

- Closure and Next Steps - Evaluation and Design Facilitators

$\circ$ Next Meeting - [Date] 


\author{
SCHOOL DISTRICT \\ School Evaluation Leadership Team \\ [Date] \\ [Time] @ The Alternative School \\ [Annotated] Agenda - Evaluation Planning Meeting \#4
}

- Revisit Accountability and Program Evaluation - Evaluation Facilitator

[Review program evaluation terms - "Act it out" Charades Activity Slides 1-5

6. Utility (useful and purposeful)

7. Feasibility (practical or realistic)

8. Propriety (proper or fair)

9. Accuracy (adequately conveys analysis)

10. Accountability (contextualized and produces value)

Accountability and Time Variable - Group discussion on Accountability and team member's various roles in "evaluation for the community"]

Handout Presentation Slides

15 minutes

- Alternative School Evaluation Worksheet- Evaluation Facilitator

[Review Alternative Accountability Metrics (Framework) Academic Achievement, School Connection and School Climate]

Handout Updated Evaluation Toolkit (Includes Evaluation Worksheet)

10 minutes

BREAK and dinner

[If you didn't get a chance to review the Alternative School Evaluation Toolkit since last meeting, do so now]

10 minutes

- Alternative School Evaluation Toolkit - Evaluation Team

[Briefly walk through the features in the Alternative Evaluation Toolkit and point out that it includes the updated Example Evaluation Worksheet]

5 minutes

- Alternative School Evaluation Planning - Evaluation Team

Handout presentation slides and Alternative Education Evaluation Toolkit

20 minutes

[Evaluation Planning Activity (Part 1 of 2) - Work with small group of other team members to make use of the tools (First page of the tool only - Questions and Indicators) to begin the evaluation planning. Plan to share out your work.

20 minutes

Evaluation Planning Activity (Part 1 of 2) - Work with your small group to make use of the tools (Second page only - Matrix and Plan) to continue the evaluation planning. Plan to share out your work.]

30 minutes

- School Description Review - Design Facilitator

Handout DRAFT School Description and discuss characteristics and any gaps.]

5 minutes

- Closure and Next Steps - Evaluation and Design Facilitators

[Next meeting date [Date] - Design Guide and Evaluation Plan]

5 minutes 


\author{
SCHOOL DISTRICT \\ School Design and Evaluation Leadership Teams \\ [Date] \\ [Time]@ The Alternative School

\section{Agenda - Final Meeting \#5}

- Welcome - Evaluation Facilitator

- Report on the students who attends - School Principal

- Review DRAFT Program Description - Design Facilitator

- Review DRAFT Alternative School Evaluation Plan - Evaluation Facilitator

- Break

- Focus Group Discussion \#1 (Process and Tools) - Facilitator

- Take the Design and Evaluation Survey (Online) - Team Members

- Focus Group Discussion (Survey Instrument) - Facilitator

- Closure and Thanks - Evaluation and Design Facilitators 


\author{
SCHOOL DISTRICT \\ School Design and Evaluation Leadership Team \\ [Date] \\ [Time] @ The Alternative School \\ [Annotated] Agenda - Meeting \#5
}

- Welcome - Evaluation Facilitator

[1. The purpose of this last meeting together is for all of us to reflect on the design and evaluation process and tools, celebrate success, and consider what we might consider doing differently next time.

2. Review Agenda - Is there anything else we need to accomplish today?]

5 minutes

- Report on the students who attend CLC - Alternative School Principal

Handout: Report on the students who attend the Alternative School

10 minutes

- Review DRAFT Program Description - Design Facilitator

[Review the four assumptions:

-Elements of Effective Alternative Schools (Shared Vision, Educational Diversity,

Relevant/Focused Curriculum, Creative Instructional Approaches, Student Assessments, Caring and Demanding Teachers, Voluntary Participation and School Choice, Comprehensive Programs, Small School Size, Shared Governance and Local Autonomy.)

-Organizational Leadership and Starting Over (Vision, Beliefs, Access, Outcomes and

Expectations, Culture, and Teaching and Learning)

-Accreditation Standards as a Framework for Design

-Evaluation that Begins with the End in Mind

Handout: DRAFT Program Description

10 minutes

- Review Alternative School Evaluation Plan - Evaluation Facilitator

[1. Review the "purpose of the evaluation" from the worksheet

2. Review elements of an effective program evaluation process: Begins with the end in mind, considers established school vision, mission and goals, involves internal and external stakeholders, supports formation of an evaluation team, uses a mix of formative and summative approaches, is practical or realistic (feasible), is contextualized and produces value (accountable), is generally useful (utility), is proper or fair (propriety), accurately conveys analysis (accuracy).

3. Review the tools included in the Evaluation Toolkit: Protocols, Evaluation Planning Worksheet, Evaluation Training, learning, and planning activities, Tools for Evaluation Teams (Curriculum, engagement, instruction, leadership and organizational structures), Initial Survey Questions and Comments Section, School Progress Indicators Section, and Evaluation Planning Matrix and Planning Sections of the Tools for Evaluation Teams. ]

Handout: DRAFT Program Evaluation Plan

10 minutes

Break - 5 minutes

- Focus Group Discussion \#1 (Process and Tools) - Facilitator (Protocol)

- Take the Design and Evaluation Survey (Online) - Team Members

- Focus Group Discussion \#2 (Survey Instrument) - Facilitator (Protocol)

75 minutes

- Closure and Thanks - Facilitators

5 minutes 


\section{Example: Zeeland School District Alternative School Evaluation Scope of Work}

\section{SCOPE OF WORK}

\section{[School District]}

\section{Introduction:}

For the purpose of this Scope of Work, CONTRACTOR shall include FACILITATOR and INNOVATIVE SCHOOL shall include ALTERNATIVE, CHARTER, or MAGNET SCHOOL.

The intent of the proposed process is to design or redesign an innovative school "from scratch" and conduct a produces that results in a School Program Guide and Evaluation Plan.

CONTRACTOR (Researchers) shall perform all of the work required by the Agreement and any Exhibits or change orders. The scope of services that CONTRACTOR is required to perform for the PROJECT consists of the following:

\section{Goals:}

1. To consult the school district in the design (or redesign) of an innovative school.

2. To serve as facilitators to design an evaluate alternative high school.

\section{Tasks:}

- Gain a thorough understanding of the school district, alternative school, other cooperating organizations and their students' needs.

- Facilitate working meetings of a design and evaluation team, appointed by the school district using the Guide to Designing Innovative Schools and the Toolkit for Alternative High School Program Evaluation for the purpose of operational planning for education options for area youth at risk of high school failure.

- Offer advice regarding best practices and recommended models of alternative and innovative education, including, as appropriate, leading visits to other alternative schools.

- Advise the superintendent of school district and the district leadership team regarding composition of the redesign and evaluation team and other decisions as may be appropriate for the evaluation of WAS. 
- Provide research and perspective on Federal and State Law and school district policy in collaboration with the Northwest Association of Accredited Schools (now AdvancED), the Oregon Department of Education and School District.

- Provide a written School Program Guide and Evaluation Report to the superintendent of the school district and the district leadership team regarding the design (or redesign) and plan for evaluation of the alternative school.

- Other tasks as may be required.

\section{Deliverables:}

1. Regular reports detailing progress toward completion of tasks.

2. Attendance and facilitation of at least five team meetings and other meetings as needed.

3. Completion of components of a design and evaluation, including recommended support.

4. Continued support throughout the design (redesign) and evaluation process.

5. Other deliverables as may be required. 


\title{
Example: Evaluation Planning Worksheet (Completed)
}

\author{
Alternative High School Evaluation Planning Worksheet \\ Alternative School: Whyroads Alternative School (WAS)
}

\section{Type/Mission of the School (Brief school description):}

Mission Statement: The Whyroads is an alternative school dedicated to helping students to discover their passion and develop the strong academic and life skills required for healthy, vibrant lives of lifelong learning and positive participation in the community.

Core Value: Our learning community commits to continuously improving the quality of our work while creating a rich, equitable learning environment.

\section{Fundamental Beliefs:}

- Strong Academic and Life Skills: Students will be able to establish goals, organize tasks and set priorities in order to demonstrate the academic and interpersonal skills necessary to further their educations - personally and formally - beyond high school.

- Healthy, Vibrant Lives: Students will be able to set and reflect on personal health goals in the areas of nutrition, physical activity, lifestyle, positive relationships and mental and emotional well-being.

- Positive Participation in the Community: Students will be able to examine controversial events, issues, or problems from a variety of perspectives and contribute positively to their community.

Student Population: The Whyroads Alternative School (WAS) programs serve 66 Academy Students, 44 Options Students, 25 Evening Program Students, 12 Middle School Students (Grades 7-8) and 19 Structured Classroom Students (grades 7-12).

School Setting: WAS serves a total of 166 total students when full. In the 2012-13 school year there were 8 fewer students due to the temporary closure of the middle school structured classroom. All students are served at a school site (previously a church) with multiple small meeting rooms, small classrooms, offices and a cafeteria that serves as a common meeting place and multipurpose room for physical education classes.

Organizations that support the school (Characteristics of the school):

Zeeland School District - Public resident school district supports student placement, professional development, planning and budget for WAS as well as 7 elementary schools, Zeeland Middle School (ZMS) and Zeeland High School (ZHS).

School and Community Partnerships - WAS maintains staff offices and dedicated meeting spaces that support multiple types of programs and counseling. These services range from mental health and special education to health and post-secondary transition programs.

\section{Purpose of the Evaluation:}

- Clarify WAS' purpose, strengths, program expectations and outcomes for students.

- What does WAS do best?

- How does WAS fit within other district options? 
- Establish a clear set of metrics to monitor and evaluate student success at WAS.

- Define clear criteria for student admission to WAS, based on research.

- Align expectations with ZMS/ZHS course requirements for transcripts and graduation.

- Direct students to GED options at Mount Hood and Portland Community Colleges.

- Establish enrollment target, enrollment procedure and staff ratio.

What is the timeline for the evaluation? Winter 2013, with the design (program guide) and evaluation activities (evaluation plan) concluded by March 13, 2013.

How will the evaluation results be used and by whom? School District Board, Superintendent and District Leadership Team in the context of annual budget planning. The school and community for communicating its mission and purpose.

\section{Shared District Vision that resulted from the School Design Process:}

\section{BELIEFS}

$>$ Strive to provide everything to every student.

$>$ See the potential in everyone involved.

$>$ Teachers act as guides, advisors and coaches.

$>$ We are proud of our school.

\section{ACCESS}

$>$ Students choose to attend.

$>$ The school will have a safe learning environment

$>$ The materials and staff to reach desired academic outcomes.

$>$ Staff members are creative, caring, smart and skilled.

OUTCOMES and EXPECTATIONS

$>$ The student to staff ratio is at a high enough level to provide support that is reflected in positive student outcomes.

$>$ The school will emphasize meeting student needs on a non-traditional timeline.

$>$ Students and the school community will fully recognize the real outcomes of the learning experience.

$>$ Academics will prepare students for the next steps of their lives.

\section{CULTURE}

$>$ Staff and students are committed to long-term success.

$>$ The school has a strong link to community and parents.

$>$ Students will have access to mental health supports to develop the social emotional skills necessary.

> The school emphasizes quality over quantity and supports the academic social emotional needs of students.

$>$ The school has a culture built on relationships.

$>$ The school has high expectations, both academic and behavioral, for staff and students.

TEACHING AND LEARNING

$>$ The school has an environment and curriculum that are flexible and individualized.

$>$ The school staff has a knowledge of student needs and interests which guides the structure of learning.

$>$ Students will have multiple opportunities to learn and demonstrate learning. 
Example: Alternative High School Accountability Metrics

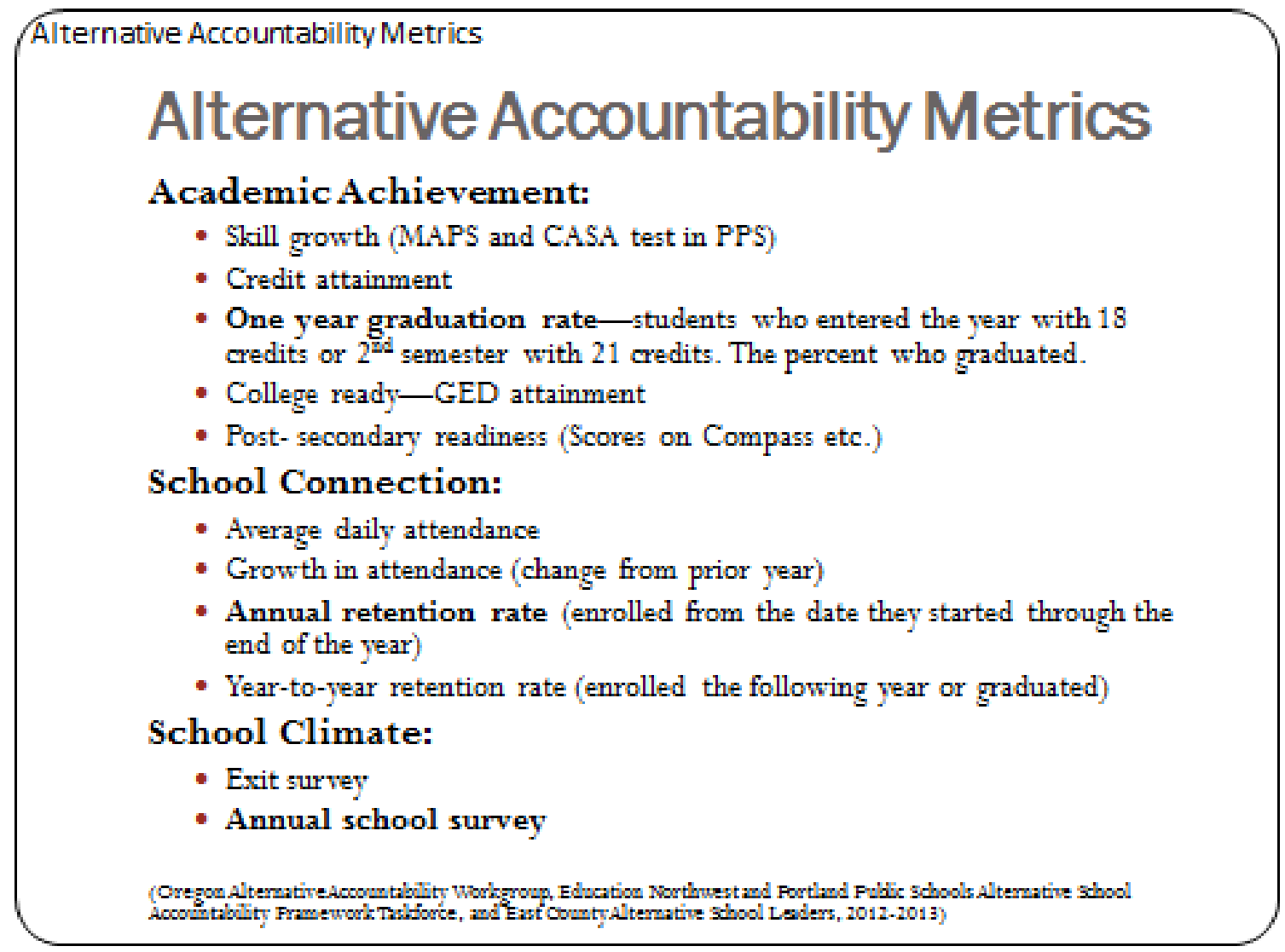


Example: Whyroads Alternative School Evaluation Report

\title{
EXAMPLE FINAL REPORT [Date]
}

\author{
EXTERNAL EVALUATION \\ WHYROADS ALTERNATIVE SCHOOL
}

\author{
A Project of the \\ Zeeland School District \\ Design and Evaluation Team
}




\section{Sample Final Report Table of Contents}

Note: This table of contents is a sample and does not refer directly to pages that follow.

TABLE OF CONTENTS

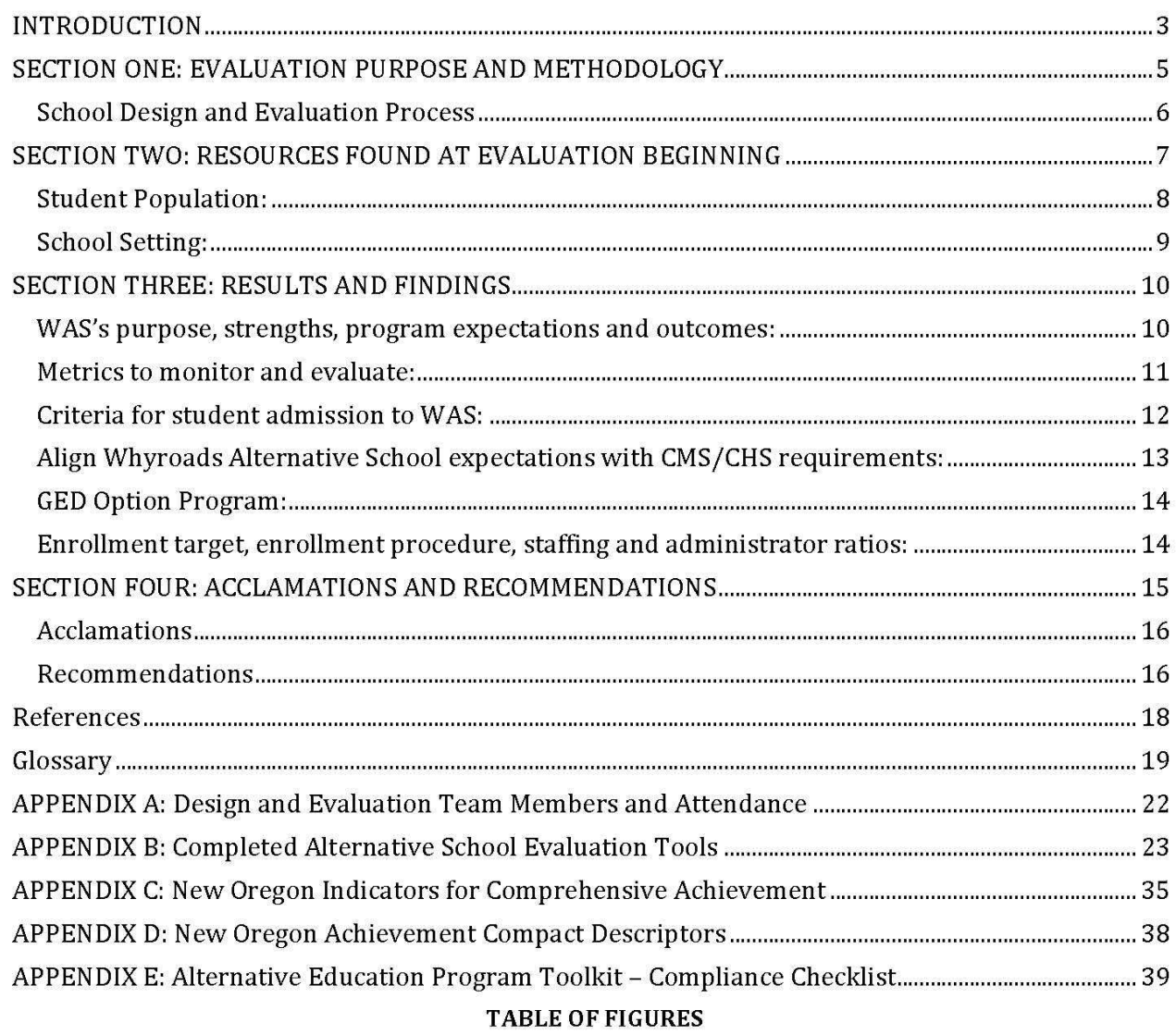

Figure 1: Types of Schools, Adapted from Chenoweth and Everhart ............................................. 4

Figure 2: Students that attend Whyroads Alternative School......................................................... 9

Figure 3: Percent of Special Needs Students and Look and Feel at Whyroads School....................... 9

Figure 4: Alternative Accountibility Metrics ……........................................................................ 12

TABLE OF TABLES

Table 1: Elements of Successful Alternative Schools....................................................................... 5

Table 2: Purpose, Timeline and Use of the Evaluation .................................................................... 6

Table 3: Revised Mission, Core Value, and Fundamental Belief Statements ..................................... 8

Table 4: Shared District Vision and "Look for" that resulted from the School Design Process........... 11

Table 5: Students deemed eligible for alternative education under State law .................................. 13

Table 6: Whyroads Alternative School Staff Names and Titles........................................................ 15

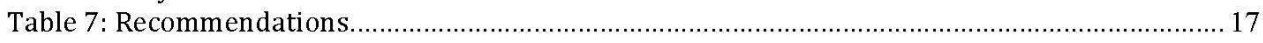

Alternative School Evaluation Toolkit Updated 3/1/2013 (cc) EY-No-sA

Please send feedback to drewhinds@gmail.com 


\section{INTRODUCTION}

Schools like Whyroads Alternative School (WAS) have been called alternative schools, referral schools, and schools of choice (Raywid, 1994) and are sometimes described as "ambulances" for students that have experienced significant challenges or events that have put them at risk of dropping out of school. Schools that serve as an alternative to traditional schools are typically small in size and employ teachers that are both caring and demanding. These schools often use creative instructional approaches and have local autonomy often resulting in relevant and focused curriculum that looks different (Barr \& Parrett, 1997) compared to traditional schools.

Alternative schools often serve some of the most vulnerable students and their programs present a challenge to evaluate using traditional school performance measures such as test scores, attendance and graduation rate. One of the reasons for this is that definitions vary as to what an alternative school actually is, making it difficult to determine indicators that would reliably indicate quality alternative school education programming. Another reason is that alternative high schools are often designed with a purpose to serve a more specialized population than traditional schools. Most students attending these types of schools have experienced some sort of disruption in their education and for one reason or another may be at risk of not graduating on time with their peers.

Figure 1 below is a visual representation of the typology of alternative schools in contrast with traditional and charter schools. Alternative schools are 
schools that are an alternative to traditional schools but usually share some characteristics with traditional schools such as appropriately licensed teachers, diploma requirements, and academic standards. In contrast, Oregon charter schools are schools of choice, chartered by a district, where any student could attend. Charter schools have been provided flexibility in areas like teacher licensure, registration and curriculum but are held locally accountable by a separate charter board of directors responsible for monitoring school performance. The overlap represents situations where comparable programming may be offered.

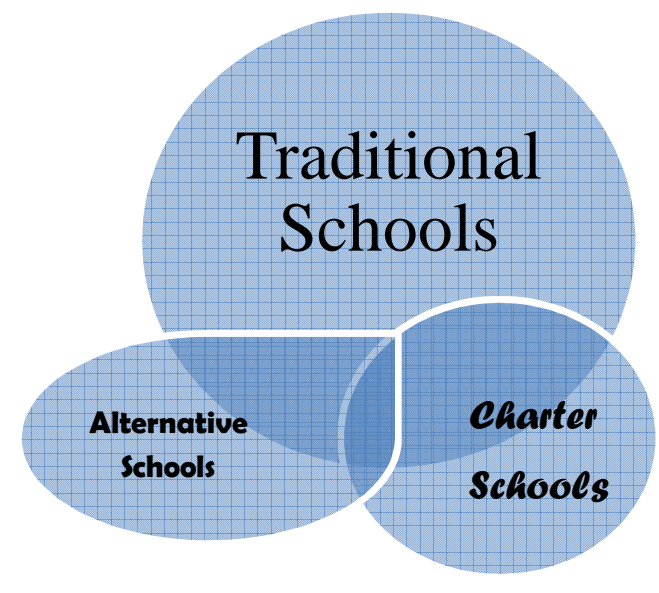

Figure: Types of Schools, Adapted from Chenoweth and Everhart

Successful alternative schools consider all elements of effective alternative schools (see Table 1, below.) Alternative schools should be accredited, which describes quality educational programming in aspects such as mission, curriculum, 
instruction, assessment, leadership and organization, school services, facilities and finance (Northwest Accreditation Commission, 2011). School program descriptions should be developed by alternative schools that communicate a shared vision of the school, consider all the elements and use accreditation standards as a framework for the school design and improvement.

During the past 25 years, thousands of alternative public schools, magnet schools, experimental schools and other non-traditional programs have been developed and documented to be effective in teaching reluctant learners (Barr \& Parrett, 2001). Although alternative education settings vary in both mission and goals, researchers have identified sets of elements intended to be used in describing successful alternative schools (Leiding, 2008; NWREL, Paglin, \& Fager, 1997; ODE, 2006; Schargel \& Smink, 2001). Barr and Parrett (1997) describe these as elements of successful alternative schools.

Table: Elements of Successful Alternative Schools

1. Shared Vision

2. Educational Diversity

3. Relevant and Focused Curriculum

4. Creative Instructional Approaches

5. Student Assessments

6. Caring and Demanding Teachers

7. Voluntary Participation and School Choice

8. Comprehensive Programs

9. Small School Size

10. Shared Governance and Local Autonomy

Source: Barr and Parrett (1997)

Alternative school program evaluations should attend to all of these elements, the accreditation standards geared to improvement, and account for 
[Oregon State Standards for District Success, which include curriculum, instruction, assessment, leadership engagement, and structures (ODE, 2012). An alternative school program evaluation should consider the established school vision, mission or goals (Program Description), involve internal and external stakeholders (community involvement), and use a mix of both formative (informative) and summative (summary) approaches.

\section{SECTION ONE: EVALUATION PURPOSE AND METHODOLOGY}

Local evaluations should account for what is happening at the school and the extent to which it is cost effective to serve students in alternative environments. Lessons learned about maximizing external evaluations (Education Northwest, 2013) suggest school districts be clear about evaluation needs, plan to use appropriate measures, build a strong working relationship with the evaluator, ensure data presentations are useful, build capacity for internal evaluation and maximize the use of evaluation findings. Evaluations should answer many questions, such as: What's working and what's not? Is the program making a difference? Should it continue, expand, or be cut?

Collaboration among Zeeland school and district staff, and direction from both the current and previous district superintendents resulted in the establishment of the following purpose, timeline and intended use for the evaluation. 
Table: Purpose, Timeline and Use of the Evaluation

\section{Purpose of the Evaluation:}

- Clarify WAS's purpose, strengths, program expectations and outcomes for students.

- Establish a clear set of metrics to monitor and evaluate student success at WAS.

- Define clear criteria for student admission to WAS, based on research.

- Align expectations with ZMS/ZHS course requirements for transcripts and graduation.

- Direct students to GED options at Mount Hood and Portland Community Colleges.

- Establish enrollment target, enrollment procedure, and staff ratio.

\section{Evaluation Timeline:}

Evaluation occurred winter 2013, with the design (program guide) and evaluation activities (evaluation plan) concluding March 13, 2013. A full-day site visit occurred in January, followed by two Design Team Meetings, two Evaluation Team Meetings, and a final meeting to reflect, present final products, and discuss next steps.

\section{Use of Evaluation Results:}

The design guide and evaluation plan will be shared with the district superintendent and school board, will be used by the district and school leadership teams in the context of annual school program budget planning, and will support required annual evaluations.

\section{School Design and Evaluation Process}

A unique characteristic of the WAS evaluation was the inclusion of a school design (or redesign) process that included consensus-building activities that resulted in a shared district vision of the school. A benefit of this process was increased awareness and communication between WAS and central office staff about what WAS has to offer students. The design process was followed by an evaluation process that included members of the design team in the formation of an evaluation plan intended to support future program evaluations. During the course of the design and evaluation processes, the school made plans to change its name to Whyroads School and the school leadership team made revisions to the mission, core value and fundamental belief statements. 


\section{SECTION TWO: RESOURCES FOUND AT EVALUATION BEGINNING}

The Whyroads Alternative School has existed for many years and served generations of successful students in the community. The current school principal has been at WAS for almost twenty years and has worked to build a leadership team that values collaboration and meets regularly about their curriculum, innovative forms of assessment, and the needs of individual students. As mentioned, as a part of the design and evaluation process the school leadership team updated their mission, core value, and fundamental belief statements. The revised statements are included below along with a description of the student population and setting.

Table: Revised Mission, Core Value, and Fundamental Belief Statements

\section{Mission Statement:}

The Whyroads Alternative School is an alternative school dedicated to helping students to discover their passion and develop the strong academic and life skills required for healthy, vibrant lives of lifelong learning and positive participation in the community.

\section{Core Value:}

Our learning community commits to continuously improving the quality of our work while creating a rich, equitable learning environment.

\section{Fundamental Beliefs:}

- Strong Academic and Life Skills: Students will be able to establish goals, organize tasks and set priorities in order to demonstrate the academic and interpersonal skills necessary to further their educations-personally and formally—beyond high school.

- Healthy, Vibrant Lives: Students will be able to set and reflect on personal health goals in the areas of nutrition, physical activity, lifestyle, positive relationships, and mental and emotional well-being.

- Positive Participation in the Community: Students will be able to examine controversial events, issues, or problems from a variety of perspectives and contribute positively to their community. 


\section{Student Population:}

The Whyroads Alternative School (WAS) programs serve 66 Academy Students, 44 Options Students, 25 Evening Program Students, 12 Middle School Students (Grades 7-8) and 19 Structured Classroom Students (grades 7-12). The WAS student population demographics and characteristics are further explained by the two figures that follow.

\section{School Setting:}

The Whyroads Alternative School is a public school in the Zeeland School District. Zeeland School District is a public resident school district supports student placement, professional development, planning, and budget for WAS as well as seven elementary schools, a Middle School, and a High School.

WAS serves a total of 166 total students when full. In the 2012-13 school year there were 8 fewer students due to the temporary closure of the middle school structured classroom. All students are served at a school site (previously a church) with multiple small meeting rooms, small classrooms, offices and a cafeteria that serves as a common meeting place and multipurpose room for physical education classes. WAS maintains staff offices and meeting space that support multiple types of counseling. These services range from mental health and special education to health and post-secondary transition. 


\section{SECTION THREE: RESULTS AND FINDINGS}

\section{WAS's purpose, strengths, program expectations and outcomes:}

As described in section two, the school design process was conducted to clarify WAS's purpose, strengths, program expectations and outcomes for students. Elements of successful alternative schools were combined with accreditation standards to provide support to the design team that was made up of diverse stakeholders from the school, district and community. Two design team meetings resulted in a shared vision of the school and a draft of a program guide to support development and evaluation.

The design process was followed by two, two-hour evaluation team meetings that included members of the design team in the formation of an evaluation plan. As mentioned previously in this report, during the design and evaluation processes, the school made plans to change its name from Whyroads Learning Center to Whyroads School and the school leadership team made revisions to the schools mission, core value and fundamental belief statements. In addition, the current school principal, of 18 years, announced her retirement at the end of this school year, raising the level of concern and increasing engagement among members of the school and district leadership teams. The table below includes descriptions of the districts' shared vision that resulted from the design process. 
Table: Shared District Vision from the School Design Process

\section{BELIEFS}

$>$ Strive to provide everything to every student.

$>$ See the potential in everyone involved.

$>$ Teachers act as guides, advisors, and coaches.

$>$ We are proud of our school.

Look for: Advising-time and surveys indicate engagement and pride among staff and students, teacher and class schedules reflect time acting as guides and provide services to students.

\section{ACCESS}

$>$ Students choose to attend.

$>$ The school will have a safe learning environment

$>$ The materials and staff to reach desired academic outcomes.

$>$ Staff members are creative, caring, smart, and skilled.

Look for: Students have choice, staff are dedicated, and attendance rate growth.

\section{OUTCOMES and EXPECTATIONS}

$>$ The student to staff ratio is at a high enough level to provide support that is reflected in positive student outcomes.

$>$ The school will emphasize meeting student needs on a non-traditional timeline.

$>$ Students and the school community will fully recognize the real outcomes of learning.

$>$ Academics will prepare students for the next steps of their lives.

Look for: Students are growing, earning credits, completing requirements, earning college credits, taking college placement tests, enrolling in post-secondary education, and getting jobs.

\section{CULTURE}

$>$ Staff and students are committed to long-term success.

$>$ The school has a strong link to community and parents.

$>$ Students will have access to mental health supports to develop the social skills.

$>$ The school emphasizes quality over quantity and supports the academic social emotional needs of students.

$>$ The school has a culture built on relationships.

$>$ The school has high expectations, both academic and behavioral, for staff and students. Look for: Artifacts demonstrate that school culture is positive, parent advisory group and students reflect that expectations are clear, mental health supports are available on-site.

\section{TEACHING AND LEARNING}

$>$ The school has an environment and curriculum that are flexible and individualized.

$>$ The school staff has a knowledge of student needs and interests which guides the structure of learning.

$>$ Students will have multiple opportunities to learn and demonstrate learning. Look for: Evidence demonstrates that teachers are adjusting instruction based on student needs, students are able to formatively demonstrate what they know in at a flexible pace. 
Metrics to monitor and evaluate:

The design and evaluation team activities facilitated discussions and resulted in working products that resulted in alternative metrics to monitor and evaluate student success at WAS. Among those products was a list of alternative accountability metrics in the figure below.

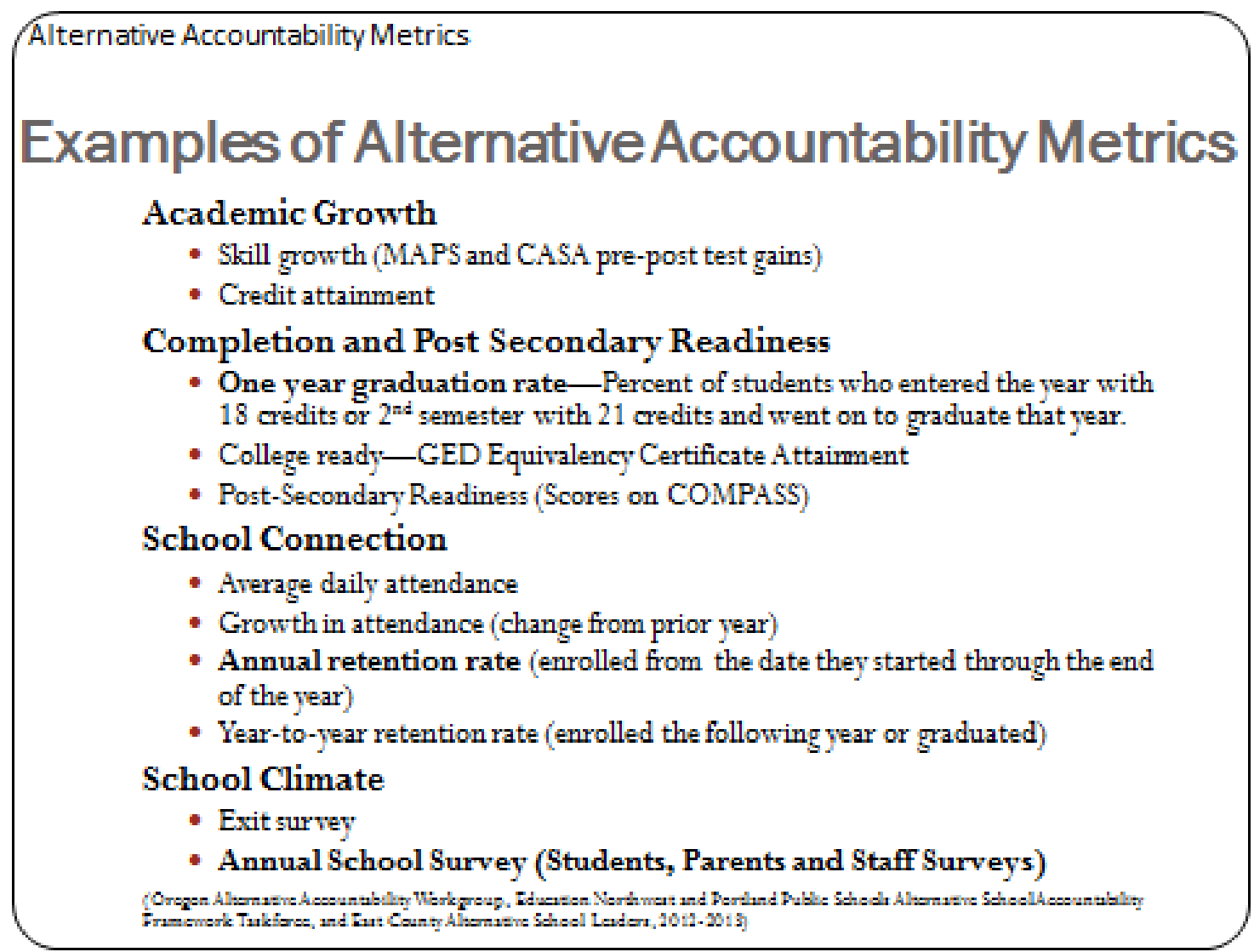

Figure: Alternative Accountibility Metrics

Current WAS data includes state assessments (reading, math, writing and science), scores on college placement, and percent of students who enrolled in college after graduation, those who took college classes in high school, and who attended college for at least two years. WAS tracks overall attendance for students who attend 
full-time and tracks hours of instruction provided for students attending school parttime. The administrator and staff annually reflect on survey data collected from parents, staff, students and exit surveys from students that leave early.

\section{Criteria for student admission to Whyroads Alternative School:}

The District Student Placement Team has previously suggested that students referred to WAS must be behind in the skills and credits required to graduate with their peers but more specific criteria or placement process were not present at the time of the evaluation. However, administrators, teachers, parents and students expressed a desire for more specific placement criteria and intake process.

The expressed mission of WAS is to help student's complete high school and continue on with strong academic and life skills, leading healthy and vibrant lives, and positively participating in the community. Upon entry, WAS student academic transcribed standings vary from zero credits, one-half year behind, one-year behind to more than one year behind. Student behavior accommodations vary widely from the need to develop good academic habits to rehabilitation to the need for treatment of behavior issues or conditions that have been formally or informally identified. WAS students include those who have met one or more of the following state criteria that deem them eligible for alternative education: 
Table: Students deemed eligible for alternative education under State law

- Are not meeting or are exceeding standards and Essential Skills,

- Have an attendance pattern so erratic that they are not benefiting from the educational program,

- Are being considered for expulsion or have been expelled,

- Demonstrate a pattern of severe disciplinary problems,

- Are pregnant or parenting,

- Are 16 or 17 years old, and whose parents have applied for an exemption from compulsory attendance,

- Are emancipated or have initiated the procedure for emancipation, or

- Are otherwise deemed eligible according to the district's policies and procedures for placing students into alternative education programs.

\section{Align Whyroads Expectations with High School Requirements:}

The Zeeland School District has facilitated school-based professional learning communities (PLCs) and data teams and conducted district-wide trainings to accomplish the alignment of Zeeland Middle School (ZMS) and Zeeland High School (ZHS), and Whyroads Alternative School. The work of the design and evaluation team noted this work and observed that the curriculum maps had been updated to align with the new Common Core Standards for Math and English Language Arts and Literacy. The evaluation team also noted that the high school curriculum maps were used as models for determining the minimum course requirements. Recent trainings on Common Core Math (Math Practice Standards) were provided at both the Zeeland High School and Whyroads Alternative School locations.

\section{GED Option Program:}

The original evaluation purpose included instructions to direct students to GED options at Mount Hood and Portland Community Colleges but discussion among the design and evaluation team revealed a shift in the previously held district vision. A GED 
Certificate formally designates students as having the "ability to benefit" from college or university and make them eligible for scholarships and financial assistance to attend college. Students that meet the requirements of the GED may also continue to attend school and go on to achieve a regular diploma and college credits through dual-credit programs.

The development of a GED Option Program at WAS would generate additional state average daily membership revenue and better serve some populations of students, many of whom are currently being referred to the college campus without tight monitoring of instructional supports, outcomes, or program quality. State-level achievement compacts and annual reporting have recently been revised to account for a five-year completer rate that rewards districts for supporting students in obtaining the GED as a high school equivalency certificate in addition to a four-year and five-year regular high school diploma. Based upon these new understandings expressed by the design and evaluation team, WAS has expressed an interest in developing GED Option programming to meet student needs.

\section{Enrollment target, procedure, staffing and administrator ratios:}

Figure 2 and 3 were developed by the WAS principal to illustrate the student population. Student program enrollment counts were reported in the Student Population section of this report but did not include staffing or administrator ratios. The program description and evaluation planning documentation describe program enrollment targets and typical class size. District placement procedures described earlier in this report are used in counselor referral and student placement but budgeting processes will require 
formally reported staff and administrator ratios. The scope and purpose of the evaluation did not include a review of financial or full-time/part-time staff employment records but staff and titles are reported in Table 6 below.

Table: Whyroads Alternative School Staff Names and Titles

\begin{tabular}{|l|l|l|l|}
\hline $\begin{array}{l}\text { Staff } \\
\text { Name }\end{array}$ & Title & $\begin{array}{l}\text { Staff } \\
\text { Name }\end{array}$ & Title \\
\hline & Nurse & & Main Street Teacher \\
\hline & Teacher & & 4C The Future Coordinator \\
\hline & Custodian & & Principal \\
\hline & Middle School Teacher & Options Coordinator \\
\hline & Educational Assistant & & Teacher \\
\hline & Educational Assistant & & Educational Assistant \\
\hline & Media Assistant & School Psychologist \\
\hline & Trillium Therapist & Teacher \\
\hline & Teacher / Councilor & Evening Program Coordinator \\
\hline & Teacher & Special Ed. Records Manager \\
\hline & Evening Program Teacher & & Educational Assistant \\
\hline & Turn Styles Teacher & Teacher \\
\hline & Cook & Secretary \\
\hline & Teacher & Teacher \\
\hline & Educational Assistant & & \\
\hline
\end{tabular}

It should be noted that staff included above may not be employed by Zeeland School District and serve as part of the school community through part-time partnerships and grant-funded initiatives.

\section{SECTION FOUR: ACCLAMATIONS AND RECOMMENDATIONS}

As described earlier in this report, schools like Whyroads Alternative School are sometimes described as "ambulances" for students that have experienced significant challenges or events that have put them at risk of dropping out of school. 
WAS is a family-like atmosphere where students and adults speak to one another with respect on a first-name basis. As one student put it, "It just feels like a family to me." Staff at the school are committed to excellence and over the past three years three-quarters of their graduates have gone on to post-secondary education. The following acclamations and recommendations highlight the observations made during the evaluation process.

\section{Acclamations:}

The Whyroads Alternative School is to be acclaimed for consistently meeting as professional learning communities to gather and reflect on data, discuss and modify curriculum maps and consider levels of student growth, performance, and proficiency. WAS gives students opportunities to extend learning beyond the normal course offerings and offers Reading Apprenticeship. Teachers consistently post learning objectives for lessons and that practice is reinforced and monitored by school leadership. WAS is to be acclaimed for the ECMC scholarship program, senior transitions, alternative pathways paid college classes, and other support services which provide additional supports for students making transition to post-secondary education.

\section{Recommendations:}

The following recommendations are offered by the evaluation team in combination with the perspectives drawn by external facilitators who supported the evaluation and planning process. These recommendations are included in the following table. 
Table: Evaluation Recommendations

- Schedule regular status updates for the evaluation planning team (Appendix A) to meet and reflect on the data indicators described in the Completed WAS Alternative High School Program Evaluation Planning Tool (Appendix B).

- Use the District Achievement Compact Descriptors (Appendix D) and the Indicators for Comprehensive Achievement (Appendix C) in future school improvement and evaluation planning to demonstrate characteristics of a Model School and assure the school will not be identified as a Focus or Priority School.

- Use the Alternative Education Program Toolkit - Compliance Checklist to meet the legal requirements of annually evaluating the alternative program (Appendix E).

- Continue to strategically communicate and promote the shared district vision, mission and goals in the transition to the new name of Whyroads School.

- Update the WAS Continuous Improvement Plan with the new name, vision, school mission, values, beliefs and goals. The updates should include alternative accountably metrics (one-year graduation rate, annual retention rate, and year-to-year retention rate), and the Metrics to Monitor and Evaluate described in this report. These updates should also be reflected in the Data Review and Analysis, Theories of Action, Action Planning, and Evidence of Implementation Sections of the Improvement Plan.

- Develop clear written procedures for admission to Whyroads Alternative School, Rosemary Anderson East Campus and other district alterative placement options. These procedures should include typical characteristics of students and a step-by-step process that the school placement coordinator, counselors, and administrators at both the middle and high school will use.

- Determine maximum teacher and administrator ratios for each district program and provide written procedures for councilor referral and student placement. These procedures should be revisited at least annually along with the program evaluation to reflect back on how the students are being served, what is and is not working, if the program is making a difference, and if it should be continued, expanded, or be cut.

- Offer professional development on sheltered language instruction and cultural diversity in addition to the equity and tolerance training offered in previous years. Use disaggregated data to identify populations and characteristics of students that are traditionally underperforming in schools and district programs. Consider putting 
into place hiring procedures that assure teachers reflect the diversity
and cultural background of the students they serve.
- Incorporate data and planning on Educator Effectiveness to
support the district, school, and program in conducting accurate
evaluations WAS Staff and Leadership.
- Initiate a planning process to identify quality GED Option Program
and/or Early College Program models, curriculum, diagnostic and
formative tools that will support implementation of a GED Option
Program to meet district and student needs.

\section{Glossary}

- Accountability - in the context of alternative high school program evaluation, accountability refers to the responsible use of resources (time and tools) to produce value as a result [of the evaluation] for the community of students, parents and members of the region or state.

- Alternative High School- a public or private school or separate class group designed to best serve students' educational needs and interests and assist students in achieving the academic standards of the school district and the state. The majority of alternative high school students are enrolled in secondary grades (9-12). The school offers individualized instruction, low teacher/student ratios, flexible scheduling, and varied instructional methods to meet the learning needs of students.

- Alternative High School Evaluation- a combination of both formative and summative observational records, data and information about what is happening in the school. Evaluation and information collecting is conducted to inform decisionmaking and may be referred to as value-added or mixed-method evaluation. In general, evaluation examines schools to inform recommendations regarding annual state registration, school district approval and to make recommendations for programmatic refinement that positively impact alternative high school students.

- Alternative Program- A program may have some features of an alternative school, but a program, especially an "alternative school program," is part of and in service to a larger and more comprehensive school. That is to say a program is not a comprehensive school. A school, including an alternative high school, is able to stand alone to meet regional accreditation standards, including (a) an autonomous mission, (b) educational program (curriculum, instruction, and assessment system), (c) leadership and organization, (d) supports for learning, (e) finance and facilities, and $(\mathrm{g})$ plans for improvement. School programs, in service to a larger traditional school, may have one or more of the features of alternative schools. "School program," as defined here, is also distinguished from "educational program" (referred to as the curriculum, instruction, and assessment of a school). 
- At-risk Students- students with one or more at-risk indicators such as not meeting or exceeding state standards, behind in credits earned, pregnant/parenting, multiple suspensions, expulsion or infrequent attendance. At-risk students may also be referred to as vulnerable students or students at risk of educational failure (dropping out of school).

- Charter School- A charter school, in Oregon, is a school of choice operated under a contract ("charter") between a charter authorizer and a group of parents, teachers, and members of the community. Charter schools are required to meet requirements set forth in Oregon Revised Statute (ORS) 338.015 which include the use of flexible learning environments and innovative teaching and assessment methods that "better meet individual student academic needs and interest."

- Compliance Indicators- indicators designed to determine the degree to which the program is following the law.

- Comprehensive School- a school able to offer credits, services and instruction in standards and essential skills to support students in graduation with a regular high school diploma.

- Criteria- a set description by which something can be judged. In an alternative high school program evaluation, criteria must be simple enough for evaluators to understand, yet complex enough to thoroughly explain the tools and indicators that describe what is being observed.

- Design (evaluation)- A plan for conducting an evaluation; e.g., data collection schedule, report schedules, questions to be addressed, analysis plan, management plan, etc. Designs may be either preordinate (designed ahead of time) or emergent (emerging over time).

- Evaluation- A systematic investigation of the value, importance, or significance of something or someone along defined dimensions (e.g. a program, project, or specific program or project component) (Yarbrough \& Joint Committee on Standards for Educational Evaluation., 2011, p. 287).

- Evaluation Team- balanced evaluation team made up of both internal stakeholders and external members who are knowledgeable about the school's mission, purpose and policies, leadership, curriculum, instruction and assessment, support systems and planning.

- Evaluation Utility- is used to describe the extent to which program stakeholders find the evaluation process and products valuable in meeting their needs (Yarbrough, 2011). 
- Evaluation Checklist- a list that serves as a reminder of the process, procedures, and tasks that needs to be addressed during an evaluation.

- Evaluation Propriety- depicts what is proper, fair, legal, right, acceptable and ethical in an evaluation. Considers the rights of stakeholders and intent to ensure that an evaluation will be conducted legally, ethically, and with due regard for the welfare of those involved in the evaluation as well as those affected by its results (Yarbrough, 2011).

- External Stakeholders- those not having, or having less of, a stake in the school.

- External Evaluator- an evaluator from outside the school that is the subject of the evaluation and may serve as the facilitator as well as a member of the evaluation team. Typically external evaluators have entered into some form of a contract with the school district or regional education service district and offer an objective viewpoint to the team.

- Externally Validated- confirmation of the shared beliefs of the school, its mission, function and the results being achieved from members outside the school organization. School visits often serve as a consensus-building process where internal and external stakeholders come to some level of agreement about the strengths of the school and the needed improvements, based upon findings.

- Feasibility-in the context of program evaluation, feasibility refers to the extent to which resources and other factors allow an evaluation to be conducted in a satisfactory manner (Yarbrough \& Joint Committee on Standards for Educational Evaluation., 2011, p. 288).

- Formative Evaluation-Evaluation designed and used to improve an organization [alternative high school], especially when it is still being developed (Yarbrough \& Joint Committee on Standards for Educational Evaluation., 2011, p. 288)

- Goals-Strategic and specific, measurable, attainable, results-based, time-bound (SMART) objectives usually established by schools during annual school improvement planning (O'Neill, 2006).

- Indicators- specific narrative descriptors that describe a particular degree to which practice, performance or behavior are observed to have been achieved.

- Internally Validated-shared beliefs about the school, its mission, function and the results being achieved. School visits often serve as a consensus-building process where internal and external stakeholders come to some level of agreement about the strengths of the school and the needed improvements, based upon established findings. 
- Internal Stakeholders- those inside the local district or school who are affected by or with interest in the school and/or the students who attend the school.

- Logic Model- schematic organizer that accounts for the characteristics of students, staff, administrators and members of the community. The graphic organizer supports drawing conclusions (left to right) about strategies, resources and information involved in accomplishing desired results in order to accomplish desirable outcomes. Logic models are often used in program evaluations involving complex organizations, such as alternative schools, that serve an evaluation purpose that requires a mixed of both method and approach.

- Program- a set of specific activities and dedicated resources (inputs) designed for an intended purpose, or to achieve an intended process, product, service output with quantifiable goals and objectives. An example of a program within an alternative high school would be a program for young parents, a behavior or reading intervention program.

- Regional Accreditation - A valid and standards-based school review that includes annual reports, self-assessments, school-site visits and assurance of reciprocity of credits and diplomas earned from other regionally or nationally accredited schools.

- School Design- A process of using conceptual frameworks, assumptions, and procedural steps to complete planning that follows an educational needs assessment, and before the implementation and full development of a designed school. For the purpose of this research proposal, it will be assumed that program evaluation is imbedded in effective school design.

- Summative Evaluation- An evaluation designed to present conclusions about the merit or worth of an object [program or organization] and recommendations about whether it should be retained, altered, or eliminated. 
Table: Design and Evaluation Team Members and Attendance

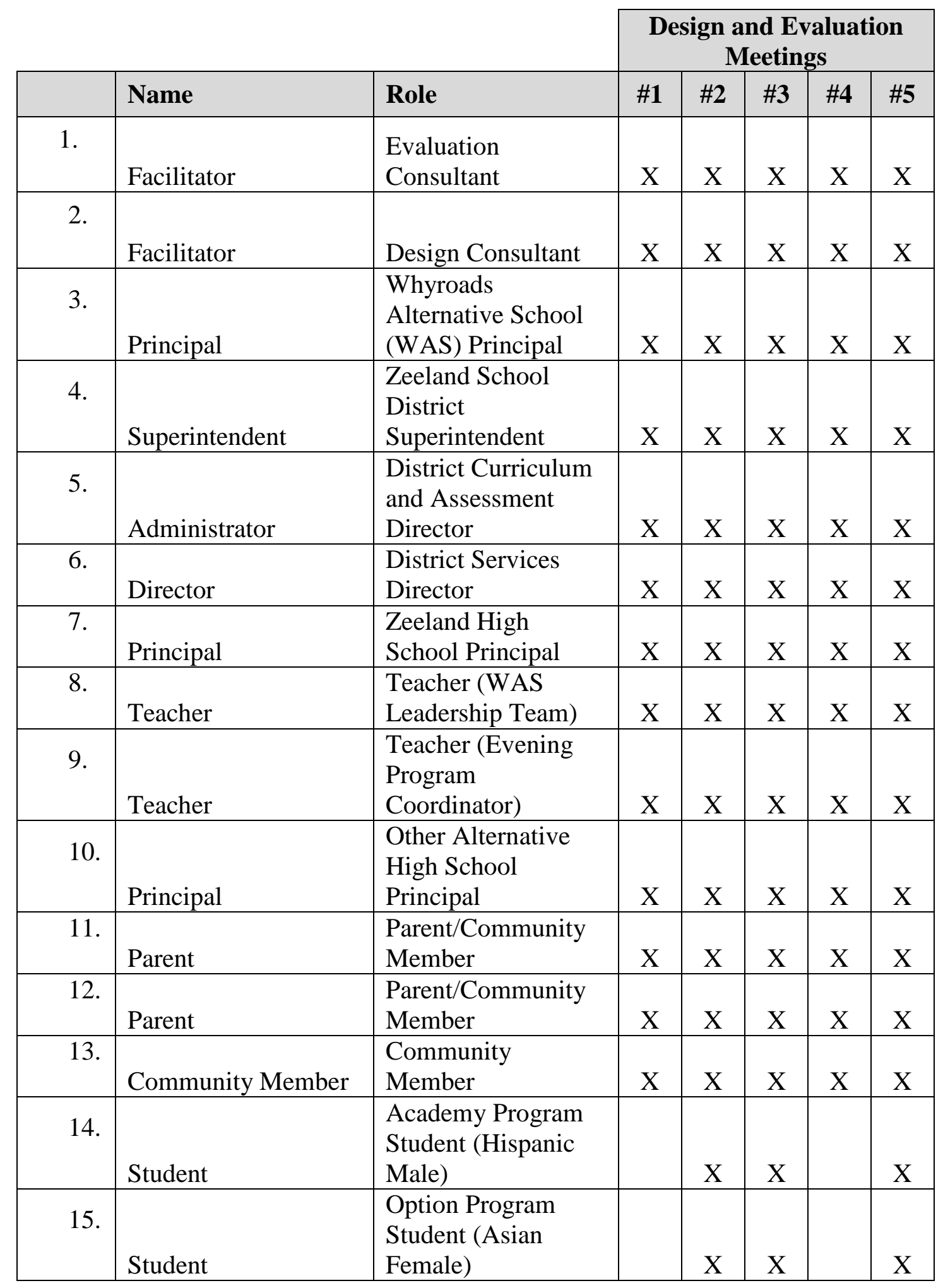




\title{
Alternative High School Evaluation Tool: $\underline{\text { Assessment }}$ "Assessment for learning and assessment of learning",
}

\author{
Initial Survey Questions and Comments - Assessment Evaluation Workgroup \\ Instructions: Read and consider the questions, check yes/no and expand your response with comments.
}

\section{Research-Based Principle:}

1. Do you believe that administrators, staff, students, parents and the community receive enough training to understand assessment?

[Strongly Disagree] [ Disagree] [ Neutral] [ Agree] [Strongly Agree]

Comment and Evidence: Professional Learning Community (PLC) Staff Meetings but lack training on quality assessment.

Research-Based Principle:

2. Do you believe that those involved in the process of teaching and learning regularly use data in decision making?

[Strongly Disagree] [ Disagree] [ Neutral] [ Agree] [Strongly Agree]

Comment and Evidence: Cycle notes and Staff Meetings

Research-Based Principle:

3. Do you believe that the school curriculum results in high expectations for student performance?

[ ]SD [ ${ }^{*}$ D [ ]N [ ]A [ ]SA

[Strongly Disagree] [ Disagree] [ Neutral] [ Agree] [Strongly Agree]

Comment and Evidence: Teacher logs of the types of assessments.

\section{School Progress Indicators - Assessment Evaluation Workgroup}

Instructions: Indicate how effectively the school has been in addressing each of the following issues.

\begin{tabular}{|l|l|l|l|}
\hline $\begin{array}{l}\text { "Exemplary" indicates that the school consistently demonstrates } \\
\text { practices described, "Effective" indicates adequate and "In Need } \\
\text { of Improvement" not at all. }\end{array}$ & $\begin{array}{l}\text { Exemplary } \\
\text { Practices }\end{array}$ & $\begin{array}{l}\text { Effective } \\
\text { Practices }\end{array}$ & $\begin{array}{l}\text { In Need of } \\
\text { Improvement }\end{array}$ \\
\hline $\begin{array}{l}\text { 1. Uses data-based decision making } \\
\text { Comment: Data team, cycle notes }\end{array}$ & $\mathrm{X}$ & $\mathrm{X}$ & \\
\hline $\begin{array}{l}\text { 2. Uses student, classroom, school and program data } \\
\text { Comment: Clip stick of types of assessment (Quiz, ticket-out, } \\
\text { door, test, assignment) }\end{array}$ & & $\mathrm{X}$ & \\
\hline $\begin{array}{l}\text { 3. Uses multiple assessments to evaluate learning, instruction and } \\
\text { interventions } \\
\text { Comment: }\end{array}$ & $\mathrm{X}$ & & \\
\hline $\begin{array}{l}\text { 4. Uses the results of assessments to modify curriculum and } \\
\text { instruction } \\
\text { Comment: }\end{array}$ & & & \\
\hline $\begin{array}{l}\text { 5. Establishes classroom and school goals of assessment literacy } \\
\text { Comment: }\end{array}$ & & & \\
\hline $\begin{array}{l}\text { 6. Other: } \\
\text { Comment: }\end{array}$ & & \\
\hline
\end{tabular}




\section{Evaluation Planning Matrix - Assessment Evaluation Workgroup}

Instructions: Discuss possible objectives of your evaluation process and determine how you will know those objectives were met, what feedback tools you plan to use and when they will be reassessed.

\begin{tabular}{|l|l|l|l|}
\hline $\begin{array}{l}\text { Assessment Evaluation Objectives } \\
\text { What do you want to know? }\end{array}$ & $\begin{array}{l}\text { Stakeholder } \\
\text { Groups } \\
\text { Who? }\end{array}$ & $\begin{array}{l}\text { Tool, Data or Instrument } \\
\text { (Feedback tools) } \\
\text { How will you know it? }\end{array}$ & $\begin{array}{l}\text { Design Timeline \& } \\
\text { Results } \\
\text { (Start, and restart } \\
\text { dates) } \\
\text { When will you know } \\
\text { it? }\end{array}$ \\
\hline $\begin{array}{l}\text { 1. Are there a wide range of assessment } \\
\text { styles or types? }\end{array}$ & Students & Daily tally & Monthly \\
\hline $\begin{array}{l}\text { 2. Are there multiple opportunities to } \\
\text { demonstrate mastery? }\end{array}$ & Students & Tally & Monthly \\
\hline $\begin{array}{l}\text { 3. Do teachers use data from } \\
\text { assessments to modify curriculum and } \\
\text { instruction? }\end{array}$ & Teachers & PLC Cycle Notes & Per cycle \\
\hline $\begin{array}{l}\text { 4. Does my child demonstrate learning in } \\
\text { multiple ways? }\end{array}$ & Community & Student plan and profile & Conferences \\
\hline
\end{tabular}

\section{Evaluation Plan - Assessment Evaluation Workgroup}

Instructions: Further discuss objectives for the evaluation and summarize the objectives in a shorter statement from above. Further consider the formative or summative reporting periods and update status.

\begin{tabular}{|l|l|l|l|}
\hline $\begin{array}{l}\text { Assessment Evaluation Objectives } \\
\text { (From above but more concise) }\end{array}$ & $\begin{array}{l}\text { Stakeholder } \\
\text { Groups }\end{array}$ & Formative and Summative Evidence & Status \\
\hline 1. Range of assessment & Students & Daily tally & \\
\hline 2. Multiple opportunities & Students & Daily tally & \\
\hline 3. Modify instruction based on data & Teachers & PLC cycle & \\
\hline 4. Demonstrate Learning & Community & Conferences & \\
\hline
\end{tabular}

Completed by: Evaluation Team (Lead - Curriculum Director and Whyroads Teacher)

Date: March, 2013 


\title{
Alternative High School Evaluation Tool: Curriculum "Aligned, Managed and Monitored Curriculum"
}

\author{
Initial Survey Questions and Comments - Curriculum Evaluation Workgroup \\ Instructions: Read and consider the questions, check yes/no and expand your response with comments.

\section{Research-Based Principle:} \\ 1. Do you believe that teachers in the school are involved in a process to \\ develop/align curriculum to determine what students need to know, understand and \\ be able to do? \\ [Strongly Disagree] [ Disagree] [ Neutral] [ Agree] [Strongly Agree] \\ Comment and Evidence: Curriculum mapping and CCSS Integration. \\ Research-Based Principle: \\ 2. Do you believe that instruction will be aligned with the expectations of the school \\ district and state i.e. Diploma, Essential Skills, Performance Tasks and beyond? \\ [Strongly Disagree] [ Disagree] [ Neutral] [ Agree] [Strongly Agree] \\ Comment and Evidence: training and student plans and profiles. \\ Research-Based Principle: \\ 3. Do you believe that the classroom instruction at other schools in the grade level \\ or subject have similar expectations for student performance? \\ [Strongly Disagree] [ Disagree] [ Neutral] [ Agree] [Strongly Agree] \\ Comment and Evidence: Wide variety of teacher expectations. \\ School Progress Indicators - Curriculum Evaluation Workgroup \\ Instructions: Indicate how effectively the school has been in addressing each of the following issues.
}

\begin{tabular}{|l|c|c|c|}
\hline $\begin{array}{l}\text { "Exemplary" indicates that the school consistently demonstrates } \\
\text { practices described, "Effective" indicates adequate and "In Need of } \\
\text { Improvement" not at all. }\end{array}$ & $\begin{array}{l}\text { Exemplary } \\
\text { Practices }\end{array}$ & $\begin{array}{l}\text { Effective } \\
\text { Practices }\end{array}$ & $\begin{array}{l}\text { In Need of } \\
\text { Improvement }\end{array}$ \\
\hline $\begin{array}{l}\text { 1. Curriculum practices are aligned with standards, assessments and } \\
\text { desired student outcomes } \\
\text { Comment: }\end{array}$ & $\mathrm{X}$ & $\mathrm{X}$ & \\
\hline $\begin{array}{l}\text { 2. Effective process of curriculum development, planning and } \\
\text { alignment of curriculum } \\
\text { Comment: }\end{array}$ & $\mathrm{X}$ & & \\
\hline $\begin{array}{l}\text { 3. Process of monitoring, evaluating and revising curriculum to ensure } \\
\text { successful student transitions } \\
\text { Comment: }\end{array}$ & $\mathrm{X}$ & \\
\hline $\begin{array}{l}\text { 4. Rigorous academic core curriculum for all students } \\
\text { Comment: }\end{array}$ & $\mathrm{X}$ & & \\
\hline $\begin{array}{l}\text { 5. Curriculum that provides coordinated opportunities for career- } \\
\text { related learning experiences } \\
\text { Comment: }\end{array}$ & & & \\
\hline $\begin{array}{l}\text { 6. Other: } \\
\text { Comment: }\end{array}$ & & \\
\hline
\end{tabular}




\begin{tabular}{|c|c|c|c|}
\hline $\begin{array}{l}\text { Evaluation Planning Matrix - Currict } \\
\text { Instructions: Discuss possible objectiv } \\
\text { objectives were met, what feedback to }\end{array}$ & $\begin{array}{l}n \text { Evaluatio } \\
\text { f your evalı } \\
\text { you plan to }\end{array}$ & $\begin{array}{l}\text { kgroup } \\
\text { process and determine } h \\
\text { id when they will be reas }\end{array}$ & $\begin{array}{l}\text { you will know those } \\
\text { sed. }\end{array}$ \\
\hline $\begin{array}{l}\text { Curriculum Evaluation Objectives } \\
\text { What do you want to know? }\end{array}$ & $\begin{array}{l}\text { Stakeholder } \\
\text { Groups } \\
\text { Who? }\end{array}$ & $\begin{array}{l}\text { Tool, Data or Instrument } \\
\text { (Feedback tools) } \\
\text { How will you know it? }\end{array}$ & $\begin{array}{l}\text { Design Timeline \& Results } \\
\text { (Start, and restart dates) } \\
\text { When will you know it? }\end{array}$ \\
\hline $\begin{array}{l}\text { 1. Are students receiving content and } \\
\text { skills based on standards? }\end{array}$ & Students & Curriculum maps & Annually \\
\hline $\begin{array}{l}\text { 2. Do students have annual career } \\
\text { related learning opportunities? }\end{array}$ & Students & Student plan and profile & Annually \\
\hline $\begin{array}{l}\text { 3. Am I revising my curriculum to } \\
\text { insure student success? }\end{array}$ & Teachers & $\begin{array}{l}\text { Annotated curriculum } \\
\text { maps }\end{array}$ & Annually \\
\hline $\begin{array}{l}\text { 4. Is the curriculum appropriately } \\
\text { rigorous? }\end{array}$ & Community & Updated curriculum maps & Annually \\
\hline
\end{tabular}

\section{Evaluation Plan - Curriculum Evaluation Workgroup}

Instructions: Further discuss objectives for the evaluation and summarize the objectives in a shorter statement from above. Further consider the formative or summative reporting periods and update status.

\begin{tabular}{|l|l|l|l|}
\hline $\begin{array}{l}\text { Curriculum Evaluation Objectives } \\
\text { (From above but more concise) }\end{array}$ & $\begin{array}{l}\text { Stakeholder } \\
\text { Groups }\end{array}$ & Formative and Summative Evidence & Status \\
\hline 1.Content based on standards & Students & Curriculum maps & \\
\hline 2.Career related learning & Students & Student plan and profile & \\
\hline 3. Revise curriculum & Teachers & Annotated maps & \\
\hline 4. Rigorous & Community & Updated maps & \\
\hline
\end{tabular}

Completed by: Evaluation Team (Lead - Curriculum Director and Whyroads Teacher)

Date: March, 2013 


\title{
Alternative High School Evaluation Tool: Engagement "Engaged in relevant learning activities"
}

\author{
Initial Survey Questions and Comments - Engagement Evaluation Workgroup \\ Instructions: Read and consider the questions, check yes/no and expand your response with comments.

\section{Research-Based Principle:} \\ 1. Do you believe students are engaged in core academic achievement and growing? \\ [Strongly Disagree] [ Disagree] [ Neutral] [ Agree] [Strongly Agree] \\ $\left[{ }^{*}\right] \mathrm{SD}[\mathrm{D}[\mathrm{N}$ [ ] $\mathrm{A}[\mathrm{SA}$ \\ Comment and Evidence: High degree of focus on the Common Core State \\ Standards, Professional Learning Communities, and Classroom Practices

\section{Research-Based Principle:} \\ 2. Do you believe there is continuous two-way communication with students and their \\ families? \\ [Strongly Disagree] [ Disagree] [ Neutral] [ Agree] [Strongly Agree] \\ Comment and Evidence: Students given multiple opportunities to succeed \\ Research-Based Principle: \\ 3. Do you believe that parents and community members are welcomed partners in \\ supporting student achievement? \\ [Strongly Disagree] [ Disagree] [ Neutral] [ Agree] [Strongly Agree] \\ Comment and Evidence: Community relationship is strong (community service and \\ scholarships) but connection with parents is a challenge. \\ School Progress Indicators - Engagement Evaluation Workgroup \\ Instructions: Indicate how effectively the school has been in addressing each of the following issues.
}

\begin{tabular}{|l|l|l|l|}
\hline $\begin{array}{l}\text { "Exemplary" indicates that the school consistently demonstrates } \\
\text { practices described, "Effective" indicates adequate and "In Need of } \\
\text { Improvement" not at all }\end{array}$ & $\begin{array}{l}\text { Exemplary } \\
\text { Practices }\end{array}$ & $\begin{array}{l}\text { Effective } \\
\text { Practices }\end{array}$ & $\begin{array}{l}\text { In Need of } \\
\text { Improvement }\end{array}$ \\
\hline $\begin{array}{l}\text { 1. Students are able to identify what they need to know, be able to do } \\
\text { and understand } \\
\text { Comment: }\end{array}$ & $\mathrm{X}$ & \\
\hline $\begin{array}{l}\text { 2. Teachers are able to identify what they need to teach and what the } \\
\text { students need to know, be able to do and understand } \\
\text { Comment: }\end{array}$ & $\mathrm{X}$ & & \\
\hline $\begin{array}{l}\text { 3. Students participate in self-directed learning and are able to } \\
\text { demonstrate proficiency in activities where they are progressing and } \\
\text { know where to get help if they need it } \\
\text { Comment: }\end{array}$ & $\mathrm{X}$ & & \\
\hline $\begin{array}{l}\text { 4. Administrators encourage and support teachers in maintaining } \\
\text { communication with staff and their families } \\
\text { Comment: }\end{array}$ & & & \\
\hline $\begin{array}{l}\text { 5. School policies, programs and organization engage students and } \\
\text { their families as active partners with the school } \\
\text { Comment: }\end{array}$ & & \\
\hline $\begin{array}{l}\text { 6. Other: } \\
\text { Comment: }\end{array}$ & & & \\
\hline
\end{tabular}




\begin{tabular}{|c|c|c|c|c|}
\hline \multicolumn{5}{|c|}{$\begin{array}{l}\text { Evaluation Planning Matrix - Engagement Evaluation Workgroup } \\
\text { Instructions: Discuss possible objectives of your evaluation process and determine how you will know those } \\
\text { objectives were met, what feedback tools you plan to use and when they will be reassessed. }\end{array}$} \\
\hline $\begin{array}{l}\text { Engagement Evaluation Objectives } \\
\text { What do you want to know? }\end{array}$ & $\begin{array}{l}\text { Stakeholder } \\
\text { Groups } \\
\text { Who? }\end{array}$ & $\begin{array}{l}\text { Tool, Data or Instrument } \\
\text { (Feedback tools) } \\
\text { How will you know it? }\end{array}$ & \multicolumn{2}{|c|}{$\begin{array}{l}\text { Design Timeline \& Results } \\
\text { (Start, and restart dates) } \\
\text { When will you know it? }\end{array}$} \\
\hline $\begin{array}{l}\text { 1. Are students able to identify what } \\
\text { they need to know and be able to do? }\end{array}$ & Students & $\begin{array}{l}\text { Random sampling based } \\
\text { on posted learning targets }\end{array}$ & \multicolumn{2}{|c|}{ Ask kids two-times a year } \\
\hline $\begin{array}{l}\text { 2. Can student identify academic } \\
\text { strengths and weaknesses }\end{array}$ & Students & $\begin{array}{l}\text { Educational plan and } \\
\text { profile }\end{array}$ & \multicolumn{2}{|c|}{ Annual } \\
\hline $\begin{array}{l}\text { 3. Can teachers identify what } \\
\text { students need to know and do? }\end{array}$ & Teachers & Posted learning targets & \multicolumn{2}{|c|}{$\begin{array}{l}\text { Poste - daily } \\
\text { Random data check four- } \\
\text { times a year }\end{array}$} \\
\hline $\begin{array}{l}\text { 4. Do parents feel they have an } \\
\text { opportunity to engage in their child's } \\
\text { education? }\end{array}$ & Community & $\begin{array}{l}\text { Parent survey and } \\
\text { conferences }\end{array}$ & \multicolumn{2}{|c|}{$\begin{array}{l}\text { Parent survey }-1 x \text { a year } \\
\text { Conferences }-2 x \text { a year }\end{array}$} \\
\hline \multicolumn{5}{|c|}{$\begin{array}{l}\text { Evaluation Plan - Engagement Evaluation Workgroup } \\
\text { Instructions: Further discuss objectives for the evaluation and summarize the objectives in a shorter statement from } \\
\text { above. Further consider the formative or summative reporting periods and update status. }\end{array}$} \\
\hline $\begin{array}{l}\text { Engagement Evaluation Objectives } \\
\text { (From above but more concise) }\end{array}$ & $\begin{array}{l}\text { Stakeholder } \\
\text { Groups }\end{array}$ & \multicolumn{2}{|c|}{ Formative and Summative Evidence } & Status \\
\hline 1.Identify learning targets & Students & \multicolumn{2}{|l|}{ Learning targets } & \\
\hline 2.ID strengths and weaknesses & Students & \multicolumn{2}{|l|}{ Educational plan and profile } & \\
\hline $\begin{array}{l}\text { 3. ID what students need to know and } \\
\text { do }\end{array}$ & Teachers & \multicolumn{2}{|l|}{ Posted learning targets } & \\
\hline 4. Opportunity to engage & Community & \multicolumn{2}{|l|}{ Survey and conferences } & \\
\hline
\end{tabular}

Completed by: Evaluation Team (Lead - Whyroads Teacher and Zeeland Student Services Director)

Date: March, 2013 


\title{
Alternative High School Evaluation Tool: Instruction "Sustainable Instructional Capacity"
}

\author{
Initial Survey Questions and Comments - Instruction Evaluation Workgroup \\ Instructions: Read and consider the questions, check yes/no and expand your response with comments.
}

\section{Research-Based Principle:}

1. Do you believe that the school will provide time for teachers to meet regularly to review curriculum and information about how students are doing? [Strongly Disagree] [ Disagree] [ Neutral] [ Agree] [Strongly Agree] Comment and Evidence: Professional Learning Community (Tuesdays), before and after school offerings are different formats.

\section{Research-Based Principle:}

2. Do you believe that the school is consistently monitoring classroom instruction to ensure that there is alignment with state and local standards?

[Strongly Disagree] [ Disagree] [ Neutral] [ Agree] [Strongly Agree] Comment and Evidence: Walk through visits, data, define and monitor.

\section{Research-Based Principle:}

3. Do you believe that the school is providing professional mentoring or other ongoing classroom supports to ensure high levels of student achievement?

[Strongly Disagree] [ Disagree] [ Neutral] [ Agree] [Strongly Agree]

Comment and Evidence: Lack of district resources for a full-time coach. Staff makes it work with in-building mentors and a strong leadership team.

\section{School Progress Indicators - Instruction Evaluation Workgroup}

Instructions: Indicate how effectively the school has been in addressing each of the following issues.

\begin{tabular}{|l|l|l|l|}
\hline $\begin{array}{l}\text { "Exemplary" indicates that the school consistently demonstrates } \\
\text { practices described, "Effective" indicates adequate and "In Need of } \\
\text { Improvement" not at all. }\end{array}$ & $\begin{array}{l}\text { Exemplary } \\
\text { Practices }\end{array}$ & $\begin{array}{l}\text { Effective } \\
\text { Practices }\end{array}$ & $\begin{array}{l}\text { In Need of } \\
\text { Improvement }\end{array}$ \\
\hline $\begin{array}{l}\text { 1. Teachers are provided time and encouraged to meet regularly to } \\
\text { examine student work in a way that informs instructional practices } \\
\text { Comment: How much time? }\end{array}$ & $\mathrm{X}$ & $\mathrm{X}$ & \\
\hline $\begin{array}{l}\text { 2. Teachers are encouraged and supported in classroom action } \\
\text { research, evaluation and informal assessment } \\
\text { Comment: What does this involve? }\end{array}$ & & & \\
\hline $\begin{array}{l}\text { 3. Administrators provide targeted interventions for low-performing } \\
\text { teachers in using research-based instruction that is aligned with } \\
\text { state and local standards and assessments } \\
\text { Comment: Classroom work? }\end{array}$ & & $\mathrm{X}$ \\
\hline $\begin{array}{l}\text { 4. Administrators and Teachers use student assessment data to } \\
\text { guide professional development of teachers/administrators. } \\
\text { Comment: }\end{array}$ & $\mathrm{X}$ & & \\
\hline $\begin{array}{l}\text { 5. Administrators and teachers are provided professional } \\
\text { development in content, pedagogy, and diversity } \\
\text { Comment: What is targeted? What constitutes diversity? }\end{array}$ & & $\mathrm{X}$ & \\
\hline $\begin{array}{l}\text { 6. Other: } \\
\text { Comment: }\end{array}$ & & & \\
\hline
\end{tabular}




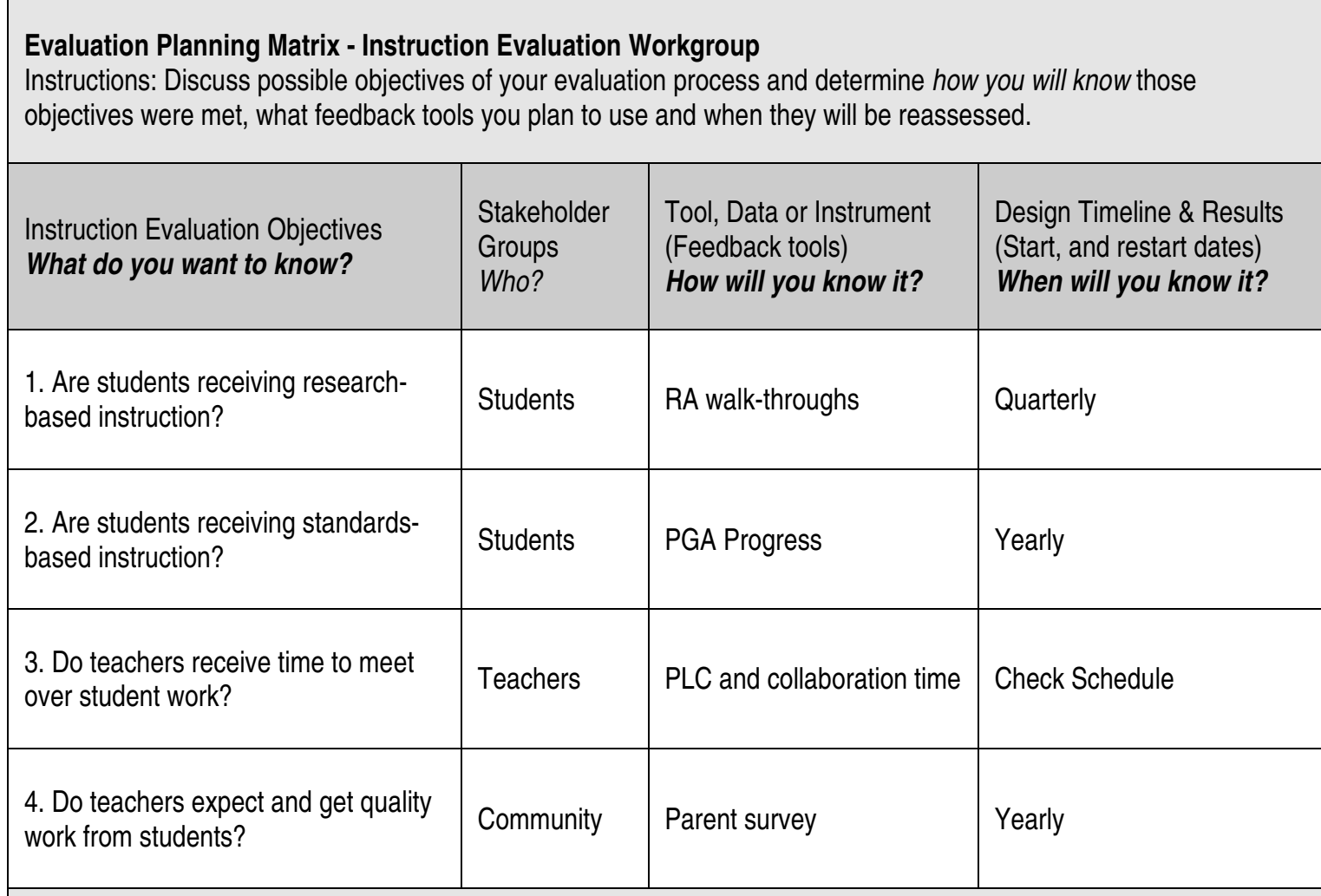

\section{Evaluation Plan - Instruction Evaluation Workgroup}

Instructions: Further discuss objectives for the evaluation and summarize the objectives in a shorter statement from above. Further consider the formative or summative reporting periods and update status.

\begin{tabular}{|l|l|l|l|}
\hline $\begin{array}{l}\text { Instruction Evaluation Objectives } \\
\text { (From above but more concise) }\end{array}$ & $\begin{array}{l}\text { Stakeholder } \\
\text { Groups }\end{array}$ & Formative and Summative Evidence & Status \\
\hline 1. Research-based instruction & Students & RA walk-throughs & \\
\hline 2. Standards-based instruction & Students & PGA process & \\
\hline 3. Time to meet & Teachers & PLC time & \\
\hline 4. Quality work & Community & Parent survey & \\
\hline
\end{tabular}

Completed by: Evaluation Team (Lead - Whyroads Teacher and Zeeland Student Services Director)

Date: March, 2013 


\title{
Alternative High School Evaluation Tool: Leadership "Effective Leadership"
}

\author{
Initial Survey Questions and Comments - Leadership Evaluation Workgroup \\ Instructions: Read and consider the questions, check yes/no and expand your response with comments.
}

\section{Research-Based Principle:}

1. Do you believe that the school has a vision and mission that is widely supported by teachers and administrators?

[Strongly Disagree] [ Disagree] [ Neutral] [ Agree] [Strongly Agree]

Comment and Evidence:

Research-Based Principle:

2. Do you believe that the school has focused attention and support for identifying, discussing and dealing with serious problem areas?

[Strongly Disagree] [ Disagree] [ Neutral] [ Agree] [Strongly Agree] Comment and Evidence:

\section{Research-Based Principle:}

3. Are teachers provided with scheduled time for ongoing collaboration with gradelevel or subject-like groups?

[Strongly Disagree] [ Disagree] [ Neutral] [ Agree] [Strongly Agree]

Comment and Evidence:

School Progress Indicators - Leadership Evaluation Workgroup

Instructions: Indicate how effectively the school has been in addressing each of the following issues.

\begin{tabular}{|c|c|c|c|}
\hline $\begin{array}{l}\text { "Exemplary" indicates that the school consistently demonstrates } \\
\text { practices described, "Effective" indicates adequate and "In Need of } \\
\text { Improvement" not at all. }\end{array}$ & $\begin{array}{l}\text { Exemplary } \\
\text { Practices }\end{array}$ & $\begin{array}{l}\text { Effective } \\
\text { Practices }\end{array}$ & $\begin{array}{l}\text { In Need of } \\
\text { Improvement }\end{array}$ \\
\hline $\begin{array}{l}\text { 1. Demonstrated determination through a clear vision of excellence } \\
\text { in policies, newsletters, press releases, news stories, and other } \\
\text { forms of communication } \\
\text { Comment: }\end{array}$ & & $X$ & \\
\hline $\begin{array}{l}\text { 2. Publicized student performance of all required subgroups, even if } \\
\text { the information reflects low school or subgroup performance } \\
\text { Comment: Please define publicized }\end{array}$ & & $X$ & \\
\hline $\begin{array}{l}\text { 3. Time provided for teacher collaboration and support for the } \\
\text { development and maintenance of professional learning communities } \\
\text { Comment: }\end{array}$ & $X$ & & \\
\hline $\begin{array}{l}\text { 4. Systemic efforts in place to monitor, evaluate, and sustain student } \\
\text { achievement progress } \\
\text { Comment: }\end{array}$ & $X$ & & \\
\hline $\begin{array}{l}\text { 5. Progress toward the established goals are monitored and publicly } \\
\text { reported } \\
\text { Comment: Who is considered the public? }\end{array}$ & & $X$ & \\
\hline $\begin{array}{l}\text { 6. Other: } \\
\text { Comment: }\end{array}$ & & & \\
\hline
\end{tabular}




\begin{tabular}{|c|c|c|c|c|}
\hline \multicolumn{5}{|c|}{$\begin{array}{l}\text { Evaluation Planning Matrix - Leadership Evaluation Workgroup } \\
\text { Instructions: Discuss possible objectives of your evaluation process and determine how you will know those } \\
\text { objectives were met, what feedback tools you plan to use and when they will be reassessed. }\end{array}$} \\
\hline $\begin{array}{l}\text { Leadership Evaluation Objectives } \\
\text { What do you want to know? }\end{array}$ & $\begin{array}{l}\text { Stakeholder } \\
\text { Groups } \\
\text { Who? }\end{array}$ & $\begin{array}{l}\text { Tool, Data or Instrument } \\
\text { (Feedback tools) } \\
\text { How will you know it? }\end{array}$ & \multicolumn{2}{|c|}{$\begin{array}{l}\text { Design Timeline \& Results } \\
\text { (Start, and restart dates) } \\
\text { When will you know it? }\end{array}$} \\
\hline $\begin{array}{l}\text { 1. What is the leadership doing to } \\
\text { follow-up on student concerns? }\end{array}$ & Students & Student survey & \multicolumn{2}{|l|}{ Annual } \\
\hline $\begin{array}{l}\text { 2. Do students believe staff actively } \\
\text { works to solve problems? }\end{array}$ & Students & Student survey & \multicolumn{2}{|l|}{ Annual } \\
\hline $\begin{array}{l}\text { 3. Do teachers have time and } \\
\text { opportunity for input on school issues? }\end{array}$ & Teachers & $\begin{array}{l}\text { Program meetings and all } \\
\text { staff meetings }\end{array}$ & \multicolumn{2}{|c|}{ Schedule check } \\
\hline $\begin{array}{l}\text { 4. Is student performance regularly } \\
\text { published? }\end{array}$ & Community & $\begin{array}{l}\text { State report card and } \\
\text { newsletter }\end{array}$ & \multicolumn{2}{|c|}{ Annual } \\
\hline \multicolumn{5}{|c|}{$\begin{array}{l}\text { Evaluation Plan - Leadership Evaluation Workgroup } \\
\text { Instructions: Further discuss objectives for the evaluation and summarize the objectives in a shorter statement from } \\
\text { above. Further consider the formative or summative reporting periods and update status. }\end{array}$} \\
\hline $\begin{array}{l}\text { Leadership Evaluation Objectives } \\
\text { (From above but more concise) }\end{array}$ & $\begin{array}{l}\text { Stakeholder } \\
\text { Groups }\end{array}$ & \multicolumn{2}{|c|}{ Formative and Summative Evidence } & Status \\
\hline 1. Student concerns & Students & \multicolumn{2}{|l|}{ Student survey } & \\
\hline 2. Solve school problems & Students & \multicolumn{2}{|l|}{ Student survey } & \\
\hline 3. Staff input & Teachers & \multicolumn{2}{|l|}{ Staff and program meetings } & \\
\hline 4. Performance published & Community & \multicolumn{2}{|c|}{ State report card and newsletters } & \\
\hline
\end{tabular}

Completed by: Evaluation Team (Lead - Zeeland Superintendent and Whyroads Principal)

Date: March, 2013 


\title{
Alternative High School Evaluation Tool: Structures "Integrated Systems and Structures"
}

\author{
Initial Survey Questions and Comments - Structures Evaluation Workgroup \\ Instructions: Read and consider the questions, check yes/no and expand your response with comments
}

\section{Research-Based Principle:}

1. Does the school provide teachers with low-performing students' adequate assistance and support?

[Strongly Disagree] [ Disagree] [ Neutral] [ Agree] [Strongly Agree]

Comment and Evidence:

Research-Based Principle:

2. Are there professional mentors or other ongoing classroom supports that are intended to ensure high levels of student achievement?

[Strongly Disagree] [ Disagree] [ Neutral] [ Agree] [Strongly Agree]

Comment and Evidence: Not sure what is meant by coaches.

Research-Based Principle:

3. Does the school maintain transition plans to help ease the transition of students between schools, programs and onto the world of work and/or post-secondary education?

[Strongly Disagree] [ Disagree] [ Neutral] [ Agree] [Strongly Agree] Comment and Evidence:

School Progress Indicators - Structures Evaluation Workgroup

Instructions: Indicate how effectively the school has been in addressing each of the following issues.

\begin{tabular}{|l|l|l|l|}
\hline $\begin{array}{l}\text { "Exemplary" indicates that the school consistently demonstrates } \\
\text { practices described, "Effective" indicates adequate and "In Need of } \\
\text { Improvement" not at all. }\end{array}$ & $\begin{array}{l}\text { Exemplary } \\
\text { Practices }\end{array}$ & $\begin{array}{l}\text { Effective } \\
\text { Practices }\end{array}$ & $\begin{array}{l}\text { In Need of } \\
\text { Improvement }\end{array}$ \\
\hline $\begin{array}{l}\text { 1. Provided ongoing targeted professional development and training } \\
\text { in content, pedagogy and diversity } \\
\text { Comment: }\end{array}$ & $\mathrm{X}$ & & \\
\hline $\begin{array}{l}\text { 2. Provided time and encouragement for teachers to meet regularly } \\
\text { to examine and discuss student work collaboratively and use this } \\
\text { information to inform the learning process } \\
\text { Comment: }\end{array}$ & $\mathrm{X}$ & $\mathrm{X}$ & \\
\hline $\begin{array}{l}\text { 3. Flexibility in the school day is designed to support student } \\
\text { achievement and success } \\
\text { Comment: }\end{array}$ & $\mathrm{X}$ & & \\
\hline $\begin{array}{l}\text { 4. Provided effective transition between grades, to postsecondary } \\
\text { education or the world of work } \\
\text { Comment: }\end{array}$ & $\mathrm{X}$ & & \\
\hline $\begin{array}{l}\text { 5. Integrated school and behavioral systems with other state and } \\
\text { regional services to support students and their families with both } \\
\text { formal and informal interventions } \\
\text { Comment: }\end{array}$ & & & \\
\hline $\begin{array}{l}\text { 6. Other: } \\
\text { Comment: }\end{array}$ & & & \\
\hline
\end{tabular}




\begin{tabular}{|c|c|c|c|}
\hline \multicolumn{4}{|c|}{$\begin{array}{l}\text { Evaluation Planning Matrix - Structures Evaluation Workgroup } \\
\text { Instructions: Discuss possible objectives of your evaluation process and determine how you will know those } \\
\text { objectives were met, what feedback tools you plan to use and when they will be reassessed. }\end{array}$} \\
\hline $\begin{array}{l}\text { Structures Evaluation Objectives } \\
\text { What do you want to know? }\end{array}$ & $\begin{array}{l}\text { Stakeholder } \\
\text { Groups } \\
\text { Who? }\end{array}$ & $\begin{array}{l}\text { Tool, Data or Instrument } \\
\text { (Feedback tools) } \\
\text { How will you know it? }\end{array}$ & $\begin{array}{l}\text { Design Timeline \& Results } \\
\text { (Start, and restart dates) } \\
\text { When will you know it? }\end{array}$ \\
\hline $\begin{array}{l}\text { 1. Do students transition to post- } \\
\text { secondary education successfully? }\end{array}$ & Students & $\begin{array}{l}\text { Percentage of students } \\
\text { who enroll in post- } \\
\text { secondary education }\end{array}$ & $\begin{array}{l}\text { Annual: Educational plan } \\
\text { and profile }\end{array}$ \\
\hline $\begin{array}{l}\text { 2. Do students have support in } \\
\text { transitioning to post-secondary } \\
\text { education? }\end{array}$ & Students & $\begin{array}{l}\text { College tours and number } \\
\text { of college classes }\end{array}$ & $\begin{array}{l}\text { Annual: Educational plan } \\
\text { and profile }\end{array}$ \\
\hline $\begin{array}{l}\text { 3. Do teachers have the time to meet } \\
\text { and inform the learning process? }\end{array}$ & Teachers & $\begin{array}{l}\text { PLC } \\
\text { Collaborations } \\
\text { Year-round schedule }\end{array}$ & Schedule \\
\hline $\begin{array}{l}\text { 4. Do parents feel a part of their } \\
\text { child's transition? }\end{array}$ & Community & $\begin{array}{l}\text { Senior Transitions } \\
\text { Parent survey }\end{array}$ & $\begin{array}{l}\text { Transitions - Monthly } \\
\text { Survey - Annually }\end{array}$ \\
\hline
\end{tabular}

\section{Evaluation Plan - Structures Evaluation Workgroup}

Instructions: Further discuss objectives for the evaluation and summarize the objectives in a shorter statement from above. Further consider the formative or summative reporting periods and update status.

\begin{tabular}{|l|l|l|l|}
\hline $\begin{array}{l}\text { Structures Evaluation Objectives } \\
\text { (From above but more concise) }\end{array}$ & $\begin{array}{l}\text { Stakeholder } \\
\text { Groups }\end{array}$ & Formative and Summative Evidence & Status \\
\hline 1. Successful transition & Students & Student plan and profile & \\
\hline 2. Support in transition & Students & Schedule & \\
\hline 3. Time to inform learning & Teachers & Schedule & \\
\hline 4. Part of transition & Community & Senior transition survey & \\
\hline
\end{tabular}

Completed by: Evaluation Team (Lead - Zeeland Superintendent and Whyroads Principal)

Date: March, 2013 
APPENDIX B: DISTRICT ALTERNATIVE EDUCATION POLICIES

\section{Current OSBA Alternative Education Programs Sample Policy (Adopted 2008)}

The Board is dedicated to providing educational options for all students. It is recognized there will be students in the district whose needs and interests are best served by participation in an alternative education program.

A list of alternative education programs will be approved by the Board annually. The superintendent may provide for the involvement of staff, parents and the community in recommending alternative education programs for Board approval. Annual evaluation of alternative education programs will be made in accordance with ORS 336.655 and OAR 581-022-1350. The superintendent will develop administrative regulations as necessary to implement this requirement.

Alternative education programs will consist of instruction or instruction combined with counseling. These programs may be public or private. Private alternative education programs shall be registered with the Oregon Department of Education. Alternative education programs must meet all the requirements set forth in ORS 336.625, 336.631 and 336.637. [A qualified district may contract with a qualified private alternative education to provide services to a qualified home-schooled child.]

Students, upon parent request, may be placed in an alternative education program if the district determines that the placement serves the student's educational needs and interests and assists the student in achieving district and state academic content standards. Such placement must have the approval of the student's resident district and, as appropriate, the attending district. The district will also consider and propose alternative education programs for students prior to expulsion or leaving school as required by law.

The district shall pay the actual alternative education program cost or an amount equal to 80 percent of the districts estimated current year's average per-student net operating expenditure, whichever is less. The district will enter into a written contract with district-approved private alternative programs.

Source: (OSBA, 2008) 


\section{Marked-up OSBA District Alternative Education Policies}

The Board is dedicated to providing educational options [alternative education programs] for all students. It is recognized there will be students in the district whose needs and interests are best served by participation in an alternative education program. [For the purposes of this policy, the term "program" includes "school." In order to provide innovative and more flexible ways of educating children, the district may establish alternative education programs.]

A lis Alternative education programs will be approved by the Board annually. The superintendent may [must] provide for the involvement of staff, parents and the community in recommending [developing and at least annually evaluating] alternative education [policies, procedures and] programs for Board approval. Annmal evaluation of alternative education programs will be made in accordance with ORS 336.65[1]5[665] and OAR 581-022-1350. [The district must notify students and parents or guardians of students of the law regarding alternative education programs, the availability of existing alternative education programs and procedures for students, parents, or guardians of students residing in the district to request the establishment of new alternative education programs.] The superintendent will develop [is responsible for developing] administrative regulations as necessary to implement this requirement.

Alternative education programs will consist of instruction [aligned with adopted standards, essential skills and graduation requirements] or instruction combined with guidance and counseling. These programs may be public or private. Private alternative education programs shall be registered with the Oregon Department of Education [(ODE) prior to being approved by districts and must meet requirements described in OAR 581-021-0073]. Alternative education programs must meet all the requirements set forth in ORS 336.625, 336.631 and 336.637. -A qualified district may contract with a qualified private alternative education to provide services to a qualified home-schooled child.

Students, upon parent request, may be placed in an alternative education program [are those whose educational needs and interests are best served by participation in such programs and include students identified in accordance with OAR 581-0221350(5)(a).] if t The district [,in consultation with the parents or legal guardian,] determines that the placement serves the student's educational needs and interests and assists the student in achieving district and state academic content standards[, essential skills and graduation requirements]. Such placement must have the approval of the student's resident district and, as appropriate, the attending district [may require the parent to submit a letter of intent to both their resident and attending districts]. The district will also consider and propose alternative education programs for students prior to [suspension,] expulsion or leaving school as required by law. [Student records (OAR 581-022-1660-1670), education transcripts and records of credits earned toward graduation will be maintained by the school district (OAR 581-022-1130-1131).] 
The district shall pay the actual alternative education program cost or an amount equal to 80 percent of the district's estimated current year's average per-student net operating expenditure, whichever is less [, according to ORS 336.635]. The district will enter into a written contract with district-approved private alternative programs. [For purposes of making claims for state school funds, the district will comply in accordance with OAR 581-022-1350(8) and 581-023 and ensure that data for each student in public and private alternative programs are included in all required assessments and district reporting. An "annual statement of expenditures" (ORS 336.635(4) is required as a part of the at least annual evaluation described in ORS 336.655. The district evaluation must also include the schools' compliance with federal and state laws and a review to ensure that the program enhances the ability of the district and its student to achieve district and state standards required for graduation.]

[Highly qualified and effective teachers are required by both state and federal law. Federal law requires Local Education Agencies (Districts) and public alternative schools to employ licensed teachers that hold a valid Oregon teaching license appropriate for the grade level and subject matter being taught. Private alternative education programs (third-party contractors), that are registered with the ODE (ORS 336.631) are not required to employ only licensed teachers or administrators. Teachers and administrators in private programs are not considered employees of any school district for purposes of ORS 342.173 (ORS 336.635(5) and any basic, standard, initial or continuing teaching license issued by the Teacher Standards and Practices Commission (TSPC) is valid for teaching all subjects and grade levels in an alternative education program (ORS 336.635(7)).]

[Licensed, qualified and effective teachers are required in online (distance) and blended (distance combined with face-to-face learning) educational programs. Distance learning teachers, employed by a distance learning program in Oregon, employed to deliver education outside the school district, shall hold a valid Oregon teaching license appropriate for the grade level and subject matter being taught. An out of state distance learning teacher employed by a distance learning program in or outside of Oregon shall provide verification satisfactory to the Teacher Standards and Practices Commission (TSPC) that the teacher holds a current valid teaching license from any state for the appropriate grade level and subject matter. A school district may contract with a postsecondary institution accredited by the Northwest Association of Schools and Colleges for distance instruction at the high school level provided restrictions and approvals required by ORS 342.173 have been met (OAR 584-036-0017)]

The superintendent will develop [funding and] administrative regulations as necessary to implement these policies.

Source: Oregon School Boards Association (2008) Marked by Edwards and Hinds (2012) 
APPENDIX C: DRAFT OREGON INDICATORS FOR SCHOOL DISTRICTS

\begin{tabular}{|c|c|c|}
\hline $\begin{array}{c}\text { Sub- } \\
\text { Category }\end{array}$ & $\begin{array}{l}\text { NEW } \\
\text { Indicator } \\
\text { ID }\end{array}$ & Indicator Description \\
\hline $\begin{array}{l}\text { District \& } \\
\text { School } \\
\text { Structure and } \\
\text { Culture }\end{array}$ & DSC 1.1 & $\begin{array}{l}\text { The school's principal and staff work together to create a safe, } \\
\text { respectful, culturally-inclusive environment with consistent } \\
\text { school rules and expectations. }\end{array}$ \\
\hline $\begin{array}{l}\text { District \& } \\
\text { School } \\
\text { Structure and } \\
\text { Culture }\end{array}$ & DSC 1.2 & $\begin{array}{l}\text { The school's mission and goals reflect high expectations and a } \\
\text { vision for equity for meeting the needs of all stakeholders. }\end{array}$ \\
\hline $\begin{array}{l}\text { District \& } \\
\text { School } \\
\text { Structure and } \\
\text { Culture }\end{array}$ & DSC 1.3 & $\begin{array}{l}\text { The school's leadership plans for and implements professional } \\
\text { development preparing teachers to support parents in the } \\
\text { education of their children by providing in-classroom } \\
\text { opportunities and at-home opportunities for parents. }\end{array}$ \\
\hline $\begin{array}{l}\text { District \& } \\
\text { School } \\
\text { Structure and } \\
\text { Culture } \\
\end{array}$ & DSC 1.4 & $\begin{array}{l}\text { School staff identify students who need additional learning time } \\
\text { to meet standards and provides timely and effective programs of } \\
\text { assistance. }\end{array}$ \\
\hline $\begin{array}{l}\text { District \& } \\
\text { School } \\
\text { Structure and } \\
\text { Culture }\end{array}$ & DSC 1.5 & $\begin{array}{l}\text { School staff assist students in successful transitions, as applicable } \\
\text { from early childhood into elementary, elementary to middle } \\
\text { school, middle school to high school and high school to post- } \\
\text { secondary. }\end{array}$ \\
\hline $\begin{array}{l}\text { District \& } \\
\text { School } \\
\text { Structure and } \\
\text { Culture }\end{array}$ & DSC 1.6 & $\begin{array}{l}\text { School staff coordinates and integrates services and programs } \\
\text { with the aim of optimizing the entire educational program to } \\
\text { improve student learning. }\end{array}$ \\
\hline $\begin{array}{l}\text { Educator } \\
\text { Effectiveness }\end{array}$ & EE 2.1 & $\begin{array}{l}\text { All instructional staff at the school collaboratively plan for sound } \\
\text { instruction in a variety of instructional modes. }\end{array}$ \\
\hline $\begin{array}{l}\text { Educator } \\
\text { Effectiveness }\end{array}$ & EE 2.2 & $\begin{array}{l}\text { All teachers use instructional strategies and initiatives that are } \\
\text { grounded in evidence-based practices, strengthen the core } \\
\text { academic program, increase the quality and quantity of learning } \\
\text { time and address the learning needs of all students. }\end{array}$ \\
\hline $\begin{array}{l}\text { Educator } \\
\text { Effectiveness }\end{array}$ & EE 2.3 & $\begin{array}{l}\text { Professional development activities for all staff (principals, } \\
\text { teachers and paraprofessionals) are aligned to ensure continued } \\
\text { growth in content knowledge as well as in effective instructional } \\
\text { delivery. }\end{array}$ \\
\hline $\begin{array}{l}\text { Educator } \\
\text { Effectiveness }\end{array}$ & EE 2.4 & $\begin{array}{l}\text { Instructional teams use a variety of data to assess strengths and } \\
\text { weaknesses of the curriculum and instructional strategies and } \\
\text { make necessary changes. }\end{array}$ \\
\hline
\end{tabular}




\begin{tabular}{|c|c|c|}
\hline $\begin{array}{l}\text { Educator } \\
\text { Effectiveness }\end{array}$ & EE 2.5 & $\begin{array}{l}\text { All instructional staff in the school use sound classroom } \\
\text { management practices that encourage student engagement and } \\
\text { effect student learning. }\end{array}$ \\
\hline $\begin{array}{l}\text { Educator } \\
\text { Effectiveness }\end{array}$ & EE 2.6 & $\begin{array}{l}\text { Educator evaluations and support systems incorporate the } \\
\text { elements of Oregon's framework of educator effectiveness. }\end{array}$ \\
\hline $\begin{array}{l}\text { Family \& } \\
\text { Community } \\
\text { Involvement }\end{array}$ & FC 3.1 & $\begin{array}{l}\text { School staff create and maintain a welcoming environment for all } \\
\text { families and community members. }\end{array}$ \\
\hline $\begin{array}{l}\text { Family \& } \\
\text { Community } \\
\text { Involvement }\end{array}$ & FC 3.2 & $\begin{array}{l}\text { School staff create and maintain connections between the school } \\
\text { community and the broader community to support student } \\
\text { learning. }\end{array}$ \\
\hline $\begin{array}{l}\text { Family \& } \\
\text { Community } \\
\text { Involvement }\end{array}$ & FC 3.3 & $\begin{array}{l}\text { The school's key documents (minimally, the school's } \\
\text { improvement plan, parent involvement plan, compact and } \\
\text { student/parent handbook) are annually reviewed for revision and } \\
\text { disseminated to all families in the school and translated as } \\
\text { needed. }\end{array}$ \\
\hline $\begin{array}{l}\text { Family \& } \\
\text { Community } \\
\text { Involvement }\end{array}$ & FC 3.4 & $\begin{array}{l}\text { School staff educate families and provide needed resources for } \\
\text { supporting their children's learning. }\end{array}$ \\
\hline $\begin{array}{l}\text { Family \& } \\
\text { Community } \\
\text { Involvement }\end{array}$ & FC 3.5 & $\begin{array}{l}\text { School staff ensure families have the opportunity for meaningful } \\
\text { involvement in the school. }\end{array}$ \\
\hline $\begin{array}{l}\text { Family \& } \\
\text { Community } \\
\text { Involvement }\end{array}$ & FC 3.6 & $\begin{array}{l}\text { School leadership includes families on all decision-making and } \\
\text { advisory committees and ensures training for such areas as } \\
\text { policy, curriculum, budget, school reform initiatives and safety. }\end{array}$ \\
\hline $\begin{array}{l}\text { Family \& } \\
\text { Community } \\
\text { Involvement }\end{array}$ & FC 3.7 & $\begin{array}{l}\text { School staff involves parents and students in setting student goals } \\
\text { and preparing the student for post-secondary education and } \\
\text { careers. }\end{array}$ \\
\hline $\begin{array}{l}\text { Family \& } \\
\text { Community } \\
\text { Involvement }\end{array}$ & FC 3.8 & $\begin{array}{l}\text { School staff uses a variety of tools on a regular basis to facilitate } \\
\text { two-way communication among stakeholders. }\end{array}$ \\
\hline $\begin{array}{l}\text { Teaching \& } \\
\text { Learning }\end{array}$ & TL 4.1 & $\begin{array}{l}\text { All instructional staff at the school are engaged in aligning } \\
\text { instruction and local assessments to state standards. }\end{array}$ \\
\hline $\begin{array}{l}\text { Teaching \& } \\
\text { Learning }\end{array}$ & TL 4.2 & $\begin{array}{l}\text { A system is in place for assessing and monitoring student } \\
\text { achievement relative to state standards. }\end{array}$ \\
\hline $\begin{array}{l}\text { Teaching \& } \\
\text { Learning }\end{array}$ & TL 4.3 & $\begin{array}{l}\text { All instructional staff at the school are engaged in the analysis of } \\
\text { student assessments that are aligned with standards. }\end{array}$ \\
\hline
\end{tabular}




\begin{tabular}{|c|c|c|}
\hline $\begin{array}{l}\text { Teaching \& } \\
\text { Learning }\end{array}$ & TL 4.4 & $\begin{array}{l}\text { All instructional staff at the school use assessment data in } \\
\text { planning and delivering differentiated, standards based } \\
\text { instruction. }\end{array}$ \\
\hline $\begin{array}{l}\text { Technical \& } \\
\text { Adaptive } \\
\text { Leadership }\end{array}$ & LDR 5.1 & $\begin{array}{l}\text { A distributed leadership process is used to build the capacity of } \\
\text { others in the school. }\end{array}$ \\
\hline $\begin{array}{l}\text { Technical \& } \\
\text { Adaptive } \\
\text { Leadership }\end{array}$ & LDR 5.2 & $\begin{array}{l}\text { School leadership ensures that classroom observations and other } \\
\text { observations of teacher behaviors are aligned with evaluation } \\
\text { criteria and professional development needs. }\end{array}$ \\
\hline $\begin{array}{l}\text { Technical \& } \\
\text { Adaptive } \\
\text { Leadership }\end{array}$ & LDR 5.3 & $\begin{array}{l}\text { School leadership has established team structures with clear and } \\
\text { specific duties. }\end{array}$ \\
\hline $\begin{array}{l}\text { Technical \& } \\
\text { Adaptive } \\
\text { Leadership }\end{array}$ & LDR 5.4 & $\begin{array}{l}\text { School leadership is afforded proper authority to make necessary } \\
\text { decisions that result in increased learning outcomes. }\end{array}$ \\
\hline $\begin{array}{l}\text { Technical \& } \\
\text { Adaptive } \\
\text { Leadership }\end{array}$ & LDR 5.5 & $\begin{array}{l}\text { School leaders actively promote a shared vision for equity, } \\
\text { cultural competence and high expectations. }\end{array}$ \\
\hline $\begin{array}{l}\text { Technical \& } \\
\text { Adaptive } \\
\text { Leadership }\end{array}$ & LDR 5.6 & $\begin{array}{l}\text { The principal has the skills to guide, direct and motivate the staff } \\
\text { toward increased student achievement. }\end{array}$ \\
\hline $\begin{array}{l}\text { Technical \& } \\
\text { Adaptive } \\
\text { Leadership }\end{array}$ & LDR 5.7 & $\begin{array}{l}\text { The principal ensures that all teachers are highly qualified in their } \\
\text { assignment. }\end{array}$ \\
\hline $\begin{array}{l}\text { Technical \& } \\
\text { Adaptive } \\
\text { Leadership }\end{array}$ & LDR 5.8 & $\begin{array}{l}\text { School leadership has a plan to recruit and retain highly qualified } \\
\text { staff. }\end{array}$ \\
\hline $\begin{array}{l}\text { Technical \& } \\
\text { Adaptive } \\
\text { Leadership }\end{array}$ & LDR 5.9 & $\begin{array}{l}\text { School leadership facilitates an annual evaluation of the } \\
\text { implementation and results achieved by the school's } \\
\text { improvement plan. }\end{array}$ \\
\hline $\begin{array}{l}\text { Technical \& } \\
\text { Adaptive } \\
\text { Leadership }\end{array}$ & LDR 5.10 & $\begin{array}{l}\text { School leadership facilitates a needs assessment based on } \\
\text { student achievement and the key areas of effectiveness } \\
\text { (technical and adaptive leadership, educator effectiveness, } \\
\text { teaching and learning, district and school structure and culture } \\
\text { and family and community involvement). }\end{array}$ \\
\hline
\end{tabular}

Source: Oregon Department of Education (2013) 


\begin{tabular}{|c|c|}
\hline $\begin{array}{l}\text { 4-Year Cohort } \\
\text { Graduation Rate }\end{array}$ & $\begin{array}{l}\text { The percent of students that earn a regular high school diploma within four years of first entering } 9 \text { th } \\
\text { grade. Includes students who transfer into the district after } 9 \text { th grade and excludes students transferring } \\
\text { out of the district. }\end{array}$ \\
\hline $\begin{array}{c}\text { 5-Year } \\
\text { Completion Rate }\end{array}$ & $\begin{array}{l}\text { The percent of students who earned a regular diploma, modified diploma, extended diploma, adult high } \\
\text { school diploma or GED within five years of entering high school. Calculated as the percent of students } \\
\text { who earned such diploma or certificate within five years of entering 9th grade divided by the size of the } \\
\text { cohort. }\end{array}$ \\
\hline $\begin{array}{l}\text { Earning 9+ } \\
\text { College Credits }\end{array}$ & $\begin{array}{l}\text { \% of students who have received, or earned the right to receive. } 9 \text { or more college credits while enrolled } \\
\text { in high school or earlier. Credits can be earned through any means approved by local school board } \\
\text { policy, including but not limited to AP exam. I8 course completion, dual credit course completion, } \\
\text { community college or university enrollment. Calculated as the percent of students who earned at least } 9 \\
\text { college credits by the end of their fifth or final year in high school divided by the size of the cohort. }\end{array}$ \\
\hline $\begin{array}{c}\text { Post-Secondary } \\
\text { Enrollment }\end{array}$ & $\begin{array}{l}\text { Number of students enrolled in a postsecondary institution (community college, technical certificate } \\
\text { program, or } 4 \text {-year institution) within } 16 \text { months of high school completion. Defined as the number of } \\
\text { completers in a particular cohort that enroll in post secondary education divided by the number of } \\
\text { completers in that cohort. }\end{array}$ \\
\hline
\end{tabular}

\section{Progression: Sufficient progress toward college and career readiness?}

\begin{tabular}{|c|c|}
\hline $\begin{array}{l}\text { 3rd Grade } \\
\text { Reading Proficiency }\end{array}$ & $\begin{array}{l}\text { The percent of 3rd grade students who met or exceeded in reading. Includes only those students } \\
\text { enrolled on the first school day in May that have also been enrolled in the district for a full academic year. } \\
\text { Includes as "Met" those extended assessments that met the alterantive achievement standards. subject } \\
\text { to the } 1.0 \text { percent cap. The 2010-11 reading results have been recores against the } 2011-12 \text {. } \\
\text { achievement standards. }\end{array}$ \\
\hline $\begin{array}{l}\text { 5th Grade } \\
\text { Math Proficiency }\end{array}$ & $\begin{array}{l}\text { The percent of } 5 \text { th grade students who met or exceeded in math. Includes only those students enrolled } \\
\text { on the first school day in May that have also been enrolled in the district for a full academic year. } \\
\text { Includes as "Met" those extended assessments that met the alterantive achievement standards. subject } \\
\text { to the } 1.0 \text { percent cap. }\end{array}$ \\
\hline $\begin{array}{c}\text { 6th Grade } \\
\text { Not Chronically Absent }\end{array}$ & $\begin{array}{l}\text { The percent of students who were present at least } 90 \% \text { of enrolled school days while enrolled in } 6 \text { th } \\
\text { grade (not chronically absent). Calculated as the number of students who are not chroncically absent in } \\
6 \text { th grade divided by the number of students enrolled in sixth grade. Includes only those students } \\
\text { enrolled (resident) in the district on the first school day in May that have been enrolled in the district for a } \\
\text { full academic year. }\end{array}$ \\
\hline $\begin{array}{c}\text { 8th Grade } \\
\text { Math Proficiency }\end{array}$ & $\begin{array}{l}\text { The percent of } 8 \text { th grade students who met or exceeded in math. Includes only those students enrolled } \\
\text { on the first school day in May that have also been enrolled in the district for a full academic year. } \\
\text { Includes as "Met" those extended assessments that met the alterantive achievement standards. subject } \\
\text { to the } 1.0 \text { percent cap. }\end{array}$ \\
\hline $\begin{array}{l}\text { 9th Grade } \\
\text { Credits Earned }\end{array}$ & $\begin{array}{l}\text { \% of students who have earned at least } 6 \text { credits on the date that is } 12 \text { months past firstenrollment in } \\
9 \text { th grade. Calculated as the number of students who have earned at least } 6 \text { credits within } 12 \text { months of } \\
\text { first enrollment in } 9 \text { th gade divided by the fall enrollment of first-time } 9 \text { th graders. Includes only those } \\
\text { students who have also been enrolled in the district for a full acadernic year. }\end{array}$ \\
\hline $\begin{array}{c}\text { 9th Grade } \\
\text { Not Chronically Absent }\end{array}$ & $\begin{array}{l}\text { The percent of students who were present at least } 90 \% \text { of enrolled school days while enrolled in } 9 \text { th } \\
\text { grade (not chronically absent). Calculated as the number of students who are not chroncically absent in } \\
9 \text { th grade divided by the number of students enrolled in ninth grade. Includes only those students } \\
\text { enrolled (resident) in the district on the first school day in May that have been enrolled in the district for a } \\
\text { full academic year. }\end{array}$ \\
\hline
\end{tabular}

\section{Equity: Are students succeeding across across all build ings and populations?}

For 2011-12, this is the count of schools on the federal title 1 school improvement list. For 2012-13. Priority / Focus Schools this will be the counts of federally designated Focus and Priority Schools. For 2013-14 and later, this will be the counts of federally-designated Focus and Priority Schools, plus any other schools (regardless of Tite I status) that receive the lowest rating on the New Oregon Report Card.

Disadvantaged student groups includes students who are: (1) economically disadvantaged: (2) limited Disadvantaged Students English proficient; (3) students with disabilities: (4) Black (not of Hispanic orign): (5) Hispanic origin; (6) American Indian / Alaskan native: (7) Pacific lslander.

\section{Investment: What is the public investment in the district?}

\begin{tabular}{|l|}
\hline Formula Revenue \\
\hline Local revenue not passed through formula \\
\hline Federal revenue \\
\hline
\end{tabular}




\section{Appendix E: Sample Oregon's New High School Report Card}

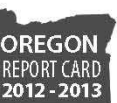

NAME OF HIGH SCHOOL

2000 Oregon Blvd. | Anytown, 0R 97213

(503) 555-2000 | www.schools.hsd.k12.or.us/oregonhs

\author{
SUPERINTENDENT Di. Jane Doe \\ PRINCIPAL John Doe \\ GRADES SERVED $9-12$
}

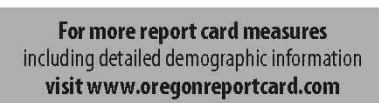

\section{FROM THE PRINCIPAL}

Dear Parents and Community Members,

This redesigned annual report card issued by the Oregon Department of Education affers a com prehensive picture of what Anytown High School offers.

In the 2012-2013 school year, Anytown High School received an Overall State Rating of average. That means our students are performing about as well on standards-based tests and graduating in about the same numbers as students at other Oregon high schools. When compared to schools with similar student demographics, Anytown High School is above average. That means our students are generally outperforming those at like-schools.

Key academic highlights:

- $89 \%$ met/exceeded state standards for reading

- $80 \%$ met/exceeded state standards for math

- Our graduation rate for students who attended Anytown High School all four years increased by 10 percentage points

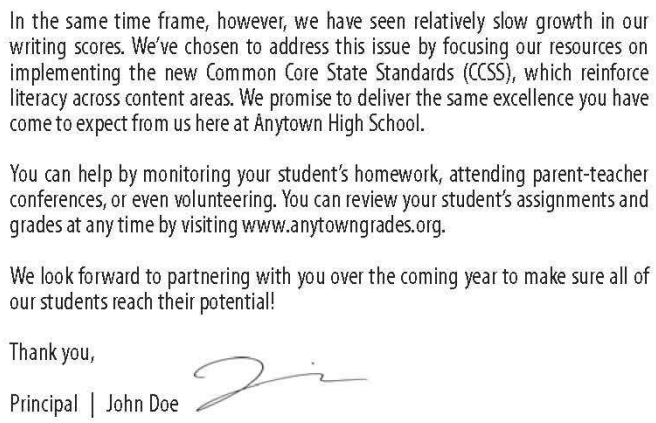

In the same time frame, however, we have seen relatively slow growth in our writing scores. We've chosen to address this issue by focusing our resources an implementing the new Common Core State Standards (CCSS), which reinforce literacy across content areas. We promise to deliver the same excellence you have come to expect from us here at Anytown High School.

You can help by monitoring your student's homework, attending parent-teacher conferences, or even volunteering. You can review your student's assignments and grades at any time by visiting www. anytowng rades.org.

We look forward to partnering with you over the coming year to make sure all of our students reach their potential!

Thank you,

Principal | John Doe

\section{SCHOOL PROFILE}

\section{Enrollment}

Change from previous year

Students attending $90 \%$ or more

of enrolled days

$87 \%$

Average class size in core classes

Change from previous year

Based on certified teachers in the classroom and

students en rolled in core classes - English math

science and social studies classes required for

science and
graduation

\section{STUDENTS}

Select Demographics

English language learners

Students whose first language is not English who

receive direct language instruction or who have

completed a language instruction program

Low income students

Students with disabilities

Number of different languages spoken:

\section{OVERALL STATE RATING HOW ARE STUDENIS AT THIS SCHOOL PERFORMING COMPARED TO THOSE AT OTHER SCHOOLS?}

The overall state rating is intended to summarize this school's particular successes and challenges. It's based on a combination of four factors. Three of these factors come from standards-based test scores from 11 th graders in reading and math. The fourth is graduation rate. Please be aware that this rating is based mainly on high-stakes testing and accordingly, represents a limited view of student performance. Other aspects of this report card are designed to put this rating in the proper context.

Compared to other high schools statewide, this school is about average.

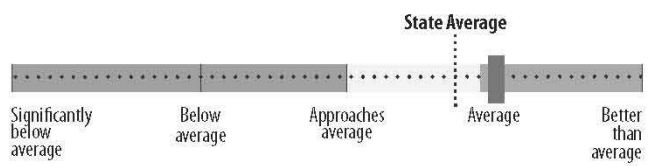

Significantly below average $=$ Falls into the bottom $\mathrm{x} \%$ of $s$ chools Below average $=$ Falls between $x \%$ and $x \%$ of schools Approaches average $=$ Falls between $\mathrm{x} \%$ and $\mathrm{x} \%$ of schools Average $=$ Falls between $x \%$ and $x \%$ of schools Better than average $=$ Falls into the top $x \%$ of schools
Compared to high schools with similar student demographics, this school is better than average.

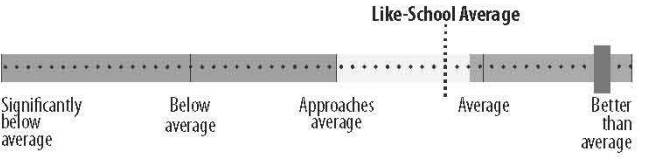

Significantly below average $=$ Falls into the bottom $x \%$ of schools

Below average $=$ Falls between $\mathrm{x} \%$ and $\mathrm{x} \%$ of $\mathrm{schools}$

Approaches average $=$ Falls between $x \%$ and $x \%$ of schools

Average $=\mathrm{Fa}$ als between $\mathrm{x} \%$ and $\mathrm{x} \%$ of $\mathrm{sch}$ cols

Better than average $=$ Falls into the top $x \%$ of schools 


\section{Sample Oregon's Next Generation School Report Card (Continued)}

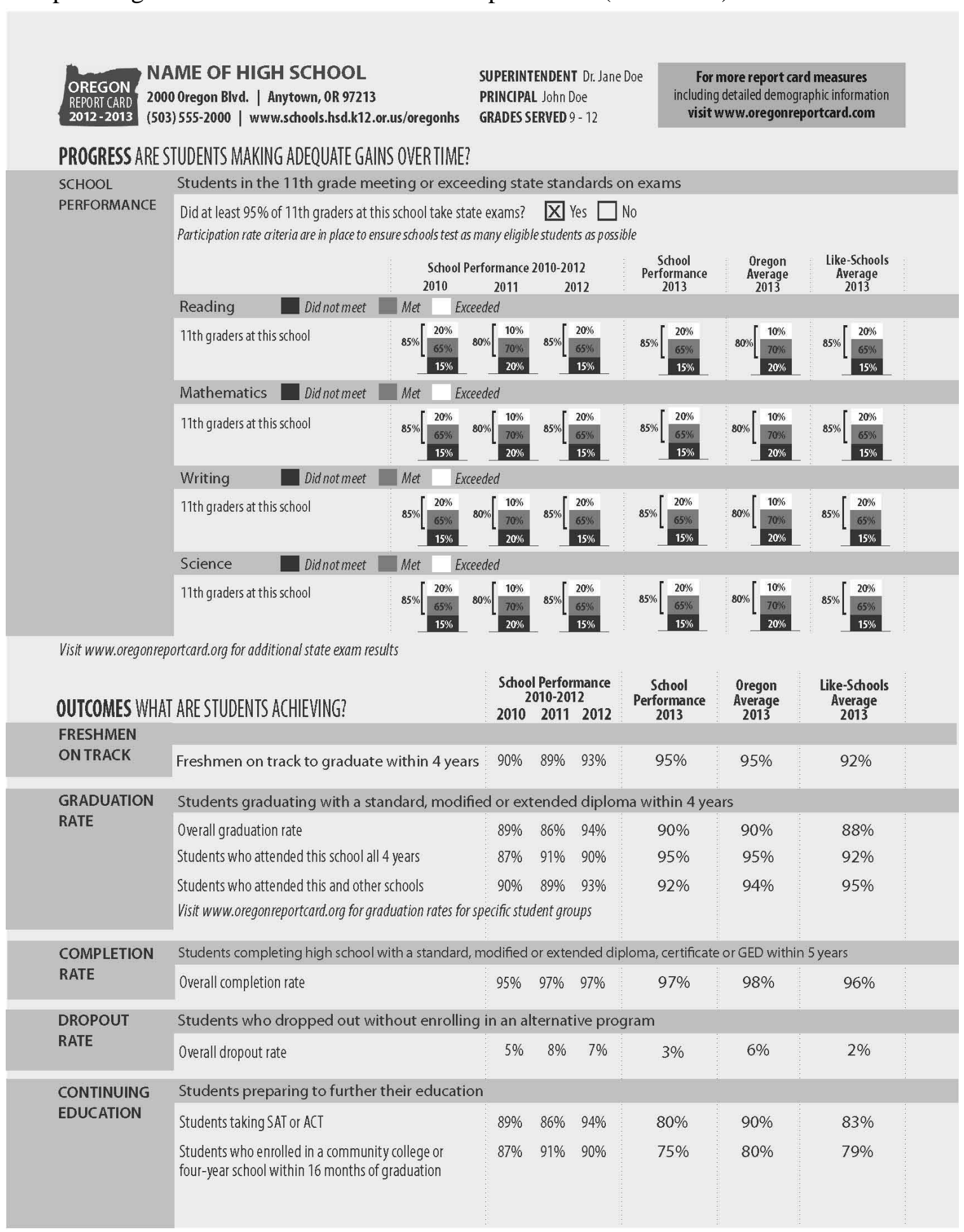




\section{Sample Oregon's Next Generation School Report Card (Continued)}

\begin{tabular}{|c|c|c|c|c|c|c|c|c|c|c|c|c|c|}
\hline $\begin{array}{ll}\text { OREGON } & \text { NAI } \\
\text { REPORT CARD } & 2000 \\
2012-2013 & (503)\end{array}$ & $\begin{array}{l}\text { ME OF H } \\
\text { Oregon Blvd. } \\
555-2000\end{array}$ & $\begin{array}{l}\text { HIG S } \\
\text { I Anytc } \\
\text { www.sd }\end{array}$ & $\begin{array}{l}\mathrm{CHO} \\
\text { own, } 0 \mathrm{R} \\
\text { hools.h }\end{array}$ & $\begin{array}{l}\text { OL } \\
97213 \\
\text { d.k12.or.us/o }\end{array}$ & gonhs & \multicolumn{4}{|c|}{$\begin{array}{l}\text { SUPERINTENDENT Dr. Jane Doe } \\
\text { PRINCIPAL John Doe } \\
\text { GRADES SERVED } 9-12\end{array}$} & \multicolumn{4}{|c|}{$\begin{array}{l}\text { For more report card measures } \\
\text { including detailed demographic information } \\
\text { visit www.oregonreportcard.com }\end{array}$} \\
\hline \multicolumn{14}{|c|}{ OUTCOMES (CONTINUED) } \\
\hline \multirow{13}{*}{$\begin{array}{l}\text { STUDENT GROUP } \\
\text { OUTCOMES }\end{array}$} & \multicolumn{13}{|c|}{ Key outcomes for key student groups at this school compared to the same groups statewide } \\
\hline & \multicolumn{13}{|c|}{ Only groups at this school with 10 or more students are represented to ensure confidentiality. } \\
\hline & Per & $\begin{array}{l}\text { School } \\
\text { Iformance } \\
2013\end{array}$ & $\begin{array}{l}\text { Oregon } \\
\text { Average }\end{array}$ & $\begin{array}{l}\text { School } \\
\text { Compared to } \\
\text { OR Average }\end{array}$ & & & $\begin{array}{l}\text { School } \\
\text { rformance } \\
2013\end{array}$ & $\begin{array}{l}\text { Oregon } \\
\text { Average }\end{array}$ & $\begin{array}{l}\text { School } \\
\text { Compared to } \\
\text { OR Average }\end{array}$ & & $\begin{array}{l}\text { Sdhool } \\
\text { formance } \\
2013\end{array}$ & $\begin{array}{l}\text { Oregon } \\
\text { Average }\end{array}$ & $\begin{array}{l}\text { School } \\
\text { Compared to } \\
\text { OR Average }\end{array}$ \\
\hline & \multicolumn{4}{|c|}{ English language learners (ELL) } & \multicolumn{5}{|c|}{ American Indian/Alaskan native } & \multicolumn{4}{|c|}{ Multi-racial/Multi-ethnic } \\
\hline & $\begin{array}{l}\text { OnTrack } \\
\text { Graduation } \\
\text { Completion } \\
\text { Dropout }\end{array}$ & $\begin{array}{l}95 \% \\
90 \% \\
97 \% \\
3 \%\end{array}$ & $\begin{array}{c}95 \% \\
85 \% \\
98 \% \\
6 \%\end{array}$ & $\begin{array}{l}- \\
+5 \% \\
-1 \% \\
-3 \%\end{array}$ & $\begin{array}{l}\text { OnTra } \\
\text { Gradu } \\
\text { Comp } \\
\text { Dropo }\end{array}$ & etion & $\begin{array}{l}95 \% \\
90 \% \\
97 \% \\
3 \%\end{array}$ & $\begin{array}{l}95 \% \\
85 \% \\
98 \% \\
6 \%\end{array}$ & $\begin{array}{l}-- \\
+5 \% \\
-1 \% \\
-3 \%\end{array}$ & $\begin{array}{l}\text { On Track } \\
\text { Graduation } \\
\text { Completion } \\
\text { Dropout }\end{array}$ & $\begin{array}{l}95 \% \\
90 \% \\
97 \% \\
3 \%\end{array}$ & $\begin{array}{c}95 \% \\
85 \% \\
98 \% \\
6 \%\end{array}$ & $\begin{array}{c}-- \\
+5 \% \\
-1 \% \\
-3 \%\end{array}$ \\
\hline & \multicolumn{4}{|c|}{ Low income students } & \multicolumn{5}{|c|}{ Asian/Pacific Islander } & \multicolumn{4}{|l|}{ Females } \\
\hline & $\begin{array}{l}\text { On Track } \\
\text { Graduation } \\
\text { Completion } \\
\text { Dropout }\end{array}$ & $\begin{array}{c}95 \% \\
90 \% \\
97 \% \\
3 \%\end{array}$ & $\begin{array}{l}95 \% \\
85 \% \\
98 \% \\
6 \%\end{array}$ & $\begin{array}{l}-- \\
+5 \% \\
-1 \% \\
-3 \%\end{array}$ & $\begin{array}{l}\text { OnTra } \\
\text { Gradu } \\
\text { Comp } \\
\text { Dropo }\end{array}$ & $\begin{array}{l}\text { k } \\
\text { tion } \\
\text { etion } \\
\text { ut }\end{array}$ & $\begin{array}{l}95 \% \\
90 \% \\
97 \% \\
3 \%\end{array}$ & $\begin{array}{l}95 \% \\
85 \% \\
98 \% \\
6 \%\end{array}$ & $\begin{array}{c}- \\
+5 \% \\
-1 \% \\
-3 \%\end{array}$ & $\begin{array}{l}\text { On Track } \\
\text { Graduation } \\
\text { Completion } \\
\text { Dropout }\end{array}$ & $\begin{array}{l}95 \% \\
90 \% \\
97 \% \\
3 \%\end{array}$ & $\begin{array}{c}95 \% \\
85 \% \\
98 \% \\
6 \%\end{array}$ & $\begin{array}{l}-- \\
+5 \% \\
-1 \% \\
-3 \%\end{array}$ \\
\hline & \multicolumn{4}{|c|}{ Students with disabilities } & \multicolumn{5}{|c|}{ Bladk/African-American } & \multicolumn{4}{|c|}{ Males } \\
\hline & $\begin{array}{l}\text { On Track } \\
\text { Graduation } \\
\text { Completion } \\
\text { Dropout }\end{array}$ & $\begin{array}{c}95 \% \\
90 \% \\
97 \% \\
3 \%\end{array}$ & $\begin{array}{c}95 \% \\
85 \% \\
98 \% \\
6 \%\end{array}$ & $\begin{array}{l}-- \\
+5 \% \\
-1 \% \\
-3 \%\end{array}$ & $\begin{array}{l}\text { OnTra } \\
\text { Gradu } \\
\text { Comp } \\
\text { Dropo }\end{array}$ & $\begin{array}{l}\text { k } \\
\text { tion } \\
\text { etion } \\
\text { ut }\end{array}$ & $\begin{array}{c}95 \% \\
90 \% \\
97 \% \\
3 \%\end{array}$ & $\begin{array}{c}95 \% \\
85 \% \\
98 \% \\
6 \%\end{array}$ & $\begin{array}{c}-- \\
+5 \% \\
-1 \% \\
-3 \%\end{array}$ & $\begin{array}{l}\text { On Track } \\
\text { Graduation } \\
\text { Completion } \\
\text { Dropout }\end{array}$ & $\begin{array}{l}95 \% \\
90 \% \\
97 \% \\
3 \%\end{array}$ & $\begin{array}{l:}95 \% \\
85 \% \\
98 \% \\
6 \%\end{array}$ & $\begin{array}{c}-- \\
+5 \% \\
-1 \% \\
-3 \%\end{array}$ \\
\hline & \multicolumn{4}{|c|}{ Migrant students } & \multicolumn{5}{|c|}{ Hispanic/Latino } & & & & \\
\hline & $\begin{array}{l}\text { On Track } \\
\text { Graduation } \\
\text { Completion } \\
\text { Dropout }\end{array}$ & $\begin{array}{c}95 \% \\
90 \% \\
97 \% \\
3 \%\end{array}$ & $\begin{array}{l}95 \% \\
85 \% \\
98 \% \\
6 \%\end{array}$ & $\begin{array}{c}-- \\
+5 \% \\
-1 \% \\
-3 \%\end{array}$ & $\begin{array}{l}\text { OnTra } \\
\text { Gradu } \\
\text { Comp } \\
\text { Dropo }\end{array}$ & $\begin{array}{l}\text { k } \\
\text { tion } \\
\text { etion }\end{array}$ & $\begin{array}{c}95 \% \\
90 \% \\
97 \% \\
3 \%\end{array}$ & $\begin{array}{l}95 \% \\
85 \% \\
98 \% \\
6 \%\end{array}$ & $\begin{array}{c}-- \\
+5 \% \\
-1 \% \\
-3 \%\end{array}$ & & & & \\
\hline & \multicolumn{4}{|c|}{ Talented and Gifted (TAG) students } & \multicolumn{5}{|c|}{ White (not of Hispanic origin) } & & & & \\
\hline & $\begin{array}{l}\text { On Track } \\
\text { Graduation } \\
\text { Completion } \\
\text { Dropout }\end{array}$ & $\begin{array}{l}95 \% \\
90 \% \\
97 \% \\
3 \%\end{array}$ & $\begin{array}{c}95 \% \\
85 \% \\
98 \% \\
6 \%\end{array}$ & $\begin{array}{c}-- \\
+5 \% \\
-1 \% \\
-3 \%\end{array}$ & $\begin{array}{l}\text { OnTra } \\
\text { Gradu } \\
\text { Comp } \\
\text { Dropo }\end{array}$ & $\begin{array}{l}\text { ck } \\
\text { ation } \\
\text { etion } \\
\text { ut }\end{array}$ & $\begin{array}{c}95 \% \\
90 \% \\
97 \% \\
3 \%\end{array}$ & $\begin{array}{l}95 \% \\
85 \% \\
98 \% \\
6 \%\end{array}$ & $\begin{array}{c}-- \\
+5 \% \\
-1 \% \\
-3 \%\end{array}$ & & & & \\
\hline
\end{tabular}

CURRICULUM \& LEARNING ENVIRONMENT What is this school doing to improve student learning and to prepare students for the future? SCHOOL READINESS

Students who rate their physical \& emotional health very good/excellent: $78 \%$

Students who rate this school as very safe: $89 \%$
School meets the national standard of 225 minutes/week of physical education (PE) for each enrolled student

Bullying and harassment prevention program

Peer conflict mediation program

Universal/daily breakfast program

School-based health clinic

Teen parent program

Counseling for emotional, academic and behavioral issues

City Clinic, a private non-profit, has partnered with this school to provide free or reduced-cost health services

\section{Sample Oregon's Next Generation School Report Card (Continued)}


NAME OF HIGH SCHOOL

2000 Oregon Blvd. | Anytown, 0R 97213

(503) 555-2000 | www.schools.hsd.k12.or.us/oregonhs
SUPERINTENDENT Dr. Jane Doe PRINCIPAL John Doe GRADES SERVED $9-12$

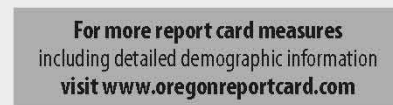

\section{CURRICULUM \& LEARNING ENVIRONMENT ICNIINUED)}

\section{ACADEMIC SUPPORT}

Academic Foundations: limited enrollment 9 th grade class designed to bolster study habits, enhance basic skills and improve arganization

Peer tutoring program

Bilingual/ESL model program: support based on language proficiency level and grade level

Special education program: support for students with qualified learning disabilities

Murtagh Center, a private non-profit, has partnered with this school to provide on-campus afterschool homework assistance

The Parent-Teacher Association (PTA) funded two teacher's aide positions

\section{CAREER \& TECHNICAL EDUCATION}

\section{Business education}

Marketing

Family \& consumer science

Graphic communications

Computer-aided design/computer-aided manufacturing

(CAD/CAM)

The Chamber of Commerce has partnered with this

school to provide job shadow opportunities; all

students are required to complete a job shadow to graduate

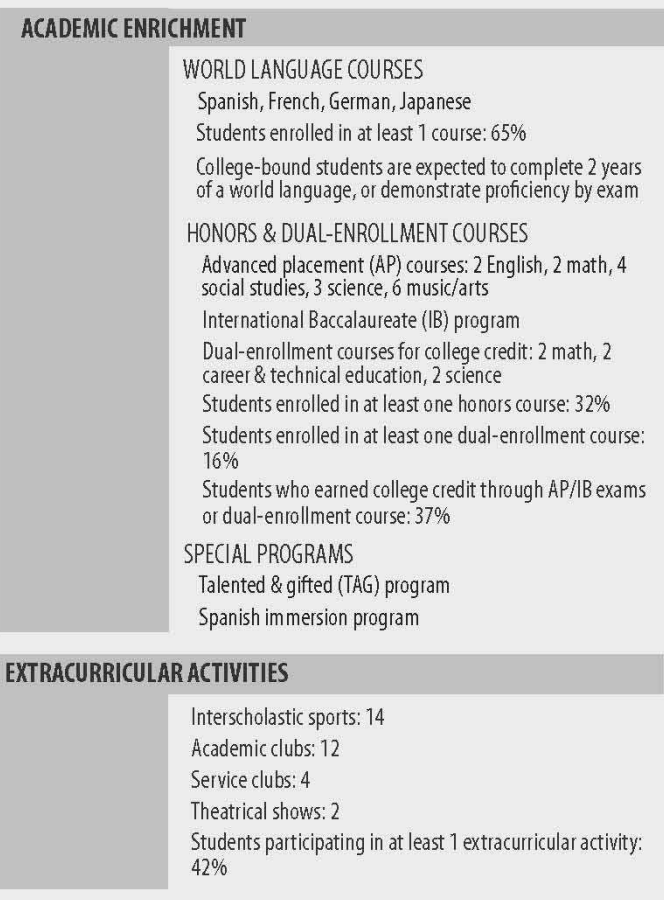

FEDERAL TITLE 1 DESIGNATION

$\mathbf{X}$ Priority $\square$ focus $\square$ Model

This designation applies only to high poverty schools that qualify for federal Title 1 funds. Priority schools rank in the bottom $5 \%$ of high poverty schools in the state. These schools generally have very low student test scores and need additional support to make improvements. 


\section{APPENDIX F: SURVEY INSTRUMENT}

Note: The proceeding survey was converted from print to an electronic format using a website service which allowed direct export to simple formats such as spreadsheets for analysis and graphic development. In some cases the questions, numbering or wording were slightly modified in order to meet technical and character space limitations.

\section{Survey (For use in Evaluation Study) \\ Portland State University \\ Graduate School of Education - Educational Leadership and Policy}

Please complete the following survey and provide written comments. We are interested in what you believe is an effective process for designing and evaluating alternative high schools. Your answers will be kept confidential and will be combined with the responses of other school leaders and included in generalizable quotes and response summaries. The survey covers three sections: demographic information; the design process; and the evaluation process.

DIRECTIONS: In section I, if you lead more than one high school or program, please think about the high school in which you devote the most time when answering the questions.

Section I: School and Participant Demographic Information

This section asks about your school and background experience.

Please place an $\mathrm{X}$ next to $\mathrm{ONE}$ response to each question unless otherwise directed.

a. School Information

1. In what part of Oregon is your school located? (Please select one.)

Portland Metro-Area

North Coast

South Coast

Willamette Valley

Central Oregon

Southern Oregon

Eastern Oregon

Other (Please identify):

2. What grade levels are taught at your school? (Please check all that apply.)

$6 \_7 \_8 \_9 \_10 \_11 \_12$ Other (Please identify):

3. How many students are enrolled in your school approximately?

4. Is your school located in its own building? 
a.___ Yes _ No

b. If No, where is it located?

5. How many teachers (full-time equivalent) work in your school approximately?

6. Is your school a traditional public, alternative public, public charter, public magnet, or private school? (Please check all that apply.)

Traditional Public

Alternative Public

Public Charter

Public Magnet

Private

Other (Please describe):

\section{b. School Leadership Experience}

1. What is your educational role or title?

2. How many years have you been a school leader (administrator or teacher leader) in any setting?

3. How many years have you been a school leader (administrator or teacher leader) in an alternative high school setting?

4. Are you a licensed school administrator? Yes No

5. Have you participated in a Design Process that resulted in the development of a school vision and Program Description?

a. __ Yes N No

b. If yes, please briefly describe the school's program description:

6. Have you participated in a School Evaluation Process that resulted in the development of an evaluation plan using the Alternative School Evaluation Toolkit?

a. __ Yes _ No

b. If yes, please briefly describe the school's evaluation plan: 
Section IIa: Effective Alternative High School Design Process

This section asks your perceptions, as a school leader, about the effectiveness of the alternative high school design process about which you have been informed. Research Questions:

1. Is the process under development (School Design Process) an effective process for designing innovative alternatives to traditional high schools?
a. __ Yes No
b. Please comment about the design process:

2. Were there obstacles you experienced in attempting to design an alternative school?
a. __ Yes No
b. Please comment about obstacles:

3. Did the Design Process address obstacles you experienced when attempting to design an alternative school?
a. __ Yes No
b. If yes, please comment about how well the process addressed the obstacles:

4. Did you believe that the design team had a positive impact on the school design process?
a. _ Yes No
b. Please comment about design team:

5. Did the School Design Process have a positive impact on students at-risk of high school failure (dropping out of school)?

a. __ Yes__ No

b. Please comment about the potential for this process to positively impact at-risk students: 
Section IIb: Four Assumptions in Designing Alternatives to Traditional High Schools:

Research Question: How essential are the four assumptions imbedded in the process regarding what leaders need to know to design alternatives to traditional high schools?

Elements of Effective Alternative Schools: Shared Vision, Educational Diversity, Relevant and Focused Curriculum, Creative Instructional Approaches, Student Assessments, Caring and Demanding Teachers, Voluntary Participation and School Choice, Comprehensive Programs, Small School Size, Shared Governance and Local Autonomy.

Directions: Please rate each item using the scale "Not Essential" to "Absolutely Essential." Please use the "Comment" section following each group of items if you wish to discuss the ratings you gave.

Scale: 1 = Not Essential 2 = Somewhat Essential 3 = Mostly Essential 4 = Absolutely Essential How essential are each of the following to designing an innovative alternative high school?

Assumption \#1:

Elements of Effective Alternative Schools Circle One Response

1. Considering all of the elements of effective alternative schools. $1 \quad 2 \quad \begin{array}{lll}3 & 4\end{array}$

2. Taking a considerable amount of time to develop a shared vision and mission (purpose) for the new school.

3. Diversifying the educational program based on the needs and interests of students.

4. Developing relevant and focused curriculum that meaningfully connects students to school.

5. Forming a community of learners centered around creative and flexible Instructional approaches.

6. Using assessments for learning rather than of learning.

$\begin{array}{llll}1 & 2 & 3 & 4 \\ 1 & 2 & 3 & 4 \\ 1 & 2 & 3 & 4 \\ 1 & 2 & 3 & 4 \\ 1 & 2 & 3 & 4\end{array}$

7. Hiring caring and demanding teachers who choose to work in the school.

8. Engaging all participants through voluntary participation in the school.

$\begin{array}{llll}1 & 2 & 3 & 4 \\ 1 & 2 & 3 & 4\end{array}$

9. Comprehensive educational programs that are equitable for all students.

$\begin{array}{llll}1 & 2 & 3 & 4\end{array}$

10. Organizing around small school size for a personalized learning environment.

$\begin{array}{llll}1 & 2 & 3 & 4\end{array}$

11. Sharing governance and having local autonomy that increases "ownership" of the school by all involved. $\begin{array}{llll}1 & 2 & 3 & 4\end{array}$

12. Are there other elements of an effective alternative schools that would be helpful? a. Yes No ___ Not sure 
b. If yes, please describe other elements of effective alternative schools (not included above):

13. Please comment about elements of effective alternative schools:

Scale: 1 = Not Essential 2 = Somewhat Essential 3 = Mostly Essential 4 = Absolutely Essential

How essential are each of the following to designing an innovative alternative high school?

Assumption \#2:

Organizational Leadership and Starting Over Circle One

Response

1. Leading a design team to agree to start over from the beginning of a design process.

$\begin{array}{llll}1 & 2 & 3 & 4\end{array}$

2. Design team agrees it is more efficient to start over and design a new school than to remodel and existing school.

$\begin{array}{llll}1 & 2 & 3 & 4\end{array}$

3. Using organizational leadership strategies to achieve team consensus regarding starting over to design a new school.

$\begin{array}{llll}1 & 2 & 3 & 4\end{array}$

4. Considering cultural and symbolic leadership as a strategy to achieve team consensus when starting over to design a new school.

5. Considering visionary leadership as a strategy to achieve team consensus when starting over to design a new school.

$\begin{array}{llll}1 & 2 & 3 & 4\end{array}$

6. Considering historical perspective leadership to achieve team consensus when starting over to design a new school.

$\begin{array}{llll}1 & 2 & 3 & 4\end{array}$

7. Please comment about leadership and starting over:

Scale: 1 = Not Essential 2 = Somewhat Essential 3 = Mostly Essential 4 = Absolutely Essential How essential are each of the following to designing an innovative alternative high school? Assumption \#3:

Accreditation Standards as a Framework for Design Circle One Response 
1. Using accreditation standards as a framework for school design.

$\begin{array}{llll}1 & 2 & 3 & 4\end{array}$

2. Developing a mission (purpose), beliefs and expectations for student learning.

$\begin{array}{llll}1 & 2 & 3 & 4\end{array}$

3. Designing curriculum for mission fulfillment.

$\begin{array}{llll}1 & 2 & 3 & 4\end{array}$

4. Planning quality instruction for student learning.

$\begin{array}{llll}1 & 2 & 3 & 4\end{array}$

5. Formulating assessments for student learning.

$\begin{array}{llll}1 & 2 & 3 & 4\end{array}$

6. Leading and organizing for student learning.

$\begin{array}{llll}1 & 2 & 3 & 4\end{array}$

$\begin{array}{llllll}\text { 7. Delineating school services and supports for learning. } & 1 & 2 & 3 & 4\end{array}$

8. Identifying facilities and finance for support of student learning. $\begin{array}{lllll}1 & 2 & 3 & 4\end{array}$

9. Please comment about accreditation standards:

Scale: 1 = Not Essential 2 = Somewhat Essential 3 = Mostly Essential 4 = Absolutely Essential

How essential are each of the following to designing an innovative alternative high school?

\section{Assumption 4:}

Program Evaluation that Begins With the End in Mind

Circle One Response

1. Planning for a program evaluation from the beginning of the design process with the full development of the new school in mind.

$\begin{array}{llll}1 & 2 & 3 & 4\end{array}$

2. Advocating for a formative evaluation of educational

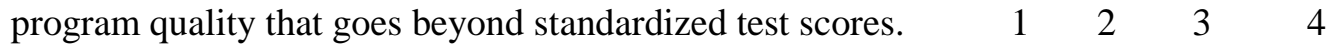

3. Compiling an inventory of school practice and policy. $\quad \begin{array}{llllll}1 & 2 & 3 & 4\end{array}$

4. Complying with federal and state laws. $\quad \begin{array}{lllll}1 & 2 & 3 & 4\end{array}$

5. Maintaining a checklist of quality indicators for alternative schools.

$\begin{array}{llll}1 & 2 & 3 & 4\end{array}$

6. Encouraging creative thinking about what an alternative school can be within the constraints of program evaluation. $\quad \begin{array}{llllll}1 & 2 & 3 & 4\end{array}$ 
7. Considering the context and circumstance under which the alternative school was designed to be established for program evaluation.

$\begin{array}{llll}1 & 2 & 3 & 4\end{array}$

8. Establishing the outcomes for which the alternative school will be held accountable in the future when fully implemented. $\begin{array}{llllll}1 & 2 & 3 & 4\end{array}$

9. Please comment about program evaluation:

\section{Section IIIa: Effective Alternative High School Evaluation Process Characteristics}

Below are 10 elements that others have found to be important in a program evaluation process. Please rank the elements in order of how essential they are to an alternative school evaluation.

The most important process elements should be listed first (1) and least important last (10).

\section{The Evaluation Process Characteristics:}

_ begins with the end in mind.

_ considers established school vision, mission or goals (program description).

_ involves internal and external stakeholders.

_ supports the formation of an evaluation team.

_ uses a mix of both formative (informative) and summative (summary) approaches.

_ is practical or realistic (feasible).

_ is contextualized and produces value (accountable).

is generally useful (utility).

is proper or fair (propriety).

accurately conveys analysis (accuracy).

Please comment about the Evaluation Process Characteristics: 
Section IIIb: Effective Alternative High School Evaluation Toolkit Elements

Below are 7 tools included in the Alternative High School Program Evaluation Toolkit.

Please rank the tools in order of how essential they are to an alternative school evaluation.

The most important process elements should be listed first (1) and least important last (7).

1. The Evaluation Toolkit Elements:

Protocols that support a facilitator in involving a team of internal and external stakeholders.

Evaluation Planning Worksheet that supports communication of the evaluation purpose, timeline, activities and an explanation of how the results will be used.

Evaluation training, learning and planning activities (data collection, information gathering, reflection, reporting etc.) that support the evaluation team in using the Toolkit.

Tools for Evaluation Teams (assessment, curriculum, engagement, instruction, leadership and organizational structures) that support those at the school in learning from their success, identifying current challenges, planning for improvement and more effectively telling their story.

Initial Survey Questions and Comments Section of the Tools for Evaluation Teams that provides an opportunity for members of the evaluation team (in workgroups) to convey thoughts, observations and evidence.

School Progress Indicators Section of the Tools for Evaluation Teams that provide an opportunity for the evaluation team to come to consensus on what is meant by "Exemplary", "Effective" and "In Need of Improvement" as they make use of the Tools for Assessment, Curriculum, Engagement, Instruction, Leadership and Structures.

Evaluation Planning Matrix and Planning Tool (simplified logic model) that supports the facilitator and members of the team in developing and communicating an evaluation plan.

Please comment about the Evaluation Toolkit Elements:

Note: Thank you for completing this survey. We appreciate the time you take to respond to each question. The information you have provided will be used to further the understanding of designing and evaluating alternative high schools. Please return/submit the completed survey. 


\section{APPENDIX G: 2012 OREGON ALTERNATIVE EDUCATION REPORT}

\section{Alternative Education Programs}

What is an Alternative Education Program?

An alternative education program is a school or separate class group designed to best serve students' educational needs and interests and assist students in achieving the academic standards of the school district and the state. (ORS 336.615)

School districts provide alternative education programs for students who need

- additional academic supports because they do not meet state academic standards,

- additional academic supports because they are exceeding academic standards, or

- additional behavioral supports.
Alternative education programs are also provided for students who

- are pregnant or are parenting,

- have been expelled from school,

- have dropped out of school, or are at risk of dropping out, or

- need additional supports to earn a diploma

In general, Oregon student enrollment in alternative education remained at similar levels as compared with past years, while there continued to be a decline in the number of programs and services. Reductions in district resources are likely the primary reason for the decrease in the number of alternative education programs and services in 2012. Districts report that on average they serve an estimated 15,000 students in alternative education statewide.

"Alternative education program" means a school or separate class group designed to best serve students educational needs and interests and assist students in achieving the academic standards of the school district and the state (ORS 336.615).

Alternative Education Services in Oregon

By Type of Program Service -- Number of Students

Source: ODE Alternative Education Data Collection

\begin{tabular}{|c|c|c|c|c|c|c|}
\hline School Year & \multicolumn{2}{|c|}{2010} & \multicolumn{2}{|c|}{2011} & \multicolumn{2}{|c|}{2012} \\
\hline Type of Operation & $\begin{array}{l}\text { Number } \\
\text { of } \\
\text { Students }\end{array}$ & $\begin{array}{l}\text { Percent of } \\
\text { Alt. Ed. } \\
\text { Students }\end{array}$ & $\begin{array}{l}\text { Number } \\
\text { of } \\
\text { Students }\end{array}$ & $\begin{array}{l}\text { Percent of } \\
\text { Alt. Ed. } \\
\text { Students }\end{array}$ & $\begin{array}{l}\text { Number } \\
\text { of } \\
\text { Students }\end{array}$ & $\begin{array}{l}\text { Percent of } \\
\text { Alt. Ed. } \\
\text { Students }\end{array}$ \\
\hline Resident School District & 11,655 & $75.79 \%$ & 10,075 & $74.22 \%$ & 11,835 & $77.21 \%$ \\
\hline Another School District & 49 & $0.32 \%$ & 17 & $0.13 \%$ & 10 & $0.07 \%$ \\
\hline Private Program & 2,192 & $14.25 \%$ & 2,008 & $14.79 \%$ & 2,060 & $13.44 \%$ \\
\hline Community College & 1,166 & $7.58 \%$ & 1,162 & $8.56 \%$ & 1,075 & $7.01 \%$ \\
\hline $\begin{array}{l}\text { Educational Service District } \\
\text { (ESD) }\end{array}$ & 252 & $1.64 \%$ & 220 & $1.62 \%$ & 296 & $1.93 \%$ \\
\hline Other Program & 65 & $0.42 \%$ & 92 & $0.68 \%$ & 42 & $0.27 \%$ \\
\hline Terminated Program & 0 & $0.00 \%$ & 0 & $0.00 \%$ & 10 & $0.07 \%$ \\
\hline Total & 15,379 & & 13,574 & & 15,328 & \\
\hline
\end{tabular}

District alternative schools and programs, smaller learning communities, programs within schools as well as a variety of alternative, charter and magnet schools and programs of choice are utilized to meet individualized student learning needs. District and school report cards depict summative data for all students enrolled at these schools and districts. In addition, school districts offer a variety of guidance and career counseling services, tutoring, small-group instruction, online/blended learning, career related learning experiences, and proficiency credit options to support student achievement.

District alternative schools and programs, smaller learning communities, programs within schools as well as a variety of alternative, charter and magnet schools and programs of choice are utilized to meet individualized student learning needs. District and school report cards depict summative data for all students enrolled at these schools and districts. In addition, school districts offer a variety of guidance and career counseling services, tutoring, small-group instruction, online/blended learning, career related learning experiences, and proficiency credit options to support student achievement.

Oregon Statewide Report Card 2011-12 $\quad 1 \quad$ Oregon Department of Education - www.ode.state.or.us Contact for this section: Drew Hinds, 503-947-5799, Drew. Hinds@state.or.us 


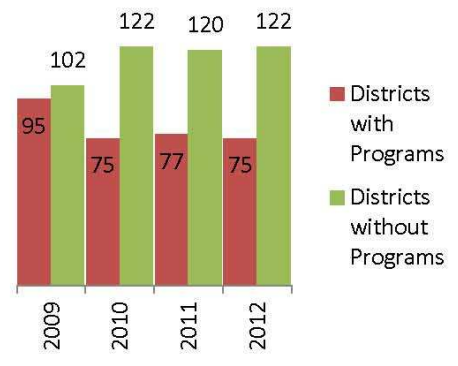

Source: ODE Alternative Education Data Collection
Alternative education is included in school district improvement planning and goal setting. Often alternative schools are regionally accredited as "special purpose schools" and are required to be at least annually evaluated by districts to assure they are comprehensive, contributing instruction on content standards and essential skills, and offering the courses required for high school graduation with an Oregon Diploma, Extended Diploma, Modified Diploma or Alternative Certificate. Some school districts have begun including educational program data and information about schools/programs of choice in achievement compacts required in Oregon's next generation system of accountability. At least annual evaluation and site visits are required and result in "compliance" information that supports school boards in their annual approval of programs. These program evaluations are required to include the review of an annual statement of expenditures to ensure that the program enhances the ability of the district and its students to achieve district and state standards (ORS 336.655

The majority of alternative education is estimated to occur in schools and programs operated by the student's resident school district $(40 \%)$, but a consistent percentage of alternative program services have been offered by private organizations $(30 \%)$ and community colleges $(15 \%)$ with the rest occurring in programs operated by the Education Service District (ESD) or in another district, school or program. In general, with statewide reductions in funding, school districts have continued the trend of being selective about additional services they are able to provide and programs where they place students.

\section{Alternative Education Services in Oregon}

By Type of Program Service -- Number of Programs

\begin{tabular}{|l|c|c||c|c|c|c|}
\hline School Year & \multicolumn{2}{|c|}{2010} & \multicolumn{2}{c|}{2011} & \multicolumn{2}{c|}{2012} \\
\hline Type of Operation & $\begin{array}{c}\text { Number of } \\
\text { Programs }\end{array}$ & $\begin{array}{c}\text { Percent of } \\
\text { Programs }\end{array}$ & $\begin{array}{c}\text { Number of } \\
\text { Programs }\end{array}$ & $\begin{array}{c}\text { Percent of } \\
\text { Programs }\end{array}$ & $\begin{array}{c}\text { Number of } \\
\text { Programs }\end{array}$ & $\begin{array}{c}\text { Percent of } \\
\text { Programs }\end{array}$ \\
\hline Resident School District & 173 & $41.00 \%$ & 165 & $40.94 \%$ & 168 & $43.75 \%$ \\
\hline Another School District & 12 & $2.80 \%$ & 15 & $3.72 \%$ & 11 & $2.86 \%$ \\
\hline Private Program & 125 & $29.60 \%$ & 117 & $29.03 \%$ & 101 & $26.30 \%$ \\
\hline Community College & 68 & $16.10 \%$ & 63 & $15.63 \%$ & 58 & $15.10 \%$ \\
\hline Educational Service District (ESD) & 28 & $6.60 \%$ & 23 & $5.71 \%$ & 25 & $6.51 \%$ \\
\hline Other Program & 7 & $1.70 \%$ & 6 & $1.49 \%$ & 7 & $1.82 \%$ \\
\hline Terminated Program & 9 & $2.10 \%$ & 14 & $3.47 \%$ & 14 & $3.65 \%$ \\
\hline Total & $\mathbf{4 2 2}$ & & 403 & & 384 & \\
\hline
\end{tabular}

Source: ODE Alternative Education Data Collection

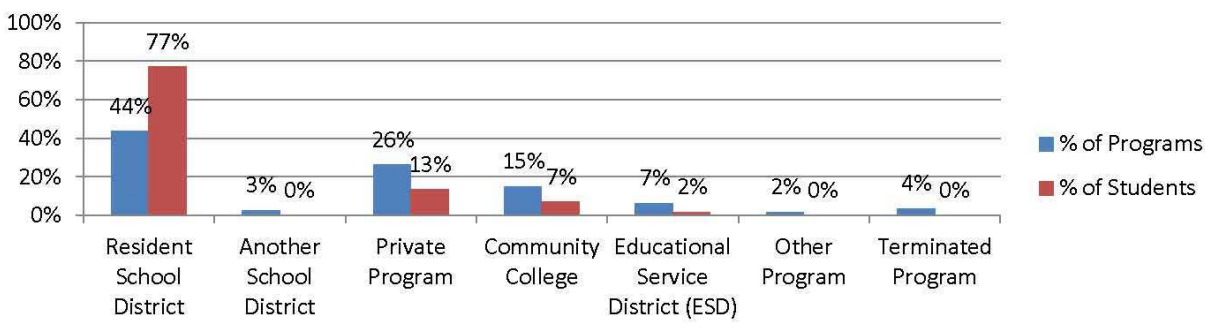


Type of Program Services Statewide

Alternative education programs must continue to be designed and evaluated for quality as well as compliance to assure they address the diverse student needs the social behaviors as well as knowledge/skills with a level of rigor that will enable youth to be successful in post-secondary education and careers. The National Alternative Education Association (NAEA) describes youth attending alternative education programs as students who were found to have not been succeeding in the traditional education setting. Traditional school staff is left to respond to the needs of an increased number of students that might benefit from alternative programs and attempt to do so through personalized learning experiences in accordance with a student's education plan and profile. A number of school districts have responded by offering differing types of online/blended learning and intervention programs. Alternative schools and programs offer innovative, non-traditional approaches to teaching and learning which helps to prevent these students from becoming dropouts and assists the state and district in serving all students.

For the past two years federal School Improvement Grants (SIG) have provided significant resources to alternative schools. Common issues have emerged with the "transformation model" for improvement chosen by these schools. Eight alternative schools were among the sixteen schools statewide that received School Improvement Grant (SIG) funding. The National Dropout Prevention Center (NDPC) published Alternative Schools: Best Practices for Development and Evaluation, Effective Strategies for School Improvement, which suggests that the simple reporting of output indicators such as class graduation rate, suspension rate, attendance rate, etc., is only a snapshot of one brief moment in time relating to the operation and effectiveness of the [alternative] school. In order to accurately evaluate alternative programs in the context for which they are designed, it is imperative that district and school leaders and program directors collect longitudinal data to document the impacts of their programming and the quality of student services over time.

Alternative Education Services in Oregon By Type of Program Service -- Number of Services

\begin{tabular}{|l|c|l|l|}
\hline TYPES OF PROGRAM SERVICES STATEWIDE & $\begin{array}{l}\text { Number of } \\
\text { Services Provided } \\
2010\end{array}$ & $\begin{array}{l}\text { Number of } \\
\text { Services Provided } \\
2011\end{array}$ & $\begin{array}{l}\text { Number of } \\
\text { Services Provided } \\
2012\end{array}$ \\
\hline Students with At-Risk Behaviors & 296 & 281 & 262 \\
\hline Remediation, Credit Recovery, or GED & 270 & 240 & 247 \\
\hline Pregnant or Pa renting Students & 95 & 85 & 91 \\
\hline Students Advanced Beyond Standards & 73 & 67 & 62 \\
\hline Other Programs & 29 & 29 & 27 \\
\hline Total Number of Services & 763 & 702 & 689 \\
\hline
\end{tabular}

Source: ODE Alternative Education Data Collection

\begin{tabular}{|c|c|c|c|}
\hline \multicolumn{4}{|c|}{$\begin{array}{l}\text { Alternative Education Services in Oregon } \\
\text { By Grade Range - Number of Students }\end{array}$} \\
\hline GRADE RANGE & $\begin{array}{l}\text { Number of } \\
\text { Students Using } \\
\text { Services } 2010\end{array}$ & $\begin{array}{l}\text { Number of } \\
\text { Students Using } \\
\text { Services } 2011\end{array}$ & $\begin{array}{l}\text { Number of } \\
\text { Students Using } \\
\text { Services } 2012\end{array}$ \\
\hline Secondary & 13,519 & 11,993 & 13,764 \\
\hline Elementary & 1,860 & 1,581 & 1,564 \\
\hline Total Services & 15,379 & 13,574 & 15,328 \\
\hline
\end{tabular}

Links to Reference Documents

Oregon Alternative Education: www.ode.state.or.us/go/AlternativeEd

Oregon Positive Behavioral Interventions and Supports (PBIS): $\underline{w w w . o d e . s t a t e . o r . u s / s e a r c h / p a g e / ? i d=553}$

Oregon Response to Intervention (RTI): www.ode.state.or.us/search/page/?id=315

Alternative Schools: Best Practices for Development and Evaluation: Effective Strategies for School Improvement: http://www.eric.ed.gov/ERICWebPortal/detail?accno=ED481475 